\title{
EVALUATION CHARACTERIZATION OF MECHANISMS CONTROLLING FATE AND EFFECTS OF ARMY SMOKES
}

\section{Subtitle: Transport, Transformations, Fate, and Terrestrial Ecological Effects of Brass Obscurants}

\author{
Final Report
}

\author{
Dominic A. Cataldo, Ph.D. \\ Peter Van Voris, Ph.D. \\ Michael W. Ligotke, M.S. \\ J. P. McKinley, Ph.D. \\ Harvey Bolton, Jr., Ph.D. \\ Shu-mei W. Li, M.S. \\ Robert J. Fellows, Ph.D. \\ Kristin M. McFadden, B.A.
}

\section{August 1990}

\author{
Supported by: \\ U.S. Army Medical Research and \\ Development Command \\ Fort Detrick, Frederick, MD 21701-5012
}

Project Order No. 89PP9903

\author{
Pacific Northwest Laboratory \\ Richland, Washington 99352 \\ Operated for the U.S. Department of Energy \\ by Battelle Memorial Institute
}

Approved for public release; distribution unlimited 


\title{
DISCLAIMER
}

This report was prepared as an account of work sponsored by an agency of the United States Government. Neither the United States Government nor any agency thereof, nor Battelle Memorial Institute, nor any of their einployees, makes any warranty, expressed or implied, or assumes any legal liability or responsibility for the accuracy, completeness, or usefulness of any information, apparatus, product, or process disclosed, or represents that its use would not infringe privately owned rights. Reference herein to any specific commercial product, process, or service by trade name, trademark, manufacturer, or otherwise, does not necessarily constitute or imply its endorsement, recommendation, or favoring by the United States Government or any agency thereof, or Battelle Memorial Institute. The views and opinions of authors expressed herein do not necessarily state or reflect those of the United States Government or any agency thereof.

\author{
PACIFIC NORTHWEST LABORATORY \\ operated by \\ BATTELLE MEMORIAL INSTITUTE \\ for the \\ UNITED STATES DEPARTMENT OF ENERGY \\ under Contract DE-ACO6-76RLO 1830
}

Printed in the United States of America

Availabic to DOE and DOE contractors from the

Office of Scientific and Technical Information, P.O. Box 62, Oak Ridge, TN 37831; prices available from (615) 576-8401. FTS 626-8401.

Available to the public from the National Technical Information Service, U.S. Department of Commerce, 5285 Port Royal Rd., Springfield, VA 22161.

NTIS Price Codes, Microfiche A01

Printed Copy

\begin{tabular}{cr}
\hline Price Code & Page Range \\
\hline A02 & $1-10$ \\
A03 & $11-50$ \\
A04 & $51-75$ \\
A05 & $76-100$ \\
A06 & $101-125$ \\
A07 & $126-150$ \\
A08 & $151-175$ \\
A09 & $176-200$ \\
A10 & $201-225$ \\
A11 & $226-250$ \\
A12 & $251-275$ \\
A13 & $276-300$ \\
A14 & $301-325$
\end{tabular}

\begin{tabular}{cc}
\hline Price Code & Page Range \\
\hline A15 & $326-350$ \\
A16 & $351-375$ \\
A17 & $376-400$ \\
A18 & $401-425$ \\
A19 & $426-450$ \\
A20 & $451-475$ \\
A21 & $476-500$ \\
A22 & $501-525$ \\
A23 & $526-550$ \\
A24 & $551-575$ \\
A25 & $576-600$ \\
A99 & $601-U p$
\end{tabular}




\title{
EVALUATION AND CHARACTERIZATION OF MECHANISMS CONTROLLING FATE AND EFFECTS OF ARMY SMOKES
}

\author{
Subtitle: Transport, Transformations, Fate, and \\ Terrestrial Ecological Effects of \\ Brass Obscurants
}

\section{Final Report}

Dominic A. Cataldo, Ph. D Michael W. Ligotke, M. S. Harvey Bolton, Jr., Ph. D Robert J. Fellows, Ph. D
Peter Van Voris, Ph. D

J. P. McKinley, Ph. D

Shu-mei W. Li, M. S.

Kristin M. McFadden, B. A.

\section{August 1990}

Supported by:

U.S. Army Medical Research and Development Command

Fort Detrick, Frederick, MD 21701-5012

\section{Project Order No. 89PP9903}

\section{Pacific Northwest Laboratory}

Richland, Washington 99352

Operated for the U.S. Department of Energy

by Battelle Memorial Institute

Project Officer: Wayne R. Mitchell

U.S. Army Biomedical Research and

Development Laboratory

Fort Detrick, Frederick, MD 21701-5010

Approved for Public Release;

Distribution Unlimited

The findings of this report are not to be construed as official Department of the Army position unless so designated by other authorized documents 
Unclassified

SECURITY CLASSIFICATION OF THIS PAGE

\section{REPORT DOCUMENTATION PAGE}

1a. REPORT SECURITY CLASSIFICATION

-Inclassified

2a. SECURITY CLASSIFICATION AUTHORITY

3. DISTRIBUTION / AVAILABILITY OF REPORT

2b. DECLASSIFICATION/DOWNGRADING SEHEDULE

Approved for public release;

distribution unlimited

4. PERFORMING ORGANIZATION REPORT NUMBER(S)

5. MONITORING ORGANIZATION REPORT NUMBER(S)

6a. NAME OF PERFORMING ORGANIZATION

Pacific Northwest Laboratory

6b. OFFICE SYMBOL

7a. NAME OF MONITORING ORGANIZATION

(If applicable)

6c. ADDRESS (City, State, and ZIP Code)

Richland, Washington 99352

7b. ADDRESS (City, State, and ZIP Code)

8a. NAME OF FUNDING / SPONSORING

ORGANIZATION U.S. Army Medical

Research \& Development Command

8c. ADDRESS (City, State, and ZIP Code)

Fort Detrick

Frederick, Maryland 21701-5012 8b. OFFICE SYMBOL (If applicable)
9. PROCUREMENT INSTRUMENT IDENTIFICATION NUMBER

Army Project Order No. 89PP9903

10. SOURCE OF FUNDING NUMBERS

\begin{tabular}{l|l|l}
\hline PROGRAM & PROJECT & TASK
\end{tabular}

ELEMENT NO. NO. 3E1- NO.

$62720 \mathrm{~A}$
NO.

00

00

WORK UNIT ACCESSION NO. 029

11. TITLE (Include Security Classification)

(U) Evaluation and Characterization of Mechanisms Controlling Fate and Effects of Army Smokes

12. PERSONAL AUTHOR(S) Dominic A. Cataldo, Michael W. Ligotke, Harvey Bolton, Jr., Robert J.

$-$ 13a. TYPE OF REPORT 13b. TIME COVERED

Final

16. SUPPLEMENTARY NOTATION

Subtitle: Transport, Transformations, Fate and Terrestrial Ecological Effects of 17 Rrass obscurants COSATI CODES

\begin{tabular}{|c|c|c|}
\hline FIELO & GROUP & SUB-GROUP \\
\hline 07 & 02 & \\
\hline 07 & 03 & \\
\hline
\end{tabular}
Smokes; Wind tunnel; Brass powder; Ecological effects; RA 3

19. ABSTRACT (Continue on reverse if necessary and identify by block number)

The primary objective of this study was to characterize the fate and response of soil and biotic components of the terrestrial environment to aerosols, deposited brass, and brass in combination with fog oil. Important physical, chemical, and biotic aspects were investigated using an environmental wind tunnel. Air/surface deposition rates were determined for foliar and soil surfaces, both in the absence and presence of fog oil. Deposition velocities for foliage ranged from 0.1 to $1.0 \mathrm{~cm} / \mathrm{s}$ at wind speeds of 2 to $10 \mathrm{mph}$, respectively. Foliar contact toxicity was assessed using five different types of terrestrial vegetation representative of Army training sites and surrounding environments. No significant foliar contact toxicity was observed for brass. The weathering and chemistry of brass aerosols deposited and amended to soils was assessed, along with the impacts of acid precipitation and moisture regimes on weathering rates. Rates of brass weathering and the fate of solubilized $\mathrm{Cu}$ and $\mathrm{Zn}$ are discussed. The influence of soil weathering processes and brass solubilization on seed germination indicated no detectable effects of brass. However, moderate toxicity effects were noted after

(Continued on reverse side)

DTIC USERS

21. ABSTRACT SECURITY CLASSIFICATION

Unclassified

22b. TELEPHONE (Inciude Area Code) 22c. OFFICE SYMBOL

301-663-7325 SGRD-RMI-S

Previous editions are obsolete.
SECURITY CLASSIFICATION OF THIS PAGE

Unclassified 


\section{(Abstract Cont.)}

160 days of soil incubation. The effects were proportional to soil-loading levels. Influence of soil weathering processes and contaminant solubilization on soil microbiological activities indicated that soil dehydrogenaser activity was more susceptible to impacts than was phosphatase activity or microbial biomass. Nitrifying bacteria and heterotrophic bacteria were not significantly affected by brass. Invertebrates (earthworms) associated with soil contaminated with brass were only slightly impacted, and only at loading rates $>445 \mu \mathrm{g} / \mathrm{cm}^{2}$. 


\section{FOREWORD}

Opinions, interpretations, conclusions and recommendations are those of the author and are not necessarily endorsed by the U.S. Army.

$X$ Where copyrighted material is quoted, permission has been obtained to use such material.

Where material from documents designated for limited distribution is quoted, permission has been obtained to use the material.

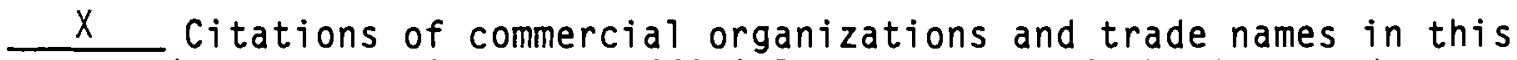
report do not constitute an official Department of the Army endorsement or approval of the products or services of these organizations.

$\frac{X}{a}$ In conducting research using animals, the investigator ( $s$ ) adhered to the "Guide for the Care and Use of Laboratory Animals," prepared by the Committee on Care and Use of Laboratory Animals of the Institute of Laboratory Animal Resources, National Research Council (NIH Publication No. 86-23, Revised 1985.)

$X$ For the protection of human subjects, the investigator ( $s$ ) have adhered to policies of applicable Federal Law 45CFR46.

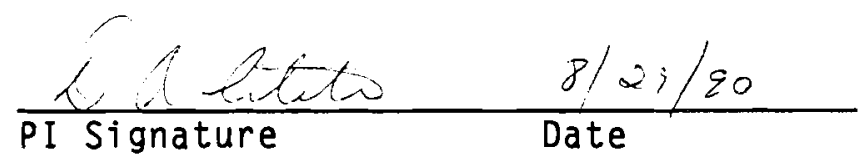




\section{EXECUTIVE SUMMARY}

The environmental fate and effects of brass were investigated for the two principal routes of exposure, namely airborne deposition of brass and brass/fog oil obscurant mixtures, and via soil amendment to simulate soil weathering and potential impacts from soil deposition. Aerosols containing brass were generated and characterized, and deposition to both foliar surfaces and soils was determined. Impacts of deposited brass were assessed on the basis of both contact toxicity and plant absorption from soils. Soil amendment studies were performed to ascertain weathering rates and the effects of brass concentration on both plant growth and soil microbial processes. In addition, soil columns were employed to determine whether brass weathering influenced the migration of $\mathrm{Cu}$ and $\mathrm{Zn}$ through soil profiles.

In these studies, brass aerosol mass concentrations ranged from 132 to $177 \mathrm{mg} / \mathrm{m}^{3}$ during the brass only (BR) wind-speed tests, were approximately $90 \mathrm{mg} / \mathrm{m}^{3}$ during the brass rangefinding tests, and ranged from 19 to $83 \mathrm{mg} / \mathrm{m}^{3}$ during the brass/fog oil (BR/FO) wind-speed tests. Results of particle size distributions indicated an Aerodynamic Mass Mediam Diameter (AMMD) for brass aerosols of about 5 to $6 \mu \mathrm{m}$.

The deposition velocity $\left(V_{d}\right)$ of brass alone to foliar surfaces increases with increasing wind speed, and ranged from $0.1 \mathrm{~cm} / \mathrm{s}$ at $0.9 \mathrm{~m} / \mathrm{s}(2 \mathrm{mph})$ to $1.0 \mathrm{~cm} / \mathrm{s}$ at $4.5 \mathrm{~m} / \mathrm{s}(10 \mathrm{mph})$. Interception or collection efficiency was higher for sagebrush than for the other plant species. The deposition velocity of brass delivered as BR/FO aerosols ranged from 0.3 to $60 \mathrm{~cm} / \mathrm{s}$ for foliar surfaces, and is substantially greater than observed for brass alone. Deposition to bush bean and tall fescue foliage is nearly an order of magnitude less than for sagebrush and pines. The codeposition of the fog oil to the leaf surface apparently either acted to prevent resuspension of the deposited brass or had an effect on brass agglomeration, increasing its effective size and deposition rate.

Contact toxicity of brass alone was not observed at mass loading rates of up to $700 \mu \mathrm{g} / \mathrm{cm}^{2}$. Exposure of plants to aerosols containing BR/FO resulted in moderate toxicity, but this is assumed to be the result of the FO and not the brass. Brass deposition to foliage has only a short-term minimal effect on plant gas-exchange processes, and is believed to result from the shading effect of foliar deposited brass. Similarly, dry matter production in brass-contaminated plants is reduced, and is believed to result from the shading effect. No residual effects of second-harvest biomass production were noted following brass deposition, indicating no significant weathering and foliar absorption of $\mathrm{Cu}$ or $\mathrm{Zn}$.

The $\mathrm{pH}$ of soils receiving brass decreased with increasing amendment level and time of incubation. The $\mathrm{pH}$ of soils increased by 0.8 to $1.0 \mathrm{pH}$ units over the 440 -day incubation period. Selective extractions were employed to evaluate brass weathering and to determine the fate of 
solubilized $\mathrm{Cu}$ and $\mathrm{Zn}$. In general, the amount of extractable $\mathrm{Cu}$ and $\mathrm{Zn}$ in soils increased by 100 days post-amendment and changed little by 440 days. In the intervening period, weathered $\mathrm{Cu}$ and $\mathrm{Zn}$ likely become tightly sorbed to nonexchangeable sites. This process results in some disruption in the extractable quantities of other ions in soil. Most notably, P decreases, while ammonia and nitrate concentrations increase; this likely results from a disruption of soil microbial processes.

Seed germination studies with bush bean, alfalfa, and tall fescue indicate no effects of brass at any of the concentrations employed or after up to 450 days of weathering. However, after 160 days of soil incubation, plants developed visual toxicity symptoms which included necrosis and chlorosis. Only moderate damage was noted for concentrations of $500 \mu \mathrm{g} \mathrm{brass} / \mathrm{g}$ and less. In general, the toxicity of brass, based on visual symptomology, became more severe with increasing incubation or weathering time. Biomass production in plants reflected the soil concentration trends for visual symptoms, in that severe dry-weight reductions were observed at soil concentrations of $>500 \mu \mathrm{g}$ brass $/ \mathrm{g}$ soil. The concentrations of $\mathrm{Cu}$ and $\mathrm{Zn}$ in plant tissues were proportional to soil brass levels. Analysis of the nutrient ion concentrations of tall fescue grown on brass-amended soil showed that the elevated soil concentrations of $\mathrm{Cu}$ and $\mathrm{Zn}$ caused the tissue concentrations of $\mathrm{Mg}$ and $\mathrm{Mn}$ to increase by a factor of 2 to 3, levels of Fe to increase by a factor of 7 to 100 , and $P$ levels to decrease by a factor of 2 to 3 . This disruption in ion homeostasis can account for the observed phytotoxicity of brass. Similar ion imbalances were not observed for bush bean.

The degree of brass flake impact on soil microbial activities was dependent on soil type, brass concentration, and the microbial index studied. Soils with higher organic matter and cation exchange capacity (CEC), such as the Cinebar soil, tended to be less impacted by the brass flake than soil with lower organic matter and CEC, such as Burbank soil. Organic matter in soils can adsorb and bind heavy metals, depending upon $\mathrm{pH}$. The soil organic matter also contributes to the CEC of the soil, thereby influencing the bioavailability, and hence, toxicity of deposited heavy metals. The greater the CEC of the soil, the greater is its ability to adsorb and immobilize heavy metals and to reduce their toxic effects. The CEC and organic matter of the soils used in this study can be ranked as Burbank < Palouse $\leq$ Palouse + $\mathrm{OM}<$ Cinebar. Thus Burbank soil, with its low CEC and low organic matter content, was shown to be most impacted by the brass flake exposure.

Impact of brass on soil microbial activities increased with increase in brass concentration. Concentration above $500 \mu \mathrm{g} / \mathrm{g}$ caused severe inhibition of several soil microbial activities, especially soil dehydrogenase, which was diminished to below detection. Soil dehydrogenase, or the activity of the soil microbial community was more susceptible to the toxicity of brass flake than was soil phosphatase or soil microbial biomass, which were moderately affected by the addition of brass flake. Soil nitrifying bacteria and total heterotrophic bacteria in general were not 
significantly affected by the brass flake. Among the soil microbial parameters studied, impact ranking was soil dehydrogenase activity $>$ phosphatase activity $>$ microbial biomass $>$ microbial population (total heterotrophic and nitrifying bacteria) $\approx$ microbial species diversity index. When soil was exposed to a mixed smoke containing brass flake and fog oil, the deleterious effect was less intense than in soil exposed to brass only, suggesting a beneficial synergistic effect of fog oil.

Brass flake deposited to soil has only a slightly deleterious effect on the earthworms at mass loading levels of $>445 \mu \mathrm{g} / \mathrm{cm}^{2}$. Exposure of earthworms to BR/FO aerosols at mass loading rates of $200 \mu \mathrm{g}$ brass $/ \mathrm{cm}^{2}$ had no effect on survivability, and only moderately affected tactile activity. Thus there is no indication that fog oil ameliorates or intensifies the effects of brass.

Brass flake was neutron-activated to produce a $65 \mathrm{Zn}$ tagged brass and was applied to column surfaces to determine the mobility of weathered soluble constituents using $\mathrm{Zn}$ as the indicator ion. Based on analysis of the indicators of migration it is clear that appreciable downward migration of $\mathrm{Zn}$, and likely $\mathrm{Cu}$, does not occur to any great extent over the period employed (440 days). Although slight differences in migration rates was noted for the four soils, it is clear that the CEC of these soils is effective in retarding solubilized brass constituents. For Cinebar soil, leached with $\mathrm{pH} 6.5$ versus 4.5 rainwater, no significant differences $(P \geq 0.1)$ are noted in migration; this likely indicates that the added acidity did not exceed the buffering capacity of the soil. 


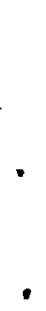

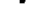




\section{IABLEOE CONTENTS}

REPORT DOCUMENTATION PAGE ................................................................................ iii

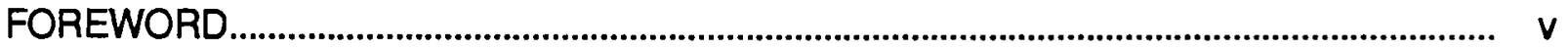

EXECUTIVE SUMMARY .......................................................................................... vii

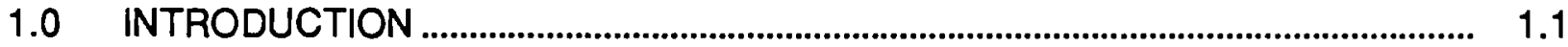

1.1 Review of the Environmental Behavior of Brass and Its Major

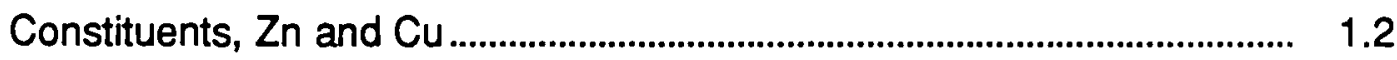

1.2 Project Objectives....................................................................................... 1.7

2.0 MATERIALS AND METHODS ............................................................................... 2.1

2.1 Aerosol Wind Tunnel Research Facility...................................................... 2.1

2.1.1 Environmental Wind Tunnel ............................................................. 2.2

2.1.2 Wind Tunnel Test Section ................................................................. 2.3

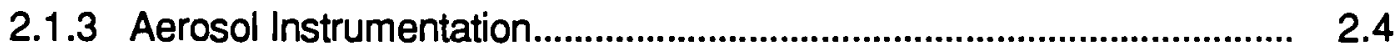

2.2 Aerosol Exposure Conditions................................................................... 2.5

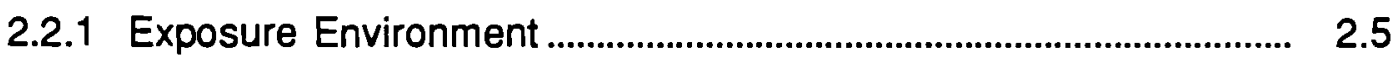

2.2.2 Brass and Mixed-Brass and Fog Oil Test Series.............................. 2.. 2.5

2.2.3 Test Procedures and Measured Conditions........................................ 2.6

2.3 Obscurant (Aerosol) Generation................................................................... 2.7

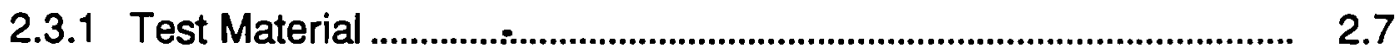

2.3.2 Brass Aerosol Generation ........................................................... 2.09

2.3.3 Mixed-Brass and Fog-Oil Aerosol Generation .................................. 2.11

2.4 Obscurant (Aerosol) Characterization ........................................................ 2.12

2.4.1 Aerosol Mass Concentration and Chemical Composition ............... 2.13

2.4.2 Aerosol Particle Size Distribution ....................................................... 2.15

2.4.3 Brass and Mixed-Brass and Fog Oil Particle-Deposition

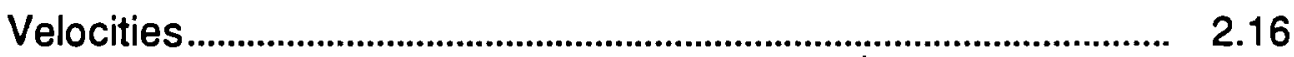

2.5 Characterization of Brass.................................................................. 2.16

2.5.1 Chemical Characterization of Brass Flake........................................ 2. 2.16

2.5.2 Digestion and Extraction of Brass and Brass Contained in

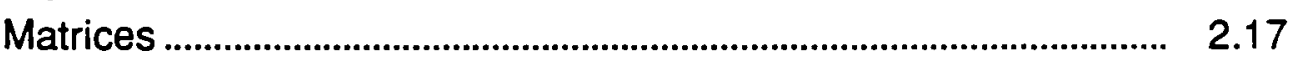

2.5.3 Soil Extraction Methods....................................................................... 2.17

2.6 Preparation and Characterization Soils.................................................... 2.18

2.6.1 Soil Characteristics ............................................................................ 2.18

2.6.2 Brass Amendment and Incubation ................................................ 2.20

2.6.3 Soil Column Studies....................................................................... 2.20 


\section{IABLE OE CONTENTS (Cont)}

2.7 Plant and Soil Selection and Plant Cultivation .......................................... 2.21

2.7.1 Plant Selection and Cultivation........................................................ 2.21

2.8 Plant/Soil Measurements....................................................................... 2.22

2.8.1 Foliar-Contact Toxicity Responses..................................................... 2.22

2.8.2 Photosynthetic Measurements............................................................ 2.23

2.8.3 Quantitation of Exposure/Dose ..................................................... 2.25

2.8.4 Post-Exposure Simulated Rainfall..................................................... 2.25

2.9 Microbial Methods ...................................................................................... 2.27

2.10 Soil-Invertebrate Assay ........................................................................... 2.29

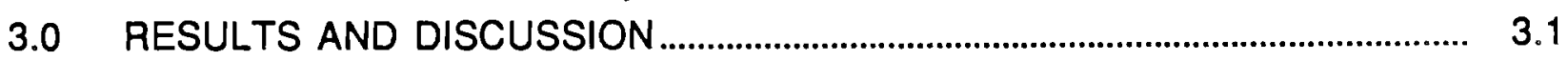

3.1 Obscurant (Aerosol) Characterization ............................................................. 3.1

3.1.1 Aerosol-Mass Concentration and Chemical Composition............... 3.1

3.1.2 Aerosol-Particle Size Distribution........................................................ 3.5

3.1.3 Aerosol Deposition Velocity to Suspended Surrogate

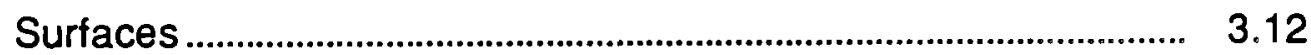

3.2 Soil/Plant Mass Loading and Deposition Velocities.................................... 3.15

3.2.1 Vegetation Mass Loading and Foliar Retention of Brass Flake and Brass Flake/Fog Oil ..................................................... 3.15

3.2.2 Mass Loading of Brass Flake to Exposed Soils................................. 3.23

3.3 Contact Phytotoxicity .................................................................................... 3.27

3.3.1 Contact Phytotoxicity of Brass Flake Deposited to Foliar Surfaces

3.3.2 Metabolic Responses to Brass-Flake Exposure During WindSpeed Tests.

3.4 Residual Effects of Foliar-Deposited Brass on Dry-Matter Production in Tall Fescue.

3.4.1 Wind-Speed Tests: Brass Flake.

3.4.2 Wind-Speed Tests: Brass Flake/Fog Oil....................................... 3.33

3.4.3 Range-Finding Tests: Brass Flake.................................................. 3.33

3.5 Plant/Soil Amendment Studies ..................................................................... 3.35

3.5.1 Soil Chemistry of Amended Brass.................................................. 3.35

3.5.2 Toxicity and Availability of Brass Components to Plants................. 3.53 


\section{IABLE OF CONTENTS (Cont)}

3.6 Soil Microbial Effects of Brass Flake

3.68

3.6.1 Soil Dehydrogenase Activity

3.68

3.6.2 Soil Phosphatase Activity.

3.6.3 Soil ATP - Soil Microbial Biomass

3.6.4 Total Soil Heterotrophic Bacteria.

3.6.5 Soil Microbial Diversity Index

3.6.6 Soil Nitrifying Bacteria

3.7 Effects of Brass and Brass/Fog Oil on Soil Invertebrates

3.103

3.8 Soil Mobility of Brass - Soil Column Studies.

3.106

4.0 CONCLUSIONS

4.1

4.1 Aerosol Characterization.

4.1

4.2 Deposition Velocities for Plant and Soil Surfaces.

4.1

4.3 Contact Phytotoxicity and Residual Effects of BR and BR/FO Aerosols..

4.4 Brass-Soil Amendment Studies.

4.2

4.5 Soil Columns and Brass Mobility in Soil.

4.5 
FIGURE 2.1 Pacific Northwest Laboratory Aerosol Wind Tunnel Research Facility.

FIGURE 2.2 Closed-Loop Wind Tunnel, Aerosol Generation and Injection, and Primary Test Section.

FIGURE 2.3 Schematic of the Sonic Nozzle Aerosol Generator Developed to Disperse Brass-Flake Powder as an Obscurant Aerosol

FIGURE 2.4 Temperature-Controlled Fog Oil Aerosol Generator Used in Conjunction with the Brass Generator for Mixed Smokes

FIGURE 2.5 Schematic Diagram of Gas-Exchange System Used in Making Net-Photosynthetic and Dark-Respiration Measurements

FIGURE 2.6 Post-Exposure Simulated-Rainfall System ..............................................

FIGURE 3.1 Aerosol Particle-Size Distribution of Total Mass, Brass, and Fog-Oil Components of the Aerosol During Test BR/FO-04

FIGURE 3.2 Aerosol Particle-Size Distributions Measured During Tests BR-12 and BR-13, Two of Four Brass Wind-Speed Tests

FIGURE 3.3 Aerosol Particle-Size Distributions Measured During Tests BR-18 and BR-19, Two of Four Range-Finding Tests.

FIGURE 3.4 Aerosol Particle-Size Distributions Measured During Tests BR/FO-04 and BR/FO-06, Two of Four Wind-Speed Exposure

Tests.

FIGURE 3.5 Deposition Velocities, Ud, to Horizontally Suspended $47 \mathrm{~mm}$ Coupons for Brass, Brass/Fog Oil, and the Brass and Fog-Oil Components of the Aerosols.

FIGURE 3.6 Whole-Plant Net-Photosynthesis and Dark-Respiration Rates $\left(\mu\right.$ mole $\left.\mathrm{CO}_{2}\right)$ for a Tall Fescue and a Ponderosa Pine Plant Exposed to Atmospheric Brass Flake for $60 \mathrm{~min}$ at $\sim 150 \mathrm{mg} / \mathrm{m}^{3}$ and $50 \%$ Relative Humidity and $10 \mathrm{mph}$ Wind Speed.

FIGURE 3.7 Flow Chart for the Processing of Samples from the Brass Flake Direct Soil AmendmentWeathering Experiment.

FIGURE 3.8 The Effect of Brass-Flake Concentration on Soil Dehydrogenase Activity

FIGURE 3.9 An Example Calculation of the Ecological Dose of Brass Flake Causing $50 \%$ Inhibition $\left(E C D_{50}\right)$ of Microbial Activity

FIGURE 3.10 Ecological Dose of Brass Flake Causing 50\% Inhibition $\left(E c D_{50}\right)$ of Soil Dehydrogenase Activity. 
FIGURE 3.11 The Effect of Brass-Flake/Fog-Oil-Mixed Smoke on Soil Dehydrogenase Activity

FIGURE 3.12 The Effect of Brass-Flake Concentration on Soil Phosphatase Activity

FIGURE 3.13 Ecological Dose Causing $50 \%$ Inhibition $\left(E_{c D_{50}}\right)$ of Soil Phosphatase Activity.

FIGURE 3.14 The Effect of Brass-Flake/Fog-Oil Mixed Smoke on Soil Phosphatase Activity.

FIGURE 3.15 The Effect of Brass-Flake Concentration on ATP - Soil Microbial Biomass.

FIGURE 3.16 Ecological Dose Causing $50 \%$ Inhibition $\left(\mathrm{ECD}_{50}\right)$ of ATP - Soil Microbial Biomass

FIGURE 3.17 The Effect of Brass-Flake/Fog-Oil Mixed Smoke on ATP - Soil Microbial Biomass.

FIGURE 3.18 The Effect of Brass-Flake Concentration on the Population of Total Soil Heterotrophic Bacteria

FIGURE 3.19 The Effect of Brass-Flake/Fog-Oil Mixed Smoke on the Population of Total Soil Heterotrophic Bacteria

FIGURE 3.20 The Effect of Brass-Flake Concentration on Soil Microbial Species Diversity.

FIGURE 3.21 The Effect of Brass-Flake/Fog-Oil Mixed Smoke on Soil Microbial Species Diversity.

FIGURE 3.22 The Effect of Brass-Flake Concentration on Soil Nitrifying Bacteria-Nitrosomonas Species.

FIGURE 3.23 The Effect of Brass-Flake Concentration on Soil Nitrifying Bacteria-Nitrobacter Species

FIGURE 3.24 The Effect of Brass-Flake/Fog-Oil Mixed Smoke on Soil Nitrifying Bacteria-Nitrosomonas Species

FIGURE 3.25 The Effect of Brass-Flake/Fog-Oil Mixed Smoke on Soil Nitrifying Bacteria-Nitrobacter Species 
TABLE 1.1 Water-Quality Criteria for $\mathrm{Cu}$ and $\mathrm{Zn}$.

TABLE 2.1 Brass and Brass/Fog-Oil Test Series.

TABLE 2.2 Environmental Conditions, Wind Speed, and Exposure Duration During Brass (BR) and Brass/Fog-Oil (BR/FO) Obscurant Tests

TABLE 2.3 Selected Properties of Soils Used in the Study of Brass Effects

TABLE 2.4 Coding for Modified Daubenmire Rating Scale and Associated Phytotoxicity Symptoms

TABLE 3.1 Chemical Composition of Aerosol Samples

TABLE 3.2 Average Aerosol Mass Concentrations During Exposure Tests.

TABLE 3.3 Chemical Composition of Size-Segregated Aerosol Samples

Collected Using an Andersen Cascade Impactor - Test

BR/FO-04

TABLE 3.4 Aerosol Particle Size Distributions for BR and BR/FO Tests

TABLE 3.5

Foliar Mass Loading of Brass Flake to Vegetation During

Wind-Speed Tests.

TABLE 3.6 Foliar Mass Loading of Brass Flake to Vegetation During

Brass/Fog-Oil Wind-Speed Tests.

TABLE 3.7 Foliar Mass Loading of Brass Flake to Vegetation During Range-Finding Tests.

TABLE 3.8 Values for Deposition Velocity $\left(V_{d}\right)$ of Brass Flake to Vegetation During Wind-Speed Tests

TABLE 3.9 Deposition Velocities $\left(V_{d}\right)$ of Brass Flake to Vegetation During BR/FO Wind-Speed Tests.

TABLE 3.10 Deposition Velocities $\left(V_{d}\right)$ of Brass Flake to Vegetation During Range-Finding Tests.

TABLE 3.11 Soil Mass-Loading Values for Burbank, Cinebar, and Palouse Soils Following Atmospheric Exposure to Brass Flake During Wind-Speed Tests.

TABLE 3.12 Soil Mass-Loading Values for Burbank, Cinebar, and Palouse Soils Following Atmospheric Exposure to Brass-Flake/Fog-Oil Wind-Speed Tests. 
LIST OF TABLES (Cont.)

TABLE 3.13 Soil Mass-Loading Values for Burbank, Cinebar, and Palouse Soils Following Atmospheric Exposure to Brass Flake During Range-Finding Tests.

TABLE 3.14 Soil Deposition Velocity $\left(V_{d}\right)$ Values $(\mathrm{cm} / \mathrm{s})$ for Burbank, Cinebar, and Palouse Soils Following Atmospheric Exposure to Brass Flake During Wind-Speed Tests.

TABLE 3.15 Soil Deposition Velocity $\left(V_{d}\right)$ Values $(\mathrm{cm} / \mathrm{s})$ for Burbank, Cinebar, and Palouse Soils Following Atmospheric Exposure to Brass Flake During BR/FO Wind-Speed Tests.

TABLE 3.16 Soil Deposition Velocity $\left(V_{d}\right)$ Values $(\mathrm{cm} / \mathrm{s})$ for Burbank, Cinebar, and Palouse Soils Following Atmospheric Exposure to Brass Flake During Range-Finding Tests.

TABLE 3.17 Plant Symptomatology to Atmospheric Brass-Flake Exposure During Wind-Speed Tests

TABLE 3.18 Plant Symptomatology to Atmospheric Brass-Flake/Fog-Oil Wind-Speed Test Exposures

TABLE 3.19 Effects of Brass-Flake Aerosol Wind-Speed Test on the Regrowth (Dry-Matter Production) of Exposed Tall Fescue at 30 and 60 Days Post-Exposure.

TABLE 3.20 Effects of Brass-Flake/Fog-Oil Aerosol Wind-Speed Tests on the Regrowth (Dry-Matter Production) of Exposed Tall Fescue at 30 and 60 Days Post-Exposure

TABLE 3.21 Effects of Brass-Flake Aerosol Range-Finding Tests on the Regrowth (Dry-Matter Production) of Exposed and Exposed/Leached Tall Fescue at 30 and 60 Days Post-Exposure.

TABLE 3.22 Moisture Content and pH of Brass-Amended Soils Sampled at 100 to 440 Days After Preparation.

TABLE 3.23 Comparison of Readily Soluble Components in FreonDisplaced Pore Waters of Control and Brass-Amended Soils (100 Days)

TABLE 3.24 Comparison of Extractable Cu Distributions in Control and Brass-Amended Soils Before Subtraction of Control-Soil Contribution.

TABLE 3.25 Comparison of Extractable $\mathrm{Zn}$ Distributions in Control and Brass-Amended Soils Before Subtraction of Control-Soil Contribution. 
LIST OF TABLES (Cont.)

TABLE 3.26 Summary Comparison of Selective Extraction Techniques For Brass-Amended Soils: Cu

TABLE 3.27 Summary Comparison of Selective Extraction Techniques for Brass-Amended Soils: $\mathrm{Zn}$.

TABLE 3.28 Solubilization of Components of Brass-Amended Soils by Hot-Water Extraction and Comparison to Direct Pore-Water Displacement: Metal Analyses.

TABLE 3.29 Solubilization of Components of Brass-Amended Soils by Hot-Water Extraction and Comparison to Direct Pore-Water Displacement: Anion and Organic Analyses.

TABLE 3.30 Average Percent Germination for Bush Beans, Alfalfa, and Tall Fescue Seeded in Soil Coupons Amended with Brass

Flake at Different Concentrations (Planting 0 Time)

TABLE 3.31 Average Percent Germination for Bush Beans, Alfalfa, and Tall Fescue Seeded in Soil Coupons Amended with Brass Flake at Different Concentrations (Planting $C$ )

TABLE 3.32 Plant Symptomatology to Brass-Soil Amendment. Symptomatology Determinations Made 60 Days After Planting (A) and 160 Days After Amendment of Brass Flake to the Various Soils at 0,25, 100,500, and $2500 \mathrm{ppm}$.

TABLE 3.33 Plant Symptomatology to Brass-Soil Amendment. Symptomatology Determinations Made 60 Days After Planting (C) and 470 Days After Amendment of Brass Flake to the Various Soils at 0, 25, 100, 500 , and $2500 \mathrm{ppm}$

TABLE 3.34 Average Final Dry Weight $(\mathrm{g})$ of Bush Beans and Segments Grown in Soils Amended with Brass Flake at Different Concentrations.

TABLE 3.35 Average Final Dry Weight (g) of Tall Fescue Grown in Soils Amended with Brass Flake at Different Concentrations...

TABLE 3.36 Average Tissue Concentrations of $\mathrm{Cu}$ and $\mathrm{Zn}$ in Tall Fescue Grown in Soils Amended with Brass Flake at Different Concentrations.

TABLE 3.37 Average Tissue Concentration of $\mathrm{Mg}, \mathrm{Mn}, \mathrm{P}$, and $\mathrm{Fe}$ in Tall Fescue Grown in Soils Amended with Brass Flake at Different Concentrations

TABLE 3.38 Average Tissue Concentrations of $\mathrm{Cu}$, and $\mathrm{Zn}$ in Bush Beans Grown in Soils Amended with Brass Flake at Different Concentrations as Determined Through ICAP Analysis. 
LIST OF TABLES (Cont.)

TABLE 3.39 Brass $\mathrm{ECD}_{50}$ Values for Microbial Parameters

TABLE 3.40 The Effect of Brass-Flake/Fog-Oil-Mixed Smoke on Soil

Dehydrogenase Activity.

TABLE 3.41 Equation for the Best Fit from the Dose-Response Curve for Soil Dehydrogenase Activity as Affected by Brass.

TABLE 3.42 Comparison of Exposures of Brass Flake and Mixed Smoke of Brass/Fog Oil on Soil Dehydrogenase Activity.

TABLE 3.43 The Effect of Brass-Flake Concentration on Soil Phosphatase Activity.

TABLE 3.44 Equation for the Best Fit from the Dose-Response Curve for Soil Phosphatase Activity as Affected by Brass.

TABLE 3.45 The Effect of Brass-Flake/Fog-Oil-Mixed Smoke on Soil Phosphatase Activity.

TABLE 3.46 Comparison of Exposures of Brass Flake and Mixed Smoke of Brass/Fog Oil on Soil Phosphatase Activity

TABLE 3.47 The Effect of Brass-Flake Concentration on ATP - Soil Microbial Biomass.

TABLE 3.48 The Effect of Brass-Flake/Fog-Oil-Mixed Smoke on ATP Soil Microbial Biomass.

TABLE 3.49 Equation for the Best Fit from the Dose-Response Curve for Soil ATP - Soil Microbial Biomass as Affected by Brass.

TABLE 3.50 Comparison of Exposures of Brass Flakes and a Mixed Smoke of Brass/Fog Oil on ATP - Soil Microbial Biomass

TABLE 3.51 The Effect of Brass-Flake Concentration on the Population of Total Soil Heterotrophic Bacteria

TABLE 3.52 The Effect of Brass-Flake/Fog Oil-Mixed Smoke on the Population of Total Soil Heterotrophic Bacteria

TABLE 3.53 The Effect of Brass Flake Concentration on Soil Microbial Species Diversity...

TABLE 3.54 The Effect of Brass-Flake Concentration on Soil Nitrifying Bacteria - Nitrosomonas sp

TABLE 3.55 The Effect of Brass-Flake Concentration on Soil Nitrifying Bacteria-Nitrobacter sp. 
TABLE 3.56 The Effect of Brass-Flake/Fog-Oil-Mixed Smoke on Soil Nitrifying Bacteria-Nitrosomonas sp

TABLE 3.57 The Effect of Brass-Flake/Fog-Oil-Mixed Smoke on Soil Nitrifying Bacteria-Nitrobacter $\mathrm{sp}$.

TABLE 3.58 Influence of Soil-Deposited Brass Flake on the Survival of Earthworms (Eisenia foetida).

TABLE 3.59 Influence of Soil-Deposited Brass Flake/Fog Oil on the Survival of Earthworms (Eisenia foetida)

TABLE 3.60 Mobility of Activated Brass Flake (Zinc-65) in Soil Columns with Time 3.107 


\subsection{INTRODUCTION}

The U.S. Army has deployed a number of smokes and obscurants to visually mask the movement of troops and vehicles during combat. Effective training scenarios for our armed forces require that troop maneuvers simulate, as closely as possible, the conditions most likely to be encountered under live combat situations (e.g., hardware, weapons fire, terrain, weather, vegetation, and smoke concentrations). Within the framework of the training operations, the Army has a regulatory responsibility to ensure that the use of smokes and obscurants does not adversely affect the health of local residents, or the environment, both on and near the training sites. The environments of these training centers range from high deserts to semitropical forests, thus complicating this responsibility.

The Health Effects Research Division of the U.S. Army Biomedical Research and Development Laboratory (USABRDL) has been assigned the responsibility of determining the potential environmental effects associated with using smokes and obscurants in training and testing. As part of USABRDL's planned program in response to this concern, the present study was designed to evaluate the transport, the chemical transformation, and the terrestrial ecological effects of several of the smokes currently used in training throughout the United States. The present study expands on prior field studies in two major aspects. First, smoke and obscurant testing is conducted within a special recirculating wind tunnel that ensures containment of the smoke and allows simulation of a variety of environmental conditions (i.e., varying wind speeds, mass loading/dose, and simulated rainfall under controlled conditions of temperatures and lighting), under dynamic exposure conditions. Secondly, the use of controlled and selected conditions permits elucidation of complex chemical processes including weathering and bioavailability of associated obscurant contaminants.

The USABRDL has two primary reasons for evaluating the environmental effects of smokes/obscurants used during troop maneuvers and training:

- to ensure that obscurants do not permanently change, damage, or alter vegetation and soils at training sites such that the sites no longer simulate a specific combat terrain

- to comply with the National Environmental Policy Act (NEPA), which requires an Environmental Assessment be conducted before smokes and obscurants are used during training missions within U.S. territorial boundaries. 
It should be noted that the health and environmental effects of Army smokes and obscurants have been studied intensively over the past 30 years; these research efforts have recently been compiled and reviewed by Shinn et al. (1985). In general, research into the effects of obscurant smokes has concentrated on animal and aquatic toxicity, with relatively little effort being expended in understanding soil/plant or ecological effects. The vast majority of the efforts used direct artificial dosing of organisms or aqueous amendments of suspected toxicants. While this may be appropriate and necessary in many instances, it may not be appropriate in developing an understanding of the potential impact of the recurrent use of obscurant smokes at heavily used training sites, mainly because there is no established correlation between 1) airborne smoke/obscurant concentration, deposition on soils and plants (duration and physical parameters affecting deposition), and 2) the ultimate effect, environmental deterioration.

Because the obscurant smokes currently in the U.S. Army arsenal are used in various combinations, under a variety of training situations, over diverse terrains and vegetative communities, concerns have focused on potential synergisms and antagonisms of the smokes on local environments. The fate and effects of individual smokes (RP, WP, FO, and $\mathrm{HC}$ ), and smoke combinations (FO/HCMP, FO/HC and FOMP) were investigated previously using controlled wind tunnel methodology (Van Voris et al. 1987; Cataldo et al. 1989; Cataldo et al. 1990a, and Cataldo et al. 1990b). The following studies will describe the behavior and potential impacts of brass and brass/fog oil on a variety of environmental components.

\subsection{REVIEW OF THE ENVIRONMENTAL BEHAVIOR OF BRASS AND ITS MAJOR CONSTITUENTS. Zn AND CU}

Normal Cu concentrations found in soils range from 5 to $150 \mathrm{ppm}$, a value of $50 \mathrm{ppm}$ representing a typical surface soil (Bowen 1979). For $\mathrm{Zn}$, the normal range is 10 to $250 \mathrm{ppm}$, with a typical value of about $100 \mathrm{ppm}$. Major natural sources of $\mathrm{Cu}$ are sulfide and hydroxycarbonate minerals; for $\mathrm{Zn}$, major sources are sulfide, oxide and silicate minerals (Brady 1974). Both $\mathrm{Cu}$ and $\mathrm{Zn}$ are essential plant micronutrients that are required in relatively small amounts. Cu functions during chlorophyll synthesis and carbohydrate and protein metabolism, is a catalyst for respiration, and is an enzyme constituent. $\mathbf{Z n}$ is required during formation of growth hormones, and for promotion of protein synthesis and seed production and maturation. On a relative scale of elements needed by alfalfa at bloom stage, Mo ranked as 1; Cu ranks 30; Zn 70; Fe 300; and Mg 20,000 (Brady 1974). Cu functions during chlorophyll synthesis and during carbohydrate and protein metabolism, and it is a catalyst for respiration and an enzyme constituent. $\mathrm{Zn}$ is required during the formation of growth 
hormones and for promoting protein synthesis and seed-production and -maturation. Normal levels in plants are 3 to 20 ppm Cu and 10 to 200 ppm Zn; above these values, toxicity begins to occur.

\section{Bequlatory Constraints}

EPA water quality criteria recommendations are listed in Table 1.1. Both $\mathrm{Cu}$ and $\mathrm{Zn}$ freshwater toxicity are dependent on water hardness; values listed are for $100 \mathrm{mg} / \mathrm{L}$ hardness rating (EPA 1987). Typical concentrations in U.S. water supplies are 0 to $600 \mathrm{ppb}$ $\mathrm{Cu}$ and 60 to7000 ppb, respectively (Rubin 1974). No contaminant limits have been established for soils because of the wide range of endogenous soil concentrations based on soil origin, and the wide range of soil sorptive capacities. Thus, the rates of brass weathering and solubilization in soils, the impact of these processes on the migration of $\mathrm{Cu}$ and $\mathrm{Zn}$ to surface waters, and the levels at which adverse biotic effects are noted, become important in setting guidelines for training installations.

\section{IABLE 1.1. WATER QUALITY CRITERIA FOR CU AND Zn}

\begin{tabular}{lcl}
\hline \multicolumn{1}{c}{$\begin{array}{c}\text { Water } \\
\text { Conditions }\end{array}$} & $\mathrm{Cu}$ & $\mathrm{Zn}$ \\
& \multicolumn{2}{c}{$(\mu \mathrm{gram} / \mathrm{L})$} \\
\hline Fresh, acute (a) & 18 & $120^{(\mathrm{b})} 320^{(\mathrm{c})}$ \\
Fresh, chronic (a) & 12 & $110^{(\mathrm{b})}$ \\
Marine, acute & 2.9 & 95 \\
Marine, chronic & 2.9 & 86 \\
Drinking Water (d) & 1000 & 5000 \\
\hline
\end{tabular}

\footnotetext{
(a) In $100 \mathrm{mg} / \mathrm{L}$ water hardness as $\mathrm{CaCO}_{3}$.

(b) Value stated on wall chart distributed by EPA based on EPA 440/5-86-001.

(c) Value in text of EPA 440/5-86-001.

(d) For taste and odor quality only; insufficient data for determination of potential toxicity to humans.
}

The composition of brass flake used by the military is nominally $70 \% \mathrm{Cu}, 30 \% \mathrm{Zn}$, and $1 \%$ minor trace metals. A trace amount of stearic or palmitic acid is used as a coating. Particle size is reported as 1.7 micron diameter, with thickness of 0.08-0.32 microns (Wentsel et al. 1986a, and others). Although Cd is a common impurity in Zn (Rubin 1974), initial dissolution of brass flakes at PNL did not reveal detectable levels. Nevertheless, the preferred analysis method inductively coupled argon plasma emission spectroscopy (ICAP) 
for the proposed studies will allow for simultaneous monitoring for all the metal components of interest (Cu, Zn, Fe, Al, Cd).

\section{Soil Behavior of Brass, Copper, and Zinc}

Because of their micronutrient status, both $\mathrm{Cu}$ and $\mathrm{Zn}$ sorption by soil and plant availability have been extensively studied. Generally, decreasing $\mathrm{pH}$ results in increased plant availability of $\mathrm{Zn}$, but had no correlation with $\mathrm{Cu}$ availability. The difference was attributed partially to the marked selectivity of certain cation-exchange sites for small quantities of $\mathrm{Cu}$ (Black 1968). At high pH values, excess $\mathrm{Cu}$ would be removed by mineralization. Organic matter is a well-known sink for $\mathrm{Cu}$, particularly in coarse-textured soils, as demonstrated in a recent study (Sims 1987). In this study, $\mathrm{Cu}$ occluded to Fe-oxides was a secondary reservoir of soil $\mathrm{Cu}$. $\mathrm{Zn}$ availability for plant uptake could be correlated to the exchangeable fractions in a selective extraction procedure; however correlation of availability of $\mathrm{Cu}$ with $\mathrm{pH}$ or soil properties was shown to be much poorer.

Most studies of $\mathrm{Cu}$ and $\mathrm{Zn}$ amendment to soils are based on addition of the trace elements either in fertilizer or in sewage sludges or other complex industrial wastes. In contrast, the brass weathering studies described here provided controlled matrix conditions (soil $\mathrm{pH}$, organic matter amendment, $\mathrm{pH}$ of irrigating waster, etc.) required for correlating resultant effects of mobilized $\mathrm{Cu}$ and $\mathrm{Zn}$ on microbial systems and plant uptake.

A review of the literature related to the environmental fate and effects of brass at training and testing facilities failed to produce any data related to the airborne deposition and impacts of brass. However, a series of CRDEC publications (Wentsel 1986; Wentsel et al. 1986a, 1986b; Wentsel and Guelta 1986a, 1986b) have addressed the effects and fate of brass materiel amended to soils and and their impacts on vegetation. In general, effects for both terrestrial and aquatic systems have shown that the weathering of the submicron flakes, and release of soluble $\mathrm{Cu}$ and $\mathrm{Zn}$, which comprise $99 \%$ of the brass mass $(70$ and $30 \%$ for $\mathrm{Cu}$ and $\mathrm{Zn}$, respectively), account for the observed biotoxicity and mobility of soluble $\mathrm{Cu}$ and $\mathrm{Zn}$ in soils.

Soils amended with $20 \mathrm{mg}$ brass $/ \mathrm{g}$ soil, and weathered for up to 8-months showed solubilization and soil mobility of bioavailable forms of $\mathrm{Cu}$ and $\mathrm{Zn}$ (Wentsel and Guelta 1986a) to be dependent on soil characteristics. Low CEC (cation exchange capacity), pH 4.6 soils having $1.3 \%$ organic matter (OM) showed extractable $\mathrm{Cu}$ to be elevated by 2 to $14 \%$, and $\mathrm{Zn}$ by $10 \%$, after 8 -months of incubation. In soils having a similar $\mathrm{pH}$, but higher CEC and OM (3.6\%), substantially less solubilization and downward mobility of $\mathrm{Cu}$ and $\mathrm{Zn}$ 
was observed. Thus, the solubility and mobility (weathering) of $\mathrm{Cu}$ and $\mathrm{Zn}$ is influenced by $\mathrm{pH}, \mathrm{CEC}$, and $\mathrm{OM}$ content of soils. A need exists to evaluate a wider range in soil type, with particular emphasis on $\mathrm{pH}$ and $\mathrm{OM}$ content.

\section{Biotic Effects of Brass, Copoer. and Zinc}

Plant Effects. The severity of observed plant effects will also be affected by which variety and/or species of plants exposed to plant available forms of the materials. Bowen (1987) has reported significant differences in the ability of the roots of different species such as rice and tomato to accumulate $\mathrm{Cu}$ and $\mathrm{Zn}$ from solution cultures with even larger differences evident between different cultivars of each species. When he applied the material to the leaf blades, however, no differences were evident between the two cultivars of either species, perhaps indicating a more mobile form of the ions may be produced in the roots. The ions are freely mobile within the plant and in some species such as cattail (Typha latifolia) preferentially accumulate in the shoot when exposed to elevated levels in the soil (Babcock et al. 1983).

Recent work indicates that the majority of $\mathrm{Cu}$ and $\mathrm{Zn}$ in the plant is in a conjugated, organic ligand form (Reese and Wagner 1987). Mullens et al. (1986) have reported that $\mathrm{Cu}$ and $\mathrm{Zn}$ were transported in the xylem and phloem in the forms of Cu-glutamine and $\mathrm{Zn}$ alanine with less than $1 \%$ as the free ion. Once within the plant cell, they are reported to be frequently bound to phytochelatins, another group of heavy-metal-binding peptides whose specific function is to accumulate, detoxify, and metabolize of the metals (Grill et al. 1987). Within the plant cell $\mathrm{Cu}$ is associated metabolically with such metalloenzymes as diamine oxidase, polyphenyl oxidases, and cytochrome $C$ oxidases (Delhaize et al. 1986), while $\mathrm{Zn}$ is reported to be associated with over 80 other metalloenzymes (Vallee 1976).

Toxic levels of these metals are generally reported to induce chlorosis, depression of photosynthesis and respiration, and inhibition of root growth particularly with $\mathrm{Cu}$ (Foy et al. 1978). These investigators also report that $\mathrm{Cu}$ induces $\mathrm{Fe}$ deficiency by inhibiting the translocation of Fe from roots to tops (Foy et al. 1978).

The two metals also may have a toxic synergistic interaction. Excess $\mathrm{Cu}$ or $\mathrm{Zn}$ (42 $\mu \mathrm{g} / \mathrm{g}$ ) reduced yields in bush bean by $6 \%$ and $17 \%$ respectively when applied singly in nutrient culture while a combination of both reduced yield by $38 \%$ (Wallace and Berry 1983). More recently, it has been shown that both metals can inhibit various portions of phytosynthetic electron transport. In cyanobacteria, elevated levels of $\mathrm{Cu}$ apparently affect the cytochromes between PS I and II in the chloroplast electron-transport chain, while $\mathrm{Zn}$ 
affected the electron donor sites between $\mathrm{H}_{2} \mathrm{O}_{2}$ and ascorbate on the oxidizing side of PS II, (Singh and Singh 1987). Similar responses may also occur in higher plants.

Wentsel et al. (1986b) evaluated plant effects of brass flake amended to soils at levels of 0 to $1600 \mu \mathrm{g}$ brass $/ \mathrm{g}$. In general, plant effects were observed for acidic, low CEC and -OM soils at levels as low as 60 ppm. Effects appear to be dependent not only on solubilization rates for brass, but also the capacity of soils to fix or insolubilize $\mathrm{Cu}$ and possible $\mathrm{Zn}$. These studies inherently need to resolve short-term impacts from longer-term weathering processes and subsequent soil mobility. Also, no data was available with respect to subtoxic bioaccumulation of $\mathrm{Cu}$ and $\mathrm{Zn}$ into tissues, which is important in assessing food chain transfer of potentially toxic contaminants such as $\mathrm{Cu}$.

Soil Microbiology. While numerous studies have examined the effects of heavy metals on soil biotic processes, studies on the fate and effects of brass are limited. In one series of studies (Tyler 1974, 1981) soil respiration and phosphatase activity decreased in soils containing higher soluble $\mathrm{Cu}$ and $\mathrm{Zn}$ levels from a brass foundry. As the $\mathrm{Cu}$ and $\mathrm{Zn}$ concentrations in the soils increased, soil microbial activity decreased. Soluble concentrations of $\mathrm{Cu}$ and $\mathrm{Zn} 3$ or 4 times background levels were sufficient to decrease soil phosphatase activity. Numerous papers discuss the effects on soil microbial processes of $\mathrm{Cu}$ and $\mathrm{Zn}$ by themselves or in combinations with other metals. Lower soil dehydrogenase activities ( $7 \%$ of the control) were found near an abandoned zinc smelter. Drucker et al. (1979) noted a decrease in soil respiration rate and number of aerobic bacteria at soluble Cu concentrations of $10 \mu \mathrm{g} / \mathrm{g}$ soil, while $\mathrm{Zn}$ had no effect on soil respiration rate but did decrease aerobic bacterial numbers at $100 \mu \mathrm{g} / \mathrm{g}$ soil. Rogers and $\mathrm{Li}$ (1985), using both soil amended with alfalfa and unamended soil, found the concentrations of $\mathrm{Cu}$ and $\mathrm{Zn}$ which resulted in a 50\% reduction in soil dehydrogenase activity to be 29 and $177 \mu \mathrm{g} / \mathrm{g}$ for $\mathrm{Cu}$ and $\mathrm{Zn}$ respectively, in the amended soil, and 53 and $346 \mu \mathrm{g} / \mathrm{g}$ for $\mathrm{Cu}$ and $\mathrm{Zn}$ respectively, in the unamended soil. In this short-term incubation, the alfalfa increased microbial activity and may have decreased soluble metal concentration.

Long term incubations with alfalfa in the soils would increase brass weathering by increasing microbial activity, which would increase soluble $\mathrm{Cu}$ and $\mathrm{Zn}$ concentrations in the soil solution. Increased concentrations of $\mathrm{Cu}$ and $\mathrm{Zn}$ may reduce the diversity of the microorganisms present and lead to the selection of metal resistant strains (Tyler 1981).

Soil Invertebrates. The effects of soil amended brass on earthworm survival and behavior was investigated by Wentsel and Guelta (1986b). Using a standard 14-day acute toxicity test, the LC50 for brass powder was found to be 120 to $200 \mu \mathrm{g} / \mathrm{g}$ soil. Sublethal 
effects on earthworms, as measured by weight loss, were evident at soil concentrations of $120 \mu \mathrm{g} / \mathrm{g}$. The highest concentration where no weight loss was observed was at $83 \mu \mathrm{g} / \mathrm{g}$. The completeness of these data will obviate any further need for analysis of earthworm effects of brass. However, the relative toxicity thresholds of soluble $\mathrm{Cu}$ and $\mathrm{Zn}$ solubilized from brass in a wider range of soil types may need to be assessed.

Belated Behavior. Although the aquatic fate of brass materiel is outside the scope of the present project, aspects of chemical behavior in aqueous systems are pertinent to soil systems. In aqueous systems, the solubility of cations such as $\mathrm{Cu}$ depends on the rates of formation of ionic species and insoluble inorganic salts and to a large extent on the formation of stable organic complexes with $\mathrm{Cu}$. For neutral to basic natural waters with low $O M$, hydrolysis and precipitation reactions involving carbonates should dominate. Increasing water hardness also results in decreasing toxicity, since the carbonate complex tends to be less toxic (EPA 1987). This behavior becomes important for soil systems, from the standpoint of solubilization, or insolubilization, since significant differences in weathering rates should occur for calcareous vs. non-calcareous soils. The data of Wentsel (1986) clearly show the inverse relationship between water hardness $\left(\mathrm{CaCO}_{3}\right)$ and the relative rates of $\mathrm{Cu}$ and $\mathrm{Zn}$ solubilization from brass flakes, dissolution as ionic species, and subsequent competition between solution stabilization (by complexation or chelation) and sorption/precipitation. In the case of $\mathrm{Cu}$, organic matter is a primary complexant, causing increased or decreased solubility, depending on the strengths of the competing sites. For neutral to basic natural waters with low $O M$, hydrolysis and precipitation reactions involving carbonates should dominate.

\subsection{PROJECT OBJECTIVES}

The primary objectives of this study is to characterize the fate of aerosol and deposited brass material currently in inventory and to assess the response of soil and biotic components of the terrestrial environment. The physical, chemical, and biotic aspects to be investigated will include:

1) air/surface deposition rates measured by deposition velocities in an environmental wind tunnel;

2) foliar-contact toxicity using five different types of terrestrial vegetation representative of Army training sites and surrounding environments;

3) weathering and chemistry of brass aerosols deposited and amended to soils, and impacts of acid precipitation and moisture regimes on weathering rates; 
4) the influence of soil weathering processes on seed germination and plant availability of $\mathrm{Cu}$ and $\mathrm{Zn}$; and

5) the influence of weathering and contaminant solubilization on soil microbiological communities and invertebrates associated with soils. 


\subsection{MATERIALS AND METHODS}

Tests of brass (BR) and brass mixed with fog oil (BR/FO) aerosols were conducted using the Aerosol Wind Tunnel Research Facility. The wind tunnel facility, operated by Pacific Northwest Laboratory (PNL) and located on the U.S. Department of Energy's (DOE's) Hanford Site in southeastern Washington, contains an environmental wind tunnel suitable for testing obscurant smoke under a variety of environmental conditions. The facility, shown in Figure 2.1, and supporting laboratories are used for research involving the generation, transport, deposition, and characterization of aerosols and gases in complex atmospheric environments. A detailed description of the wind tunnel is provided in Section 2.1. Additional information can be found in Van Voris et al. (1987), Cataldo et al. (1989), and Ligotke et al. (1986).

In addition to describing test facilities, this section provides detailed procedural information on exposure conditions; obscurant-aerosol generation and characterization; chemical analyses; and plant, soil, and microbiological experiments.

\subsection{AEROSOL WIND TUNNEL RESEARCH FACILITY}

The Aerosol Wind Tunnel Research Facility provides a combination of several capabilities for laboratory reproduction of natural environments. Advantages of wind tunnel tests over actual field tests include controlled and reproducible (on demand) test conditions, shorter-duration projects, and cost-effective methods of providing large quantities of usable data. It is also critically important that field simulations be performed in the dynamic conditions provided by wind tunnels rather than in static or stirred exposure chambers, because several conditions are influenced by a dynamic environment. First, contaminant aging in natural environments may include chemical and physical transformations that may be influenced by sunlight, humidity, temperature, or other parameters. Second, deposition of airborne particles, whether by diffusive or inertial forces, to various test subjects such as plants, soils, and water surfaces is strongly influenced by wind speed and the flow-field characteristics generated within plant canopies or by the boundary layers of wind over leaves and other surfaces. Finally, the chemical fate of particles deposited on surfaces or the rate of transfer of contaminants from the surface to the interior of plants and soils may be altered by the aging of surface deposits under the influences of temperature, humidity, and wind speed. Under static conditions (i.e., chambers without uniform air flow, either with or without temperature and humidity control), transport, transformation, and effects of airborne materials will likely not be similar to those occurring in actual field environments. The dynamic conditions created in an environmental 


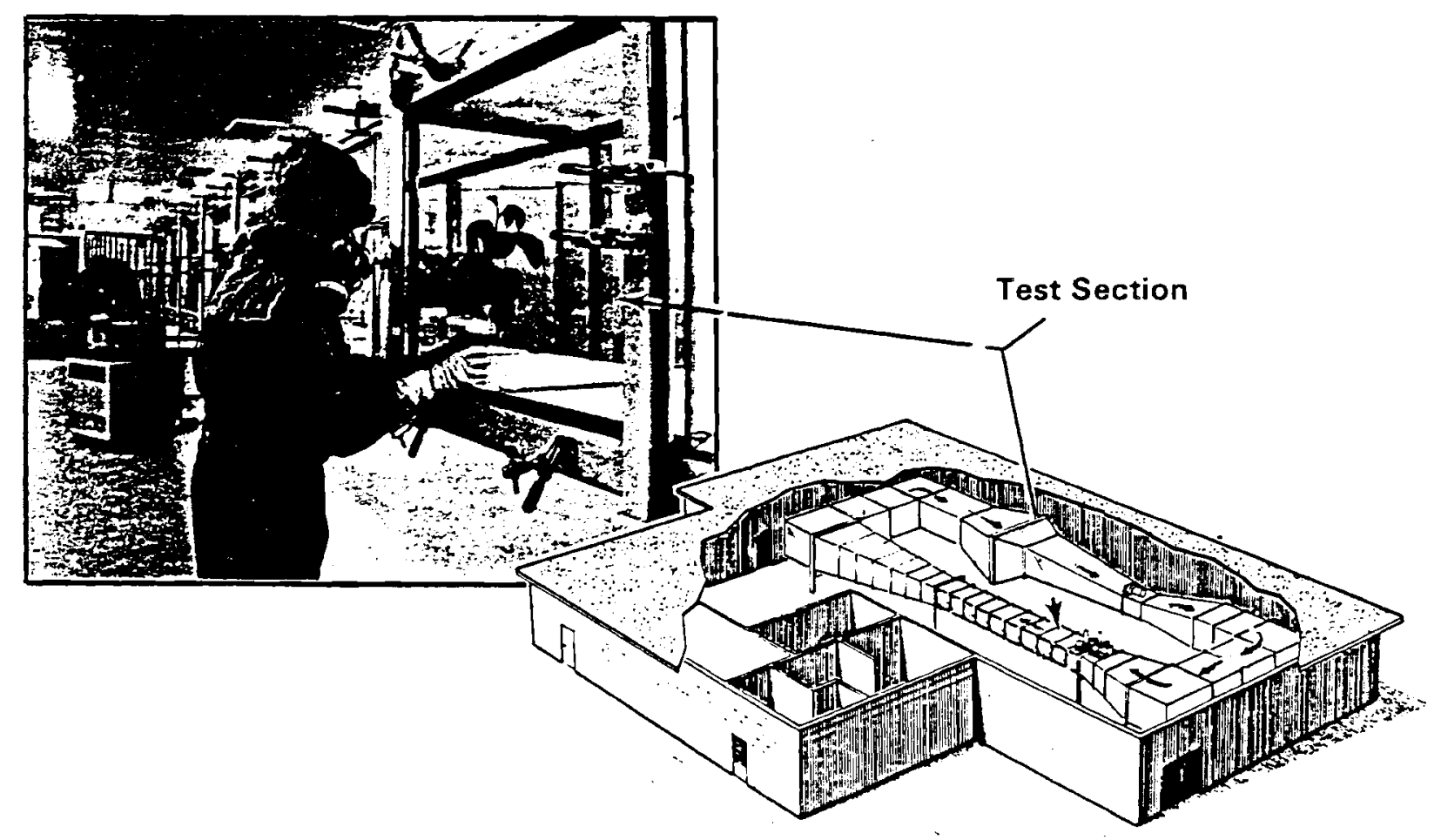

FIGURE 21. PACIFIC NORTHWEST LABORATORY AEROSOL WIND TUNNEL RESEARCH FACILITY

wind tunnel provide realistic simulation of natural environments for experiments on transport, transformation, and fate and effects.

The facility houses a sealed, recirculating (or closed-loop) wind tunnel, controlledenvironment plant growth chambers, instruments for aerosol characterization, and a computer system, and it is supported by a variety of analytical-chemistry laboratories. Designed to totally contain airborne toxic, hazardous, and radioactive materials, the facility offers a unique capability to conduct aerosol research on such materials in a dynamic environment simulating natural field conditions. Computer control and data acquisition in the wind tunnel exposure environment include temperature, humidity, illumination, wind speed, gas species concentration, and airborne-contaminant composition and dispersion.

\subsubsection{Environmental Wind Tunnel}

The environmental wind tunnel is used to study the transport, deposition, and chemical fate of airborne contaminants on physical and biological systems. The wind tunnel is ideally suited for environmental studies, because of its large, $68-\mathrm{m}^{3}\left(2400-\mathrm{ft}^{3}\right)$ volume, and because it 
is insulated and supplied with environmental-control systems. Temperature is controlled between 27 and $\sim 115^{\circ} \mathrm{C}$ by an air conditioning system, relative humidity is controlled between 5 and $95 \%$ at most temperatures by computerized injection of water vapor via an ultrasonic atomizer, and gas concentrations can be controlled by computerized injection and monitoring.

The wind tunnel is constructed of stainless steel and transparent Lexan ${ }^{\bullet}$ for resistance to chemical corrosives. A 300-psi washdown system is used to clean and decontaminate the wind tunnel following tests. Constructed as a closed-loop system as shown in Figure 2.2, the wind tunnel may also be operated in single-pass mode for many research applications by installing a $4.5-\mathrm{m}^{2}\left(48-\mathrm{ft}^{2}\right)$ bank of HEPA filters in the return section, just upwind of a $30-\mathrm{hp}$ belt-driven fan. Because of the low pressure drop across the large area of the filter bank, the maximum attainable speed in the primary test section is $31 \mathrm{~m} / \mathrm{s}(70 \mathrm{mph})$ either with or without the HEPA filters. Secondary test sections provide alternative testing locations to the $0.6-\mathrm{m}^{2}$ primary test section; two $1.5-\mathrm{m}^{2}$ test sections and one $2-\mathrm{m}^{2}$ section may be used for large test subjects.

\subsubsection{Wind Tunnel Test Section}

The primary test section of the wind tunnel is $6.1 \mathrm{~m}$ long and $0.6 \mathrm{~m}$ wide and tall, with transparent Lexan walls and ceiling (see Figure 2.1). Mean wind speed is controllable

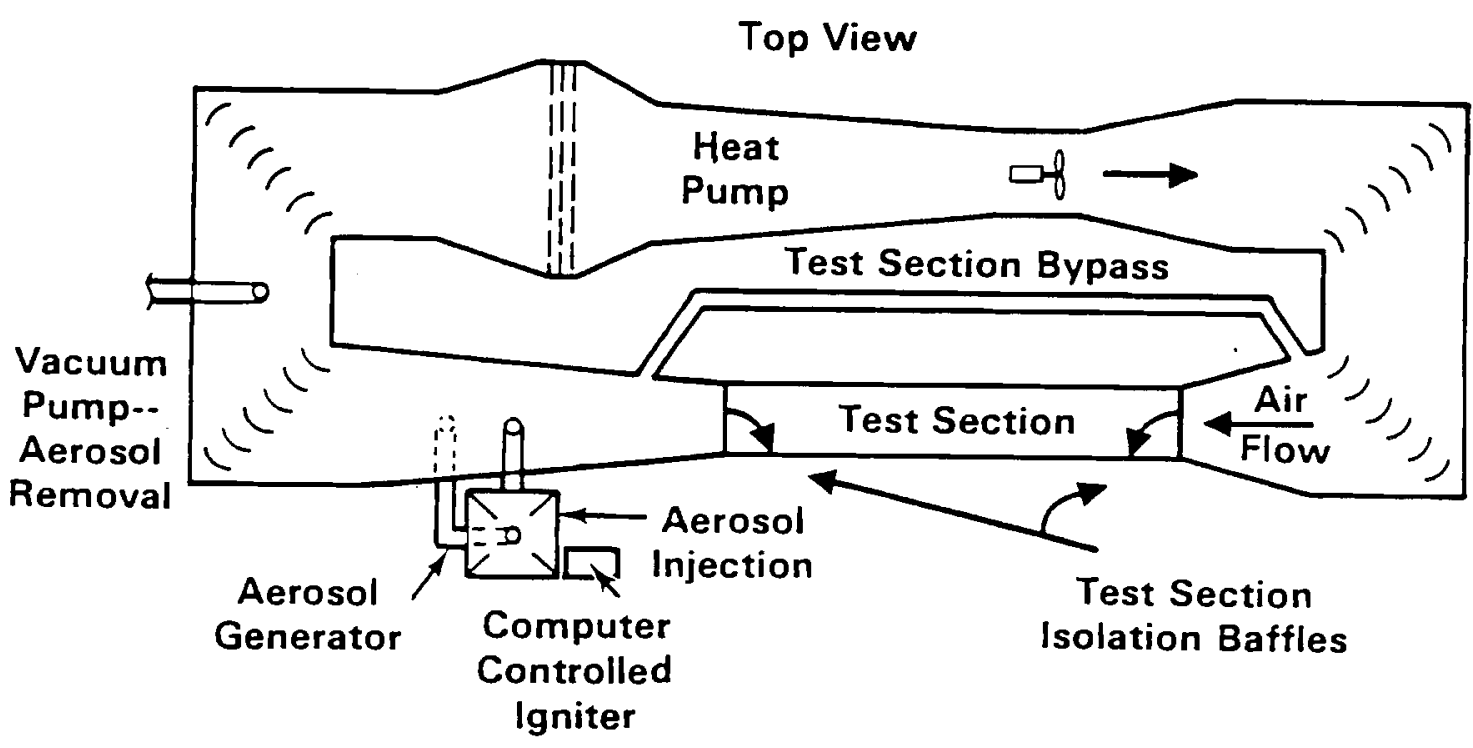

EIGURE 22. CLOSED-LOOP WIND TUNNEL, AEROSOL GENERATION AND INJECTION, AND PRIMARY TEST SECTION

\footnotetext{
- Lexan is a registered trademark of General Electric Corporation, Cleveland, Ohio.
} 
between 0.2 and $31 \mathrm{~m} / \mathrm{s}(0.5$ and $70 \mathrm{mph})$. Uniform air flow is provided by reducing the boundary layer at the inlet to the test section using a specially-shaped effuser section and turning vanes located in all corners of the wind tunnel. Velocity is uniform over the center $85 \%$ of the test-section cross-section, and velocity gradients are typically less than $4 \%$. Because aerosols usually are generated downwind of the test section, mixing is complete, and uniform contaminant concentrations are provided to test subjects. Illumination is provided to maintain plant respiration processes; four adjustable 400-W metal-halide lamps are above the test section, and UV lamps are also available. Plant pots and other portions of test subjects that do not require exposure are placed below the surface of the test section within a false floor.

Isolation baffles installed on the inlet and outlet planes of the test section facilitate tests. Upon completion of a test, these isolators are rotated upward to seal the test section from the rest of the wind tunnel. The air within the test section is then quickly cleared by purging it with clean, filtered laboratory air, thus providing a controlled end-of-test or providing an opportunity to access the test section and exchange test subjects for a second or continued exposure. During the time the test section is isolated, a bypass duct is operated, thus maintaining a dynamic atmosphere in the remainder of the wind tunnel. Because the primary test section contains only $5 \%$ of the total wind-tunnel volume, tests can be performed in series by reopening the test section and continuing testing immediately, without having to recreate the test atmosphere.

\subsubsection{Aerosol Instrumentation}

An inventory of instrumentation is available to monitor the test environment and aerosol concentration, particle size distribution and shape, and chemical composition. A computer-control and data-acquisition system is used to operate experiments and document monitoring-instrument data and status. In addition to aerosol-measuring devices, aerosol generators for generating most types of suspended particulate contaminates are available.

Aerosol mass concentrations from $<0.01 \mathrm{mg} / \mathrm{m}^{3}$ to $>10 \mathrm{~g} / \mathrm{m}^{3}$ are measured using isokinetic filter samples, laser transmissometers, and single- and multiple-particle light-scattering devices. Physical samples are analyzed gravimetrically, chemically, fluoroscopically, or by optical or scanning-electron microscopy (SEM). Particle size distributions of airborne contaminants are measured for particles with diameters ranging from 0.003 to $450 \mu \mathrm{m}$ using a variety of instruments employing inertial, diffusive, optical, hot-film, or electrical-mobility classifying procedures. One analyzer sizes and counts particles remotely using a pair of $\mathrm{He}$-Ne laser beams. That device provides several advantages: particles can be analyzed without using a physical probe that may influence air-flow and particle-deposition patterns, airborne material 
can be rapidly (in real-time) analyzed, and the need to remove toxic and hazardous materials from the wind tunnel for analysis is reduced.

\subsection{AEROSOLEXPOSURE CONDITIONS}

Exposure conditions were controlled within the wind tunnel. Not including trial tests, three series of BR or BR/FO tests were performed. Other than differences in environmental parameters and aerosol generation and composition, general operating procedures were similar for all tests. In addition to aerosol parameters, test parameters were wind speed, duration of exposure, and relative humidity (trial tests only). Temperature was controlled at ambient levels and was monitored, but it was not varied as a test parameter. After setting the test environment before each test, obscurant aerosols were generated and maintained at roughly constant levels to provide known test conditions.

\subsubsection{Exposure Environment}

Air temperature and relative humidity were monitored using a General Eastern Model 1500 Hygrocomputer. Temperature was obtained using a remote thermocouple probe, and samples drawn from the wind tunnel were filtered and condensed on a chilled mirror to measure the dew point. Relative humidity was then determined by comparing air temperature with the dew-point temperature. The hygrocomputer was calibrated by comparing it with a certifiedprecision controlled-draft sling psychrometer.

Lighting, provided by four 400-W metal-halide lamps, was not measured during the tests, but the lamps previously had been shown to provide a lighting intensity at mid-canopy height of $500 \mu \mathrm{E} / \mathrm{m}^{2} / \mathrm{s}$ photsyntheticaly active radiation PAR (400 to $700 \mathrm{~nm}$ ). In comparison,

typical maximum outside lighting (overhead sun, no clouds) is approximately $1200 \mu \mathrm{E} / \mathrm{m}^{2} / \mathrm{s}$ PAR.

Wind speed was controlled using an adjustable-speed drive connected to a 30-hp dc motor which in turn drove an axial fan. Mean, or average, wind speed was monitored using a pitot-static probe connected to an MKS Inc. Baratron differential pressure transducer. The transducer was calibrated by comparing it with a Dwyer Model 1430 micromanometer having a certified micrometer.

\subsubsection{Brass and Mixed-Brass and Foo-Oil Test Series}

Two series of trial tests and three series of plant, soil, and microbial exposure tests were performed. Trial tests were performed on both BR and BR/FO aerosols, including tests of 
the influence of low and high relative humidities on aerosol characteristics. Exposure tests included wind-speed and range-finding tests; only a wind-speed-exposure test series was performed for BR/FO aerosols. Table 2.1 lists each test series, individual tests in each series, dates, aerosol compositions, and exposure conditions.

\section{IABLE21. BRASS AND BRASS/FOG-OIL TEST SERIES}

Exposure Conditions

\begin{tabular}{llcccc}
\multicolumn{1}{c}{ Series } & \multicolumn{1}{c}{ Tests } & Date & Aerosol & $\begin{array}{c}\text { Wind Speed } \\
\text { (m/s) }\end{array}$ & $\begin{array}{c}\text { Relative Humidity } \\
\text { (\%) }\end{array}$ \\
\hline BR Trials & $\begin{array}{c}\text { BR-01 to }-09 \\
\text { BR-14 \& }-15\end{array}$ & $\begin{array}{c}12 / 88 \text { to } \\
3 / 89\end{array}$ & BR & 0.9 to 4.7 & 20 to 90 \\
BR Wind-Speed & BR-10 to -13 & $3 / 89$ & BR & 0.9 to 4.7 & 46 \\
BR Range-Finding & BR-16 to -19 & $4 / 89$ & BR & $0.9 \mathrm{~m} / \mathrm{s}$ & 46 \\
BR/FO Trial & $\begin{array}{l}\text { BR/FO-T1 to -T3 } \\
\text { BR/FO-01 \& }-02\end{array}$ & $8 / 89$ & BR/FO & 0.6 to 2.8 & $\sim 45$ \\
BR/FO Wind-Speed & BR/FO-03 to -07 & $8 / 89$ & BR/FO & 0.9 to 4.6 & 47 \\
\hline
\end{tabular}

\subsubsection{Test Procedures and Measured Conditions}

The dynamic exposure environment of the wind tunnel was used for all BR and BR/FO exposure tests to most closely represent particle-deposition phenomena in the field which are strongly influenced by wind-speed and air-flow patterns within plant canopies. Brass aerosols were generated within the wind tunnel, downwind of the test section, and FO aerosols were generated directly into the wind tunnel at a location roughly $6 \mathrm{~m}$ downwind of the brass aerosol generator (both generation methods are discussed in Section 2.3). Exposure tests were started about 2 min following the initiation of brass-aerosol generation when brass particles first circulated the wind tunnel and were present in the test section. Generation of FO aerosols was begun $3 \mathrm{~min}$ before the brass-aerosol generation to allow time for warm-up of the generator. Target concentrations were generally achieved within the first 5 to $10 \mathrm{~min}$ of each exposure. Test durations ranged from 30 to $480 \mathrm{~min}$. Tests were terminated using isolation baffles located at each end of the primary test section. Two minutes before the end of the test, aerosol generation was ended, the wind tunnel fan was turned off, isolation baffles were 
rotated into position, and filtered laboratory air was passed through the test section to flush residual brass and FO aerosol. Tests were considered ended after wind speed was stopped, because visible residual aerosol concentrations were flushed from the test section within about $1 \mathrm{~min}$.

Effluent from the wind tunnel was cleaned of particulate matter using a HEPA filter during the BR tests and a 300-cfm dual-stage water scrubber during the BR/FO tests. Material deposited to inner walls of the wind tunnel was removed using water spray, collected, removed from the rinse water using filters or separation methods, and disposed.

Table 2.2 shows the environmental and test conditions in the wind tunnel during each test. Temperature, relative humidity, and wind speed as well as aerosol mass-concentration data were recorded using the computer-control and data-acquisition system. Temperature and relative humidity, excluding the two trial test series, averaged $22.1 \pm 0.8^{\circ} \mathrm{C}$ and $46 \pm 2 \%$. Wind speed was controlled at $0.9,1.8,2.7$, and $4.5 \mathrm{~m} / \mathrm{s}$. Test-to-test variations at each wind speed averaged $3 \%$. The influence of relative humidity was investigated tests BR-03 through -05 ; relative humidities were 23,86 , and $45 \%$, respectively. Exposure durations, excluding the trial tests, ranged from 30 to $480 \mathrm{~min}$. Test BR/FO-06 was terminated after $30 \mathrm{~min}$ to avoid the excessive loading observed during the similar BR/FO-07 test.

\subsection{OBSCURANT (AEROSOL) GENERATION}

Obscurant aerosols of brass-flake powder and fog oil (FO) mixed with brass (BR/FO) were generated during exposure tests in the wind tunnel. Brass test material was characterized by physical density and by scanning electron microscopy. Generation procedures for BR were developed during the trial tests, in which the influence of generator operating characteristics and relative humidity were investigated. Brass aerosol size distributions were measured at two locations in the wind tunnel. Fog oil was obtained from the same batch used during previous obscurant tests (Cataldo et al. 1989). Fog oil aerosol-generation procedures were similar to those used in previous tests, except that the aerosol was generated directly into the wind tunnel rather than into a buffer tank.

\subsubsection{Test Material}

Test material was supplied by the U.S. Army. Brass material was from a batch labeled E3227. The FO used in all tests was from a 55-gal barrel designated SGF-2-3, Fog Oil, MIL-F 12070B, Type SGF-2, 9150-00-261-7895, Lot \#1, DLA Goo-83-C-1284. The FO was stored until use in a cool room under a nitrogen atmosphere, to prevent oxidation and the possible 
formation of sludge. No discoloration or sludge formation was observed when FO was removed from the source before the $8 / 89 \mathrm{BR} / \mathrm{FO}$ test series or during the tests.

IABLE 2.2. ENVIRONMENTAL CONDITIONS, WIND SPEED, AND EXPOSURE DURATION DURING BRASS (BR) AND BRASS/FOG OIL (BR/FO) OBSCURANT TESTS

\begin{tabular}{|c|c|c|c|c|c|}
\hline Test & Date & $\begin{array}{c}\text { Temperature } \\
\left({ }^{\circ} \mathrm{C}\right)\end{array}$ & $\begin{array}{c}\text { Relative } \\
\text { Humidity } \\
(\%)\end{array}$ & $\begin{array}{l}\text { Wind } \\
\text { Speed } \\
(\mathrm{m} / \mathrm{s})\end{array}$ & $\begin{array}{c}\text { Exposure } \\
\text { Duration } \\
\text { (min) }\end{array}$ \\
\hline \multicolumn{6}{|l|}{ BRTrials } \\
\hline BR-01 & $12 / 29 / 88$ & $23.3 \pm 0.5$ & $30 \pm 7$ & $\sim 0.9$ & $\sim 90$ \\
\hline BR-02 & $12 / 30 / 88$ & $22.3 \pm 0.2$ & $25 \pm 3$ & -0.9 & $\sim 120$ \\
\hline BR-03 & $1 / 4 / 89$ & $24.2 \pm 0.2$ & $23 \pm 1$ & $\sim 0.9$ & 132 \\
\hline BR-04 & $1 / 5 / 89$ & $22.1 \pm 0.4$ & $86 \pm 3$ & $0.93 \pm 0.03$ & $\sim 120$ \\
\hline BR-05 & $3 / 1 / 89$ & $21.3 \pm 0.1$ & $45 \pm 1$ & $0.97 \pm 0.03$ & 60 \\
\hline BR-06 & $3 / 1 / 89$ & $20.4 \pm 0.1$ & $46 \pm 1$ & $4.67 \pm 0.05$ & 60 \\
\hline BR-07 & $3 / 2 / 89$ & $19.7 \pm 0.3$ & $44 \pm 2$ & $2.70 \pm 0.01$ & 60 \\
\hline BR-08 & $3 / 2 / 89$ & $21.3 \pm 0.1$ & $44 \pm 1$ & $0.91 \pm 0.03$ & 75 \\
\hline BR-09 & $3 / 2 / 89$ & $21.5 \pm 0.2$ & $47 \pm 7$ & $0.91 \pm 0.03$ & 155 \\
\hline BR-14 & $3 / 3089$ & $22.6 \pm 0.2$ & $53 \pm 15$ & $0.89 \pm 0.03$ & 210 \\
\hline BR-15 & $3 / 30 / 89$ & $23.8 \pm 0.2$ & $56 \pm 2$ & $0.74 \pm 0.07$ & 60 \\
\hline \multicolumn{6}{|l|}{ BB Wind Speed } \\
\hline BR-10 & 3/7/89 & $21.3 \pm 0.1$ & $45 \pm 1$ & $4.49 \pm 0.05$ & 60 \\
\hline BR-11 & $3 / 8 / 89$ & $21.5 \pm 0.1$ & $47 \pm 1$ & $2.69 \pm 0.03$ & 60 \\
\hline BR-12 & 3/9/89 & $21.6 \pm 0.1$ & $46 \pm 1$ & $1.77 \pm 0.02$ & 60 \\
\hline $\begin{array}{r}\text { BR-13 } \\
\text { BRRance Finding }\end{array}$ & $3 / 10 / 89$ & $22.5 \pm 0.1$ & $46 \pm 2$ & $0.87 \pm 0.02$ & 60 \\
\hline BR-16 & $4 / 4 / 89$ & $22.4 \pm 0.2$ & $46 \pm 2$ & $0.88 \pm 0.03$ & 120 \\
\hline BR-17 & $4 / 5 / 89$ & $23.4 \pm 0.5$ & $47 \pm 2$ & $0.89 \pm 0.03$ & 240 \\
\hline BR-18 & $4 / 10 / 89$ & $22.2 \pm 0.4$ & $45 \pm 3$ & $0.87 \pm 0.02$ & 360 \\
\hline BR-19 & $4 / 11 / 89$ & $22.8 \pm 0.4$ & $46 \pm 2$ & $0.86 \pm 0.02$ & 480 \\
\hline \multicolumn{6}{|l|}{ BRFO Trials } \\
\hline BR/FO-T1 & $8 / 1 / 89$ & $20.1 \pm 0.1$ & $38 \pm 2$ & $0.58 \pm 0.01$ & 60 \\
\hline BR/FO-T2 & $8 / 2 / 89$ & $21.4 \pm 0.1$ & $46 \pm 1$ & $1.98 \pm 0.04$ & 120 \\
\hline BR/FO-T3 & $8 / 3 / 89$ & $22.2 \pm 0.1$ & $45 \pm 2$ & $1.81 \pm 0.02$ & 158 \\
\hline BR/FO-01 & $8 / 4 / 89$ & $22.4 \pm 0.2$ & $46 \pm 1$ & $1.84 \pm 0.03$ & 61 \\
\hline BR/FO-02 & $8 / 14 / 89$ & $22.1 \pm 0.2$ & $45 \pm 1$ & $2.76 \pm 0.03$ & 60 \\
\hline \multicolumn{6}{|l|}{ BRFE Wind Speed } \\
\hline BR/FO-03 & $8 / 8 / 89$ & $22.7 \pm 0.1$ & $51 \pm 1$ & $0.91 \pm 0.02$ & 60 \\
\hline BR/FO-04 & $8 / 15 / 89$ & $21.0 \pm 0.2$ & $46 \pm 1$ & $1.76 \pm 0.10$ & 62 \\
\hline BR/FO-05 & $8 / 15 / 89$ & $21.8 \pm 0.1$ & $44 \pm 3$ & $2.65 \pm 0.11$ & 60 \\
\hline BR/FO-06 & $8 / 16 / 89$ & $21.1 \pm 0.1$ & $47 \pm 2$ & $4.46 \pm 0.12$ & 30 \\
\hline BR/FO-07 & $8 / 8 / 89$ & $23.0 \pm 0.2$ & $47 \pm 1$ & $4.56 \pm 0.10$ & 60 \\
\hline
\end{tabular}


Brass material was characterized physically and by scanning electron microscopy. The bulk density of brass powder was $1.2 \mathrm{~g} / \mathrm{cm}^{3}$, and its packing density was $1.7 \mathrm{~g} / \mathrm{cm}^{3}$. Surveys by SEM indicated no obvious deformations of the source material caused by the generation processes. The brass flakes, from the source material,measured as the average flat-face dimension of the flakes, ranged from $<0.5$ to $\sim 20 \mu \mathrm{m}$, with most flakes apparently ranging between 5 and $10 \mu \mathrm{m}$; the true number of smaller flakes was not certain, however, because of their predominate tendency to attach to the top and bottom faces of the larger flakes and thus to be partially obscured. Flake thickness was $0.5 \pm 0.25 \mu \mathrm{m}$.

\subsubsection{Brass Aerosol Generation}

Brass-flake powder material was generated by a sonic nozzle to disperse the powder in the air of the wind tunnel. The nozzle consisted of a 0.25 -in. stainless-steel tube, through which the brass powder was pneumatically transferred, surrounded by a concentric annular region, through which compressed air was expanded. We experimentally determined the dimensions of the annular region and the distance beyond the face of the annular region that the 0.25 -in. nozzle extended. The selected configuration was the combination of annulus and tube extension that provided the greatest amount of static suction of the free end of the tube through which brass powder was fed into the system. Figure 2.3 is a schematic sketch of the sonicnozzle generator. An "F" drill diameter, 0.257 in., was used to provide an annular gap of 0.0035 in. The area of the annular region through which the compressed air expanded was therefore $0.0028 \mathrm{in}^{2}\left(0.018 \mathrm{~cm}^{2}\right)$. The extension of the 0.25 -in. tube through the face of the 0.26 -in. plate through which the annulus hole was drilled was set at $\sim 0.05 \pm 0.03$ in.

The sonic nozzle was attached to the top of the wind tunnel and oriented so that the feed tube was vertical and the delivery spray of brass aerosol was horizontal and in the downwind direction. A conical pattern of brass aerosol therefore was generated, expanding as the cross section of the wind tunnel expanded from 0.4 to $2.3 \mathrm{~m}^{2}$ over a length of $6 \mathrm{~m}$ immediately downwind of the test section. The aerosol then passed through the first set of turning vanes, past the downwind location of particle size measurement, through the axial-fan section and three additional sets of turning vanes, and into the wind tunnel test section. This generation procedure allowed the largest particles, flocs of agglomerated flakes, to settle under the influence of gravity and be removed from the aerosol.

In addition to the physical geometry of the brass-feed tube and the annular region of the sonic nozzle, operating characteristics of the system included control of the compressed-air pressure and brass-powder feed rate. Compressed air was passed at pressure through a flow meter and both the pressure and flow meter reading were measured; pressure was maintained 
within approximately 3 psi of target values. Pressures ranging from 40 to $95 \mathrm{psig}$ were tested and were shown to have minor impact on powder-dispersion effectiveness and aerosol particle size distribution (particle size was about $0.5 \mu \mathrm{m}$ smaller at $90 \mathrm{psi}$, see Section 3.1).

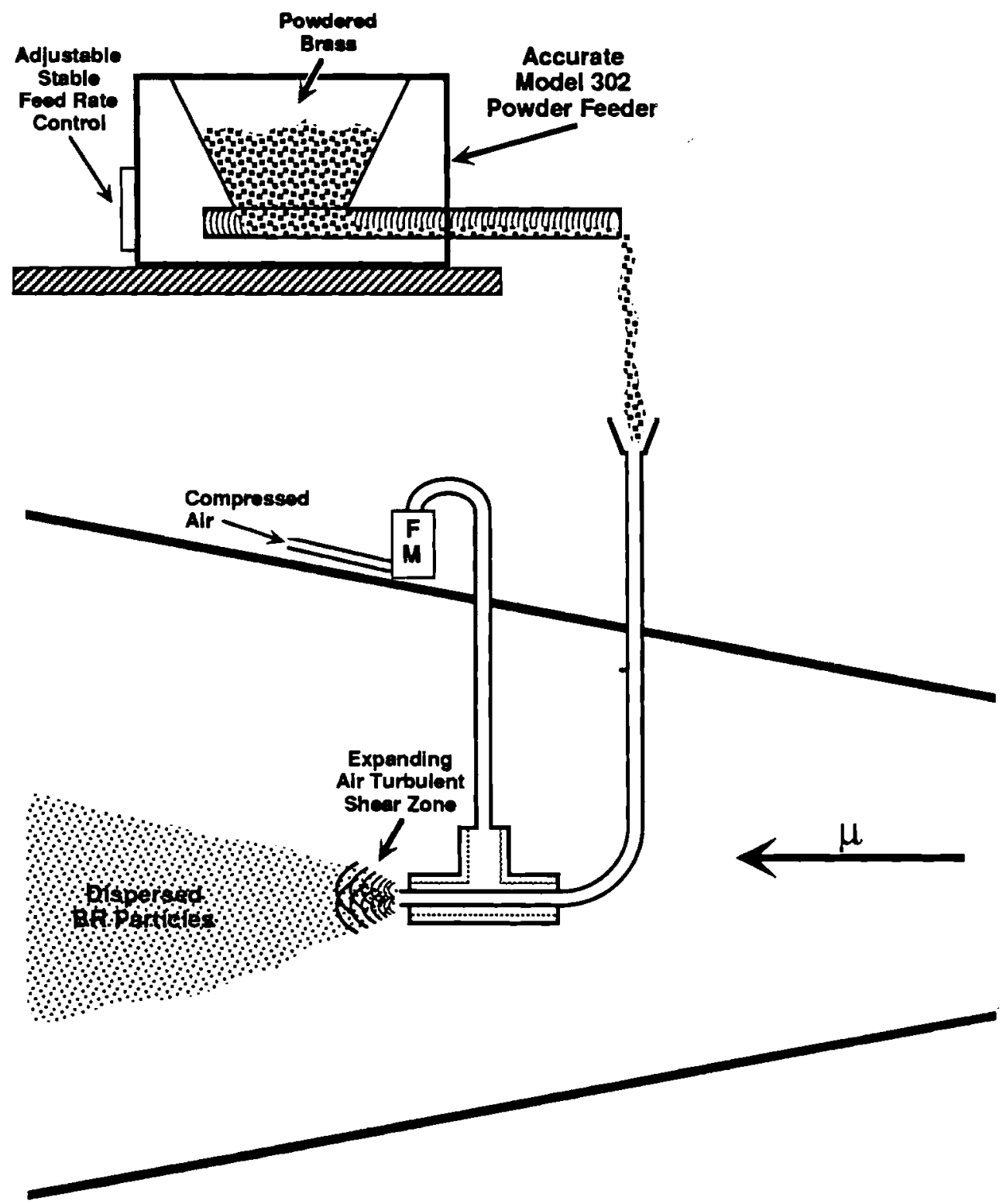

EIGURE 2.3. SCHEMATIC OF THE SONIC-NOZZLE AEROSOL GENERATOR DEVELOPED TO DISPERSE BRASS-FLAKE POWDER AS AN OBSCURANT AEROSOL 
Most exposure tests were performed at pressures of 80 to $90 \mathrm{psig}$. The Accurate Model 302 powder feeder proved to supply brass powder at a repeatable, nearly steady rate, and was a great improvement over the early manual tests. The feeder contained an 8-I powder hopper and a horizontal screw with a 1:1000 turn-rate control selector. The walls of the hopper agitated the powder and provided a constant powder head to the screw. The feeder was calibrated for settings ranging from 100 to 800 and was found to provide brass powder to the funnel at the top of the vertical feed tube of the sonic nozzle at a repeatable rates of 0.7 to $11 \mathrm{~g} / \mathrm{min}$. Consecutive measurements indicated an average powder feed rate repeatability of $\sim 1 \%(<3 \%)$. However, a decrease in feed rate of 0 to $10 \%$ per 120 min occurred. This degree of feed-rate stability was sufficient for generating brass aerosol for exposure tests in the wind tunnel.

Generation of brass followed similar procedures during each test after the first four trial tests, when the brass feed was provided manually. The static suction of the generator was determined pre- and post-test to ensure sufficient pneumatic force to convey the brass powder through the feed tube. The suction was determined by removing the funnel and sealing the top of the vertical feed tube; a static suction of 16 in. $-\mathrm{H}_{2} \mathrm{O}$ was common. The sonic nozzle was cleaned every several tests, because we observed that microscopic deposits tended to form at the sonic-flow annulus. This condition did not noticeably affect aerosol-generation effectiveness when brass was generated singly. The generator was operated at an increased brass-powder feed rate during the first 5 to $10 \mathrm{~min}$ of tests to provide a rapid build-up of aerosol concentration in the wind tunnel. The feed rate was then reduced and maintained at a stable rate for the remainder of each test unless a minor increase or decrease was required to adjust aerosol concentration.

After test BR-09 the potential for resuspension of brass particles deposited in the wind tunnel during previous tests was investigated. The total amount of brass deposits in the wind tunnel at that time was estimated to be $\sim 1000 \mathrm{~g}$. Resuspension and visible brass-aerosol formation occurred only at the greatest tested wind speeds $(4.5 \mathrm{~m} / \mathrm{s})$. At that wind speed the concentration of resuspended brass was $6 \mathrm{mg} / \mathrm{m}^{3}$, and thus did not contribute significantly to most generated brass aerosols. This otherwise invisible aerosol was observed as flecks of light reflected off of the sparse particles as they traveled through the He-Ne laser beam of the transmissometer mounted in the wind tunnel test section.

\subsubsection{Mixed-Brass and Feg-Oil Aerosol Generation}

Mixed aerosols of BR/FO were generated by operating both generators at the same time, rather than sequentially, as mixed-obscurant aerosols of WP, FO, and HC were generated during previous tests (Cataldo et al., 1990b). The brass generator was operated as described 
above, with minor modifications, and the FO generator was operated roughly $6 \mathrm{~m}$ downwind, along the west side of the wind tunnel. The two aerosols thereby were mixed in the wind tunnel.

Brass-generation rates decreased during early BR/FO wind-speed tests. The feed tube of the sonic nozzle was found to be partially plugged with an oily substance mixed with brass powder. This was attributed either to entrainment of FO droplets in the exit plane of the sonic nozzle's feed tube (perhaps caused by the structure of turbulence generated by the expanding air from the annular region) or to the presence of fine oil droplets in the source of compressed air. Compressed-air filters were serviced and found to be operating normally; this suggested that FO droplets were likely the cause of the reduced brass transport in the feed tube. Although the sonic nozzle was disassembled and cleaned prior to all but the first two (BR/FO-03 and -07) wind speed tests, the clogging problem continued to reduce the concentration of the brass component of the mixed aerosol. A 3-cm-diameter by 10-cm-long plastic flow guide was attached to the end of the sonic nozzle to prevent backflow reintrainment of $F O$ aerosol in the BR feed tube, nevertheless, results in the remaining three tests were mixed, and the clogging problem remained.

Fog oil aerosols were generated using the procedure described by Cataldo et al. (1989). Aerosols of FO liquid were produced by vaporizing the liquid and condensing the resulting FO vapors to form micrometer-size droplets. This laboratory method originally was developed to simulate the method used in the field: vaporization of FO on hot exhaust manifolds. Fog-oil liquid was pumped at steady rates from a reservoir onto a $600^{\circ} \mathrm{C}$ immersion heater contained in the inlet end of a 1-m-long, 2.5-cm-diameter stainless-steel tube, as shown in Figure 2.4. Vapor from the immersion heater was then passed through a $300^{\circ} \mathrm{C}$ region of the tube and into the wind tunnel. The carrier gas was a mixture of $96 \%$ nitrogen and $4 \%$ air, representing the low oxygen content of the field generation system (the carrier gas contained about $0.8 \%$ oxygen). The flow rate of $\mathrm{FO}$ liquid into the generator was controlled using a liquid pump calibrated between 0.3 and $5 \mathrm{~mL} / \mathrm{min}$. The flow rate was maintained at $4 \mathrm{~mL} / \mathrm{min}$ for the first $\sim 25$ min of each test to build up concentration within the wind tunnel and then was adjusted to a steady rate of $2 \mathrm{~mL} / \mathrm{min}$ for the remainder of the test.

\subsection{OBSCURANT (AEROSOL) CHABACTERIZATION}

Brass (BR) and mixed BR/FO aerosols were characterized during each trial and exposure test. Measurements were made to provide data on the aerosol mass concentration, and chemical analyses of data provided information on the chemical constituents of brass alone and of mixed aerosols. Particle size distribution was measured during each test, and special measurements were made to determine the influence on aerosol particle size 
distribution of sonic nozzle aerosol-generator operating conditions, relative humidity, and distance downwind of the generator. Surrogate-substrate deposition coupons were suspended in the air flow of the wind tunnel to provide information on the rate of deposition, or deposition velocity, of BR and BR/FO aerosols as influenced by chemical composition and wind speed. Procedures for these measurements are discussed in this section, and results are presented and discussed in Section 3.1. Subsequent sections present additional information on chemical characteristics of the material and on test subjects.

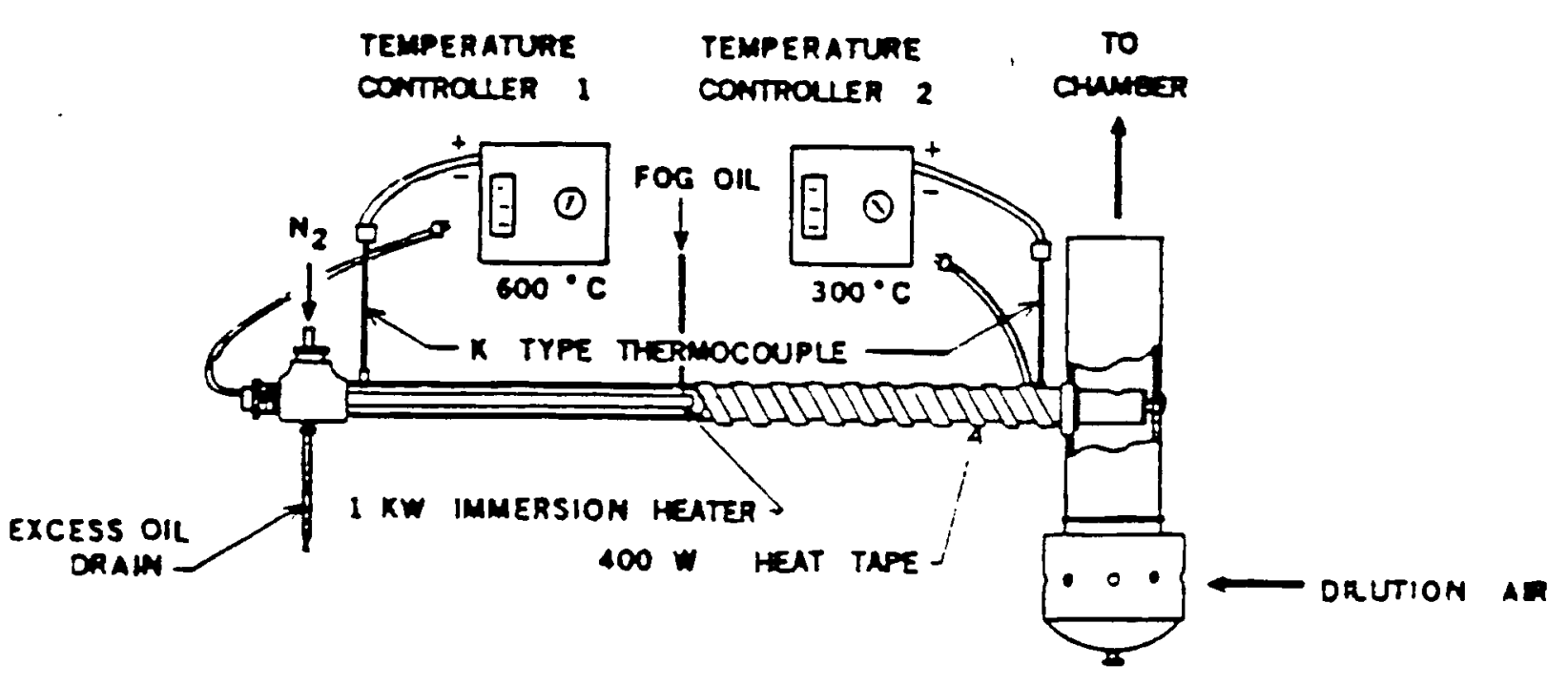

EIGURE 2.4. TEMPERATURE-CONTROLLED FOG OIL AEROSOL GENERATOR USED IN CONJUNCTION WITH THE BRASS GENERATOR FOR MIXED SMOKES

\subsubsection{Aerosol Mass Concentration and Chemical Composition}

The primary method of measuring aerosol mass concentration was to collect representative samples of the wind tunnel atmosphere on $25-\mathrm{mm}$ glass-fiber filter pads. These samples were analyzed gravimetrically, and selected filters were submitted for subsequent analysis for $\mathrm{Zn}$ and $\mathrm{Cu}$. The chemical analyses were especially important in determining the relative concentrations of BR/FO aerosols. Representative samples were obtained immediately 
downwind of the wind tunnel test section (yet upwind of the two aerosol generators) using a sharp-edged, straight sampling nozzle having a $0.48-\mathrm{cm}$ diameter and $\sim 10-\mathrm{cm}$ length between the nozzle tip and the collector. The nozzle was operated isokinetically to effectively sample all particles in the aerosols, and the flow rate was controlled so that the velocity within the probe was nearly equal to that in the surrounding test section. Sample flow rates were controlled using calibrated critical-orifice meters. Depending on test length, 6 to 18 aerosol concentration samples were obtained during each test, excluding the trials. Samples were weighed to \pm 0.05 mg using a Mettler AE163 mass balance. To limit mass loss caused by the slow evaporation rate of the FO component of the aerosol, masses were obtained 30 to $60 \mathrm{~s}$ after the sample was removed from the wind tunnel during the BR/FO tests. Selected samples were then contacted with $5 \mathrm{~mL}$ of $6 \mathrm{M} \mathrm{HNO}_{3}$ and then diluted with $0.01 \mathrm{M} \mathrm{HNO}_{3}$ for a total solvent volume of $15.0 \mathrm{~mL}$.

Measurements of aerosol mass concentration were also made using a $\mathrm{He}-\mathrm{Ne}$ laser transmissometer during each test. Obscuration data also were obtained at the $0.633-\mathrm{nm}$ wavelength of the laser. The laser beam was propagated horizontally across the test section of the wind tunnel upwind of the test subjects. These measurements were made to provide, where applicable, a minute-to-minute record of aerosol mass concentration. Measurements consisted of the ratio of the transmitted versus the emitted laser power, or intensity, at each sample interval and were recorded using the computer control and data acquisition system. Although the system did not provide usable data during several of the brass aerosol tests, because aerosol concentration was less than the detectable limit, the transmissometer provided usable information for some BR and all BR/FO tests. To improve measurement reliability, an antistatic coating was applied to the Lexan walls of the wind tunnel test section to prevent particle deposition and resulting attenuation of the laser beam. Because of its limited effectiveness, data from the transmissometer were not included in determinations of aerosol mass concentration.

The chemical compositions of BR and BR/FO aerosols were measured to provide information on three characteristics of the aerosols. First, the ratio of $\mathrm{Zn}$ to $\mathrm{Cu}$ in the aerosolconcentration and deposition-coupon samples was determined. Second, the mass of $\mathrm{Zn}$ and Cu was compared to the gross mass measured using the gravimetric procedure. The brass component of aerosol-concentration and deposition-coupon samples was determined by comparing the mass of $\mathrm{Zn}$ and $\mathrm{Cu}$ to the total mass collected, the difference being attributed to the FO component. Third, a few particle size distribution samples were analyzed to provide information on the ratio of $\mathrm{Zn}$ to $\mathrm{Cu}$ and brass to $\mathrm{FO}$ at various particle size ranges in the aerosols. Moisture uptake by brass aerosols was not anticipated. Samples from test BR-04 ( $86 \%$ relative humidity) were checked, and were found not to contain measurable moisture levels. 


\subsubsection{Aeresol Particle Size Distribution}

It is important to characterize the particle size distribution of aerosols generated for environmental transport and fate studies, because particle size is the aerosol characteristic most closely related to transport characteristics for particles greater than 0.1 to $1 \mu \mathrm{m}$ in diameter. The particle size distribution of an aerosol may be based on particle number frequency, aerosol mass, or other parameters such as surface area or particle volume. The particle size distributions of the BR and BR/FO aerosols generated during the current study were characterized by aerodynamic mass median diameter rather than actual physical diameter, because the aerodynamic diameter provided information on the inertial characteristics of the particles. These characteristics influenced particle transport through complex flow fields such as those that existed in the exposed plant canopies and accounted for the large specific gravities and nonspherical shapes of the particles. Measurements of the aerodynamic characteristics were especially useful for brass aerosols, because they have relatively larger aerodynamic mass median sizes (about $5 \mu \mathrm{m}$ ) compared with the aerodynamic mass median sizes of other obscurant materials such as RP/BR, WP, FO, and $\mathrm{HC}(\sim 1.5$ to $3 \mu \mathrm{m})$.

The size distributions of BR and BR/FO aerosols were measured using eight-stage Andersen ambient-style cascade impactors operated at approximately $24.5 \mathrm{Lpm}$. The impactors classified the sampled aerosols into nine different particle size categories, ranging approximately from 0.5 to $10 \mu \mathrm{m}$, a range encompassing nearly all of the mass of the sampled aerosols. Samples were drawn from the wind tunnel a distance of about $4 \mathrm{~m}$ upwind of the test section, in a low velocity region of the wind tunnel selected to minimize particle sampling losses at the inlet of the impactors. The inlets of the impactors were modified with a 1.9-cmdiameter, $15-\mathrm{cm}$-long inlet tube that was shaped in a gradual bend of $90^{\circ}$. Particulate matter was collected on stages within the impactors, on pre-weighed $81-\mathrm{mm}$ glass-fiber-filter substrate. Each impactor stage was analyzed gravimetrically, and one set of samples was submitted for chemical analysis. Losses associated with sampling the aerosols were documented by comparing the aerosol concentration obtained by analysis of the impactor samples to that determined by the isokinetic aerosol samples.

Samples of aerosol particle size distribution usually were obtained during the middle portions of each test, and therefore were similar. However, samples also were obtained to provide information on the influence on particle size distribution of aerosol-generator characteristics such as operating air pressure and test conditions such as wind speed and relative humidity. One measurement was also made in the settling plume trom the sonic nozzle to provide a measure of the aerosol before large agglomerated particles were lost in the return section of the wind tunnel. 


\subsubsection{Brass and Mixed Brass and Fog Oil Particle-Deposition Velocities}

The rate of particle deposition, or deposition velocity, to surrogate surfaces was measured to compare it with deposition velocities to plant and soil samples. Typically, eight 47-mm glass-fiber-filter substrates were suspended horizontally in the wind tunnel test section, sandwiched behind and between the coils of two $\sim 1-\mathrm{cm}$-diameter springs. The deposition coupons were suspended at a location upwind of the test subjects. The coupons were located at elevations of 10 to $50 \mathrm{~cm}$ above the floor of the test section. Deposition coupons were weighed before and after each test. Selected coupons were then submitted for chemical analysis. Deposition velocity was determined for each sample using the equation Ud $=(1.667$ $\left.\times 10^{4}\right) \times(M \times A) /\left(C_{m} \times \Delta t\right)$, where Ud is the deposition velocity in $\mathrm{cm} / \mathrm{s}, M$ is the mass deposited to the sample in $\mathrm{mg}, A$ is the surface area of the deposition coupons, in $\mathrm{cm}^{2}$, and $\mathrm{C}_{\mathrm{m}}$ is the average aerosol mass concentration in $\mathrm{mg} / \mathrm{m}^{3}$ throughout the test duration $\Delta \mathrm{t}$, in min. Surface area was determined to be $34 \mathrm{~cm}^{2}$, the area of the top and bottom of the filter surface less the area estimated to have been covered by the springs' coils. Although deposits of BR/FO aerosols were especially heavy on the thin leading edge of the coupons to represent as closely as possible the method used for determining the deposition rate to plant leaves the surface area used in calculations included both top and bottom areas of the coupons.

\subsection{CHARACTERIZATION OF BRASS}

\subsubsection{Chemical Characterization of Brass Flake}

Brass flake material, labeled E3227, was used for all brass-analysis and soilamendment studies in addition to the aerosol tests. Repeated leaching of brass aliquots for organic coatings with $\mathrm{CHCl}_{3}$ resulted in only minor weight loss $(<0.1 \%)$, though the organic was not absolutely characterized quantified. Moisture sorbed to the brass was negligible $(<0.1 \%)$, by oven-drying. Direct dissolution of the brass was visually complete in $\mathrm{HNO}_{3}$ concentrations of $1 \mathrm{M}$ and greater; however, there was a mass imbalance of $8 \%$ in $1 \mathrm{M} \mathrm{HNO}_{3}$ and an imbalance of $19 \%$ in an aliquot initially dissolved in $6 \mathrm{M} \mathrm{HNO}_{3}$ and then diluted (with deionized water) to $2 \mathrm{M} \mathrm{HNO}_{3}$. Since white particulate was evident, we attributed the mass loss to precipitation/sorption processes accelerated by the aqueous-dilution step. Later digestion dilutions were performed using $0.1 \mathrm{M} \mathrm{HNO}_{3}$ additions.

Single aliquots of brass (similar to those amended to soil, but without soil) were contacted with $\mathrm{H}_{2} \mathrm{O}, 0.01 \mathrm{M} \mathrm{HNO}_{3}$, and $0.1 \mathrm{M} \mathrm{HNO}_{3}$ to compare extraction efficiency. The wateronly sample was analyzed for dissolved organic carbon. It showed negligible water-soluble organic carbon, as expected from the lack of solubility of stearic and palmitic acids in water. Both the 0.01 and $0.1 \mathrm{M} \mathrm{HNO}_{3}$ leachings of brass showed total consumption of the acid, while 
the $\mathrm{pH}$ of the $1 \mathrm{M}$ solution was only roughly determined as $\sim 0.3$, or $\sim 0.5 \mathrm{M}$ acid remaining. This means that out of the $1 \mathrm{M}$ solution, assuming the brass is taken to $\mathrm{Cu}$ and $\mathrm{Zn}(\mathrm{II}), \sim 3.1$ mmoles acid was required out of a total available (in the $1 \mathrm{M} \mathrm{HNO}_{3}$ extraction) of $10 \mathrm{mmoles}$ Thus, 1.5 mmoles of acid was consumed by reactions other than simple dissolution of the brass.

\subsubsection{Digestion and Extraction of Brass and Brass Contained in Matrices}

Total digestion of brass was done in triplicate by concentrated-nitric-acid digestion in Teflon-lined sealed (Parr) bombs heated at $140^{\circ} \mathrm{C}$ for $16 \mathrm{~h}$. Samples of $0.75 \mathrm{~g}$ of amended soils, contaminated plant tissues, and aerosol samples were digested in $2.5 \mathrm{~mL}$ concentrated (Baker Ultrex) $\mathrm{HNO}_{3}$ for $16 \mathrm{~h}$, cooled, and diluted with $0.1 \mathrm{M} \mathrm{HNO}_{3}$ to $20 \mathrm{~mL}$ final volume before analysis for $\mathrm{Cu}$ and $\mathrm{Zn}$ by ICAP. As a check on extraction efficiency, a subset of soils was also analyzed using only $0.5 \mathrm{~g}$ soil to increase the acid-to-soil ratio and to compare with the limited digestions of the highest-amended soils at the time of preparation. The limited sample size required a well-dispersed initial soil mixture, and was the first test of the mixing efficiency in the pot preparations.

The mass imbalance by this approach was $5.9 \pm 0.2 \%$. Minor components found were $\mathrm{Al}(0.27 \pm 0.03 \%)$ and $\mathrm{Fe}(0.59 \pm 0.01 \%)$. Major distribution was $\mathrm{Cu}$ at $67.9 \pm 0.2 \%$ and $\mathrm{Zn}$ at $25.3 \pm 0.1 \%$, based on total digested mass. For ease in relating subsequent analyses, if we ignore the minor components and assume recovery was complete, then the percent $\mathrm{Cu}$ based on the total recovery of Cu plus $\mathrm{Zn}$ would be $72.9 \pm 0.5 \%$ and that of $\mathrm{Zn}$ would be $27.1 \pm 0.5 \%$. The expected values as stated in the literature (Wentzel et al. 1986c) were $\sim 70 \% \mathrm{Cu}, \sim 30 \% \mathrm{Zn}$, and $<1 \%$ minor impurities.

\subsubsection{Soil Extraction Methods}

Exchangeable, organically bound, and inorganically bound $\mathrm{Cu}$ and $\mathrm{Zn}$ were determined generally following the procedure of McLaren and Crawford (1973), as implemented by Wentsel and Guelta (1986b). The detection limits by ICAP for $\mathrm{Cu}$ and $\mathrm{Zn}$ are 4 and $20 \mathrm{ppb}$ in solution, respectively, in undiluted simple matrices; the interferences caused by the selective extraction solutions generally were handled by simple dilution, which results in a corresponding increase in true minimum detection limit. Carry-over from one step to the next was determined entirely by mass balance, rather than rinsing, as recommended by Sposito et al. (1982). A $0.75 \mathrm{~g}$ aliquot of soil was contacted with $30 \mathrm{~mL}$ of $0.1 \mathrm{M} \mathrm{K}_{4} \mathrm{P}_{2} \mathrm{O}_{7}$ with shaking overnight; a separate $1.5 \mathrm{~g}$ aliquot was contacted with $30 \mathrm{~mL} 0.01 \mathrm{M} \mathrm{CaCl}_{2}$ for $24 \mathrm{~h}$, separated, and the residue contacted with $30 \mathrm{~mL} 2.5 \%$ acetic acid for $24 \mathrm{~h}$. Residual metal component was deter-

mined by acid digestion of the dried residues (from both the $\mathrm{K}_{4} \mathrm{P}_{2} \mathrm{O}_{7}$ and the $\mathrm{CaCl}_{2}$ and acetic 
acid extraction sequences) in Teflon-lined (Parr) bombs, similar to the analysis for total brass in : the amended soils. Since we were interested primarily in available $\mathrm{Cu}$ and $\mathrm{Zn}$, we did not classify the residual metals in terms of oxide, crystalline, or silicate mineral structures. The portion extracted in $\mathrm{CaCl}_{2}$ is termed exchangeable; that found in the acetic acid fraction, after correction for residual $\mathrm{CaCl}_{2}$, is termed inorganically bound; the difference between the $\mathrm{K}_{4} \mathrm{P}_{2} \mathrm{O}_{7}$-extracted metals and the sum of the exchangeable and inorganically bound components is termed organically bound.

Hot-water extraction of soil aliquots used a $20: 1$ solution-to-soil ratio $(0.75 \mathrm{~g} / 15 \mathrm{~mL})$ in a Teflon-lined (Parr) bomb held at $104^{\circ} \mathrm{C}$ for $6 \mathrm{~h}$ and cooled prior to opening. This is a preferred method for evaluating bioavailable concentrations of ions in soil. Another method of choice, because it causes no intrusive chemical changes to the soil system, is direct porewater analysis. Basically, this method involves displacing unbound water from soils using a nonmiscible medium (freon, in this instance). Its drawback is that it lacks suitable sample size for detailed chemical analysis.

\subsection{PREPARATION AND CHARACTERIZATION OF SOILS}

\subsubsection{Soil Characteristics}

Soils used in the study were as follows: 1) Burbank fresh (collected 1988), 2) Palouse (collected 1988), 3) Palouse plus organic matter (0.22\% alfalfa), and 4) Cinebar (1988 batch). All soils were air-dried and sieved $(<2 \mathrm{~mm}$ ) to preserve the biological activity in the fresh soils; the degree of air-drying of the 1988 collections were not air-dried to complete dryness.

Selected properties of the soils are listed in Table 2.3. The effect of brass flake on soil microbial properties was investigated in three studies of four soils. The four soils used in these studies were 1) Burbank: Burbank sandy loam (sandy, skeletal, mixed, xeric, Torriorthent), a soil representing the desert areas of Washington, Oregon, and Idaho and 


\section{IABLE 2.3. SELECTED PROPERTIES OF SOILS USED IN THE STUDY OF BRASS EFFECTS}

\begin{tabular}{lccc}
\hline \multicolumn{1}{c}{ Soil Property } & $\begin{array}{c}\text { Burbank } \\
\text { Sandy Loam }\end{array}$ & $\begin{array}{c}\text { Palouse } \\
\text { Silt Loam }\end{array}$ & $\begin{array}{c}\text { Cinebar } \\
\text { Clay Loam }\end{array}$ \\
\hline$\%$ Sand & 45.1 & 1.1 & 35.2 \\
$\%$ Silt & 51.4 & 77.5 & 51.4 \\
$\%$ Clay & 4.0 & 21.4 & 13.4 \\
$\%$ Ash & 98.0 & 93.8 & nd (a) \\
pH (at 100\% field capacity) & 7.4 & 5.4 & 5.6 \\
Organic carbon $(\%)$ & 0.5 & 1.7 & 7.2 \\
Sulfur $(\%)$ & 0.053 & 0.043 & nd \\
Nitrogen $(\%)$ & 0.061 & 0.16 & 0.44 \\
Total P ( $\mu \mathrm{g} / \mathrm{g})$ & 2400 & 3770 & 3400 \\
Phosphate-P $(\mu \mathrm{g} / \mathrm{g})$ & 4.8 & 5.8 & 26 \\
Carbonate/Bicarbonate $(\%)$ & $<0.1$ & $<0.1$ & $<0.1$ \\
Ammonium-N $(\mu \mathrm{g} / \mathrm{g})$ & 6.1 & 18.3 & 15 \\
CEC (meq/100 g) & 5.5 & 23.8 & 38.2 \\
& & & \\
\hline
\end{tabular}

(a) $\mathrm{nd}=$ not determined

having a low cation-exchange capacity (CEC), low organic matter (OM), and a pH of 7 to 7.5 ; 2) Cinebar: Cinebar clay loam, a Washington forest soil from the Cascade Mountain Range and having high $\mathrm{OM}$ and $\mathrm{CEC}$ and $\mathrm{a} \mathrm{pH}$ of 5.5 to 6 ; 3) Palouse: Palouse silt loam (fine-silty, mixed, mesic, Pachic Ultic Haploxeroll), a soil typifying agricultural soils of eastern Washington, Idaho, and eastern Oregon and having moderate $\mathrm{CEC}$ and $\mathrm{OM}$ and a $\mathrm{pH}$ of 5.4; and 4) Palouse + OM: Palouse soil amended with $0.22 \%(w / w)$ dried alfalfa (ground and sieved through a 60-mesh screen).

A long-term pot study of brass-flake weathering was initiated in July 1988 . The four soils described above were amended with $0,25,100,500$, and $2500 \mu \mathrm{g}$ brass flake/g ovendried soil, and brought to -0.03 MPa water potential (approximately $66 \%$ of field moisture capacity) with distilled water. Soils were placed in plastic-lined pint cartons and covered with black polyethylene beads to minimize surface evaporation and were incubated at ambient temperature in the greenhouse. The greenhouse was kept at $12.8^{\circ} \mathrm{C}$ (day) and $4.4^{\circ} \mathrm{C}$ (night) during winter months and $26.7^{\circ} \mathrm{C}$ (day) and $18.3^{\circ} \mathrm{C}$ (night) during summer months, with a $12-\mathrm{h}$ day/night cycle. 


\subsubsection{Brass Amendment and Incubation}

Air-dried soils were mixed with brass to the highest target concentration $(2500 \mu \mathrm{g} / \mathrm{g}$ soil, on an oven-dry basis) and then subsampled for dilution to the next concentration $(500 \mu \mathrm{g} / \mathrm{g}$ ) with additional soil before being brought to $\sim 66 \%$ of field capacity with glassdistilled water. Similarly, sequential dilutions were used to prepare the lower amendment concentrations. Aliquots of both air-dried and moistened soils were reserved for analysis, and the remainder was potted into plastic-lined pint cartons and covered with poly beads to minimize surface evaporation. Target weight in the cartons was $400 \mathrm{~g}$ soil (oven-dried); however, Cinebar soil equivalent to only about $340 \mathrm{~g}$ would fit in the pot.

The reserved soil aliquots were checked for percent moisture and the pot weights then readjusted to reflect the target moisture level. The redetermined \%moisture in the air-dried soils was also used in the calculated brass concentration. Percent moistures in Burbank, Cinebar, Palouse and Palouse + OM were $0.69,8,13$, and $13 \%$, respectively. This step was necessitated by the variation in drying of the soils during soil storage and during actual preparation.

The level of brass in the amended fractions was determined by concentrated-nitricacid digestion of amended soils in sealed Teflon-lined (Parr) bombs. Native $\mathrm{Cu}$ and $\mathrm{Zn}$, as determined in digestions of unamended soils, must be subtracted from the digestion results of amended soils. For these studies, we have calculated the amount of brass recovery to be the sum of $\mathrm{Cu}$ and $\mathrm{Zn}$ alone, neglecting the contribution of minor components ( $\leq 1 \%)$; a calculated value of $99 \%$ of target would, therefore, be total agreement. After background correction, the amount of brass recovered by acid digestion, as a percent of target, averages $92 \%$ over all soil types and amendment concentrations. The percent $\mathrm{Cu}$ of the sum of $\mathrm{Cu}$ and $\mathrm{Zn}$ contribution averages $73.6 \%$ overall. This is consistent with the average of $72.9 \%$ in the brass-only Parr bomb digests, as described earlier.

\subsubsection{Soil Column Studies}

To determine the relative mobility of brass-flake constituents in soil, a series of 2.45- $\times 20-\mathrm{cm}$ columns were packed to a depth of $16 \mathrm{~cm}$ with different soil types: Burbank, Cinebar, Palouse, and Palouse + OM. The columns were brought to $95 \%$ field water saturation once weekly with synthetic rainwater (Van Voris et al. 1987). The Burbank, Palouse, Palouse + $\mathrm{OM}$, and Cinebar soils were watered with $\mathrm{pH} 6.5$ rainwater, while additional columns of Cinebar and cecil were watered with $\mathrm{pH} 4.5$ rainwater to provide data on the effects of acid rainfall. The columns were equilibrated with the artificial rainwater for 4 weeks before "activated" brass-flake amendment. For amendment, a $0.5-\mathrm{cm}$ lens of brass flake 
(2.81 g/column) containing $7.5 \mathrm{mg}\left(0.24-\mathrm{MBq}{ }^{65} \mathrm{Zn}\right)$ of neutron-activated brass flake (specific activity $23.42 \mathrm{MBq}{ }^{65} \mathrm{Zn} / \mathrm{g}$ brass) was layered to the top of each soil column.

Following amendment, the columns were watered weekly for 48 weeks, during which the column eluants were collected and counted in a gamma counter (Model 5530, Packard Instruments, Downers Grove, Illinois) to determine whether any of the brass had leached through. In addition, the columns were scanned with a Gamma probe (Model 44-2 and Model 2200 scaler ratemeter, Ludlum Instruments, Sweetwater, Texas) at three times over the course of the experiment (dates given in text) to determine if ${ }^{65} \mathrm{Zn}$ in the brass lens had moved down into the column.

\subsection{PLANT AND SOIL SELECTION AND PLANT CULTIVATION}

\subsubsection{Plant Selection and Cultivation}

The native species sagebrush, ponderosa pine, and short-needle pine are found associated with different training environments throughout the United States or are used in revegetation, while bush bean (used as a sensitive indicator species for soft crops), the pines, and fescue are important agronomic species found adjacent to many training installations. Plant sources and characteristics are as follows:

- Big Sagebrush (Artemisa tridentata, vaseyana). A medium-size, perennial shrub found over vast expanses of the arid and semiarid western states. It grows in relatively harsh environments on alkaline soils and at elevations from sea level to 7000 ft. Source: Native Plants Inc., Sandy, Utah. Age: 2-year-old seedlings.

- Ponderosa Pine (Pinus ponderosa). A large coniferous-forest species common to western North America. It grows at a range of elevations and is relatively tolerant to drought. It requires moderate soil fertility. Source: MacHugh Nursery, Eltopia, Washington. Age: 2-year-old seedlings.

- Short-Needle Pine (Pinus echinata). A coniferous tree indigenous to the southeastern United States. This variety is used extensively in reforestation. Source: J.P. Rhody Nursery, Gilbertsville, Kentucky. Age: 2-year-old seedlings.

- Tall Fescue (Eestcua elator). A perennial, cool-season bunchgrass that grows well on dry or wet, alkaline or acid soils. It has a rather ubiquitous range. Source: Native Plants Inc., Sandy, Utah. Grown from seed. 
- Bush Bean (Phasedus vulgaris, tendergreen). An agronomic species that is relatively sensitive to chemical insults, based on previous experience. Source: W.A. Burpee and Co., Chicago, Illinois. Grown from seed.

These five species provided a range of canopy type, cuticular structure, and thickness. They were suitable for evaluating phytotoxic responses to obscurant smokes and for evaluating deposition velocity under a range of environmental conditions. Ponderosa pine, short needle pine, and sagebrush were maintained in the greenhouse before use. These species were allowed to go dormant in the fall; in December, the greenhouse temperature was increased and photoperiod was adjusted artificially to break dormancy. Before their experimental use in the spring, groups of these plants were transferred to growth chambers, where they were allowed to equilibrate for 30 days at day/night temperatures of $32^{\circ} \mathrm{C} / 21^{\circ} \mathrm{C}$, a $16-\mathrm{h}$ photoperiod (approximately $500 \mathrm{mE} \mathrm{m}^{-2} \mathrm{~s}^{-1}$, PAR, at leaf surface), and $50 \%$ relative humidity. Bush bean was planted and grown in growth chambers under the same conditions. Tall fescue was grown from seed and maintained at day/night temperatures of $27^{\circ} / 15^{\circ} \mathrm{C}$, a $10-\mathrm{h}$ photoperiod (approximately $500 \mathrm{mE} \mathrm{m}^{-2} \mathrm{~s}^{-1}$, PAR, at leaf surface), and $50 \%$ relative humidity.

Both pine species were grown on a commercially available loam soil, while the sagebrush, tall fescue, and bush bean were grown on Burbank silt-sand. The latter were used to evaluate direct foliar-contact toxicity, and at no time was the soil of these test systems exposed to brass.

\subsection{PLANT/SOIL MEASUREMENTS}

\subsubsection{Foliar-Contact Toxicity Responses}

In evaluating direct foliar-contact toxicity, plant canopies were exposed to smokes under a range of concentrations, times, and atmospheric conditions. In all cases, soils were isolated from canopies by bagging the soil containers at the lower plant stem to preclude any indirect effects from soil contamination. All foliar exposures were conducted in the illuminated portion of the wind tunnel test section.

Toxicity responses (those that are readily visualized or phenotypic) from direct contact of smokes with foliar surfaces were evaluated using a modified Daubenmire (1959) rating scale (Table 2.4). This nonparametric approach provides a rapid comparison of gross 
IABLE2,4. CODING FOR MODIFIED DAUBENMIRE RATING SCALE AND ASSOCIATED PHYTOTOXICITY SYMPTOMS

Symptom/Intensity Description

Modified Daubenmire Rating Scale

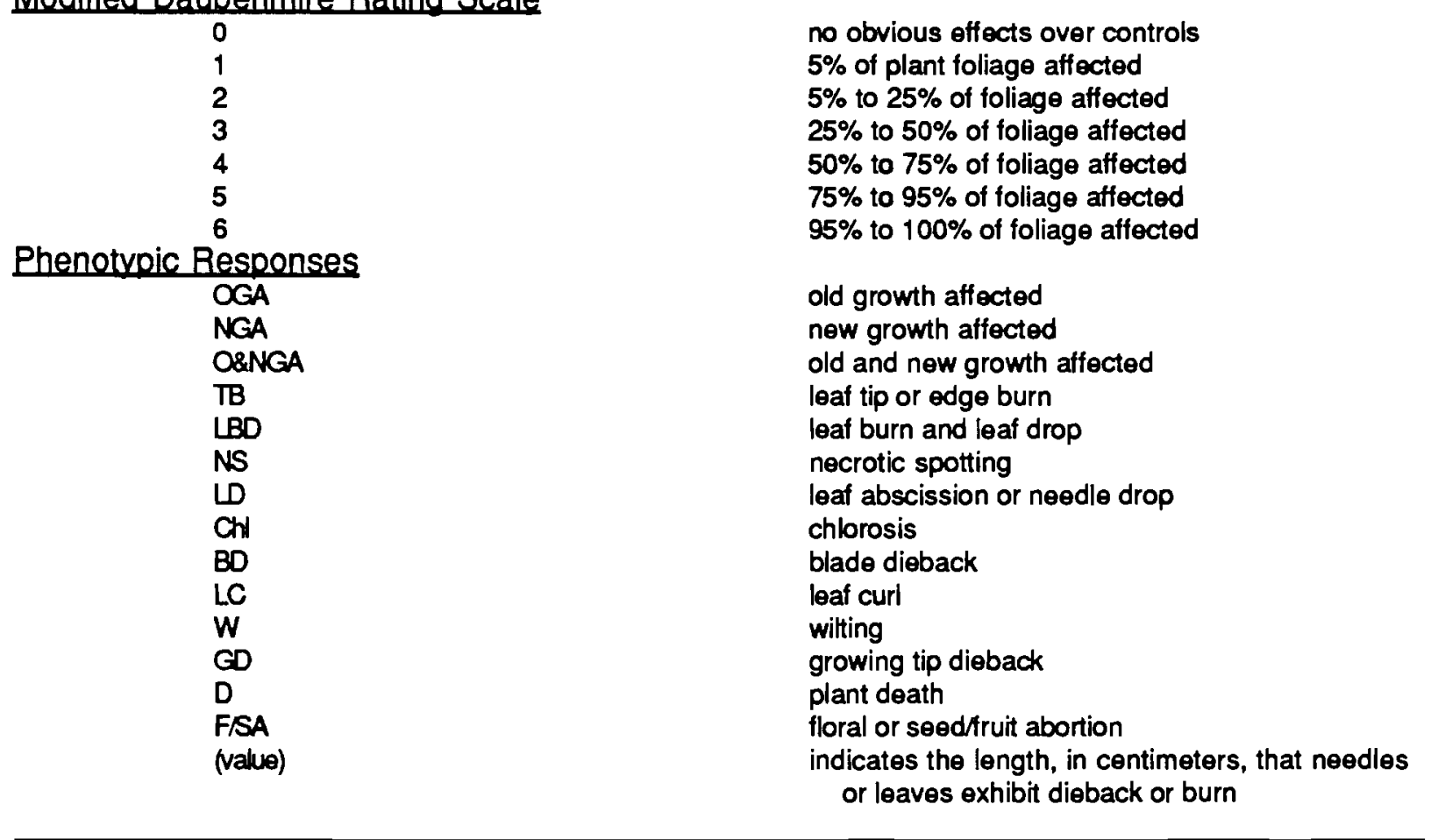

toxicity, and its relative intensity with time of post-exposure. Grasses that were harvested 3 to 4 weeks after exposure (direct-canopy effects) were permitted to regrow through one or more subsequent harvests, and dry matter production was monitored. Regrowth and monitoring allows any residual plant effects resulting from foliar absorption and root accumulation of smoke components to be evaluated.

\subsubsection{Photosynthetic Measurements}

Infrared Gas Analyzer (IRGA) Measurements. The exchange of $\mathrm{CO}_{2}$ from the plants can be measured by an IRGA. A gas-analysis system was constructed in the wind tunnel facility; a simplified schematic of its components is given in Figure 2.5. 


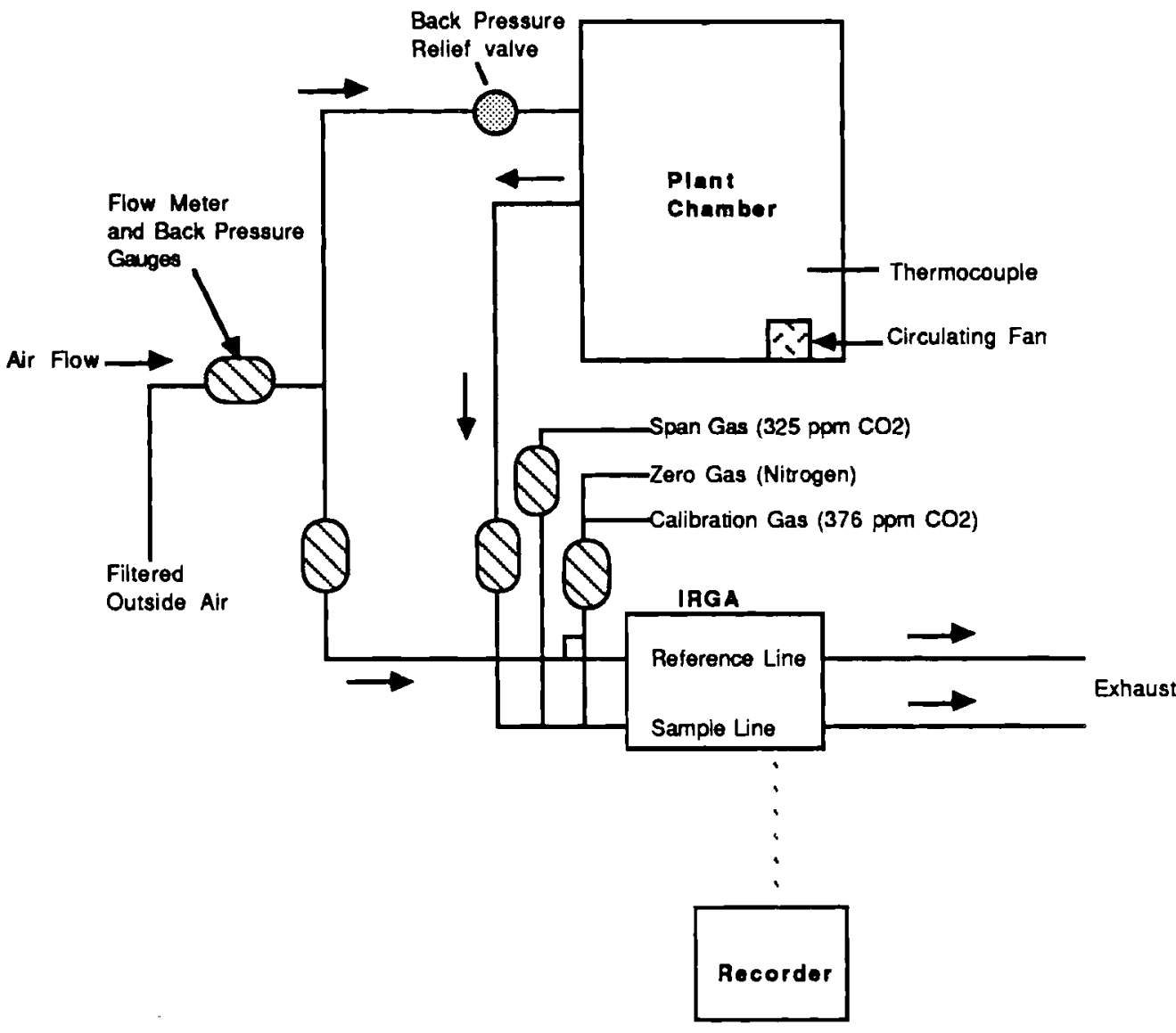

EIGURE2.5. SCHEMATIC DIAGRAM OF GAS-EXCHANGE SYSTEM USED IN MAKING NET-PHOTOSYNTHETIC AND DARK-RESPIRATION MEASUREMENTS

A Horiba Model PIR2000 IRGA in the absolute configuration was used to measure differences in $\mathrm{CO}_{2}$ concentration $(\mu \mathrm{L} / \mathrm{L})$ between air that had passed through the plant chamber and the original filtered outside air. To minimize environmental differences, the cylindrical plexiglass plant chamber $\left(45 \mathrm{~L}^{\mathrm{cm}}{ }^{3}\right)$ was placed in the same large growth chamber in which the plants were maintained during the exposure series. Plant-chamber temperature was maintained within $\pm 1^{\circ} \mathrm{C}$ of that of the growth chamber. Light intensity at canopy level in the plant chamber was $\sim 95 \%$ of that of the growth chamber $\left(400 \mu \mathrm{E} \mathrm{m}^{-2} \mathrm{~s}^{-1}\right)$. Flow rates (10 $\mathrm{L} / \mathrm{min}$ ) and back pressures were used to calculate rates of net carbon exchange (NCE) ( $\mu \mathrm{mol}$ $\mathrm{CO}_{2}$ /second/plant). Individual plants were measured before exposure and at various times during the experiment. Control plants not exposed to brass flake were also measured intermittently over this period to provide a point of reference. 


\subsubsection{Quantitation of Exposure/Dose}

To evaluate plant-toxicity responses to airborne contaminants, one needs a basis for intercomparing treatments and variables. To provide a specific dose value for each plant, in all of the toxicity studies the point of reference is the mass-loading value or exposure dose, as opposed to air concentration or exposure duration. The mass-loading rate is determined by measuring the amount of brass deposited to a unit area or weight of foliage.

Brass-flake foliar mass loading was determined by removing exposed foliar tissue randomly from the plants, placing the tissue in a nylon mesh bag, and washing off the loose flake with a mixture of $\sim 20 \%(\mathrm{v} / \mathrm{v})$ ethanol:0.4\% Tween $20: 80 \%$ water and filtering the leachate through a fiber glass filter in a buchner funnel. The washed leaf tissue and the glass-filter pad were then separately extracted with $1 \mathrm{~N}$ nitric acid and analyzed for $\mathrm{Cu}$ and $\mathrm{Zn}$ through ICAP. The data were then combined. Additional analysis of the leachate following filtration showed that all of the material was trapped in the filter.

Mass loading to soils was estimated from loading to soil coupons, following which samples of known surface area were extracted and analyzed for $\mathrm{Cu}$ and $\mathrm{Zn}$ with the proper controls. Interception efficiency based on type of receptor surface (namely the type of canopy structure)were quantified from computed deposition velocities. The velocities are calculated from the air concentration, exposure duration, and the quantity of brass flake deposited per unit surface area. Deposition-velocity results were compared for exposure variables, including duration and wind speed.

\subsubsection{Post-Exposure Simulated Rainfall}

The intensity of phytotoxic responses to foliar contaminants can be modified by the presence or absence of surface moisture. Immediately following exposure, subsets of exposed plants were subjected to a simulated rainfall (Figure 2.6) equivalent to $1.0 \mathrm{~cm}$, as described in Cataldo et al. (1981). Simulated rainfall allowed us to evaluate both the ameliorating effects of foliar surface wash-off and any intensification of effects caused by increased foliar uptake resulting from the presence of surface moisture. 


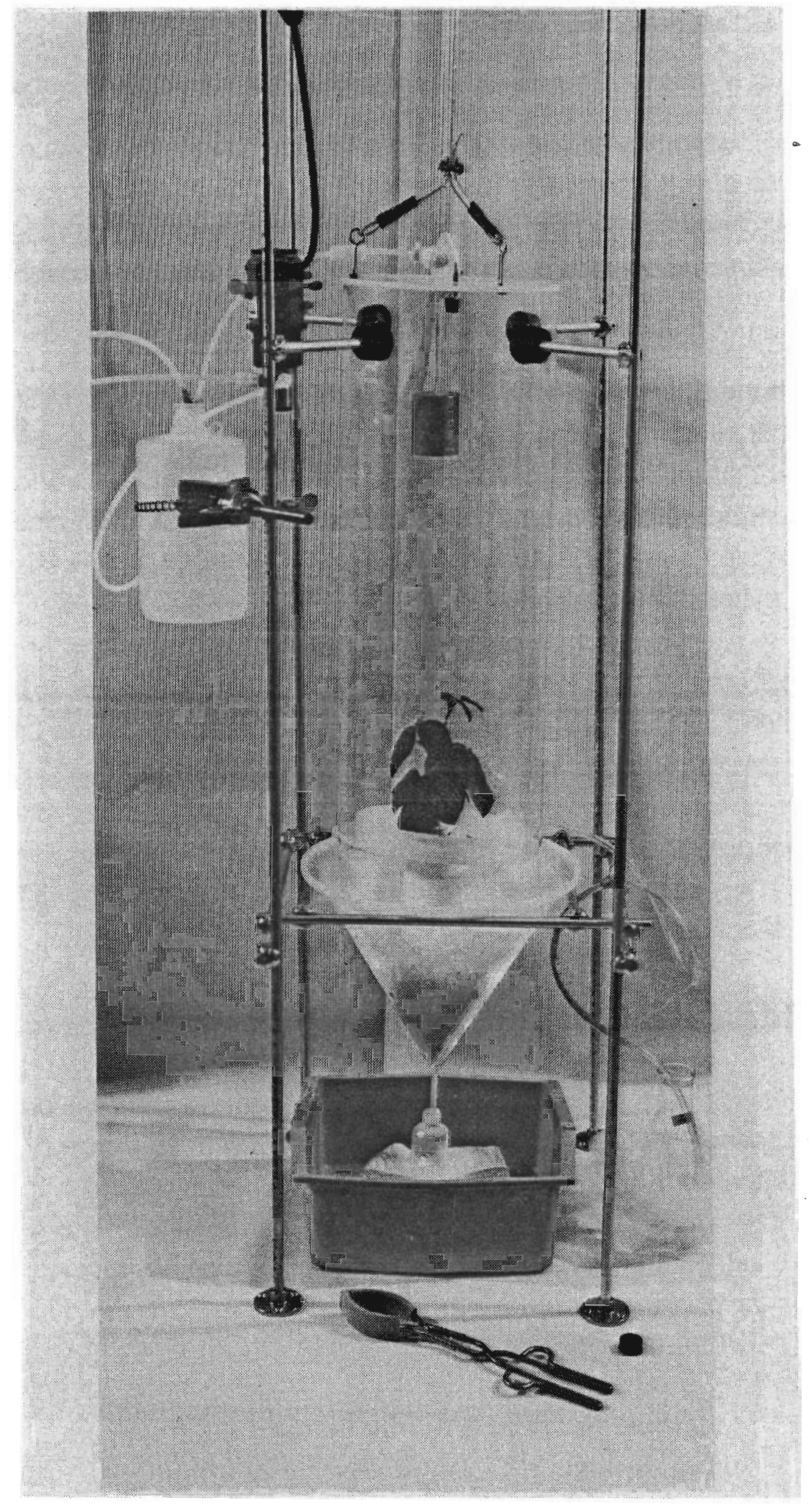

FIGURE 2.6. POST-EXPOSURE SIMULATED-RAINFALL SYSTEM 


\subsection{MICROBIALMETHODS}

The effect of long-term brass weathering on soil microbial parameters was studied. Aliquots of soils for microbial assays were taken out of the greenhouse in late November 1988 (150 days), March 1989 (270 days), and September 1989 (420 days). Soil samples for microbial analysis were stored at $4^{\circ} \mathrm{C}$ for less than 2 weeks, before microbial assays were performed. Soil moisture contents were also determined $\left(110^{\circ} \mathrm{C}, 48 \mathrm{~h}\right)$ to calculate a soil dry weight and to allow results to be reported based on gram dry weight of soil.

A short-term brass-flake incubation study was performed in July 1989 . Soils were amended with brass flake and brought to the desired water potential in the same manner as in the long-term pot studies. Soils were then incubated at ambient room temperature $\left(22^{\circ} \mathrm{C}\right)$ until being assayed for microbial effects at 4 and 28 days.

A third study was performed in August 1989, in conjunction with the mixed-brass-andfog-oil (BR/FO) aerosols in a wind tunnel under varied wind speeds. Distilled water was added to large petri dishes $(150 \times 15 \mathrm{~mm})$ containing $50 \mathrm{~g}$ of air-dried soil to bring the water potential of the soil to $-0.03 \mathrm{MPa}$. Soils were exposed to the BR/FO mixed smoke for $1 \mathrm{~h}$ at wind speeds of $0.9 \mathrm{~m} / \mathrm{s}$ (Test\# BR/FO-03) and $4.5 \mathrm{~m} / \mathrm{s}$ (Test\# BR/FO-07). Soil moisture lost during each exposure was measured by weight loss and was replaced by adding deionized water immediately after the exposure. Average moisture losses of the four soils were $3.83 \%$ and $7.36 \%$ for the $0.9 \mathrm{~m} / \mathrm{s}$ and $4.5 \mathrm{~m} / \mathrm{s}$ exposures, respectively. Soil microbial assays were performed immediately after the exposure and again after a 28-day incubation at ambient laboratory temperature $\left(22^{\circ} \mathrm{C}\right)$.

Soil dehydrogenase activity was assayed by a modification of the procedure of Tabatabai (1982). Aliquots of soil (1.5 g wet weight) were mixed with $0.015 \mathrm{~g} \mathrm{CaCO}_{3}, 0.3 \mathrm{~mL}$ of $1 \%$ glucose, and $0.25 \mathrm{~mL}$ of the substrate, 2,3,5-triphenyltetrazolium chloride $(3 \% \mathrm{w} / \mathrm{v})$. After incubation at $22^{\circ} \mathrm{C}$ for $24 \mathrm{~h}, 10 \mathrm{~mL}$ of methanol was added to the soil to stop the reaction and to extract the product, 2,3,5-triphenylformazan (TPF). The solution was mixed thoroughly, centrifuged at $12,000 \times \mathrm{g}$ for $10 \mathrm{~min}$, and the absorbance of the supernatant determined at $485 \mathrm{~nm}$ on a Beckman DU-50 spectrophotometer. Soil dehydrogenase activity, expressed as micrograms TPF produced per gram of dry soil per $24 \mathrm{~h}$, was determined by comparing absorbence values to a standard curve prepared with reagent-grade TPF and methanol.

Soil phosphatases activity was determined by a modification of the procedure of Tabatabai (1982) for acid phosphatase. One gram of soil was placed in 15-mL centrifuge tubes with $4 \mathrm{~mL}$ of modified universal buffer (MUB), which consists of $0.605 \mathrm{~g}$ tris (hydroxymethyl) amino methane, $0.580 \mathrm{~g}$ maleic acid, $0.70 \mathrm{~g}$ citric acid, $0.341 \mathrm{~g}$ boric acid, and $24.4 \mathrm{~mL}$ 
$1 \mathrm{M} \mathrm{NaOH}$, in $250 \mathrm{~mL}$ final volume with the $\mathrm{pH}$ adjusted to 6.50 . One milliliter of the substrate, p-nitrophenol phosphate ( $0.025 \mathrm{M}$ prepared with MUB buffer), was added to each tube. The tubes were stoppered, vortexed, and incubated for one hour at $37^{\circ} \mathrm{C}$. One milliliter of $0.5 \mathrm{M}$ $\mathrm{CaCl}_{2}$ and $4 \mathrm{~mL}$ of $0.5 \mathrm{M} \mathrm{NaOH}$ were added to the tubes to stop the reaction. The mixtures were centrifuged at $12,000 \times \mathrm{g}$ for $10 \mathrm{~min}$, and the absorbance of supernatant was determined at $400 \mathrm{~nm}$ with a spectrophotometer. Phosphatase activity, expressed as micrograms of p-nitrophenol produced per gram soil per hour, was determined by comparing absorbence values to a standard curve prepared with reagent-grade $p$-nitrophenol.

A modification of the procedure of Parkinson and Paul (1982) was used to determine the amount of adenosine 5'-triphosphate (ATP) in soil. One gram of soil was placed in a 50-mL centrifuge tube with $5 \mathrm{~mL}$ of $0.5 \mathrm{M} \mathrm{NaHCO}_{3}(\mathrm{pH} 8.5)$ and $15 \mathrm{~mL}$ chloroform. The tubes were stoppered and vortexed on high speed for $15 \mathrm{~s}$. Another $7.5 \mathrm{~mL}$ of $0.5 \mathrm{M} \mathrm{NaHCO}_{3}$ was added to the tube, which was vortexed for an additional $15 \mathrm{~s}$. The mixtures were centrifuged at $3500 \times \mathrm{g}$ for $5 \mathrm{~min}$ at $2^{\circ} \mathrm{C}$. An aliquot of the top aqueous phase (approximately $5 \mathrm{~mL}$ ) was removed without disturbing the lower chloroform and soil phases and transferred to a 10-mL tube. Traces of chloroform were removed from the extract by connecting tubes to a vacuum and incubating the extract in a $60^{\circ} \mathrm{C}$ water bath for at least $1 \mathrm{~min}$ or until the larger chloroform bubbles disappeared. The tubes were sealed with parafilm and stored at $-40^{\circ} \mathrm{C}$ until analysis. The ATP content was determined by adding $0.1 \mathrm{~mL}$ of sample, $0.4 \mathrm{~mL}$ of $0.1 \mathrm{M}$ tris (hydroxymethyl) amino methane (TRIS) $(\mathrm{pH} \mathrm{7.8)}$, and $0.1 \mathrm{~mL}$ of luciferin-luciferase (ATP monitoring reagent, LKB/Wallace catalog\#1243-200) to the ATP tube (as supplied by the manufacturer) and measuring the light intensity emitted from the reaction by a photometer (Pharmacia LKBWallace Model 1251 Luminometer). Since the intensity of light emitted is proportional to the concentration of ATP, the ATP concentration in the soil extracts were determined from an ATP standard curve. The ATP standard curve was constructed using reagent-grade ATP dissolved in $0.5 \mathrm{M} \mathrm{NaHCO}_{3}(\mathrm{pH} 8.5)$ and $0.1 \mathrm{M}$ TRIS in the same proportions described above.

All soil dehydrogenase and phosphatase activities and soil ATP concentrations were measured in triplicate. Mean values were compared with that of the control (unexposed) soil and results were expressed as a percent of the control.

Soil microbial-species diversity was determined by the procedure of Atlas (1984a) and Atlas and Bartha (1987). Total heterotrophic bacteria were counted on Difco nutrient-agar plates. The species diversity index was then determined by counting the different types of colonies and the number of each colony type. A widely used measure of species diversity is

- Difco is a registered trademark of Difco Laboratory, Detroit, Michigan. 
the Shannon-Weaver index $(H)$, which is a general diversity index sensitive both to species richness and to relative species abundance. It is calculated according to the equation

$$
H=C \times\left(N \log _{10} N-\sum n_{i} \log _{10} n_{i}\right) / N
$$

where $C=3.3219$

$\mathrm{N}=$ \# of individuals

$\mathrm{n}_{\mathrm{i}}=$ \# of individuals in the $\mathrm{ith}^{\text {th }}$ species

Soil nitrifying bacteria were enumerated by the microtechnique for most-probablenumber (Rowe et al. 1977) using media described by Alexander and Clark (1965). Ammonium - calcium carbonate medium for Nitrosomonas sp. type microorganisms consisted of $0.5 \mathrm{~g}$ $\left(\mathrm{NH}_{4}\right)_{2} \mathrm{SO}_{4}, 1.0 \mathrm{~g} \mathrm{~K}_{2} \mathrm{HPO}_{4}, 0.03 \mathrm{~g} \mathrm{FeSO}_{4}: 7 \mathrm{H}_{2} \mathrm{O}, 0.3 \mathrm{~g} \mathrm{NaCl}, 0.3 \mathrm{~g} \mathrm{MgSO}_{4}: 7 \mathrm{H}_{2} \mathrm{O}$, and $7.5 \mathrm{~g}$ $\mathrm{CaCO}_{3}$ in $1000 \mathrm{~mL}$ distilled water. Nitrite - calcium carbonate medium for Nitrobactersp. type microorganisms consisted of $0.006 \mathrm{~g} \mathrm{KNO}_{2}, 1.0 \mathrm{~g} \mathrm{~K}_{2} \mathrm{HPO}_{4}, 0.03 \mathrm{~g} \mathrm{FeSO}_{4}: 7 \mathrm{H}_{2} \mathrm{O}, 0.3 \mathrm{~g} \mathrm{NaCl}$, $0.1 \mathrm{~g} \mathrm{MgSO}_{4}: 7 \mathrm{H}_{2} \mathrm{O}, 0.3 \mathrm{~g} \mathrm{CaCl}_{2}$, and $1.0 \mathrm{~g} \mathrm{CaCO}_{3}$ in $1000 \mathrm{~mL}$ distilled water. The media were autoclaved at $121^{\circ} \mathrm{C}$ with $15 \mathrm{lb}$ pressure for $30 \mathrm{~min}$. Aliquots $(0.4 \mathrm{~mL})$ were transferred to 30 minitubes. A 10 -fold serial dilution of soil was prepared with sterile $0.85 \%$ saline solution. Five tubes were inoculated with $0.1 \mathrm{~mL}$ of $10^{-1}$ through $10^{-6}$ dilutions, with five replicates at each dilution. After incubation for 6 weeks at room temperature in the dark, tubes containing ammonium-calcium carbonate medium for Nitrosomonas sp. were tested for the presence of nitrite and/or nitrate, using the modified Griess-lllosvay and nitrate spot-test reagents described by Schmidt and Belser (1982). Positive tests for nitrite/nitrate in these tubes indicate the presence of Nitrosomonas sp. Tubes containing nitrite - calcium carbonate medium were tested for nitrite. A negative test indicated the presence of Nitrobactersp. Populations of both groups of nitrifying bacteria were calculated using a most-probable-number (MPN) table (Alexander 1982) and were presented as the $\log _{10}$ of the MPN per gram of dry soil.

\subsection{SOIL-INVERTEBRATE ASSAY}

An earthworm (Eisenia fetida) bioassay system was used to elucidate the toxicity of the brass constituents. An artificial soil containing $350 \mathrm{~g}$ sand, $100 \mathrm{~g}$ kaolin, and $50 \mathrm{~g}$ dried peat moss (adjusted to $\mathrm{pH} 6.5$ with $\mathrm{CaCO}_{3}$ ), was used both for culture and for the earthworm exposures. Worms were fed twice weekly with fermented alfalfa, and soil moisture was adjusted to $35 \%$ of dry weight. Exposure tests used $80 \mathrm{~g}$ of the artificial soil (placed in $100-\mathrm{x}$ $25-\mathrm{mm}$ petri plates) containing five mature worms. Three replicate plates were used for each test series, as noted in the text. The tests were terminated after 14 days, and effects were observed over this period. Effects scored included earthworm mortality and simple response to physical stimulus (touching). Mass loading or dose was determined on similar soil plates without worms. 

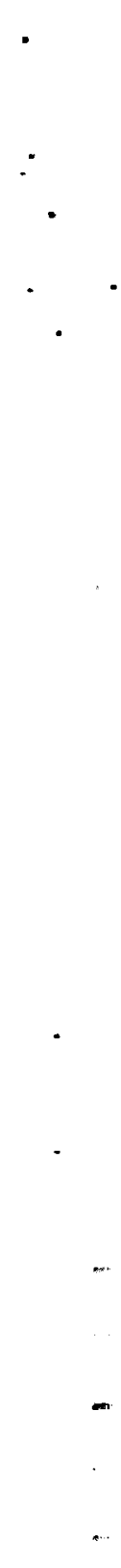


\subsection{BESULTS AND DISCUSSION}

The environmental fate and effects of brass were investigated for the two principal routes of biological exposure, airborne deposition of brass and brass/fog-oil obscurant mixtures and brass weathering in soil. Soils were amended to simulate weathering and potential impacts from deposition. Aerosols containing brass were generated and characterized, and deposition both to foliar surfaces and to soils was determined. Impacts of deposited brass were assessed based on their contact toxicity to vegetation. Soil amendment studies were performed to ascertain weathering rates and to determine the effects of different brass concentrations on plant growth and on soil microbial processes. In addition, soil columns were used to determine whether brass weathering influenced the migration of $\mathrm{Cu}$ and $\mathrm{Zn}$ through soil profiles.

\subsection{OBSCURANT (AEROSOL) CHARACTERIZATION}

Brass (BR) and brass/fog oil (BR/FO) aerosol obscurants were characterized during each test to provide data for determinining applied doses and calculating particulate-matter deposition rates, or deposition velocities. These data supported three series of plant, soil, and soil-microbiological exposures to BR and BR/FO aerosols in the wind tunnel. Aerosol data were obtained on the chemical composition of the aerosols, aerosol mass concentration, and concentrations of constituent fractions of the aerosols; aerodynamic particle size distribution; and deposition velocities to surrogate surfaces suspended in the wind tunnel test section.

\subsubsection{Aerosol Mass Concentration and Chemical Composition}

Aerosol mass concentration and the mass concentrations of the constituents brass and brass/fog oil were determined from gravimetric and chemical analysis of aerosol samples. Generated singly, brass aerosols were close to the target value of $100 \mathrm{mg} / \mathrm{m}^{3}$, but during mixed BR/FO tests, because of recurrent generator failure, the concentrations of BR aerosol were significantly lower than the target value. The concentration of FO in the BR/FO aerosols was approximately equal to the $500 \mathrm{mg} / \mathrm{m}^{3}$ target level.

The first step in determining aerosol mass concentrations was to analyze the chemical composition of the filter and the deposition coupon. Selected samples were submitted for analysis to provide information on the percentages of the total collected aerosol masses consisting of $\mathrm{Cu}$ and $\mathrm{Zn}$. Table 3.1 lists all analyzed aerosol samples. Data were corrected for low background levels of $\mathrm{Zn}$ and $\mathrm{Cu}$ in the sample substrate, but these corrections were not significant for determining aerosol concentrations. Not shown directly in the table, 
IABLE 3.1. CHEMICAL COMPOSITION OF AEROSOL SAMPLES

\begin{tabular}{|c|c|c|c|c|c|c|c|}
\hline Test & Sample & $\begin{array}{l}\text { Mass } \\
(\mathrm{mg})\end{array}$ & $\begin{array}{c}\text { Cu Mass } \\
(\mathrm{mg})\end{array}$ & $\begin{array}{c}\text { Zn Mass } \\
(\mathrm{mg})\end{array}$ & $\begin{array}{l}\mathrm{Cu} \\
(\%)\end{array}$ & $\begin{array}{l}\mathrm{Zn} \\
(\%)\end{array}$ & $\begin{array}{c}\text { Residual } \\
(\%)\end{array}$ \\
\hline BR-10 & F3 & 2.65 & 1.88 & 0.624 & 70.9 & 23.5 & 5.5 \\
\hline & F5 & 2.75 & 2.00 & 0.657 & 72.7 & 23.9 & 3.4 \\
\hline \multirow{3}{*}{$\begin{array}{l}\text { BR-11 } \\
\text { BR-12 }\end{array}$} & F3 & 2.34 & 1.61 & 0.640 & 68.8 & 27.4 & 3.8 \\
\hline & $\mathrm{F} 3$ & 2.39 & 1.68 & 0.523 & 70.3 & 21.9 & 7.8 \\
\hline & F5 & 2.22 & 1.61 & 0.517 & 72.5 & 23.3 & 4.2 \\
\hline BR-13 & $\mathrm{F} 3$ & 1.13 & 0.834 & 0.299 & 73.8 & 26.5 & -0.3 \\
\hline & F5 & 1.14 & 0.870 & 0.314 & 76.3 & 27.5 & -3.9 \\
\hline BRFO-03 & F5 & 6.08 & 0.122 & 0.043 & 2.0 & 0.7 & 97.3 \\
\hline & F6 & 6.07 & 0.068 & 0.023 & 1.1 & 0.4 & 98.5 \\
\hline \multirow[t]{5}{*}{ BRFO-04 } & $\begin{array}{l}\mathrm{F} 1 \\
\mathrm{~F} 2\end{array}$ & $\begin{array}{l}3.23 \\
5.70\end{array}$ & $\begin{array}{l}0.287 \\
0.189\end{array}$ & $\begin{array}{l}0.115 \\
0.074\end{array}$ & $\begin{array}{l}8.9 \\
3.3\end{array}$ & $\begin{array}{l}3.5 \\
1.3\end{array}$ & $\begin{array}{l}87.6 \\
95.4\end{array}$ \\
\hline & $\mathrm{F3}$ & 6.68 & 0.205 & 0.082 & 3.1 & 1.2 & 95.7 \\
\hline & $\mathrm{F} 4$ & 6.30 & 0.216 & 0.080 & 3.4 & 1.3 & 95.3 \\
\hline & F5 & 6.05 & 0.164 & 0.060 & 2.7 & 1.0 & 96.3 \\
\hline & F6 & 5.93 & 0.066 & 0.022 & 1.1 & 0.4 & 98.5 \\
\hline \multirow[t]{5}{*}{ BRIFO-05 } & $\begin{array}{l}\mathrm{F} 1 \\
\mathrm{~F} 2\end{array}$ & $\begin{array}{l}3.63 \\
5.43\end{array}$ & $\begin{array}{l}0.371 \\
0.230\end{array}$ & $\begin{array}{l}0.132 \\
0.074\end{array}$ & $\begin{array}{r}10.2 \\
4.2\end{array}$ & $\begin{array}{l}3.6 \\
1.4\end{array}$ & $\begin{array}{l}86.2 \\
94.4\end{array}$ \\
\hline & $\mathrm{F} 3$ & 5.88 & 0.204 & 0.065 & 3.5 & 1.1 & 95.4 \\
\hline & $\mathrm{F}_{4}$ & 5.42 & 0.212 & 0.068 & 3.9 & 1.3 & 94.8 \\
\hline & F5 & 5.19 & 0.196 & 0.062 & 3.8 & 1.2 & 95.0 \\
\hline & F6 & 5.22 & 0.223 & 0.073 & 4.3 & 1.4 & 94.3 \\
\hline \multirow[t]{6}{*}{ BR/FO-06 } & $F_{1}$ & 2.62 & 0.287 & 0.093 & 11.0 & 3.5 & 85.5 \\
\hline & F2 & 3.24 & 0.138 & 0.043 & 4.3 & 1.3 & 94.4 \\
\hline & F3 & 3.87 & 0.110 & 0.037 & 2.8 & 0.9 & 96.2 \\
\hline & F4 & 4.24 & 0.114 & 0.038 & 2.7 & 0.9 & 96.4 \\
\hline & F5 & 4.28 & 0.114 & 0.037 & 2.7 & 0.9 & 96.5 \\
\hline & F6 & 3.83 & 0.110 & 0.036 & 2.9 & 0.9 & 96.2 \\
\hline \multirow[t]{5}{*}{ BRUFO-07 } & $\mathrm{F} 1$ & 4.31 & 0.772 & 0.282 & 17.9 & 6.5 & 75.5 \\
\hline & $\mathrm{F2}$ & 6.57 & 0.627 & 0.221 & 9.5 & 3.4 & 87.1 \\
\hline & F3 & 7.15 & 0.636 & 0.213 & 8.9 & 3.0 & 88.1 \\
\hline & $\begin{array}{l}\text { F4 } \\
\text { F5 }\end{array}$ & $\begin{array}{l}6.59 \\
6.25\end{array}$ & $\begin{array}{l}0.631 \\
0.653\end{array}$ & 0.214 & 9.6 & 3.2 & 87.2 \\
\hline & $\begin{array}{l}\text { F5 } \\
\text { F6 }\end{array}$ & $\begin{array}{l}6.25 \\
5.66\end{array}$ & $\begin{array}{l}0.653 \\
0.388\end{array}$ & $\begin{array}{l}0.217 \\
0.132\end{array}$ & $\begin{array}{r}10.4 \\
6.9\end{array}$ & $\begin{array}{l}3.5 \\
2.3\end{array}$ & $\begin{array}{l}86.1 \\
90.8\end{array}$ \\
\hline BR-10 & DC3 & 8.25 & 5.22 & $\begin{array}{l}0.130 \\
1.98\end{array}$ & 63.3 & 24.0 & 12.7 \\
\hline & DC7 & 6.79 & 3.84 & 1.40 & 56.6 & 20.6 & 22.8 \\
\hline BR-11 & DC3 & 4.55 & 2.60 & 0.895 & 57.1 & 19.7 & 23.2 \\
\hline & $\mathrm{DC7}$ & 4.65 & 2.44 & 0.843 & 52.5 & 18.1 & 29.4 \\
\hline BR-12 & DC3 & 3.32 & 1.78 & 0.588 & 53.6 & 17.7 & 28.7 \\
\hline & DC7 & 3.30 & 2.02 & 0.684 & 61.2 & 20.7 & 18.1 \\
\hline BR-13 & DC3 & 2.12 & 1.22 & 0.438 & 57.5 & 20.7 & 21.8 \\
\hline & DC7 & 1.68 & 0.973 & 0.347 & 57.9 & 20.7 & 21.4 \\
\hline BR/FO-03 & DC2 & 1.97 & 0.454 & 0.163 & 23.0 & 8.3 & 68.7 \\
\hline & DC4 & 1.97 & 0.441 & 0.159 & 22.4 & 8.1 & 69.5 \\
\hline BR/FO-04 & $\mathrm{DC2}$ & 4.66 & 0.817 & 0.298 & 17.5 & 6.4 & 76.1 \\
\hline & $\mathrm{DC4}$ & 4.66 & 0.829 & 0.305 & 17.8 & 6.5 & 75.7 \\
\hline BR/FO-05 & $\mathrm{DC} 2$ & 10.49 & 1.804 & 0.693 & 17.2 & 6.6 & 76.2 \\
\hline & $\overline{\mathrm{DC} 4}$ & 9.54 & 1.661 & 0.635 & 17.4 & 6.7 & 75.9 \\
\hline BR/FO-06 & DC2 & 11.83 & 1.579 & 0.608 & 13.3 & 5.1 & 81.5 \\
\hline & $\overline{D C 4}$ & 10.63 & 1.593 & 0.616 & 15.0 & 5.8 & 79.2 \\
\hline BR/FO-07 & $\mathrm{DC} 2$ & 50.84 & 10.25 & 3.666 & 20.2 & 7.2 & 72.6 \\
\hline & $\mathrm{DC7}$ & 54.34 & 11.45 & 4.085 & 21.1 & 7.5 & 71.4 \\
\hline
\end{tabular}


the ratio of $\mathrm{Cu}$ to the total mass of $\mathrm{BR}(\mathrm{Cu}+\mathrm{Zn})$ in the aerosol samples was $0.740 \pm 0.014$. The difference between the total mass collected and the sum of the $\mathrm{Cu}$ and $\mathrm{Zn}$ masses, as percentages, is listed as residual percentage. Residual percentage includes impurities in the brass, such as the $\sim 1 \%$ of the mass that is stearic acid and other impurities, and also includes the mass of FO in samples from the BR/FO tests.

Isokinetic aerosol filter samples ( $F$ in the table) from BR tests had residual levels ranging from -3.9 to $7.8 \%$ of the total collected mass, and averaged $3 \pm 4 \%$. The difference between this residual and the $\sim 1 \%$ brass impurities was slight, and was attributed to measurement errors. No loss of brass mass during sample handling was anticipated, because the filter deposits were not observed to detach easily from the substrate. In contrast, the residual levels on the deposition coupon samples (DC on the table) from the BR tests ranged from 13 to $29 \%$, and averaged $22 \pm 5 \%$. This residual was not caused by an increase in the residual component of the aerosol, but was rather an artifact of the analyses: as the samples were transferred into the scintillation vials for subsequent chemical analysis, material was lost, because the brass deposits to the deposition coupons were not tightly bound, as were the deposits to the isokinetic nozzle filter substrate. In summary, the difference between the total sample mass and the total brass mass in each sample from the BR tests was $\sim 1 \%$, the level of impurities in the brass source.

Residual material in aerosol samples from the BR/FO tests was much greater than in those from the BR tests, because FO was present in the BR/FO aerosol at a concentration from 4 to 60 times greater than the concentration of brass aerosol. Because of the adhesive characteristics of the FO on the deposition-coupon samples, loss of brass from the samples during transfer to vials was believed to be minimized. The percentage of brass; as the sum of $\mathrm{Cu}$ and $\mathrm{Zn}$, decreased throughout each BR/FO test. Initially, the concentration of brass ranged from 12 to $24 \%$ of the total aerosol mass concentration. However, because clogging problems affected the performance of the sonic-nozzle brass-aerosol generator, the rate of aerosol generation decreased, and the concentration of brass declined during the tests to a final level ranging from 1.5 to $9 \%$ of the total aerosol mass concentration. The average FO aerosol mass concentrations throughout each test, assumed to be approximately equal to the residual for the BR/FO tests, ranged from 86 to $95 \%$ of the total aerosol mass concentration.

Aerosol mass-concentration results are summarized in Table 3.2. Wind speed and exposure durations are included in the table to provide information required for calculating deposition velocities to both surrogate and test-subject surfaces. Brass-aerosol mass concentrations ranged from 132 to $177 \mathrm{mg} / \mathrm{m}^{3}$ during the BR wind-speed tests, were approximately $90 \mathrm{mg} / \mathrm{m}^{3}$ during the BR range-finding tests, and ranged from 19 to 83 during the BR/FO wind-speed tests. Uncertainty limits in determining aerosol mass concentration were estimated to be less than $7 \%$ from potential errors in aerosol-sample air-flow rates and 
gravimetric procedures. Uncertainty limits for the brass concentrations were somewhat greater, because of uncertainties associated with measuring the decrease in brass-aerosol mass concentration that occurred as the brass-aerosol generator gradually became clogged during the BR/FO wind-speed tests.

IABLE 3.2. AVERAGE AEROSOL MASS CONCENTRATIONS DURING EXPOSURE TESTS

\begin{tabular}{|c|c|c|c|c|c|}
\hline Test & $\begin{array}{l}\text { Wind } \\
\text { Speed } \\
(\mathrm{m} / \mathrm{s})\end{array}$ & $\begin{array}{c}\text { Exposure } \\
\text { Duration } \\
\text { (min) }\end{array}$ & $\begin{array}{c}\text { Mass } \\
\text { Concentration } \\
\left(\mathrm{mg} / \mathrm{m}^{3}\right)\end{array}$ & $\begin{array}{c}\text { BP } \\
\text { Concentration } \\
\left(\mathrm{mg} / \mathrm{m}^{3}\right)\end{array}$ & $\begin{array}{c}\text { FO } \\
\text { Concentration } \\
\left(\mathrm{mg} / \mathrm{m}^{3}\right)\end{array}$ \\
\hline \multicolumn{6}{|l|}{ BR Wind Speed } \\
\hline BR-10 & 4.49 & 60 & $133 \pm 9$ & 132 & 0 \\
\hline BR-11 & 2.69 & 60 & $154 \pm 11$ & 152 & 0 \\
\hline BR-12 & 1.77 & 60 & $157 \pm 11$ & 155 & 0 \\
\hline BR-13 & 0.87 & 60 & $179 \pm 13$ & 177 & 0 \\
\hline \multicolumn{6}{|l|}{ BR Range Finding } \\
\hline BR-16 & 0.88 & 120 & $90 \pm 6$ & 89 & 0 \\
\hline BR-17 & 0.89 & 240 & $93 \pm 7$ & 92 & 0 \\
\hline BR-18 & 0.87 & 360 & $95 \pm 7$ & 94 & 0 \\
\hline BR-19 & 0.86 & 480 & $92 \pm 6$ & 91 & 0 \\
\hline \multicolumn{6}{|c|}{ BR/FO Wind Speed } \\
\hline BRIFO-03 & 0.91 & 60 & $600 \pm 40$ & $\sim 30$ & $\sim 570$ \\
\hline BR/FO-04 & 1.76 & 62 & $570 \pm 40$ & $26 \pm 10$ & 540 \\
\hline BR/FO-05 & 2.65 & 60 & $515 \pm 35$ & $32 \pm 9$ & 480 \\
\hline BR/FO-06 & 4.46 & 30 & $360 \pm 25$ & $19 \pm 9$ & 340 \\
\hline BRVO-07 & 4.56 & 60 & $610 \pm 45$ & $83 \pm 17$ & 530 \\
\hline
\end{tabular}

Failure to attain target concentrations of brass in the aerosols generated during the BR/FO exposure tests was not thought to greatly impact the deposition-rate aspects of the experiments. Greater relative concentrations of brass, compared with the concentrations of FO, would likely provide increased deposition mass loadings, but the calculation for deposition velocity would have provided results similar to those reported here. This conclusion was based on the observation that FO deposits on collection surfaces coated brass deposits and thus reduced the resuspension rates of brass particles.

We anticipated that the composition of the BR/FO aerosols would change as a function of particle size. This conclusion was supported by initial measurements that indicated the aerodynamic mass median diameter of BR to be $\sim 5 \mu \mathrm{m}$ and that of FO between 2 and $3 \mu \mathrm{m}$. One particle-size-distribution sample, from test BR/FO-04, was submitted for chemical analysis. The results of this analysis, shown in Table 3.3, indicate that the composition of the 
collected brass particles was similar to that collected in the other aerosol samples (Table 3.1). The ratio of $\mathrm{Cu}$ to total brass mass, $0.74 \pm 0.01$, was equal to the ratio determined from the other aerosol samples. The largest ratio measured was 0.76 , at stage 6 of the cascade impactor. Rather than indicating a change in the $\mathrm{Cu}: \mathrm{Zn}$ ratio as particle size decreases, this result most likely reflects measurement uncertainty, as only $0.04 \mathrm{mg}$ of BR were collected at that impactor stage. Brass was collected primarily in the upper four stages of the impactor, indicating that it was composed of relatively large particles. Brass/fog oil was collected in the middle impactor stages, indicating that it was composed of smaller particle

IABLE 3.3. CHEMICAL COMPOSITION OF SIZE-SEGREGATED AEROSOL SAMPLES COLLECTED USING AN ANDERSEN CASCADE IMPACTOR - TEST BR/FO-04

\begin{tabular}{cccccccc}
\hline $\begin{array}{c}\text { Particle Size } \\
(\mu \mathrm{m})\end{array}$ & $\begin{array}{c}\text { Impactor } \\
\text { Stage }\end{array}$ & $\begin{array}{c}\text { Mass } \\
(\mathrm{mg})\end{array}$ & $\begin{array}{c}\text { Cu Mass } \\
(\mathrm{mg})\end{array}$ & $\begin{array}{c}\mathrm{Zn} \text { Mass } \\
(\mathrm{mg})\end{array}$ & $\begin{array}{c}\mathrm{Cu} \\
(\%)\end{array}$ & $\begin{array}{c}\mathrm{Zn} \\
(\%)\end{array}$ & $\begin{array}{c}\text { Fog Oil } \\
(\%)\end{array}$ \\
\hline 10.0 & 0 & 0.69 & 0.182 & 0.067 & 26.4 & 9.7 & 63.9 \\
6.34 & 1 & 1.71 & 0.320 & 0.120 & 18.7 & 7.0 & 74.3 \\
4.4 & 2 & 2.07 & 0.174 & 0.062 & 8.4 & 3.0 & 88.6 \\
3.0 & 3 & 7.81 & 0.224 & 0.081 & 2.9 & 1.0 & 96.1 \\
1.90 & 4 & 10.56 & 0.093 & 0.031 & 0.9 & 0.3 & 98.8 \\
0.94 & 5 & 7.19 & 0.031 & 0.010 & 0.4 & 0.1 & 99.4 \\
0.57 & 6 & 0.95 & 0.000 & 0.000 & 0.0 & 0.0 & 100.0 \\
0.38 & 7 & 0.14 & 0.000 & 0.000 & 0.0 & 0.0 & 100.0 \\
0.00 & $\mathrm{~F}$ & 0.11 & 0.000 & 0.000 & 0.0 & 0.0 & 100.0 \\
\hline
\end{tabular}

sizes. Figure 3.1 shows the particle size distribution of the BR/FO aerosol as functions of mass $(x)$, brass $(+)$, and fog oil ("). The aerodynamic mass median diameter of the aerosol was similar to that of the FO, $\sim 2.5 \mu \mathrm{m}$, because $\sim 95 \%$ of the aerosol consisted of FO at the time the impactor sample was obtained. The AMMD of the brass constituent of the aerosol was $5.9 \mu \mathrm{m}$.

\subsubsection{Aerosol Particle Size Distribution}

The aerosol particle size distribution in the wind tunnel during exposure tests was determined, as described in Section 2.4.2, as the aerodynamic mass median diameter (AMMD) and the geometric standard deviation (GSD). This section presents results of particle size distributions determined from total particulate mass deposited to the various stages of Andersen cascade impactors during BR and BR/FO tests. Results of an analysis of the relative components of the particle size distribution during test BR/FO-04 were discussed 
above (Section 3.1.1). Brass particles analyzed using SEM were plate-like in shape, having the dimensions described above (Section 2.3.1). In contrast, FO particles were spherical oil droplets. In general, the particles in BR aerosols had greater aerodynamic sizes than those in FO aerosols. The AMMDs of brass aerosols were approximately 5 to $6 \mu \mathrm{m}$, while those of FO aerosols were shown by Cataldo (1989) to be approximately 2 to $3 \mu \mathrm{m}$. The dry brass particles also were thought to have different surface-attraction characteristics than the liquid FO droplets. Thus the transport and deposition characteristics of the two obscurant aerosols were not expected to be similar.

We investigated the effectiveness of sampling brass, FO, and BR/FO aerosols with the cascade impactors, because of the relatively large AMMD of brass aerosols. Sampling losses were possible both in the inlet and on interstage surfaces within the impactors.

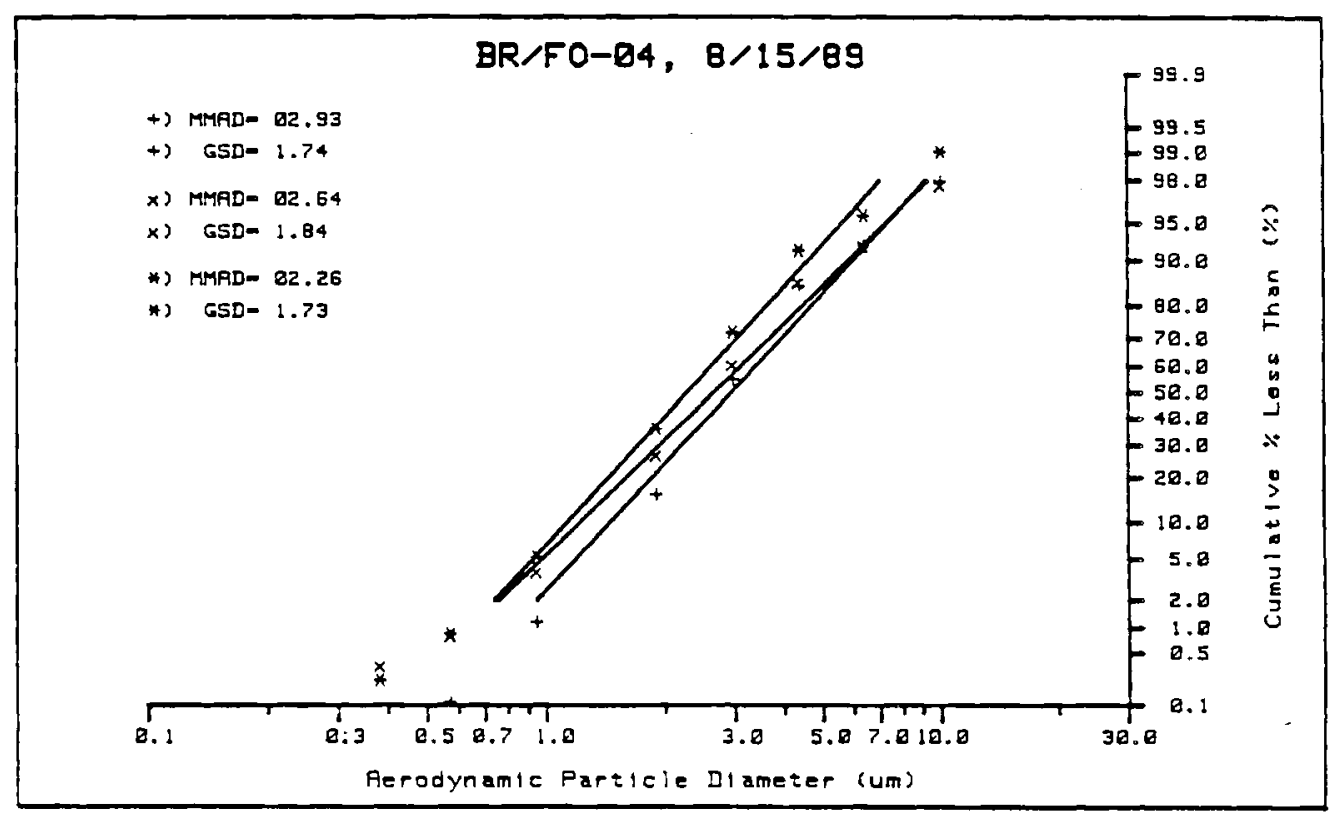

EIGURE 3.1. AEROSOL PARTICLE SIZE DISTRIBUTION OF TOTAL MASS $(X)$, BRASS (+), AND FOG OIL (*) COMPONENTS OF THE AEROSOL DURING TEST BR/FO-04. 
Excessive losses could cause reported AMMDs to be less than the actual values. Overall sampling losses were determined by comparing the aerosol mass concentration from the isokinetic aerosol sampling nozzle to that calculated by summing all mass collected on each impactor and dividing by the volume sampled. Results of this comparison showed that, while measurable sampling losses occurred when sampling brass aerosols, these losses did not greatly bias the reported AMMD. Excluding 4 of 27 samples of brass aerosol, the sampling effectiveness of the impactor procedure was shown to be $92 \pm 7 \%$. Thus, losses were limited to $\sim 8 \%$. For the single measurement of a fog-oil aerosol, the effectiveness was $100 \%$. For 8 of 9 mixed BR/FO aerosols, sampling effectiveness was $96 \pm 4 \%$. Five tests were excluded from consideration because of stage overloading, unusual aerosol-generation procedures, or test relative humidity being significantly different from the norm. These results indicate increasing sampling losses as particle size increases. To determine the effect of sampling losses on the reported AMMD of brass aerosols, mass equal to the measured losses was added to the top four and the top two impactor stages (the locations where these larger particles ideally would be expected to deposit). Under the worst assumed case, the reported results were $0.3 \mu \mathrm{m}$ less than what actually existed in the wind tunnel. Under a more reasonable case, the difference was only $0.1 \mu \mathrm{m}$. The corresponding change in GSD was only an increase of 0.03 for the worst case. The reported AMMD results therefore were judged to be within 0.1 to $0.3 \mu \mathrm{m}$ of the true AMMDs of the aerosols in the wind tunnel.

Results of particle size distributions measured during trial and exposure tests are shown in Table 3.4. Figures 3.2 through 3.4 show selected aerosol particle size distribution plotted as aerodynamic particle diameter versus cumulative percent. Result of the trial tests showed the influence of the brass sonic-nozzle aerosol generator's operating conditions on resultant aerosol particle size distribution (tests BR-01 through BR-03). No effect on particle size was measured for a range of relative humidities (tests BR-03 through BR-05), even though fog droplets were present in the aerosol during the third sampling period of BR-04. Test BR-02 showed AMMD to be $7.1 \mu \mathrm{m}$ downwind of the sonic-nozzle aerosol generator but $\sim 5.8 \pm 0.2 \mu \mathrm{m}$ at the test section. This difference was the result of the large agglomerated particles, those not completed dispersed in the generator, settling in the slow-velocity air flow through the return loop of the wind tunnel. During the BR wind speed tests the average AMMD was $5.3 \pm 0.3$, the average GSD, $1.8 \pm 0.0$. During the $B R$ range-finding tests the average AMMD was $5.1 \pm 0.3$, the average GSD, $1.85 \pm 0.1$. During the BR/FO wind speed test series the average AMMD was $2.7 \pm 0.2$, the average GSD, $1.75 \pm 0.09$. The AMMD decreased during the BR/FO tests because FO predominated in the aerosol mixture (see Section 3.1.1). A possible decrease of $\sim 0.5 \mu \mathrm{m}$ in the AMMD of brass aerosols with increasing wind speed, if real, likely was due to increased preferential impaction of the $>5 \mu \mathrm{m}$ particles on the test subjects, turning vanes, and other surfaces. No such trend was observed for the smaller AMMDs in the BR/FO aerosols. 
IABLE 3.4. AEROSOL PARTICLE SIZE DISTRIBUTIONS FOR BR AND BR/FO TESTS

\begin{tabular}{|c|c|c|c|c|c|}
\hline Test & $\begin{array}{l}\text { Wind Speed } \\
(\mathrm{m} / \mathrm{s})\end{array}$ & $\begin{array}{l}\text { Relative } \\
\text { Humidity } \\
\text { (\%) }\end{array}$ & $\begin{array}{c}\text { Aerosol Conc. } \\
\text { During Sample } \\
\left(\mathrm{mg} / \mathrm{m}^{3}\right)\end{array}$ & $\begin{array}{l}\text { AMMD } \\
(\mu \mathrm{m})\end{array}$ & GSD \\
\hline \multicolumn{6}{|l|}{ BRTrials } \\
\hline BR-01 & -0.9 & 30 & 30 & $\begin{array}{l}5.9 \\
6.0\end{array}$ & $\begin{array}{l}1.8 \\
1.8\end{array}$ \\
\hline BR-02 & $\sim 0.9$ & 25 & 20 & $\begin{array}{l}5.6 \\
5.7\end{array}$ & $\begin{array}{l}1.8 \\
1.8 \\
1.8\end{array}$ \\
\hline BR-03 & -0.9 & 23 & 170 & $\begin{array}{l}7.1 \\
5.6 \\
5.8\end{array}$ & $\begin{array}{l}1.8 \\
1.8 \\
1.8\end{array}$ \\
\hline BR-04 & 0.93 & 86 & 220 & $\begin{array}{l}5.4 \\
5.3 \\
5.3\end{array}$ & $\begin{array}{l}1.8 \\
1.9 \\
1.9\end{array}$ \\
\hline BR-05 & 0.97 & 45 & 210 & 5.2 & 1.9 \\
\hline BR-06 & 4.67 & 46 & 240 & 5.2 & 1.8 \\
\hline BR-07 & 2.70 & 44 & 270 & 5.7 & 1.8 \\
\hline BR-08 & 0.91 & 44 & 240 & 5.5 & 1.8 \\
\hline BR-14 & 0.89 & 53 & 90 & $\begin{array}{l}4.7 \\
5.0\end{array}$ & $\begin{array}{l}1.9 \\
1.8\end{array}$ \\
\hline \multicolumn{6}{|l|}{ BR Wind Speed } \\
\hline BR-10 & 4.49 & 45 & 130 & 5.0 & 1.8 \\
\hline BR-11 & 2.69 & 47 & 150 & 5.1 & 1.8 \\
\hline BR-12 & 1.77 & 46 & 160 & 5.4 & 1.8 \\
\hline \multirow[t]{3}{*}{ BR-13 } & 0.87 & 46 & 180 & 5.5 & 1.8 \\
\hline & & & & 5.6 & 1.8 \\
\hline \multirow{2}{*}{\multicolumn{6}{|c|}{ BR Range-Finding }} \\
\hline & & & & & \\
\hline BR-16 & 0.88 & 46 & 90 & 5.6 & 1.9 \\
\hline BR-17 & 0.89 & 47 & 93 & 4.9 & 1.9 \\
\hline \multirow[t]{2}{*}{ BR-18 } & 0.87 & 45 & 95 & 5.0 & 1.8 \\
\hline & & & & 4.9 & 1.8 \\
\hline \multicolumn{6}{|l|}{$\begin{array}{r}\text { BR-19 } \\
\text { BRJFO Trials }\end{array}$} \\
\hline BRJFO-T1 (BR only) & 0.58 & 38 & 90 & 5.7 & 1.8 \\
\hline BRVFO-T2 (BR only) & 1.98 & 46 & -100 & 5.2 & 1.8 \\
\hline BRJFO-T3 (FO only) & 1.81 & 45 & 540 & 2.2 & 1.7 \\
\hline BR/FO-01 & 1.84 & 46 & 640 & 3.0 & 1.8 \\
\hline \multirow{2}{*}{\multicolumn{6}{|c|}{ BR/FO Wind Speed }} \\
\hline & & & & & \\
\hline \multirow{4}{*}{ BR/FO-04 } & 0.91 & 51 & 660 & 2.6 & 1.8 \\
\hline & 1.76 & 46 & 570 & 2.9 & 1.7 \\
\hline & & & 630 & 2.6 & 1.8 \\
\hline & & & 600 & 2.3 & 1.7 \\
\hline BR/FO-05 & 2.65 & 44 & 520 & 2.6 & 1.8 \\
\hline BR/FO-06 & 4.46 & 47 & 410 & 2.8 & 1.6 \\
\hline BR/FO-07 & 4.56 & 47 & 660 & 3.0 & 1.8 \\
\hline
\end{tabular}



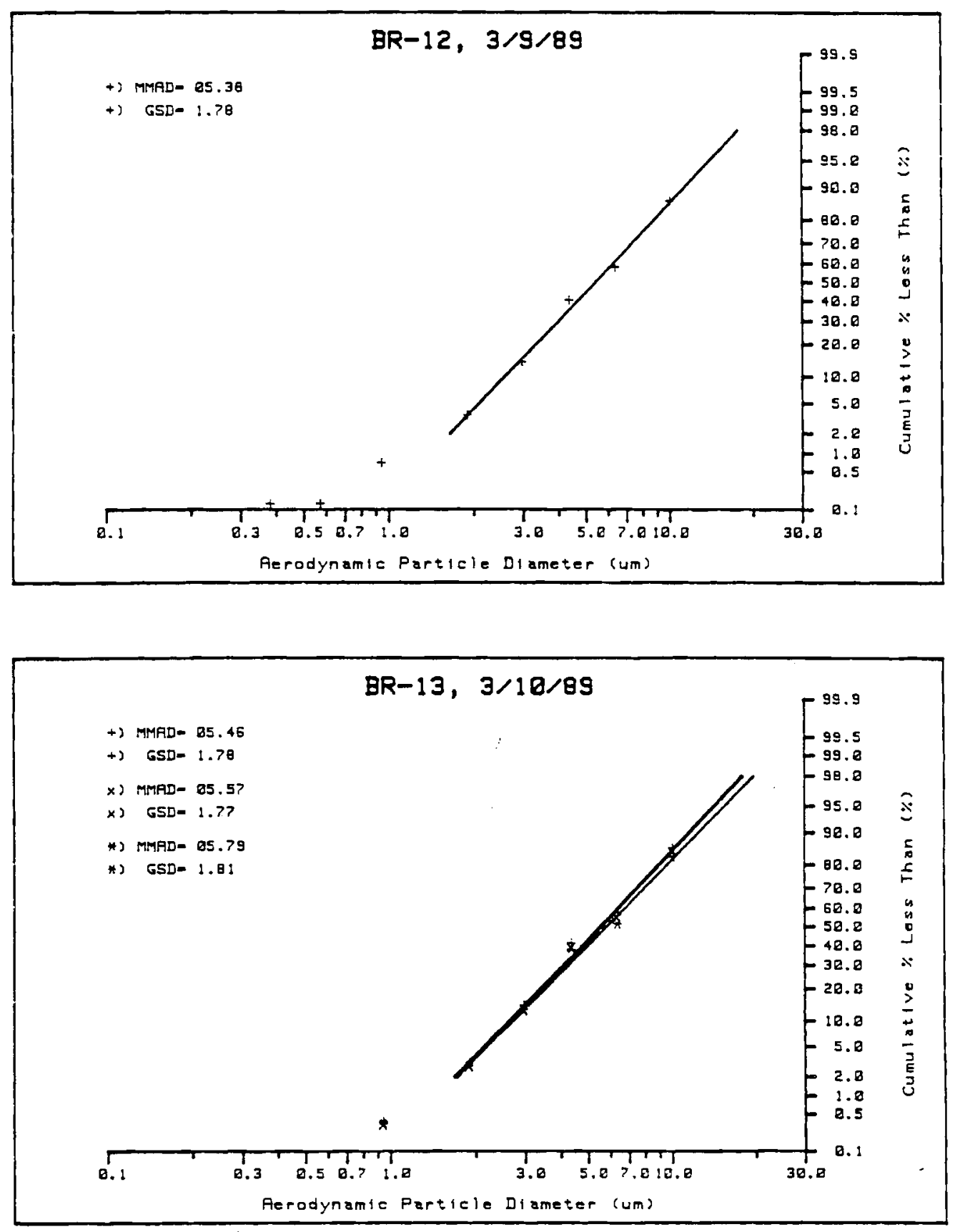

EIGURE 3.2. AEROSOL PARTICLE SIZE DISTRIBUTIONS MEASURED DURING TESTS BR-12 AND BR-13, TWO OF FOUR BRASS WIND SPEED TESTS 

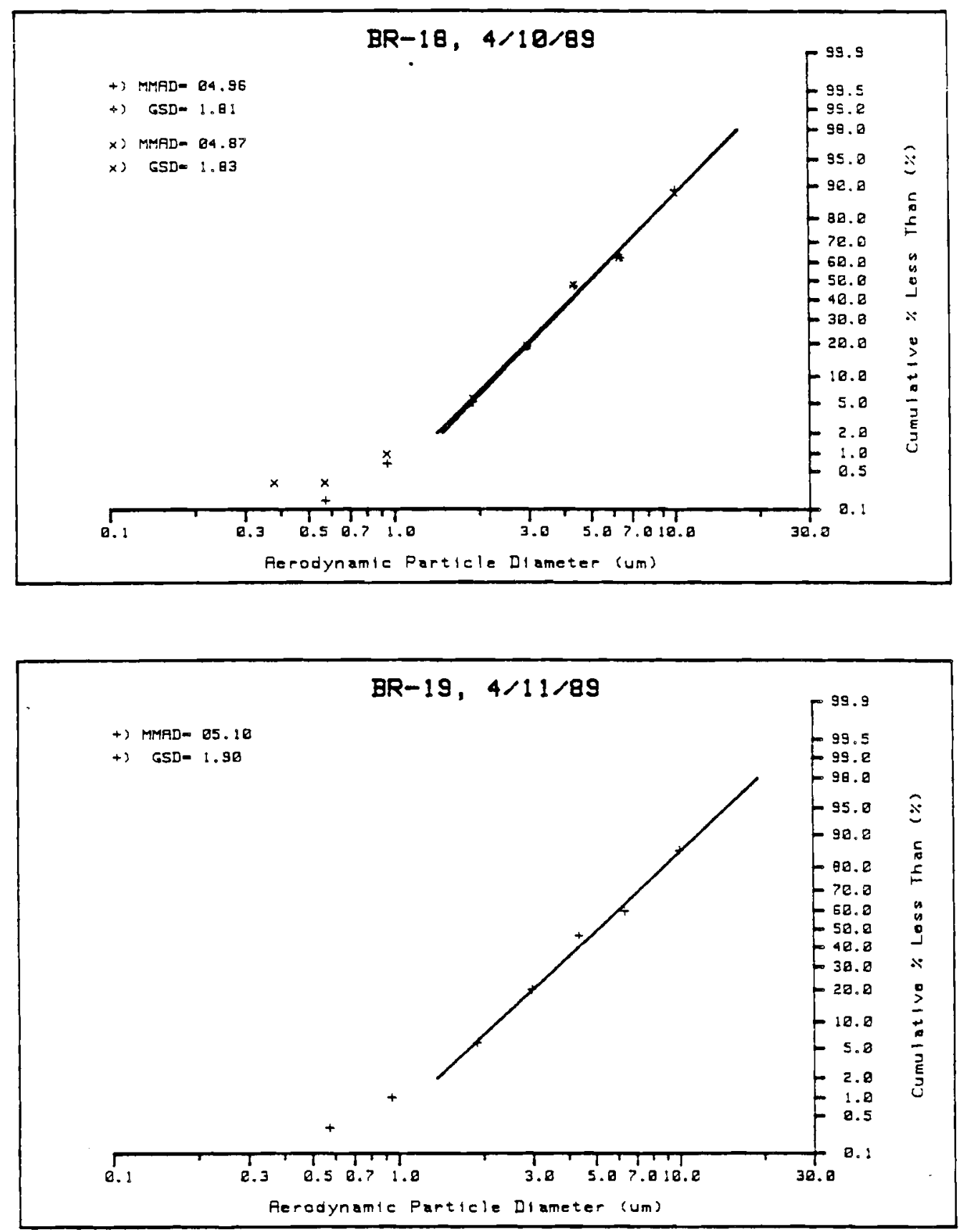

EIGURE 3.3. AEROSOL PARTICLE SIZE DISTRIBUTIONS MEASURED DURING TESTS BR-18 AND BR-19, TWO OF FOUR RANGE-FINDING TESTS 

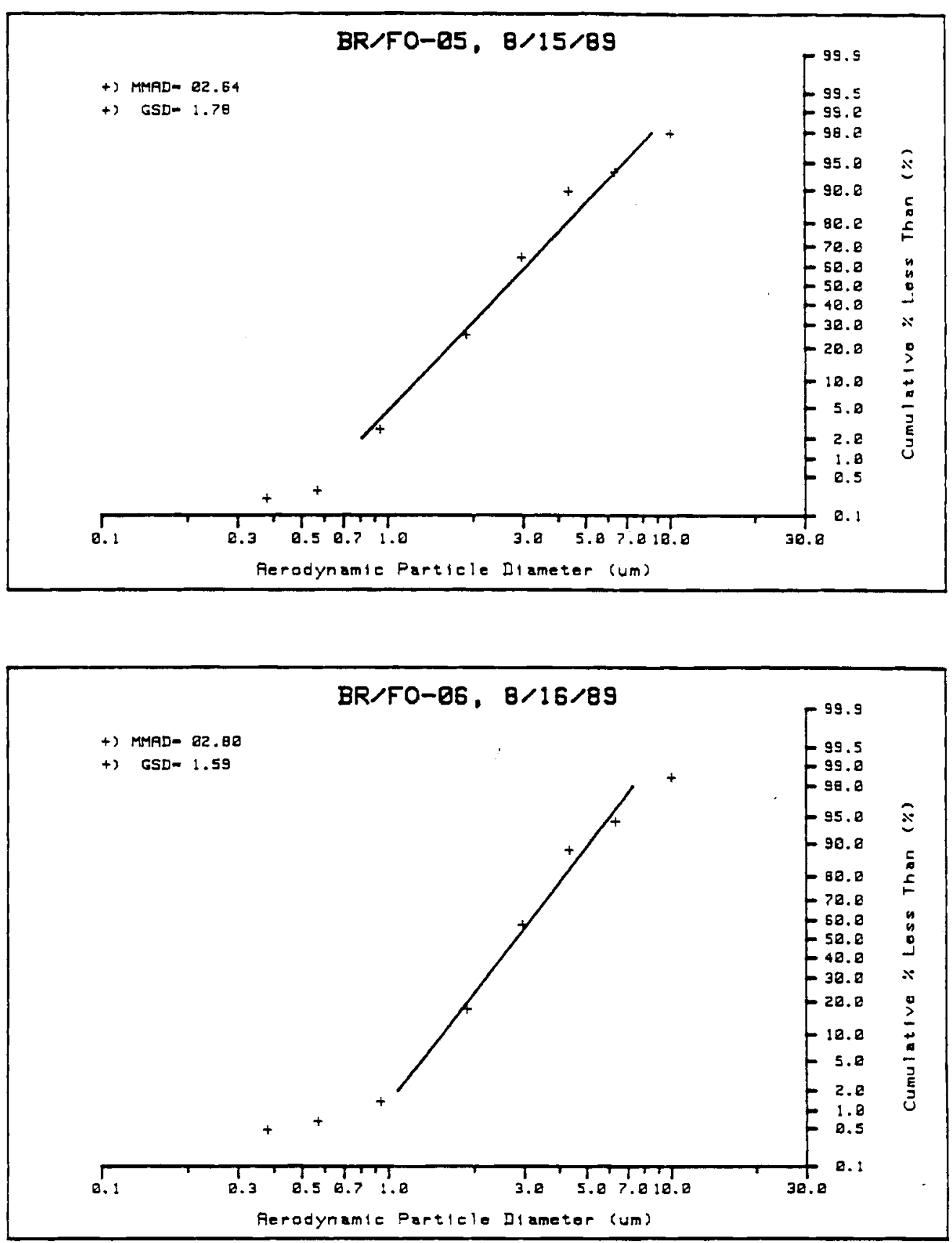

FIGURE 3.4. AEROSOL PARTICLE SIZE DISTRIBUTIONS MEASURED DURING TESTS BR/FO-04 AND BR/FO-06, TWO OF FOUR WIND-SPEED EXPOSURE TESTS 
The aerodynamic size distributions of brass, fog oil, and BR/FO aerosols were measured to provide information most suitable for characterizing the transport and deposition of their constituent particles to the surfaces of test subjects. An alternate measure of average particle size, count median diameter (CMD), also was calculated from the AMMD and GSD results. CMD provided information on the actual physical size of particles in the aerosols. The CMDs of aerosols, based on the average AMMD and GSD information, were determined using the Hatch-Choate conversion equation (Hinds 1982):

$$
C M D=\left[C C(A M M D)+(S . G .)^{1 / 2}\right]+\left(e^{3 \ln 2 G S D}\right)
$$

In the equation, CMD and $A M M D$ are in units of length, S. G. is the specific gravity of the particles, and GSD is dimensionless. Particle specific gravity was 8.6 (BR), 0.8 (FO), and 1.0 to 2.4 (BR/FO). Results of this analysis indicate that the DMDs of the aerosols were $0.6 \mu \mathrm{m}$ (BR/FO). As the actual median physical size of particles in the aerosols, CMD represents the particle size for which exist equal numbers of particles having smaller and larger diameters than the CMD. This differs from the AMMD, which represents the particle size for which equal particulate mass is distributed among particles having smaller and larger aerodynamic diameters than the AMMD. CMD is the more useful size parameter for comparing optical characteristics of most spherical-particle aerosols. It should be noted, however, that the predicted CMD for the flake-shaped brass particles differs greatly from the actual dimension ( $<0.5$ to $20 \mu \mathrm{m}$ in surface dimension, and $0.5 \pm 0.25 \mu \mathrm{m}$ in edge thickness), because the nonspherical shape of the brass particles results in smaller aerodynamic size than would be the case if the same particle mass was incorporated into a spherical particle.

\subsubsection{Aerosol Deposition Velocity to Suspended Surrogate Surfaces}

Deposition velocities of BR and BR/FO aerosols were measured during trial and exposure tests. The relative concentrations of brass and FO during the BR/FO tests (Table 3.2) and the percentages of deposits as brass and FO (Table 3.1) were also used to determine the specific deposition velocities for both components of the aerosol. Deposition velocity results are shown in Figure 3.5. The deposition velocities based on particulate mass are shown in the upper figure, and those based on the specific component in the lower figure. The amount of particulate matter and specific components depositing to the coupons was observed to be a function of both the aerosol composition and the wind speed. Uncertainty limits were estimated, where possible, by considering experimental errors and replicate data variability. Deposition velocity results generally increased exponentially with increasing wind speed from 0.9 to $4.5 \mathrm{~m} / \mathrm{s}$; deposition velocities ranged from 0.9 to $0.4 \mathrm{~cm} / \mathrm{s}$ for the brass aerosol, and from 0.03 to $0.6 \mathrm{~cm} / \mathrm{s}$ for the BR/FO aerosol. The deposition velocities of the 
brass and FO components of the BR/FO aerosols also increased with increasing wind speed; deposition velocities ranged from 0.2 to $1.6 \mathrm{~cm} / \mathrm{s}$ for the brass component, and from 0.02 to $0.5 \mathrm{~cm} / \mathrm{s}$ for the FO component. The exception to this trend was the deposition rate of the brass aerosol generated in the absence of $\mathrm{FO}$ and at the fastest tested wind speed. At 4.5 $\mathrm{m} / \mathrm{s}$, the deposition velocity of brass was approximately equal to that at $2.7 \mathrm{~m} / \mathrm{s}$. This likely was because of resuspension of the dry brass-powder deposits on the deposition coupons exposed to $4.5 \mathrm{~m} / \mathrm{s}$ winds. In contrast, the deposition velocity of the brass component of BR/FO aerosols indicated a continued increase as wind speed was increased from 2.7 to 4.5 $\mathrm{m} / \mathrm{s}$. This was attributed to the adhesive influence of FO on the deposited BR flakes.

Deposition velocities of brass increased an average of 2.0 times at wind speeds of 0.9 to 2.7 $\mathrm{m} / \mathrm{s}$, and 4.0 times at a wind speed of $4.5 \mathrm{~m} / \mathrm{s}$, as a result of the presence of $F O$ in the mixed aerosol. Deposition-velocity results for the FO component of the mixed BR/FO aerosols were not significantly influenced by the brass component, and were similar to results reported by Cataldo et al. (1989) for FO aerosols. In both studies, measured FO deposition rates increased from 0.02 to $0.05 \mathrm{~cm} / \mathrm{s}$ as wind speed increased from 0.9 to $4.5 \mathrm{~m} / \mathrm{s}$. 


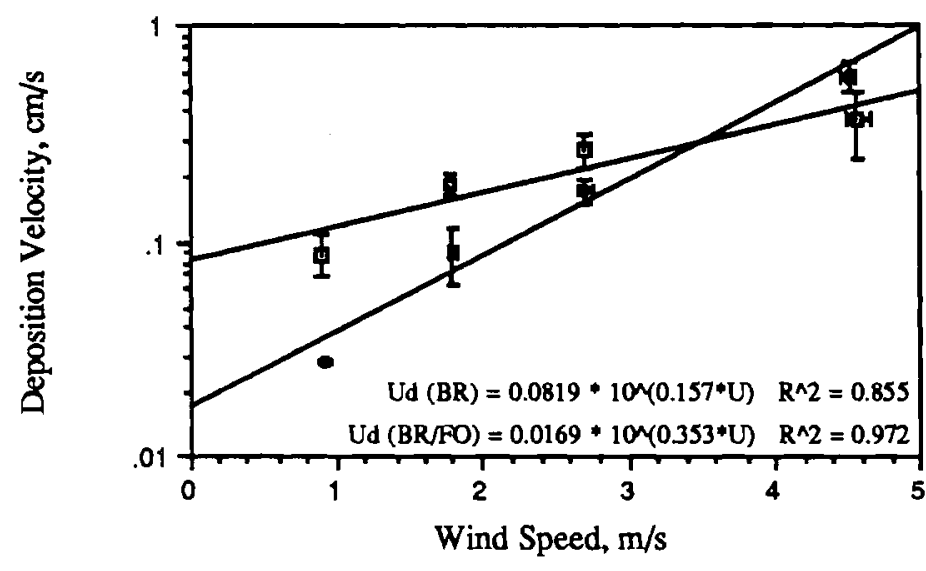

Results based on the

mass of deposits

- BR Aerosol

- BRFO Aerosol

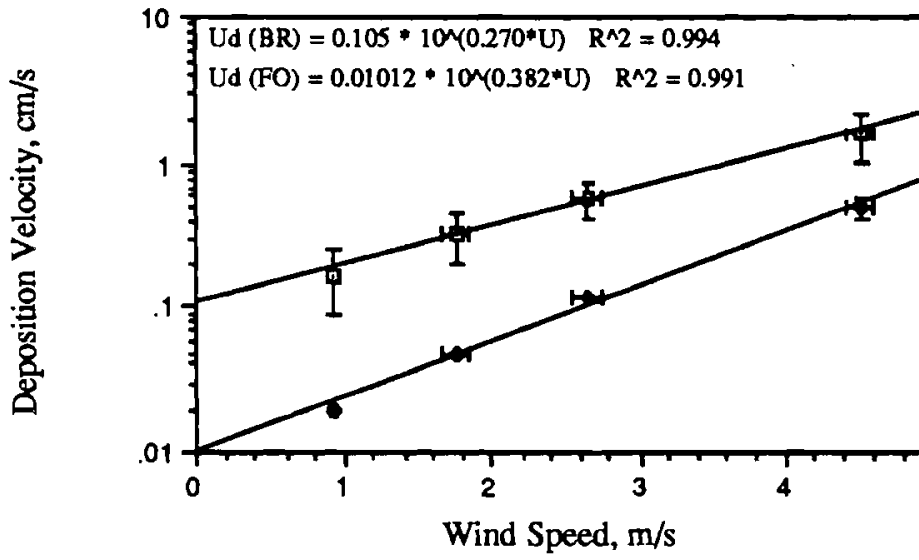

Results based on BR and FO fractions of collected mass

n BR/FO (BR)

- BRFO (FO) COUPONS FOR BRASS, BRASS/FOG OIL, AND THE BRASS AND FOG OIL COMPONENTS OF THE AEROSOLS 


\subsection{SOILPLANT MASS LOADING AND DEPOSITION VELOCITIES}

\subsubsection{Vegetation Mass Loading and Foliar Retention of Brass Flake and Brass Flake/Foo Oil}

Vegetation Mass Loading During Wind-Speed Tests: Brass Flake. Plants were exposed to brass concentrations of approximately $150 \mathrm{mg} / \mathrm{m}^{3}$ for $60 \mathrm{~min}$ at $50 \%$ RH and a wind speed of either 2 (BR-13; $0.9 \mathrm{~m} / \mathrm{s}), 4$ (BR-12; $1.8 \mathrm{~m} / \mathrm{s}), 6$ (BR-11; $2.7 \mathrm{~m} / \mathrm{s})$, or 10 (BR-10; $4.5 \mathrm{~m} / \mathrm{s}$ ) $\mathrm{mph}$. Following exposure, the leaves were sampled by washing them with a $20 \%$ $\mathrm{EtOH}(\mathrm{V} / \mathrm{N}), 1 \%$ Tween-20 (v/V) solution and trapping the flake on a fiber glass filter. Both the filter and the washed leaf were further extracted in $0.01 \mathrm{~N} \mathrm{HNO}_{3}$. The extracts were combined and analyzed using an ICAP analyzer.

Foliar mass loading between species and within species at the different wind speeds varied markedly in this test series. The results given in Table 3.5 show generally that with

IABLE 3.5. FOLIAR MASS LOADING OF BRASS FLAKE TO VEGETATION DURING WIND SPEED TESTS. TOTAL DURATION OF EXPOSURE WAS 60 MINUTES AT 50\% RELATIVE HUMIDITY.

\begin{tabular}{|c|c|c|}
\hline Species & $\begin{array}{c}\text { Wind Speed } \\
(\mathrm{m} / \mathrm{s})\end{array}$ & $\begin{array}{l}\text { Foliar Mass Loading } \\
\left(\mu \mathrm{g} / \mathrm{cm}^{2} \pm S D, n=6\right)\end{array}$ \\
\hline \multirow[t]{4}{*}{ Bush Bean } & 0.9 & $84.30 \pm 14.40$ \\
\hline & 1.8 & $149.72 \pm 37.05$ \\
\hline & 2.7 & $305.8 \pm 105.47$ \\
\hline & 4.5 & $443.94 \pm 72.04$ \\
\hline \multirow[t]{4}{*}{ Sagebrush } & 0.9 & $193.71 \pm 31.54$ \\
\hline & 1.8 & $444.07 \pm 44.28$ \\
\hline & 2.7 & $650.70 \pm 81.84$ \\
\hline & 4.5 & $1095.40 \pm 302.06$ \\
\hline \multirow[t]{4}{*}{ Ponderosa Pine } & 0.9 & $243.86 \pm 50.93$ \\
\hline & 1.8 & $622.49 \pm 133.16$ \\
\hline & 2.7 & $443.25 \pm 64.08$ \\
\hline & 4.5 & $237.01 \pm 58.55$ \\
\hline \multirow[t]{4}{*}{ Short-Needle Pine } & 0.9 & $283.78 \pm 45.76$ \\
\hline & 1.8 & $694.11 \pm 164.83$ \\
\hline & 2.7 & $546.51 \pm 129.92$ \\
\hline & 4.5 & $400.94 \pm 153.79$ \\
\hline \multirow[t]{4}{*}{ Tall Fescue } & 0.9 & $79.83 \pm 7.90$ \\
\hline & 1.8 & $238.68 \pm 15.44$ \\
\hline & 2.7 & $240.39 \pm 38.40$ \\
\hline & 4.5 & $291.85 \pm 72.34$ \\
\hline
\end{tabular}


increasing wind speed a corresponding increase in mass loading occurs, as had been seen in all previous smokes experiments. However, the highest loading for some of the species, most notably the pines, appeared to peak at a lower wind speed, that of $1.8 \mathrm{~m} / \mathrm{s}$ ( $4 \mathrm{mph}$ ). There is an increase at $1.8 \mathrm{~m} / \mathrm{s}$ over the $0.9 \mathrm{~m} / \mathrm{s}(2 \mathrm{mph})$ for the ponderosa and short needle pines, but this decreases at $2.7 \mathrm{~m} / \mathrm{s}(6 \mathrm{mph})$, and further decreases at $4.5 \mathrm{~m} / \mathrm{s}$ (10 mph). While both the bush bean and the tall fescue generally showed increased mass loading at the higher wind speeds, the increases, particularly at the highest speed $(4.5 \mathrm{~m} / \mathrm{s})$, were not as large as had been routinely seen at similar speeds with the other smokes (Van Voris et al. 1987; Cataldo et al. 1989, 1990a,1990b). Only the sagebrush appeared to follow the previously observed pattern.

Possible reasons for these observations are related both to the nature of the material itself and to the surface features of each species. First, the dry powdery nature of the material made it very difficult to sample the foliage without disturbing the layers and knocking some off, particularly when the loading was heavier and for those plants with narrow and smoothsurfaced leaves (i.e., the pines). This accounts in part for the high variations (standard deviations) in the samples. The higher wind speeds also may have resuspended the material, and therefore may have prevented higher accumulations from occurring. The tall fescue received the lowest mass loading. This species, being smooth-surfaced and possessing a canopy frequently oriented vertically to the wind, and being capable of great flexion and torsion in the wind (especially in the larger plants with longer leaves), apparently prevented large accumulations of the dry material to form. This species also received the lowest mass loading in previous studies of the other smokes. The bush bean has surfaces that are oriented horizontally to the wind direction and possesses a somewhat roughened surface, thus being able to retain the powdery material better. It should be noted that the greatest accumulations on these leaves were along the raised features caused by the veination within the lamins of the leaves, where the greatest eddies could be expected to occur. The very rough and "hairy" surface of the sagebrush with its waxy projections from the leaf appeared to be the most efficient in trapping the material from the atmosphere, and therefore showed the greatest loading values at the higher wind speeds.

\section{Vegetation Mass Loading During Wind Speed Tests: Brass Flake/Fog Oil. The} potential for increased brass-flake deposition to vegetation during cogeneration with fog oil was explored during the brass-flake/fog-oil test series. These wind-speed trials were designed to provide atmospheric concentrations of approximately $100 \mathrm{mg} / \mathrm{m}^{3}$ brass flake and $500 \mathrm{mg} / \mathrm{m}^{3}$ fog oil. In actuality, atmospheric brass-flake concentrations were $\sim 25$ to $30 \%$ of this level. The highest wind-speed run $(4.5 \mathrm{~m} / \mathrm{s})$ was cut short because the generator failed. This run was only $30 \mathrm{~min}$, as opposed to the 60 -min durations of the other wind-speed tests. 
It is interesting to compare the results for foliar mass loading for the plants exposed to BR/FO (Table 3.6) with those exposed to brass flake alone (Table 3.5). At the lower wind speeds, 0.9 and $1.8 \mathrm{~m} / \mathrm{s}$, foliar mass loadings are comparable to those of the brass flake alone for all of the species tested, even though the actual atmospheric brass concentrations were approximately 15 to $20 \%$ of those of the previous wind-speed experiment. This indicates that the presence of fog oil affects brass deposition or retention.

\section{TABLE 3.6. FOLIAR MASS LOADING OF BRASS FLAKE TO VEGETATION DURING BRASS/FOG OIL WIND-SPEED TESTS. TOTAL DURATION OF EXPOSURE WAS $60 \mathrm{~min}$ AT $50 \%$ RELATIVE HUMIDITY. DATA ARE EXPRESSED AS AVERAGES $\pm S D(n=3)$.}

\begin{tabular}{|c|c|c|}
\hline Species & $\begin{array}{l}\text { Wind Speed } \\
\qquad(\mathrm{m} / \mathrm{sec})\end{array}$ & $\begin{array}{c}\text { Brass }(\mathrm{Zn}+\mathrm{Cu}) \\
\text { Foliar Mass Loading } \\
\qquad\left(\mu \mathrm{g} / \mathrm{cm}^{2}\right)\end{array}$ \\
\hline \multirow[t]{4}{*}{ Bush Bean } & 0.9 & $38.51 \pm 1.30$ \\
\hline & 1.8 & $143.68 \pm 38.42$ \\
\hline & 2.7 & $592.38 \pm 293.41$ \\
\hline & 4.5 & $376.65 \pm 26.69$ \\
\hline \multirow[t]{4}{*}{ Sagebrush } & 0.9 & $112.92 \pm 45.75$ \\
\hline & 1.8 & $457.99 \pm 92.17$ \\
\hline & 2.7 & $1342.92 \pm 718.90$ \\
\hline & 4.5 & $919.67 \pm 134.68$ \\
\hline \multirow[t]{4}{*}{ Ponderosa Pine } & 0.9 & $317.44 \pm 132.16$ \\
\hline & 1.8 & $1382.32 \pm 226.05$ \\
\hline & 2.7 & $2522.78 \pm 542.74$ \\
\hline & 4.5 & $2187.34 \pm 716.08$ \\
\hline \multirow[t]{4}{*}{ Short-Needle Pine } & 0.9 & $499.67 \pm 97.59$ \\
\hline & 1.8 & $745.83 \pm 158.70$ \\
\hline & 2.7 & $2515.50 \pm 549.61$ \\
\hline & 4.5 & $1733.08 \pm 504.55$ \\
\hline \multirow[t]{4}{*}{ Tall Fescue } & 0.9 & $43.13 \pm 12.14$ \\
\hline & 1.8 & $488.12 \pm 164.23$ \\
\hline & 2.7 & $554.37 \pm 7.79$ \\
\hline & 4.5 & $316.51 \pm 111.55$ \\
\hline
\end{tabular}


At the next higher wind speed $(2.7 \mathrm{~m} / \mathrm{s})$, the average mass loadings for all species are higher compared with brass alone, with significant elevations in the pines (2522 and 2515 $\mu \mathrm{g} / \mathrm{cm}^{2}$ versus 443 and 547 for the ponderosa and short-needle pines, respectively, Tables 3.5 and 3.6). This is similar to what was observed in the mixed-smokes scenarios (Cataldo et al. 1990b), where the effect was attributed to the taller canopy structure and the denser fine needle structure creating more eddies in the wind stream, permitting a higher likelihood of surface contact and deposition. These same plants usually showed higher fogoil deposition in the past. This also apparently would aid in the retention of the brass flake on the leaf surfaces.

At the highest wind speed tested, $4.5 \mathrm{~m} / \mathrm{s}$, there was an apparent decrease in the foliar mass loading (Table 3.6). However, as noted above, the duration of the experiment was only $30 \mathrm{~min}$, as opposed to the previous $60 \mathrm{~min}$. Further, the atmospheric concentration during this time was only $19 \mathrm{mg} / \mathrm{m}^{3}$, or $\sim 66 \%$ of that of the other BR/FO runs.

Vegetation Mass Loading During Range-Finding Tests: Brass Flake. The rangefinding-experiment test series was used to follow continued deposition to the foliage over extended periods $(8 \mathrm{~h})$ under similar environmental conditions. It also was used to determine the persistence of the brass flake material following a simulated rainfall. The results of the foliar mass loading and leaching for these experiments are given in Table 3.7.

The results once again indicated a higher mass loading to the pine species, followed by sagebrush, bush bean, and tall fescue, as noted for the BR/FO tests. There were general increases with time of exposure in all species. These appear to be fairly constant when the sampling errors are considered. The overall values are lower for the $2 \mathrm{~h}, 1.8 \mathrm{~m} / \mathrm{s}$ conditions than for those of the wind-speed trials (e.g., 42 versus 149 for the bush bean; compare Tables 3.7 and 3.5). This reflects the lower atmospheric brass-flake concentration ( 93 versus $154 \mathrm{mg} / \mathrm{m}^{3}$ ) during the range-finding series.

When an artificial rainfall was applied to determine the leaching potential of the brass flake from the different tissue types, it was apparent that the bush bean retained the most material over time, 50 to $80 \%$, as compared with sagebrush, tall fescue, and the pines at approximately 20 to $40 \%$ retention (Table 3.7 ). The flat, broad leaf surfaces of this species may have permitted more of the flake to orient itself parallel to the surface and thus to compress, forming a series of layers to resist the effects of the leachate. On the other species much of the material was not able to achieve a uniform surface and thus was removed. 
IABLE 3.7. FOLIAR MASS LOADING OF BRASS FLAKE TO VEGETATION DURING RANGE-FINDING TESTS. WIND SPEED WAS $1.8 \mathrm{~m} / \mathrm{s}$ AND RELATIVE HUMIDITY WAS $50 \%$

\begin{tabular}{|c|c|c|c|c|c|c|}
\hline \multirow{3}{*}{$\begin{array}{l}\text { Species } \\
\text { Bush Bean }\end{array}$} & \multirow{3}{*}{$\begin{array}{c}\text { Exposure } \\
\text { Duration } \\
\text { (h) }\end{array}$} & \multicolumn{4}{|c|}{ Folix Mass Loadin } & \\
\hline & & \multicolumn{2}{|c|}{$\begin{array}{l}\text { Exposed(a) } \\
\left(\mu g^{\prime} \mathrm{cm}^{2} \pm S D, n=10\right.\end{array}$} & $\begin{array}{r}\text { Exposed/Leached(b) } \\
\left(\mu g / \mathrm{cm}^{2} \pm S D, n=4\right)\end{array}$ & $\%$ Retained & \\
\hline & & 51.80 & \pm 10.03 & $42.0 \pm 11.30$ & 77.16 & \\
\hline & 4 & 91.20 & \pm 8.84 & $50.5 \pm 4.95$ & 61.07 & \pm 7.88 \\
\hline & 6 & 143.20 & \pm 28.99 & $93.5 \pm 6.36$ & 79.34 & \pm 6.50 \\
\hline & 8 & 194.2 & \pm 17.66 & $97.5 \pm 14.85$ & 50.45 & \pm 9.34 \\
\hline \multirow[t]{4}{*}{ Sagebrush } & 2 & 97.00 & \pm 32.66 & $38.00 \pm 4.25$ & 39.22 & \pm 16.25 \\
\hline & 4 & 215.40 & \pm 83.25 & $77.50 \pm 12.02$ & 32.39 & \pm 11.51 \\
\hline & 6 & 290.20 & \pm 76.24 & $90.50 \pm 6.36$ & 25.79 & \pm 3.71 \\
\hline & 8 & 371.20 & \pm 02.38 & $85.00 \pm 9.80$ & 23.16 & \pm 3.27 \\
\hline \multirow[t]{4}{*}{ Ponderosa Pine } & 2 & 191.80 & \pm 111.93 & $41.00 \pm 4.24$ & 46.64 & \pm 9.79 \\
\hline & 4 & 392.00 & \pm 224.53 & $102.50 \pm 53.03$ & 24.02 & \pm 7.42 \\
\hline & 6 & 464.40 & \pm 222.65 & $144.00 \pm 1.40$ & 22.84 & \pm 2.64 \\
\hline & 8 & 504.00 & \pm 183.45 & $101.00 \pm 5.66$ & 21.74 & \pm 2.67 \\
\hline \multirow[t]{4}{*}{ Short Needle Pine } & 2 & 205.20 & \pm 145.30 & $66.50 \pm 9.18$ & 26.57 & \pm 17.93 \\
\hline & 4 & 202.40 & \pm 68.85 & $76.50 \pm 20.51$ & 60.06 & \pm 21.37 \\
\hline & 6 & 558.20 & \pm 178.16 & $77.00 \pm 4.24$ & 14.55 & \pm 1.92 \\
\hline & 8 & 449.20 & \pm 198.21 & $92.00 \pm 0.00$ & 19.16 & \pm 3.32 \\
\hline \multirow[t]{4}{*}{ Tall Fescue } & 2 & 70.60 & \pm 21.73 & $16.50 \pm 3.53$ & 28.38 & \pm 6.77 \\
\hline & 4 & 121.00 & \pm 33.19 & $23.50 \pm 4.94$ & 25.99 & \pm 0.07 \\
\hline & 6 & 168.20 & \pm 15.16 & $61.50 \pm 26.16$ & 37.60 & \pm 19.26 \\
\hline & 8 & 208.40 & \pm 41.54 & $42.00 \pm 5.66$ & 19.58 & \pm 3.59 \\
\hline
\end{tabular}

(a) Non-leached exposed plants.

(b) Leaching/simulated rainfall was conducted within $2 \mathrm{~h}$ of contamination. It consisted of $350 \mathrm{~mL}$ of synthetic rainwater passed through the canopy over $15 \mathrm{~min}$ and is equivalent to a $0.5-\mathrm{cm}$ rainfall. 
Deposition Velocities of Brass Flake to Vegetation During Wind-Speed Tests: Brass

Flake. Deposition velocities $\left(V_{d}\right)$ are routinely computed for experimental exposures to provide a basis for estimating the transfer of smoke constituents from air to foliar and/or soil surfaces. Once established, this parameter can be used to estimate foliar or soil mass loading and thus projected damage under field conditions, given air concentration, wind speed, and relative humidity.

In all species except for the pines, $V_{d}$ increased with increasing wind speed (Table 3.8) as with the other obscurants tested. Values of $V_{d}$ ranged from 0.01 to $1 \mathrm{~cm} / \mathrm{s}$. The pines showed increasing values of $V_{d}$ at the two lower wind speeds, but velocities tended to level off or decrease at the higher speeds. This may be caused by the reduced surface area and curvature of the needles, making retention less efficient and resuspension more likely. What is more noteworthy is the substantially higher values of $V_{d}$ for brass compared with those of the other smokes/obscurants tested. For example, in the grass and bush bean the $V_{d}$ for brass is at least 1 to 2 orders of magnitude greater than the values reported for WP and HC (Cataldo et al. 1990b). For example, $V_{d}=0.005 \mathrm{~cm} / \mathrm{s}$ for bush bean and $0.001 \mathrm{~cm} / \mathrm{s}$ for tall fescue, with WP at $1.8 \mathrm{~m} / \mathrm{s}$, and 0.002 and 0.001 for $\mathrm{HC}$, in the mixed-smoke scenarios. Values for brass alone are 0.13 for bush bean and 0.12 for tall fescue (Table 3.8). These ratios also held for the other species.

Deposition Velocities of Brass Flake to Vegetation During Wind Speed Tests: Brass Flake/Fog $O$ ill. The $V_{d}$ values observed during the brass flake/fog oil wind-speed tests (Table 3.9) again demonstrate increased deposition efficiency with increasing wind speed but are substantially higher than for brass flake alone (Table 3.8). The overall $V_{d}$ values ranged from 0.3 to $60 \mathrm{~cm} / \mathrm{s}$, representing a 3 to 100 times greater collection efficiency than for brass alone. The codeposition of the fog oil to the leaf surface apparently either prevented resuspension of the deposited brass or affected brass agglomeration, increasing its effective size and deposition rate. 
IABLE 3.8. VALUES FOR DEPOSITION VELOCITY $\left(V_{d}\right)$ OF BRASS FLAKE TO VEGETATION DURING WIND SPEED TESTS. TOTAL DURATION OF EXPOSURE WAS $60 \mathrm{~min}$ AT 50\% RELATIVE HUMIDITY. AVERAGE $\pm S D, n=6$.

\begin{tabular}{|c|c|c|}
\hline Spocies & $\begin{array}{l}\text { Wind Speed } \\
\qquad(\mathrm{m} / \mathrm{s})\end{array}$ & $\begin{array}{l}\text { Deposition Velocity }\left(V_{d}\right) \\
\left(\mathrm{cm} / \mathrm{s} \times 10^{2}\right)\end{array}$ \\
\hline \multirow[t]{4}{*}{ Bush Bean } & 0.9 & $13.01 \pm 2.22$ \\
\hline & 1.8 & $27.73 \pm 6.86$ \\
\hline & 2.7 & $56.63 \pm 19.53$ \\
\hline & 4.5 & $94.86 \pm 15.39$ \\
\hline \multirow[t]{4}{*}{ Sagebrush } & 0.9 & $29.89 \pm 4.87$ \\
\hline & 1.8 & $82.24 \pm 8.20$ \\
\hline & 2.7 & $120.50 \pm 33.67$ \\
\hline & 4.5 & $234.06 \pm 64.54$ \\
\hline \multirow[t]{4}{*}{ Ponderosa Pine } & 0.9 & $37.63 \pm 7.86$ \\
\hline & 1.8 & $115.28 \pm 24.66$ \\
\hline & 2.7 & $82.08 \pm 11.87$ \\
\hline & 4.5 & $50.64 \pm 12.51$ \\
\hline \multirow[t]{4}{*}{ Short Needle Pine } & 0.9 & $43.79 \pm 7.06$ \\
\hline & 1.8 & $128.54 \pm 30.52$ \\
\hline & 2.7 & $101.21 \pm 24.06$ \\
\hline & 4.5 & $85.67 \pm 32.86$ \\
\hline \multirow[t]{4}{*}{ Tall Fescue } & 0.9 & $12.32 \pm 2.76$ \\
\hline & 1.8 & $44.20 \pm 2.86$ \\
\hline & 2.7 & $44.52 \pm 7.11$ \\
\hline & 4.5 & $62.36 \pm 15.46$ \\
\hline
\end{tabular}


IABLE 3.9. DEPOSITION VELOCITIES $\left(V_{d}\right)$ OF BRASS FLAKE TO VEGETATION DURING BR/FO WIND SPEED TESTS. TOTAL DURATION OF EXPOSURE AT $50 \%$ RELATIVE HUMIDITY IS GIVEN IN TABLE. AVERAGE $\pm S D, n=6$.

\begin{tabular}{|c|c|c|c|c|}
\hline \multirow{3}{*}{$\begin{array}{l}\text { Species } \\
\text { Bush Bean }\end{array}$} & \multirow{3}{*}{$\begin{array}{c}\text { Exposure } \\
\begin{array}{c}\text { Time } \\
(\min )\end{array} \\
60\end{array}$} & \multirow{3}{*}{$\begin{array}{c}\text { Wind Speed } \\
(\mathrm{m} / \mathrm{s})\end{array}$} & \multirow{2}{*}{\multicolumn{2}{|c|}{$\begin{array}{c}\text { Deposition Velocity }\left(V_{d}\right) \\
\text { (em/s) }\end{array}$}} \\
\hline & & & & \\
\hline & & & 0.36 & \pm 0.01 \\
\hline & 62 & 1.8 & 1.49 & \pm 0.40 \\
\hline & 60 & 2.7 & 5.14 & \pm 2.55 \\
\hline & 30 & 4.5 & 11.01 & \pm 0.78 \\
\hline \multirow[t]{4}{*}{ Sagebrush } & 60 & 0.9 & 1.05 & \pm 0.42 \\
\hline & 62 & 1.8 & 4.74 & \pm 0.95 \\
\hline & 60 & 2.7 & 11.66 & \pm 6.24 \\
\hline & 30 & 4.5 & 26.89 & \pm 3.94 \\
\hline \multirow[t]{4}{*}{ Ponderosa Pine } & 60 & 0.9 & 2.94 & \pm 1.22 \\
\hline & 62 & 1.8 & 14.29 & \pm 2.34 \\
\hline & 60 & 2.7 & 21.90 & \pm 4.71 \\
\hline & 30 & 4.5 & 63.96 & \pm 20.94 \\
\hline \multirow[t]{4}{*}{ Short Needle Pine } & 60 & 0.9 & 4.63 & \pm 0.90 \\
\hline & 62 & 1.8 & 7.71 & \pm 1.64 \\
\hline & 60 & 2.7 & 21.84 & \pm 4.77 \\
\hline & 30 & 4.5 & 50.67 & \pm 14.75 \\
\hline \multirow[t]{4}{*}{ Tall Fescue } & 60 & 0.9 & 0.40 & \pm 0.11 \\
\hline & 62 & 1.8 & 5.05 & \pm 1.70 \\
\hline & 60 & 2.7 & 4.81 & \pm 0.07 \\
\hline & 30 & 4.5 & 9.25 & \pm 3.26 \\
\hline
\end{tabular}

Deposition Velocities of Brass Flake to Vegetation During Range-Finding Tests: Brass Flake. The deposition velocities for brass flake during the range-finding tests were once again higher than those observed for the previous obscurants tested, with $V_{d}$ values ranging from $0.07 \mathrm{~cm} / \mathrm{s}$ for bush bean and tall fescue to $0.3 \mathrm{~cm} / \mathrm{s}$ for the pines. Within the test series, the highest values were observed in the pines (Table 3.10), as expected from the massloading data presented in Table 3.7. The relative consistence in $V_{d}$ values among the exposure durations indicates that aerodynamic processes govern deposition. 
IABLE 3.10. DEPOSITION VELOCITIES $\left(V_{d}\right)$ OF BRASS FLAKE TO VEGETATION DURING RANGE-FINDING TESTS. WIND SPEED WAS MAINTAINED AT $4 \mathrm{mph}$ $(1.8 \mathrm{~m} / \mathrm{s})$ AT $50 \%$ RELATIVE HUMIDITY. AVERAGE $\pm S D, n=6$.

\begin{tabular}{|c|c|c|}
\hline Species & $\begin{array}{l}\text { Exposure } \\
\text { Duration } \\
\text { (h) }\end{array}$ & $\begin{array}{c}\text { Deposition Velocity }\left(V_{d}\right) \\
\left(\mathrm{cm} / \mathrm{s} \times 10^{2}\right)\end{array}$ \\
\hline Bush Bean & $\begin{array}{l}2 \\
4 \\
6 \\
8\end{array}$ & $\begin{array}{lll}7.99 & \pm 1.55 \\
6.81 & \pm & 0.66 \\
6.91 & \pm 1.40 \\
7.41 & \pm 0.67\end{array}$ \\
\hline Sagebrush & $\begin{array}{l}2 \\
4 \\
6 \\
8\end{array}$ & $\begin{array}{l}14.97 \pm 5.04 \\
16.08 \\
13.99 \\
13.22 \\
14.16 \pm 3.68 \\
\pm 3.91\end{array}$ \\
\hline Ponderosa Pine & $\begin{array}{l}2 \\
4 \\
6 \\
8\end{array}$ & $\begin{array}{ll}29.60 & \pm 17.27 \\
29.27 & \pm 16.77 \\
22.40 & \pm 10.74 \\
19.23 & \pm 7.00\end{array}$ \\
\hline Short-Needle Pine & $\begin{array}{l}2 \\
4 \\
6 \\
8\end{array}$ & $\begin{array}{ll}31.67 & \pm 22.42 \\
15.11 & \pm 5.14 \\
26.92 & \pm 8.59 \\
17.14 & \pm 7.56\end{array}$ \\
\hline Tall Fescue & $\begin{array}{l}2 \\
4 \\
6 \\
8\end{array}$ & $\begin{aligned} 10.90 & \pm 3.35 \\
9.04 & \pm 2.48 \\
8.11 & \pm 0.73 \\
7.95 & \pm 1.59\end{aligned}$ \\
\hline
\end{tabular}

\subsubsection{Mass Loadino of Brass Flake to Exposed Soils}

Soil Mass Leading During Wind Speed Tests: Brass Flake. Levels of mass loading of brass to soil coupons exposed during the wind-speed tests, shown in Table 3.11, indicate a general increase in mass loading to the soil surfaces with increasing wind speed. Massloading rates increase from 110 to $130 \mu \mathrm{g} / \mathrm{cm}^{2}$ at $0.9 \mathrm{~cm} / \mathrm{s}$ to 400 to $600 \mu \mathrm{g} / \mathrm{cm}^{2}$ at $4.5 \mathrm{~cm} / \mathrm{s}$. The greatest average loading under these experimental conditions was observed in the Burbank and Cinebar soils, although there was no significant difference between all three types $(P \geq 0.1)$. 


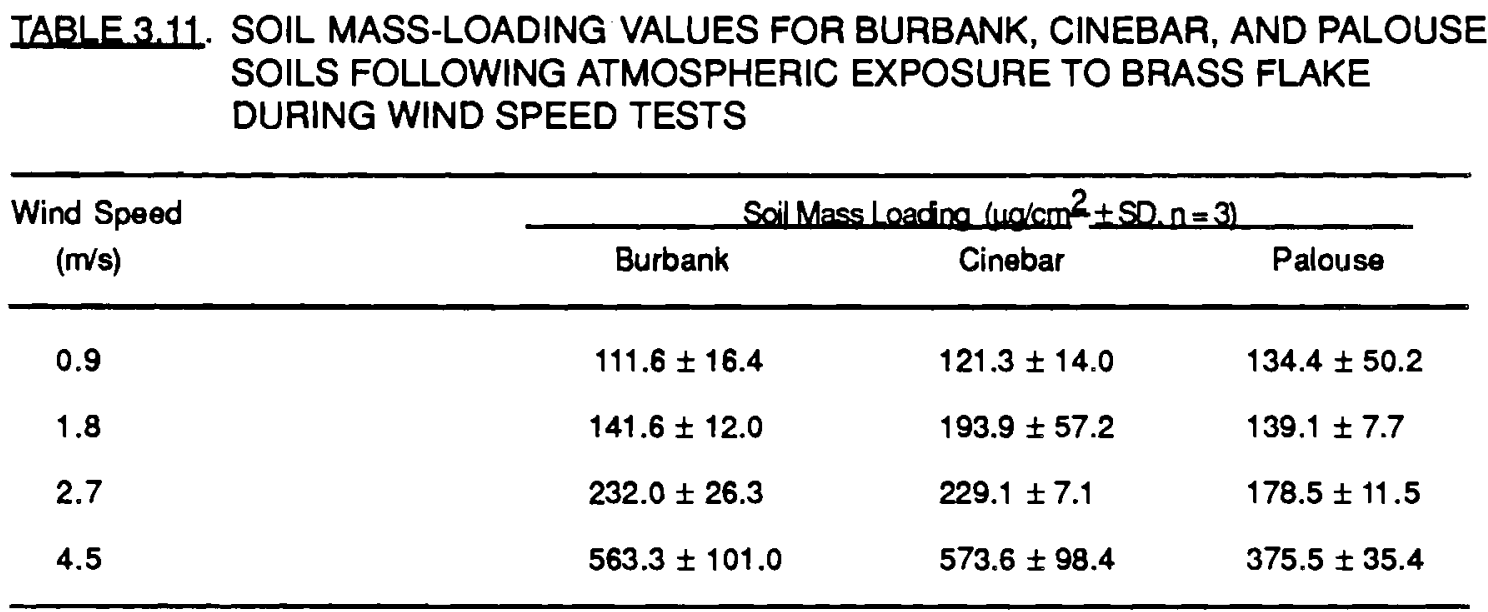

Soil Mass Loading During Wind Speed Tests; Brass Flake/Fog Oil. Mass loading values for soil coupons during the BR/FO wind-speed tests, shown in Table 3.12, indicate a general lack of correlation between wind speed and mass loading of brass in these tests. However, as noted, generation problems existed in these dual-smoke exposures. The significant increase in mass loading prompted by the presence of fog oil in the foliar studies, but is reflected in deposition velocity data discussed below.

Soil Mass Loading During Range-Finding Tests: Brass Flake. In the range-finding tests for brass alone, there appears to be no influence of soil type on mass loading (Table 3.13). Mass-loading rates ranged approximately from $90 \mu \mathrm{g} / \mathrm{cm}^{2}$ after $2 \mathrm{~h}$ of exposure to $350 \mu \mathrm{g} / \mathrm{cm}^{2}$ after $8 \mathrm{~h}$ of exposure. The increases with time were also linear, indicating constant deposition to these surfaces with time, as had been observed in the foliage.

Deposition Velocities $\left(V_{d}\right)$ of Brass Flake to Soils During Wind-Speed Tests - Brass Flake: Wind Speed Brass Flake/Fog Oili and Bange Finding Tests. In the wind: speed tests of brass alone, values of $V_{d}$ generally were comparable for each soil, and ranged from 0.2 to $1.0 \mathrm{~cm} / \mathrm{s}$ for the lowest and highest wind speeds, respectively (Table 3.14). In the presence of fog oil, values increase to approximately 1 to $2.5 \mathrm{~cm} / \mathrm{s}$ (Table 3.15). In the presence of fog oil, brass deposition was highly variable, but did not increase with increasing wind speed as much as noted for the foliar surfaces. Deposition velocities for brass alone in the rangefinding test series (Table 3.16 ) were relatively constant at $\sim 0.13 \mathrm{~cm} / \mathrm{s}$. The data do not indicate that soil type influences collection efficiency. One would expect this, based on the AMMD of the brass flake, $5 \mu \mathrm{m}$. 
IABLE 3.12. SOIL MASS-LOADING VALUES FOR BURBANK, CINEBAR, AND PALOUSE SOILS FOLLOWING ATMOSPHERIC EXPOSURE TO BRASS FLAKE/FOG OIL WIND-SPEED TESTS. AVERAGES $\pm S D(n=3)$.

\begin{tabular}{ccccc}
\hline \multirow{2}{*}{$\begin{array}{c}\text { Wind Spe日d } \\
(\mathrm{m} / \mathrm{s})\end{array}$} & $\begin{array}{c}\text { Exposure } \\
\text { Time } \\
(\mathrm{min})\end{array}$ & Burbank & Sinebar & Palouse \\
\hline 0.9 & 60 & $83.28 \pm 4.34$ & $147.17 \pm 0.54$ & $111.74 \pm 48.26$ \\
1.8 & 62 & $177.45 \pm 27.41$ & $386.76 \pm 2.55$ & $135.33 \pm 12.07$ \\
2.7 & 60 & $113.35 \pm 11.65$ & $397.46 \pm 24.39$ & $138.27 \pm 4.81$ \\
4.5 & 30 & $90.49 \pm 15.25$ & $434.67 \pm 40.94$ & $123.94 \pm 28.43$ \\
\hline
\end{tabular}

IABLE 3.13. SOIL MASS-LOADING VALUES FOR BURBANK, CINEBAR, AND PALOUSE SOILS FOLLOWING ATMOSPHERIC EXPOSURE TO BRASS FLAKE DURING RANGE-FINDING TESTS

\begin{tabular}{cccc}
\hline $\begin{array}{c}\text { Exposure } \\
\text { Duration } \\
\text { (h) }\end{array}$ & Burbank & Soil Mass Loading $\left(u g / \mathrm{cm}^{2} \pm S D . n=3\right)$ & Cinebar \\
\cline { 2 - 4 } & $94.5 \pm 14.9$ & $77.9 \pm 6.2$ & $89.1 \pm 18.7$ \\
2 & $153.7 \pm 10.6$ & $212.1 \pm 42.8$ & $199.9 \pm 26.0$ \\
4 & $248.9 \pm 30.5$ & $299.9 \pm 27.0$ & $302.9 \pm 39.3$ \\
6 & $395.2 \pm 20.9$ & $314.9 \pm 19.4$ & $349.9 \pm 32.6$ \\
8 & & & \\
\hline
\end{tabular}


IABLE 3.14. SOIL DEPOSITION VELOCITY $\left(V_{d}\right)$ VALUES $(\mathrm{cm} / \mathrm{s})$ FOR BURBANK, CINEBAR, AND PALOUSE SOILS FOLLOWING ATMOSPHERIC EXPOSURE TO BRASS FLAKE DURING WIND SPEED TESTS. TESTS CONDUCTED FOR $1 \mathrm{~h}$ AT60\% RELATIVE HUMIDITY. $\operatorname{AVERAGE} \pm S D, n=3$.

\begin{tabular}{cccc}
\hline \multirow{2}{*}{$\begin{array}{c}\text { Wind Speed } \\
(\mathrm{m} / \mathrm{sec})\end{array}$} & Burbank & Deposition $V_{\theta}$ Cinesity $\left(V_{d}\right)\left(\mathrm{cm} / \mathrm{s} \times 10^{2}\right)$ & Palouse \\
\cline { 2 - 4 } 0.9 & $17.22 \pm 2.53$ & $18.72 \pm 2.16$ & $20.74 \pm 7.75$ \\
1.8 & $26.22 \pm 2.22$ & $35.91 \pm 10.59$ & $25.76 \pm 1.43$ \\
2.7 & $42.96 \pm 4.87$ & $42.43 \pm 1.31$ & $33.06 \pm 2.13$ \\
4.5 & $120.36 \pm 21.58$ & $122.56 \pm 21.03$ & $80.24 \pm 7.56$ \\
\hline
\end{tabular}

IABLE 3.15. SOIL DEPOSITION VELOCITY $\left(V_{d}\right)$ VALUES $(\mathrm{cm} / \mathrm{s})$ FOR BURBANK, CINEBAR, AND PALOUSE SOILS FOLLOWING ATMOSPHERIC EXPOSURE TO BRASS FLAKE DURING BR/FO WIND SPEED TESTS. TESTS CONDUCTED FOR $1 \mathrm{~h}$ AT 60\% RELATIVE HUMIDITY. $\operatorname{AVERAGE} \pm S D, n=3$.

\begin{tabular}{rcccc}
\hline $\begin{array}{c}\text { Wind } \\
\text { Spe日d } \\
(\mathrm{m} / \mathrm{s})\end{array}$ & $\begin{array}{c}\text { Exposure } \\
\text { Time } \\
(\mathrm{min})\end{array}$ & Burbank & Cinebar & Palouse \\
\hline 0.9 & 60 & $0.86 \pm 0.04$ & $1.36 \pm 0.01$ & $1.03 \pm 0.45$ \\
1.8 & 62 & $1.64 \pm 0.25$ & $4.00 \pm 0.03$ & $1.20 \pm 0.04$ \\
2.7 & 60 & $0.98 \pm 0.10$ & $3.45 \pm 0.21$ & $1.20 \pm 0.04$ \\
4.5 & 30 & $2.65 \pm 0.45$ & $3.62 \pm 0.83$ & $2.71 \pm 1.20$ \\
\hline
\end{tabular}


IABLE 3.16. SOIL DEPOSITION VELOCITY $\left(V_{d}\right)$ VALUES $(\mathrm{cm} / \mathrm{s})$ FOR BURBANK, CINEBAR, AND PALOUSE SOILS FOLLOWING ATMOSPHERIC EXPOSURE TO BRASS FLAKE DURING RANGE-FINDING TESTS. TESTS CONDUCTED AT $4 \mathrm{mph}(1.8 \mathrm{~m} / \mathrm{s})$ WIND SPEED AND 50\% RELATIVE HUMIDITY. AVERAGE $\pm S D, n=3$.

\begin{tabular}{cccc}
\hline $\begin{array}{c}\text { Exposure } \\
\text { Duration } \\
\text { (h) }\end{array}$ & Burbank & Deposition Volocity $\left(V_{d}\right)\left(\mathrm{cm} / \mathrm{sec} \times 10^{2}\right)$ & Palouse \\
\cline { 2 - 4 } & $14.58 \pm 2.30$ & $12.02 \pm 0.96$ & $13.75 \pm 2.89$ \\
4 & $11.48 \pm 0.79$ & $15.84 \pm 3.20$ & $14.93 \pm 1.94$ \\
6 & $12.00 \pm 1.47$ & $14.46 \pm 1.30$ & $14.61 \pm 1.90$ \\
8 & $15.08 \pm 0.80$ & $12.02 \pm 0.74$ & $13.35 \pm 1.26$ \\
\hline
\end{tabular}

\subsection{CONTACT PHYTOTOXICITY}

\subsubsection{Contact Phytotoxicity of Brass Flake Deposited to Foliar Surfaces}

Contact Phytotoxicity Observed Following Wind-Speed and Bange-Finding Tests: Brass Flake. Plant symptomatology for the brass flake wind-speed series at 30 days postexposure is summarized in Table 3.17. With the exception of sagebrush, brass did not appear to be directly phytotoxic to any of the species tested over this time. Long-term exposures (i.e., $>3$ months, not shown) of the tree species where the material has not been allowed to incorporate into the soil similarly have resulted in no detectable impacts.

The only damage noted during this period was to sagebrush exposed to high loadings of brass in the $4.5 \mathrm{~m} / \mathrm{s}$ wind speeds. These plants received the highest mass loading of any of those tested, but the symptoms (wilting, leaf curl, and leaf drop) occurred within $24 \mathrm{~h}$ after exposure and, given the inert nature of the material, the observed phytotoxic responses may have had an unrelated cause, although it is unknown for sure at this time.

In the range-finding series (not shown), no effects were noted for any of the plant species with mass loading rates of 511 to $400 \mu \mathrm{g} / \mathrm{cm}^{2}$ foliage. Post-exposure leaching had no ameliorating or positive effect on toxicity. Plants (sagebrush and pines) appeared to remain in good condition for up to 120 days post-exposure even though the brass flake was 
still visible on their surfaces, and had not completely been lost during normal watering and handling operations in the greenhouse.

TABLE 3.17. PLANT SYMPTOMATOLOGY TO ATMOSPHERIC BRASS FLAKE EXPOSURE DURING WIND SPEED TESTS. THE SYMPTOMATOLOGY READINGS ARE THE FINAL MEASUREMENTS, TAKEN 30 DAYS POST-EXPOSURE.

\begin{tabular}{|c|c|c|c|c|}
\hline \multirow[t]{2}{*}{ Plant Species } & \multirow{2}{*}{$\begin{array}{l}\text { Wind } \\
\text { Speed } \\
(\mathrm{m} / \mathrm{s})\end{array}$} & \multirow[b]{2}{*}{$\begin{array}{l}\text { Mass Loading } \\
\left(\mu \mathrm{g} / \mathrm{cm}^{2}\right)^{(b)}\end{array}$} & \multicolumn{2}{|c|}{ Toxicity Hespoense (a) } \\
\hline & & & Damage Index & Symptoma \\
\hline \multicolumn{5}{|l|}{ Bush Bean } \\
\hline & 0.9 & $84.30 \pm 14.40$ & 1.0 & O\&NGD \\
\hline & 1.8 & $149.72 \pm 37.05$ & 1.0 & O\&NGDH \\
\hline & 2.7 & $305.82 \pm 105.47$ & 1.0 & O\&NGDH \\
\hline & 4.5 & $443.94 \pm 72.04$ & 1.0 & O\&NGDH \\
\hline
\end{tabular}

Sagebrush

$\begin{array}{rrll}0.9 & 193.71 \pm 31.54 & 1.0 & \text { O\&NGDH } \\ 1.8 & 444.07 \pm 44.28 & 1.0 & \text { O\&NGDH } \\ 2.7 & 650.70 \pm 181.84 & 1.0 & \text { O\&NGDH } \\ 4.5 & 1095.40 \pm 302.06 & 4.0(c) & \text { W, LC, LD }\end{array}$

Ponderosa Pine

$\begin{array}{llll}0.9 & 243.86 \pm 50.93 & 1.0 & \text { O\&NGDH } \\ 1.8 & 622.49 \pm 133.16 & 1.0 & \text { O\&NGDH } \\ 2.7 & 443.25 \pm 64.08 & 1.0 & \text { O\&NGDH } \\ 4.5 & 237.01 \pm 58.55 & 1.0 & \text { O\&NGDH }\end{array}$

Short Needle Pine

$\begin{array}{llll}0.9 & 283.78 \pm 45.76 & 1.0 & \text { O\&NGDH } \\ 1.8 & 694.11 \pm 164.83 & 1.0 & \text { O\&NGDH } \\ 2.7 & 546.51 \pm 129.92 & 1.0 & \text { O\&NGDH } \\ 4.5 & 400.94 \pm 153.79 & 1.0 & \text { O\&NGDH }\end{array}$

Tall Fescue

$\begin{array}{rrrr}0.9 & 79.83 \pm 17.90 & 1.0 & \text { O\&NGDH } \\ 1.8 & 238.68 \pm 15.44 & 1.0 & \text { O\&NGDH } \\ 2.7 & 240.39 \pm 38.40 & 1.0 & \text { O\&NGDH } \\ 4.5 & 291.85 \pm 72.34 & 1.0 & \text { O\&NGDH }\end{array}$

(a) Daubenmire scale and symptomatology definitions.

(b) Average Foliar Mass Loading $\pm S D(n=6)$.

(c) Two of three plants died. Remaining plant appeared healthy. 
Phytotoxicity Observed Following Wind Speed Tests; Brass Flake/Foo Oil. A slight degree of phytotoxicity occurred during the combined BR/FO exposures (Table 3.18), particularly in the bush bean and short needle pine at the higher wind speeds. In both cases, the symptoms -- necrotic spotting, blade dieback, and leaf curl -- were similar to those observed with fog oil alone (Cataldo et al. 1989). For individual plants, the sites of the most visible phytotoxic symptoms were those that also appeared to have the highest depositions of fog

IABLE 3.18. PLANT SYMPTOMATOLOGY TO ATMOSPHERIC BRASS FLAKE/FOG OIL WIND SPEED TEST EXPOSURES. THE SYMPTOMATOLOGY READINGS ARE THE FINAL MEASUREMENTS TAKEN 30 DAYS POST-EXPOSURE.

\begin{tabular}{|c|c|c|c|c|}
\hline \multirow[b]{2}{*}{ Plant Species } & \multirow[b]{2}{*}{$\begin{array}{l}\text { Wind Speed } \\
\qquad(\mathrm{m} / \mathrm{s})\end{array}$} & \multirow{2}{*}{$\begin{array}{c}\text { Brass } \\
\text { Mass Loading } \\
\left(\mu \mathrm{g} / \mathrm{cm}^{2}\right)^{(b)}\end{array}$} & \multicolumn{2}{|c|}{ Toxicity Respense ${ }^{(a)}$} \\
\hline & & & Damage Index & Symptomatology \\
\hline \multicolumn{5}{|l|}{ Bush Bean } \\
\hline & 0.9 & $38.51 \pm 1.30$ & 1.0 & O\&NGDH \\
\hline & 1.8 & $148.68 \pm 38.42$ & 1.0 & O\&NGDH \\
\hline & 2.7 & $592.38 \pm 293.41$ & 3.0 & W, LC, NS \\
\hline & 4.5 & $376.65 \pm 26.69$ & 3.0 & NGA, W, LC, NS \\
\hline
\end{tabular}

Sagebrush

$\begin{array}{rrrl}0.9 & 112.92 \pm 45.75 & 1.0 & \text { O\&NGDH } \\ 1.8 & 457.99 \pm 92.17 & 1.0 & \text { O\&NGDH } \\ 2.7 & 1342.92 \pm 718.90 & 1.7 & \text { NGA, Chl, BD, LD } \\ 4.5 & 919.67 \pm 134.68 & 3.5 & \text { Chl, W, LD, }\end{array}$

Ponderosa Pine

$\begin{array}{rrrl}0.9 & 317.44 \pm 132.16 & 1.0 & \text { O\&NGDH } \\ 1.8 & 1382.32 \pm 226.05 & 1.0 & \text { O\&NGDH } \\ 2.7 & 2522.78 \pm 542.74 & 1.5 & \text { NS } \\ 4.5 & 2187.34 \pm 716.08 & 1.5 & \text { NS }\end{array}$

Short Needle Pine

$\begin{array}{rrrl}0.9 & 499.67 \pm 97.50 & 1.0 & \text { O\&NGDH } \\ 1.8 & 745.83 \pm 158.70 & 1.0 & \text { O\&NGDH } \\ 2.7 & 2515.50 \pm 549.61 & 2.5 & \text { BD, NS, NGDH } \\ 4.5 & 1733.08 \pm 504.55 & 3.5 & \text { BD (3.5), NS }\end{array}$

Tall Fescue

$\begin{array}{llll}0.9 & 43.13 \pm 12.14 & 1.0 & \text { O\&NGDH } \\ 1.8 & 488.12 \pm 164.23 & 1.3 & \text { TB }(3.0) \\ 2.7 & 554.37 \pm 7.79 & 1.7 & \text { TB }(5.0) \\ 4.5 & 316.51 \pm 111.55 & 1.7 & \text { TB }(5.0)\end{array}$

(a) Daubenmire Scale and Symptomology Definitions.

(b) Average Foliar Mass Loading $\pm S D(n=3)$. 
oil on their surfaces. There may have been a slight synergistic effect of the brass flake, exacerbating the effects of the relatively low level of fog oil, but more likely, the fog oil may have been responsible for the majority of the damage.

\subsubsection{Metabolic Responses To Brass-Flake Exposure During Wind-Speed Tests}

The metabolic response of the plants to the brass flake in the wind-speed tests was assessed by measuring the net photosynthesis and dark respiration of selected tall fescue and ponderosa pine plants following exposures at $0.9,1.8$, and $4.5 \mathrm{~m} / \mathrm{s}(2,4$, and $10 \mathrm{mph})$. Although there was a slight reduction, immediately following exposure, in the photosynthetic rate for the 2- and 4-mph tests, no long-term deleterious effects were evident either on net photosynthesis or dark respiration for periods of up to 21 days post-exposure (Figure 3.6). It should also be noted that the brass flake on the leaves appeared to be quickly dispersed off of the leaves through plant motion occurring in the growth chambers, and from the manipulations of placing them in the photosynthesis test chambe, which occurred even though special efforts were made to prevent sudden movements of the plants during handling.

The loss of activity observed at the highest wind speeds (10 mph, Figure 3.6) was only temporary, and the plants quickly recovered. The initial loss of activity may have been due to thigmotropic responses to the force of the wind itself or to a shading effect of the brass flake on the surface of the plant leaves. These plants retained a substantial portion of the deposited brass material over the measuring period, which may have resulted in an initial reduced rate, but in a sustaining manner. 


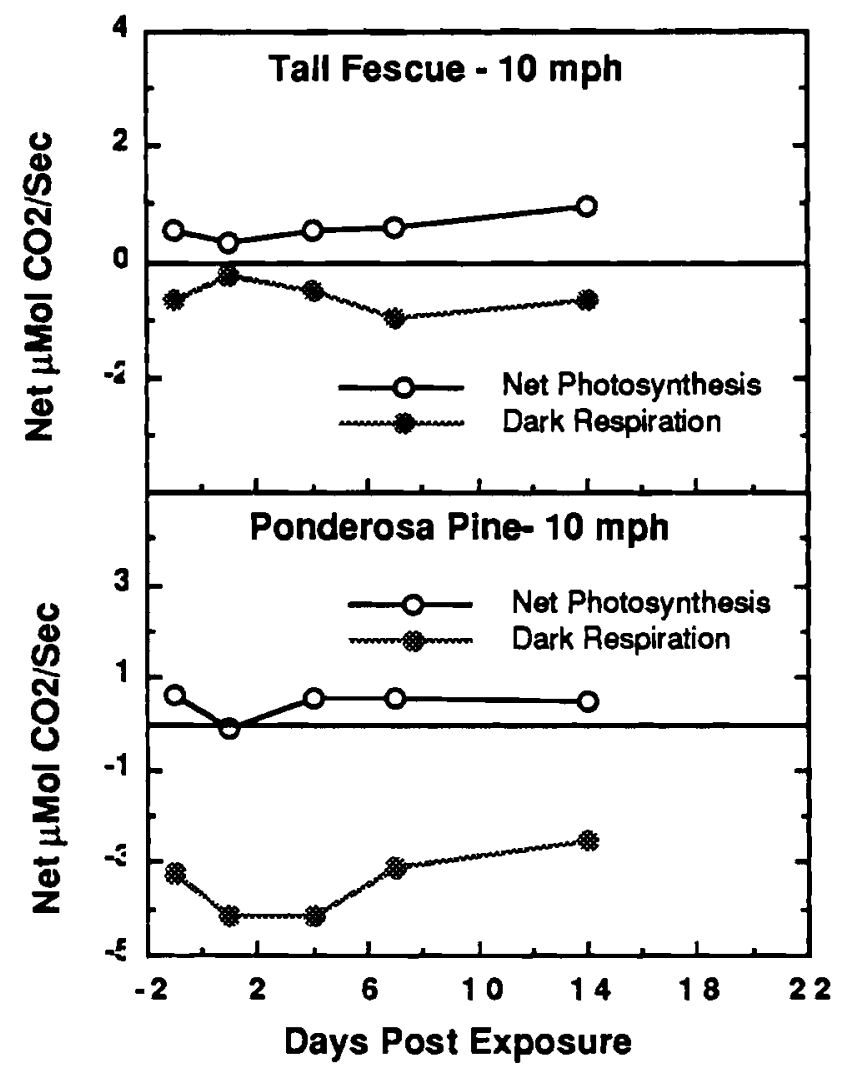

EIGURE 3.6. WHOLE-PLANT NET-PHOTOSYNTHESIS AND DARK-RESPIRATION RATES $\left(\mu \mathrm{mole} \mathrm{CO}_{2} / \mathrm{s}\right.$ ) FOR A TALL FESCUE AND A PONDEROSA PINE PLANT EXPOSED TO ATMOSPHERIC BRASS FLAKE FOR $60 \mathrm{~min}$ AT $\sim 150 \mathrm{mg} / \mathrm{m}^{3}$ AND 50\% RELATIVE HUMIDITY AND $10 \mathrm{mph}$ WIND SPEED. MEASUREMENTS WERE TAKEN AT DAY 1 AND FOR THE PERIOD FOLLOWING EXPOSURE.

\subsection{BESIDUAL EFFECTS OF FOLIAR-DEPOSITED BRASS ON DRY-MATIER PRODUCTION IN TALL FESCUE}

Tall fescue plants foliarly contaminated in the aerosol/contact toxicity tests were harvested 30-days post-exposure and allowed to regrow for an addition harvest of shoot tissues. This procedure permitted us to evaluate any residual effects of foliarly absorbed brass contaminants on biomass production. 


\subsubsection{Wind-Speed Tests: Brass Flake}

Foliar loading of the brass-flake material at the various wind speeds appeared to slightly affect the dry-matter accumulation of tall fescue over the 30-day growth period following exposure. As seen in Table 3.19, there were slightly significant ( 0.05 confidence level) reductions in the dry weight of grasses exposed at the higher wind speeds, 2.7 and $4.5 \mathrm{~m} / \mathrm{s}$, although these reductions were only approximately 12 to $18 \%$ of control tissues values.

The biomass reduction observed for the first harvest, was not seen in the second harvest treatments. Thus, it is likely that the first-harvest growth reductions were due to either the shading effect of the brass flake deposited to foliage or absorption of $\mathrm{Cu}$ and/or $\mathrm{Zn}$ associated with the brass, although the latter is unlikely.

IABLE 3.19. EFFECTS OF BRASS-FLAKE AEROSOL WIND-SPEED TESTS ON THE REGROWTH (DRY MATTER PRODUCTION) OF EXPOSED(a) TALL FESCUE AT 30 AND 60 DAYS POST-EXPOSURE

\begin{tabular}{lcc}
\hline \multirow{2}{*}{ Treatment } & \multicolumn{2}{c}{ Dry Matter Production (Average adp wt $\pm S D . n=3$ ) } \\
\cline { 2 - 3 } & First Harvest & Second Harvest \\
\hline Control & $6.26 \pm 0.47$ & $3.81 \pm 0.36$ \\
& & \\
$0.9 \mathrm{~m} / \mathrm{s}$ & $5.92 \pm 0.06^{(b)}$ & $4.38 \pm 0.24^{(b)}$ \\
$1.8 \mathrm{~m} / \mathrm{s}$ & $5.07 \pm 0.48^{(b)}$ & $4.96 \pm 0.57^{(c)}$ \\
$2.7 \mathrm{~m} / \mathrm{s}$ & $5.54 \pm 0.14^{(c)}$ & $4.59 \pm 0.55^{(c)}$ \\
$4.5 \mathrm{~m} / \mathrm{s}$ & $5.17 \pm 0.83^{(c)}$ & $3.84 \pm 0.80^{(b)}$ \\
\hline
\end{tabular}

(a) See Table 3.5 for rates of foliar mass loading.

(b) Not Significant.

(c) Significant at 0.05 confidence level using a one-tailed t-Test. 


\subsubsection{Wind-Speed Tests: Brass Flake/Fog Oil}

Highly significant $(P \leq 0.01)$ reductions were evident in dry-matter productions for tall fescue exposed to the BR/FO at the higher wind speeds (2.7 and $4.5 \mathrm{~m} / \mathrm{s}$, Table 3.20). These reductions were more severe than those observed with brass alone, but they were not observed at the second harvest after the foliage that had received the exposure was removed. The leaves appeared to retain the brass flake longer following co-exposure with fog oil. This may have promoted additional shading, thereby reducing dry-matter production from photosynthesis. Upon removal of these affected leaves and regrowth, no effects were noted, indicating that brass/fog oil aerosols have little residual impact.

IABLE 3.20. EFFECTS OF BRASS FLAKE/FOG OIL AEROSOL WIND SPEED TESTS ON THE REGROWTH (DRY-MATTER PRODUCTION) OF EXPOSED(a) TALL FESCUE AT 30 AND 60 DAYS POST-EXPOSURE

\begin{tabular}{lcc}
\hline \multirow{2}{*}{ Treatment } & \multicolumn{2}{c}{ Dry-Matter Production (Averace odv wt $\pm S D, n=3$ ) } \\
\cline { 2 - 3 } & First Harvest & Second Harvest \\
\hline Control & $9.56 \pm 0.37$ & $5.83 \pm 0.61$ \\
& & \\
$0.9 \mathrm{~m} / \mathrm{s}$ & $10.09 \pm 1.63^{(b)}$ & $6.22 \pm 0.74^{(b)}$ \\
$1.8 \mathrm{~m} / \mathrm{s}$ & $10.11 \pm 1.11^{(\mathrm{b})}$ & $6.29 \pm 0.21^{(b)}$ \\
$2.7 \mathrm{~m} / \mathrm{s}$ & $6.93 \pm 0.29^{(c)}$ & $5.60 \pm 0.43^{(b)}$ \\
$4.5 \mathrm{~m} / \mathrm{s}$ & $6.61 \pm 0.69^{(c)}$ & $5.74 \pm 0.84^{(b)}$ \\
\hline
\end{tabular}

(a) See Table XX for rates of foliar mass loading.

(b) Not Significant.

(c) Significant at 0.01 confidence level using a one-tailed t-Test.

\subsubsection{Bange-Finding Tests: Brass Flake}

As seen in Table 3.19 slightly significant $(P \leq 0.05)$ reductions in dry-matter production were evident immediately following exposure for all of the exposed plants (first harvest). With one exception, that of the 4-h exposure, this reduction was not observed after the exposed tissue was removed (second harvest). It is likely that the 4- $h$ values are erroneous, since mass loadings for the 4-h treatment were lower than that of the 6-and 8-h treatments. For those plants that were leached with a simulated rainfall immediately following exposure, and 
thus had their foliar-loading levels reduced (see Table 3.7), no differences in dry-matter accumulation compared with non-leached treated plants were apparent (Table 3.21). This may support the concept that the negative effects on dry-matter accumulation by the brass flake are the result of external shading, which reduces total carbon assimilation over the extended period of 30 days. Removing these "shaded" leaves permitted a return to the control activity levels. This again implies that the brass-flake constituents are not weathering on foliar surfaces and thus that constituents are not being absorbed into the plant through the leaves.

\section{TABLE 3.21. EFFECTS OF BRASS-FLAKE AEROSOL RANGE-FINDING TESTS ON THE REGROWTH (DRY-MATTER PRODUCTION) OF EXPOSED(a) AND EXPOSED/LEACHED(b) TALL FESCUE AT 30 AND 60 DAYS POST- EXPOSURE}

\begin{tabular}{|c|c|c|c|}
\hline \multirow{2}{*}{$\begin{array}{l}\text { Days } \\
\text { Post Exposure }\end{array}$} & \multirow[b]{2}{*}{ Treatment } & \multicolumn{2}{|c|}{ Dry Matter Production (Average g dry weight $\pm S D, n=3$ ) } \\
\hline & & Exposed & Exposed/Leached \\
\hline \multirow[t]{5}{*}{30} & Control & $9.41 \pm 1.09$ & \\
\hline & $2 \mathrm{~h}$ & $7.17 \pm 1.13^{(c)}$ & $7.71 \pm 0.76^{(d)}$ \\
\hline & $4 \mathrm{~h}$ & $6.11 \pm 0.32^{(c)}$ & $6.65 \pm 0.04^{(c)}$ \\
\hline & $6 \mathrm{~h}$ & $7.48 \pm 0.55^{(c)}$ & $7.84 \pm 1.54(d)$ \\
\hline & $8 \mathrm{~h}$ & $7.42 \pm 0.99(c)$ & $7.35 \pm 1.31^{(d)}$ \\
\hline \multirow[t]{5}{*}{60} & Control & $6.70 \pm 0.16$ & \\
\hline & $2 \mathrm{~h}$ & $5.66 \pm 0.29$ (c) & $5.58 \pm 0.09(d)$ \\
\hline & $4 \mathrm{~h}$ & $5.42 \pm 0.50^{(c)}$ & $6.39 \pm 0.07^{(d)}$ \\
\hline & $6 \mathrm{~h}$ & $7.17 \pm 0.91^{(d)}$ & $7.19 \pm 0.65^{(d)}$ \\
\hline & $8 \mathrm{~h}$ & $6.67 \pm 0.49(d)$ & $6.52 \pm 0.73^{(d)}$ \\
\hline
\end{tabular}

(a) Foliar mass-loading rates given in Table 3.7.

(b) Leaching/simulated rainfall was conducted within $2 \mathrm{~h}$ of contamination. It consisted of $350 \mathrm{~mL}$ of syntheticrainwater passed through the canopy over $15 \mathrm{~min}$, equivalent to a $0.5 \mathrm{~cm}$ rainfall.

(c) Significant at 0.05 confidence level using a one-tailed t-Test.

(d) Not significant. 


\subsection{PLANT/SOIL AMENDMENT STUDIES}

Soil amendment studies using brass flake were undertaken for three reasons. The first was to simulate the effects of brass at soil concentrations higher than those that can be reasonably produced in the wind tunnel. The second was to provide a reasonable range in soil concentrations to simulate those field instances where brass use has been recurrent. The third was to allow soil weathering rates of brass and the effect of brass on biotic processes to be evaluated. Soils were amended with $0,25,100,500$, and $2500 \mu \mathrm{g} \mathrm{brass} / \mathrm{g}$ dry wt soil and were evaluated after 100 and 440 days. Four soil treatments were used, and plant availability, toxicity, and tissue concentrations of $\mathrm{Cu}, \mathrm{Zn}$, and related soil cations were assessed. Impacts of these treatments on soil microbial processes are provided in Section 3.6.

\subsubsection{Soil Chemistry of Amended Brass}

Brass flake used for training or testing will be deposited to soil surfaces. One of the major requirements for understanding whether adverse environmental impacts from brass occur is to correlate solubilization of $\mathrm{Cu}$ and $\mathrm{Zn}$ with subsequent mobility of solubilized elements and secondary biological effects. This requires that suitable extraction methods be used to quantify soluble and/or bioavailable $\mathrm{Cu}$ and/or $\mathrm{Zn}$. Since these ions are chemically dissimilar with respect to organic complexation, sorption to mineral surfaces, and hydrolysis, a single extraction method may not be appropriate.

The only available data related to the weathering of brass in soils is that of Wentsel and Guelta (1986a). These studies showed brass powder to weather significantly over 8 months; associated biotic effects were also noted (Wentsel and Guelta 1986a; Wentsel 1986). However, these studies involved soils having very limited ranges in physicochemical characteristics (low pH and high organic matter). Thus, the purpose of the present study was to extend the available data base to include soils with higher $\mathrm{pH}$ and wider ranges of organic-matter content; soils selected for this study are representative of Northwest forest soils (Cinebar), semi-arid desert soils (Burbank), and irrigated Western cultivated soils (Palouse). The study was designed to evaluate the weathering of brass over 12 to 18 months and to correlate weathering with both terrestrial-plant and soil-microbial impacts. Two soil systems were used to evaluate weathering: soil/pot studies using all soils except Cecil, and soil column studies using all four soils.

Influence of Brass on Soil pH. Actual moisture contents of the soil pots at analysis generally were within $90 \%$ of the target moisture content (Table 3.22). Since these pots were sampled 1 day following the last watering, such levels were expected. The $\mathrm{pH}$ values 
IABLE 3.22. MOISTURE CONTENT AND PH OF BRASS-AMENDED SOILS SAMPLED AT 100 TO 440 DAYS AFTER PREPARATION

\begin{tabular}{|c|c|c|c|c|c|c|c|}
\hline \multirow[b]{2}{*}{ Soil } & \multirow[b]{2}{*}{ Parameter } & \multirow[b]{2}{*}{ Units } & \multicolumn{5}{|c|}{ TARGET BRASS CONCENTRATION ( $\mu \mathrm{g} g$ over dry soil) } \\
\hline & & & 0 & 25 & 100 & 500 & 2500 \\
\hline Burbank & $\begin{array}{l}\text { Moisture } \\
\text { Moisture } \\
\mathrm{pH} / 100 \text { days } \\
\mathrm{pH} / 250 \text { days } \\
\mathrm{pH} / 440 \text { days }\end{array}$ & $\begin{array}{l}\% / O D \\
\% / t a r g e t \\
/ \mathrm{H} 2 \mathrm{O} \\
/ \mathrm{H} 2 \mathrm{O} \\
/ \mathrm{H} 2 \mathrm{O}\end{array}$ & $\begin{array}{l}18.7 \\
81.3 \\
6.80 \\
7.45 \\
6.95\end{array}$ & $\begin{array}{c}27.1 \\
118.0 \\
7.11 \\
7.14 \\
6.94\end{array}$ & $\begin{array}{l}21.6 \\
93.8 \\
7.39 \\
7.26 \\
7.25\end{array}$ & $\begin{array}{l}20.9 \\
91.0 \\
7.43 \\
7.46 \\
7.30\end{array}$ & $\begin{array}{l}22.2 \\
96.6 \\
7.99 \\
7.89 \\
7.77\end{array}$ \\
\hline Cinebar & $\begin{array}{l}\text { Moisture } \\
\text { Moisture } \\
\mathrm{pH} / 100 \text { days } \\
\mathrm{pH} / 250 \text { days } \\
\mathrm{pH} / 440 \text { days }\end{array}$ & $\begin{array}{l}\% / O D \\
\% \text { Atarget } \\
/ \mathrm{H} 2 \mathrm{O} \\
/ \mathrm{H} 2 \mathrm{O} \\
/ \mathrm{H} 2 \mathrm{O}\end{array}$ & $\begin{array}{r}48.4 \\
105.1 \\
5.33 \\
5.34 \\
5.19\end{array}$ & $\begin{array}{r}47.8 \\
104.0 \\
5.28 \\
5.23 \\
5.00\end{array}$ & $\begin{array}{r}47.2 \\
102.7 \\
5.25 \\
5.06 \\
4.92\end{array}$ & $\begin{array}{r}47.0 \\
102.2 \\
5.25 \\
5.09 \\
5.03\end{array}$ & $\begin{array}{r}46.4 \\
100.9 \\
5.75 \\
5.45 \\
5.34\end{array}$ \\
\hline \multirow[t]{2}{*}{ Palouse } & $\begin{array}{l}\text { Moisture } \\
\text { Moisture }\end{array}$ & $\begin{array}{l}\% \text { OD } \\
\% \text { ttarget }\end{array}$ & $\begin{array}{l}24.5 \\
94.1\end{array}$ & $\begin{array}{l}24.2 \\
93.1\end{array}$ & $\begin{array}{l}25.2 \\
96.7\end{array}$ & $\begin{array}{l}25.1 \\
96.6\end{array}$ & $\begin{array}{l}25.7 \\
98.7\end{array}$ \\
\hline & $\begin{array}{l}\mathrm{pH} / 100 \text { days } \\
\mathrm{pH} / 250 \text { days } \\
\mathrm{pH} / 440 \text { days }\end{array}$ & $\begin{array}{l}/ \mathrm{H} 2 \mathrm{O} \\
/ \mathrm{H} 2 \mathrm{O} \\
/ \mathrm{H} 2 \mathrm{O}\end{array}$ & $\begin{array}{l}4.98^{(a)} \\
5.15 \\
4.98\end{array}$ & $\begin{array}{l}5.46 \\
5.20 \\
5.03\end{array}$ & $\begin{array}{l}5.49 \\
5.14 \\
5.07\end{array}$ & $\begin{array}{l}5.68 \\
5.40 \\
5.25\end{array}$ & $\begin{array}{l}6.30 \\
6.10 \\
6.02\end{array}$ \\
\hline Palouse+OM & $\begin{array}{l}\text { Moisture } \\
\text { Moisture } \\
\mathrm{pH} / 100 \text { days } \\
\mathrm{pH} / 250 \text { days } \\
\mathrm{pH} / 440 \text { days }\end{array}$ & $\begin{array}{l}\% \text { /OD } \\
\% \text { target } \\
/ \mathrm{H} 2 \mathrm{O} \\
/ \mathrm{H} 2 \mathrm{O} \\
/ \mathrm{H} 2 \mathrm{O}\end{array}$ & $\begin{array}{l}25.1 \\
96.6 \\
5.48 \\
5.34 \\
5.11\end{array}$ & $\begin{array}{l}24.3 \\
93.5 \\
5.35 \\
4.73 \\
5.00\end{array}$ & $\begin{array}{l}24.3 \\
93.3 \\
5.40 \\
5.19 \\
5.02\end{array}$ & $\begin{array}{l}23.7 \\
91.1 \\
5.68 \\
5.37 \\
5.28\end{array}$ & $\begin{array}{r}24.2 \\
93.2 \\
6.40 \\
6.23 \\
6.02\end{array}$ \\
\hline
\end{tabular}

(a) Reading done at $\sim 150$ days, the last $\sim 50$ under dark refrigeration $\left(4^{\circ} \mathrm{C}\right)$; a second analysis at 4 days was 5.41 . An earlier reading (6.4) at 100 days was suspected as being misrecorded.

both for water (not shown) and $0.01 \mathrm{M} \mathrm{CaCl}_{2}$ extractions tended to increase with increasing level of brass amendment, except in the high organic-matter Cinebar soil. Calcium chloride is used to minimize the suspension effect (i.e., the difference in sediment and supernatant $\mathrm{pH}$ ) by increasing the background electrolyte concentration; $\mathrm{CaCl}_{2}$-based $\mathrm{pH}$ values generally run slightly lower than, but are well correlated with, those in water. This generality holds in these amended soils, where the difference is usually in the range of 0.1 to $1.0 \mathrm{log}$ units. The observed increase in soil pH with increasing brass level can result either from disruption of hydrogen-ion equilibrium by the solubilized components of the brass or from secondary effects on microbial activity. However, at each amendment level, $\mathrm{pH}$ values tend to decrease with time of equilibration, indicating that equilibrium has not been reached with regard to weathered components of the brass. 
We presume the increased $\mathrm{pH}$ to result from the formation of the +2 ion following initial oxidation by dissolved oxygen, as indicated in the generalized equations

$$
\begin{aligned}
& 2 \mathrm{M}+\mathrm{O}_{2}->2 \mathrm{MO} \\
& \mathrm{MO}+\mathrm{H}_{2} \mathrm{O}->\mathrm{M}^{+2}+2 \mathrm{OH}^{-}
\end{aligned}
$$

Pore-water displacement may be the most direct indicator of truly soluble components in the soil pots. These most likely are less than would be considered available for plant uptake. Considerable variation in response of the three soils to brass amendment is noted in this limited analysis set (Table 3.23). In particular, the overall decrease in soluble ionic content in the amended Cinebar is surprising. For Burbank, the higher $\mathrm{pH}$ suggests that the solubilized $\mathrm{Cu}$ should be driven to $\mathrm{CuO}$, and the $\mathrm{Zn}$ to $\mathrm{Zn}_{5}(\mathrm{OH})_{6}\left(\mathrm{CO}_{3}\right)_{2}$ (Baes and Mesmer 1976), since the organic content of this soil is minimal. The low soluble levels of $\mathrm{Cu}$ and $\mathrm{Zn}$ indicate that this is occurring. The soil organic content and the increased dissolved organic carbon (DOC) in brass-amended Cinebar could have competing effects on dissolved $\mathrm{Cu}$, which would otherwise be expected to show slight contribution $(0.01 \%)$ as $\mathrm{Cu}^{+2}$. Zinc would be less affected by organics, and would be expected to occur as $\mathrm{Zn}^{+2}$ (Baes and Mesmer 1976). Metal distributions in brass-amended Palouse+OM should be similar to those proposed foi Cinebar. These results indicate that both $\mathrm{Cu}$ and $\mathrm{Zn}$ are behaving as expected in these soils.

Selective Extractions of Brass-Amended Soils. In Tables 3.24 and 3.25, selective extraction results are reported on a $\mu \mathrm{g} / \mathrm{g}$ oven-dry soil basis. Following subtraction of the background levels contributed by native soil minerals, defined as those levels extractable from the unamended soils, metal content is then described in terms of percent of the corresponding metal amendment (Tables 3.25 and 3.26). To provide a uniform basis on which to report metal distribution in selective extraction categories, we have used the results from Parr bomb acid digestion of the amended soils as the denominator. This procedure provides a direct method for comparing results over time, but is hampered by its inflexibility to recoveries that might reflect heterogeneity in the samples, or the general improved recoveries as summed over the sequential extraction. Recall that the Parr extractions generally yielded results about $10 \%$ lower than the target concentration, suggesting incomplete solubilization in the bomb extraction (or, more likely, the inability to prevent re-adsorption). For these data, recovery based on selective extraction from the weathered soils generally yields $\mathrm{Zn}$ recoveries in excess of the Parr bomb results, suggesting that the combination of extractants might be aiding in solubilizing the metals. 
IABLE 3.23. COMPARISON OF READILY SOLUBLE COMPONENTS IN FREON-DISPLACED PORE WATERS OF CONTROL AND BRASS-AMENDED SOILS (100 DAYS)

\begin{tabular}{|c|c|c|c|c|c|c|}
\hline Component & $\begin{array}{c}0 \\
\text { Burbank }\end{array}$ & $\begin{array}{l}2500 \\
\text { Burbank }\end{array}$ & $\begin{array}{c}0 \\
\text { Cinebar }\end{array}$ & $\begin{array}{l}2500 \\
\text { Cinebar }\end{array}$ & $\begin{array}{c}0 \\
\text { Palouse+OM }\end{array}$ & $\begin{array}{c}2500 \\
\text { Palouse+OM }\end{array}$ \\
\hline pH (pH units) & 6.81 & 8.07 & 5.22 & 5.34 & 4.90 & 5.64 \\
\hline $\mathrm{mL} / \mathrm{g} O D$ soil & 0.21 & 0.21 & 0.44 & 0.43 & 0.24 & 0.23 \\
\hline$\% \mathrm{H}_{2} \mathrm{O}$ displaced & 61.2 & 60.4 & 32.3 & 27.6 & 36.6 & 34.4 \\
\hline $\mathrm{Cu}$ & 0.01 & 0.47 & 0.01 & 0.57 & 0.01 & 1.16 \\
\hline $\mathrm{Zn}$ & $<.01$ & 0.1 & 0.02 & 6.04 & $<.01$ & 15.66 \\
\hline Al & $<.03$ & $<.03$ & 0.49 & 0.13 & 0.12 & 0.10 \\
\hline $\mathrm{Ba}$ & 0.17 & 0.21 & 3.1 & 1.0 & 0.21 & 1.7 \\
\hline $\mathrm{Ca}$ & 84.0 & 93.4 & 438.3 & 140.4 & 252.5 & 264.6 \\
\hline K & 40.4 & 55.6 & 120.2 & 75.0 & 197.0 & 162.6 \\
\hline Mg & 3.4 & 3.3 & 52.8 & 17.9 & 10.7 & 10.7 \\
\hline Mn & $<.001$ & $<.001$ & 0.30 & 7.91 & 0.02 & 0.003 \\
\hline $\mathrm{Na}$ & 2.5 & 2.7 & 9.6 & 5.4 & 3.1 & 3.0 \\
\hline $\mathrm{P}$ & 0.53 & 0.24 & 0.28 & 0.16 & 0.96 & 0.37 \\
\hline $\mathrm{Si}$ & 16.2 & 6.9 & 12.3 & 8.0 & 34.2 & 14.5 \\
\hline $\mathrm{Sr}$ & 0.35 & 0.39 & 9.95 & 3.25 & 1.81 & 1.77 \\
\hline $\mathrm{Cl}^{-}$ & 5.9 & 6.6 & 33.6 & 12.2 & 27.9 & 31.6 \\
\hline $\mathrm{NO3}^{-}$ & 367.3 & 266.3 & 2119 & 804.2 & 1230 & 1222 \\
\hline $\mathrm{SO}_{4}{ }^{2-}$ & 27.5 & 25.9 & 5.1 & 8.7 & 21.2 & 33.9 \\
\hline $\mathrm{F}^{-4}$ & 0.06 & 0.65 & 0.03 & 0.01 & 0.01 & 0.05 \\
\hline Organic C & 19.8 & 35.4 & 21.7 & 27.2 & 14.5 & 23.0 \\
\hline Inorganic C & 2.1 & 30.8 & 0.2 & 0.3 & 0.2 & 0.3 \\
\hline $\mathrm{NH} 4+$ & 0.11 & 0.44 & 0.12 & 0.15 & 0.09 & 0.22 \\
\hline meq Cations & 7.09 & 8.01 & 35.9 & 13.8 & 21.9 & 22.2 \\
\hline meq Anions & 6.86 & 7.63 & 35.2 & 13.5 & 21.2 & 21.3 \\
\hline \multicolumn{7}{|l|}{ Anion-Cation } \\
\hline Balance ${ }^{(a)}$ & 0.017 & 0.024 & 0.009 & 0.010 & 0.017 & 0.021 \\
\hline
\end{tabular}

(a) Anion-cation balance is defined as (cation meq - anion meq)/(cation meq + anion meq) 
IABLE 3.24. COMPARISON OF EXTRACTABLE CU DISTRIBUTIONS IN CONTROL AND BRASS AMENDED SOILS, PRIOR TO SUBTRACTION OF CONTRO-SOIL CONTRIBUTION(a)

\begin{tabular}{|c|c|c|c|c|c|c|}
\hline \multirow{2}{*}{$\begin{array}{c}\text { Soil/ } \\
\text { Parameter }\end{array}$} & \multirow[b]{2}{*}{ Days } & \multicolumn{5}{|c|}{ Target Brass Concentration ( $\mu \mathrm{g} \mathrm{Cu} / \mathrm{g}$ oven dry soil) } \\
\hline & & 0 & 25 & 100 & 500 & 2500 \\
\hline \multicolumn{7}{|l|}{ Burbank } \\
\hline Exchangeable & 0 & $<.4$ & $n d^{(b)}$ & nd & nd & 2.4 \\
\hline Exchangeable & 100 & 0.4 & 0.6 & 0.7 & 2.2 & 1.8 \\
\hline Exchangeable & 250 & 0.2 & 0.3 & 0.5 & 2.0 & 1.5 \\
\hline Exchangeable & 440 & $\approx 0$ & $\approx 0$ & $=0$ & 1.5 & 0.9 \\
\hline Inorganically bound & 0 & $<.4$ & nd & nd & nd & 1540 \\
\hline Inorganically bound & 100 & 0.1 & 5.1 & 33.8 & 242 & 1352 \\
\hline Inorganically bound & 250 & 0.1 & 4.9 & 34.9 & 257 & 1386 \\
\hline Inorganically bound & 440 & $\approx 0$ & 4.5 & 31.9 & 260 & 1538 \\
\hline Organically bound & 0 & 2 & nd & nd & nd & $<13$ \\
\hline Organically bound & 100 & 2.1 & 10.0 & 19.2 & 33.0 & 43.1 \\
\hline Organically bound & 250 & 1.2 & 8.9 & 15.7 & $n e g(c)$ & neg \\
\hline Organically bound & 440 & $\approx 0$ & 9.9 & 15.5 & neg & neg \\
\hline Residual, K4P2O7 & 0 & 3 & nd & nd & nd & 27 \\
\hline Residual, K4P2O7 & 100 & 14.0 & 15.4 & 26.3 & 87.3 & 313 \\
\hline Residual, K4P2O7 & 250 & 11.6 & 16.0 & 27.7 & 89.0 & 339 \\
\hline Residual, K4P2O7 & 440 & 10.3 & 15.2 & 28.0 & 107.2 & 457 \\
\hline Residual HAc & 0 & 4 & nd & nd & nd & 108 \\
\hline Residual, HAc & 100 & 13.1 & 23.8 & 44.9 & 83.3 & 191 \\
\hline Residual, HAc & 250 & nd & nd & nd & nd & nd \\
\hline Residual, HAC & 440 & nd & nd & nd & nd & nd \\
\hline \multicolumn{7}{|l|}{ Cinebar } \\
\hline Exchangeable & 0 & $<.4$ & nd & nd & nd & 37 \\
\hline Exchangeable & 100 & 0.6 & 0.7 & 0.9 & 3.9 & 34.8 \\
\hline Exchangeable & 250 & $<.4$ & $<.4$ & 0.5 & 3.9 & 39.5 \\
\hline Exchangeable & 440 & $\approx 0$ & $\approx 0$ & $\approx 0$ & 2.3 & 30.9 \\
\hline Inorganically bound & 0 & $<.4$ & nd & nd & nd & 858 \\
\hline Inorganically bound & 100 & 0.2 & 1.3 & 5.5 & 58.9 & 682 \\
\hline Inorganically bound & 250 & 0.1 & 0.9 & 5.1 & 58.2 & 653 \\
\hline Inorganically bound & 440 & $\approx 0$ & 0.7 & 4.3 & 50.2 & 580 \\
\hline Organically bound & 0 & 9 & nd & nd & nd & 526 \\
\hline Organically bound & 100 & 8.2 & 16.3 & 46.5 & 177 & 668 \\
\hline Organically bound & 250 & 6.4 & 14.1 & 39.1 & 142 & 549 \\
\hline Organically bound & 440 & 8.0 & 15.5 & 38.8 & 153 & 647 \\
\hline Residual, K4P2O7 & 0 & 11 & nd & nd & nd & 316 \\
\hline Residual, K4P2O7 & 100 & 32.6 & 41.5 & 57.3 & 129 & 446 \\
\hline Residual, K4P2O7 & 250 & 34.1 & 39.7 & 60.9 & 138 & 490 \\
\hline Residual, K4P2O7 & 440 & 33.1 & 38.1 & 57.1 & 143 & 485 \\
\hline Residual, HAc & 0 & 16 & nd & nd & nd & 874 \\
\hline Residual, HAc & 100 & 42.9 & 59.9 & 98.4 & 298 & 1140 \\
\hline Residual, HAC & 250 & nd & nd & nd & nd & nd \\
\hline Residual, HAc & 440 & nd & nd & nd & nd & nd \\
\hline
\end{tabular}


IABLE 3.24. (CONTD)

\begin{tabular}{|c|c|c|c|c|c|c|}
\hline \multirow{2}{*}{$\begin{array}{c}\text { Soill } \\
\text { Parameter }\end{array}$} & \multirow[b]{2}{*}{ Days } & \multicolumn{5}{|c|}{ Target Brass Concentration ( $\mu \mathrm{g}$ Cu/g oven dried soil) } \\
\hline & & 0 & 25 & 100 & 500 & 2500 \\
\hline \multicolumn{7}{|l|}{ Palouse } \\
\hline Exchangeable & 0 & $<.4$ & nd & nd & nd & 34 \\
\hline Exchangeable & 100 & 0.4 & 0.0 & 1.2 & 13.2 & 45.1 \\
\hline Exchangeable & 250 & $<.4$ & 0.3 & 1.0 & 14.5 & 54.2 \\
\hline Exchangeable & 440 & $\approx 0$ & $=0$ & $=0$ & 12.1 & 50.3 \\
\hline Inorganically bound & 0 & $<.4$ & nd & nd & nd & 978 \\
\hline Inorganically bound & 100 & 0.2 & 0.5 & 6.2 & 87.4 & 835 \\
\hline Inorganically bound & 250 & 0.2 & 0.7 & 6.2 & 92.3 & 885 \\
\hline Inorganically bound & 440 & $\approx 0$ & 0.6 & 5.5 & 90.6 & 901 \\
\hline Organically bound & 0 & 6 & nd & nd & nd & 475 \\
\hline Organically bound & 100 & 5.3 & 19.1 & 50.6 & 220 & 648 \\
\hline Organically bound & 250 & 4.8 & 17.1 & 49.1 & 188 & 494 \\
\hline Organically bound & 440 & 5.9 & 16.4 & 47.3 & 177 & 439 \\
\hline Residual, K4P2O7 & 0 & 4 & nd & nd & nd & 141 \\
\hline Residual, K4P2O7 & 100 & 15.3 & 20.5 & 26.8 & 57.2 & 217 \\
\hline Residual, K4P2O7 & 250 & 8.2 & 15.4 & 23.2 & 54.4 & 219 \\
\hline Residual, K4P2O7 & 440 & 14.3 & 20.5 & 30.2 & 66.5 & 260 \\
\hline Residual, HAc & 0 & 7 & nd & nd & nd & 686 \\
\hline Residual, HAc & 100 & 66.4 & 38.8 & 78.1 & 259 & 796 \\
\hline Residual, HAC & 250 & nd & nd & nd & nd & nd \\
\hline Residual, HAC & 440 & nd & nd & nd & nd & nd \\
\hline \multicolumn{7}{|l|}{ Palouse+OM } \\
\hline Exchangeable & 0 & $<.4$ & nd & nd & nd & 29 \\
\hline Exchangeable & 100 & 0.6 & 0.6 & 1.3 & 11.1 & 40.5 \\
\hline Exchangeable & 250 & $<.4$ & 0.3 & 1.1 & 13.1 & 46.1 \\
\hline Exchangeable & 440 & $\approx 0$ & $=0$ & $=0$ & 11.9 & 49.9 \\
\hline Inorganically bound & 0 & $<.4$ & nd & nd & nd & 950 \\
\hline Inorganically bound & 100 & 0.4 & 0.7 & 6.6 & 90.2 & 806 \\
\hline Inorganically bound & 250 & 0.4 & 0.7 & 6.7 & 93.9 & 851 \\
\hline Inorganically bound & 440 & $=0$ & 0.6 & 6.4 & 87.2 & 847 \\
\hline Organically bound & 0 & 6 & nd & nd & nd & 496 \\
\hline Organically bound & 100 & 5.4 & 18.1 & 53.1 & 224 & 684 \\
\hline Organically bound & 250 & 5.0 & 17.2 & 50.1 & 195.0 & 565 \\
\hline Organically bound & 440 & 4.7 & 16.1 & 50.3 & 191 & 502 \\
\hline Residual, K4P2O7 & 0 & 4 & nd & nd & nd & 126 \\
\hline Residual, K4P2O7 & 100 & 14.6 & 18.9 & 28.5 & 56.0 & 217 \\
\hline Residual, K4P2O7 & 250 & 11.3 & 16.7 & 25.4 & 51.3 & 226 \\
\hline Residual, K4P2O7 & 440 & 14.4 & 20.1 & 29.9 & 64.6 & 237 \\
\hline Residual, HAc & 0 & 8 & nd & nd & nd & 678 \\
\hline Residual, HAC & 100 & 21.1 & 39.5 & 81.9 & 263.2 & 782.3 \\
\hline Residual, HAc & 250 & nd & nd & nd & nd & nd \\
\hline Residual, HAC & 440 & nd & nd & nd & nd & nd \\
\hline
\end{tabular}

(a) $n=2$ at 0 days; $n=1$ for all other.

(b) nd: not determined.

(c) neg: negative result to the determination of this value by subtracting exchangeable plus inorganic compartments from the pyrophosphate-extractable compartment. 
IABLE 3.25. COMPARISON OF EXTRACTABLE ZN DISTRIBUTIONS IN CONTROL AND BRASS-AMENDED SOILS, BEFORE SUBTRACTION OF CONTROL-SOIL CONTRIBUTION $(n=1)$. (a)

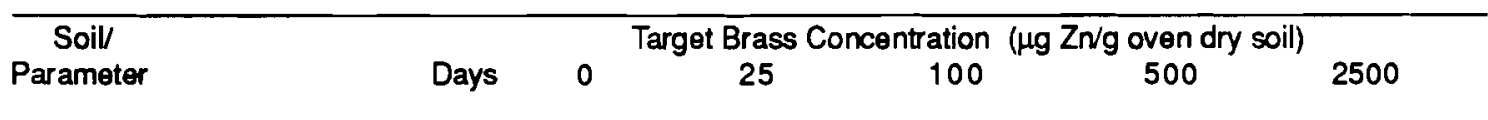

Burbank

Exchangeable

Exchangeable

Exchangeable

Exchangeable

Inorganically bound

Inorganically bound

Inorganically bound

Inorganically bound

Organically bound

Organically bound

Organically bound

Organically bound

Residual, K4P2O7

Residual, K4P2O7

Residual, K4P2O7

Residual, K4P2O7

Residual, HAc

Residual, HAc

Residual, HAc

Residual, HAc

Cinebar

Exchangeable

Exchangeable

Exchangeable

Exchangeable

Inorganically bound

Inorganically bound

Inorganically bound

Inorganically bound

Organically bound

Organically bound

Organically bound

Organically bound

Residual, K4P2O7

Residual, K4P2O7

Residual, K4P2O7

Residual, K4P2O7

Residual, HAc

Residual, HAc

Residual, HAc

Residual, HAc

$\begin{array}{rcc}0 & \leq .4 & \text { nd(b) } \\ 100 & 0.3 & 0.7 \\ 250 & 0.5 & 0.4 \\ 440 & \approx 0 & \text { nd } \\ 0 & 1 & \text { nd } \\ 100 & 0.6 & 4.3 \\ 250 & 0.7 & 3.9 \\ 440 & \approx 0 & 4.2 \\ 0 & 6 & \text { nd } \\ 100 & 10.8 & 1.6 \\ 250 & 2.5 & 3.2 \\ 440 & \approx 0 & \text { neg } \\ 0 & 10 & \text { nd } \\ 100 & 48.2 & 51.8 \\ 250 & 46.8 & 48.1 \\ 440 & 47.5 & 47.5 \\ 0 & 10 & \text { nd } \\ 100 & 51.2 & 49.7 \\ 250 & \text { nd } & \text { nd } \\ 440 & \text { nd } & \text { nd }\end{array}$

100

250

440

0

100

250

440

0

100

250

440

0

100

250

440

100

100

250

440 $\leq .4$

0.7

1.6

$=0$

6

$<.4$

3.5

3.3

12

15.7

9.0

neg

35

115

112

112

30

132

nd

nd nd
1.1
1.4
$\approx 0$
nd
16.8
14.2
16.4
nd
5.2

$$
4.2
$$

neg

nd

58.3

54.1

51.8

nd

57.3

nd

nd

nd

1.8

2.1

1.5

nd

11.1

5.2

5.6

nd

10.0

10.3

8.3

nd

116

114.9

108

nd

131

nd

nd nd

14.9

14.2

13.1

nd

79.8

71.5

86.1

nd

12.8

7.6

8

16.5

17.8

268

438

405

541

$\sim 50$

107

70.1

neg neg

nd $\quad 50$

$87.7 \quad 184$

$85.0 \quad 184$

$88.8 \quad 228$

nd $\quad \approx 36$

$64.5 \quad 99.4$

nd nd

nd nd

nd 276

$47.5 \quad 260$

$45.7 \quad 265$

$38.8 \quad 243$

nd $\quad 308$

$11.0 \quad 257$

$36.6 \quad 172$

$44.3 \quad 227$

nd 0

$55.0 \quad 52.0$

$15.1 \quad 78.0$

6.2 neg

nd 130

$142.2 \quad 274$

$145 \quad 297$

$153 \quad 288$

nd 84

$156 \quad 269$

nd $\quad$ nd 
IABLE 3.25. (CONTD)

\begin{tabular}{|c|c|c|c|c|c|c|}
\hline \multirow{2}{*}{$\begin{array}{c}\text { Soil } \\
\text { Parameter }\end{array}$} & \multirow[b]{2}{*}{ Days } & \multicolumn{5}{|c|}{ Target Brass Concentration ( $\mu \mathrm{g} \mathrm{Zn}$ g oven dry soil) } \\
\hline & & 0 & 25 & 100 & 500 & 2500 \\
\hline \multicolumn{7}{|l|}{ Palouse } \\
\hline Exchangeable & 0 & $<.4$ & nd & nd & nd & 268 \\
\hline Exchangeable & 100 & 0.4 & $<.4$ & 6.4 & 68.7 & 300 \\
\hline Exchangeable & 250 & 1.2 & 1.2 & 5.8 & 68.8 & 307 \\
\hline Exchangeable & 440 & $=0$ & $=0$ & 4.1 & 55.4 & 283 \\
\hline Inorganically bound & 0 & 1 & nd & nd & nd & 262 \\
\hline Inorganically bound & 100 & 1.5 & 1.8 & 7.1 & 31.7 & 212 \\
\hline Inorganically bound & 250 & 0.6 & 1.6 & 5.9 & 24.5 & 182 \\
\hline Inorganically bound & 440 & 0.5 & 1.5 & 6.0 & 38.7 & 258 \\
\hline Organically bound & 0 & 12 & nd & nd & nd & 104 \\
\hline Organically bound & 100 & 7.4 & 11.0 & 11.5 & 30.2 & 97.1 \\
\hline Organically bound & 250 & 3.7 & 6.9 & 11.8 & 33.7 & 98.8 \\
\hline Organically bound & 440 & neg & neg & 9.7 & 12.8 & neg \\
\hline Residual, K4P2O7 & 0 & 10 & nd & nd & nd & 60 \\
\hline Residual, K4P207 & 100 & 58.2 & 62.2 & 61.9 & 75.3 & 138 \\
\hline Residual, K4P2O7 & 250 & 46.5 & 55.7 & 58.4 & 70.1 & 133 \\
\hline Residual, K4P2O7 & 440 & 54.2 & 57.6 & 62.1 & 80.9 & 154 \\
\hline Residual, HAc & 0 & 12 & nd & nd & nd & 74 \\
\hline Residual, HAc & 100 & 66.4 & 66.7 & 73.0 & 83.6 & 141 \\
\hline Residual, HAc & 250 & nd & nd & nd & nd & nd \\
\hline Residual, HAc & 440 & nd & nd & nd & nd & nd \\
\hline \multicolumn{7}{|l|}{ Palouse+OM } \\
\hline Exchangeable & 0 & $<.4$ & nd & nd & nd & 250 \\
\hline Exchangeable & 100 & 0.8 & 1.2 & 7.4 & 68.1 & 286 \\
\hline Exchangeable & 250 & 1.0 & 1.7 & 6.7 & 69.2 & 292 \\
\hline Exchangeable & 440 & $=0$ & $=0$ & 4.7 & 59.8 & 300 \\
\hline Inorganically bound & 0 & 1 & nd & nd & nd & 272 \\
\hline Inorganically bound & 100 & 0.9 & 1.9 & 7.3 & 31.6 & 205 \\
\hline Inorganically bound & 250 & 0.5 & 1.6 & 6.2 & 26.5 & 178 \\
\hline Inorganically bound & 440 & 0.5 & 1.4 & 7.1 & 35.1 & 221 \\
\hline Organically bound & 0 & 5 & nd & nd & nd & 90 \\
\hline Organically bound & 100 & 5.2 & 8.4 & 11.1 & 31.0 & 111 \\
\hline Organically bound & 250 & 4.7 & 6.4 & 11.5 & 28.6 & 107 \\
\hline Organically bound & 440 & neg & neg & 8.7 & 8.2 & 2.9 \\
\hline Residual, K4P2O7 & 0 & 10 & nd & nd & nd & 58 \\
\hline Residual, K4P2O7 & 100 & 56.7 & 60.4 & 65.1 & 74.7 & 138 \\
\hline Residual, K4P2O7 & 250 & 53.2 & 54.2 & 58.8 & 64.6 & 134 \\
\hline Residual, K4P2O7 & 440 & 56.6 & 55.9 & 61.7 & 76.1 & 237 \\
\hline Residual, HAc & 0 & 14 & nd & nd & nd & 74 \\
\hline Residual, HAc & 100 & 60.7 & 67.0 & 72.7 & 83.5 & 139 \\
\hline Residual, HAc & 250 & nd & nd & nd & nd & nd \\
\hline Residual, HAc & 440 & nd & nd & nd & nd & nd \\
\hline
\end{tabular}

(a) $n=2$ at 0 days; $n=1$ for all others.

(b) nd: not determined.

(c) neg: negative result to the determination of this value by subtracting exchangeable plus inorganic compartments from the pyrophosphate-extractable compartment. 
IABLE 3.26. SUMMARY COMPARISON OF SELECTIVE EXTRACTION TECHNIQUES FOR BRASS-AMENDED SOILS: Cu

\begin{tabular}{|c|c|c|c|c|c|c|c|}
\hline Soil & $\begin{array}{c}\text { Concentration } \\
\text { [Target] }\end{array}$ & $\begin{array}{l}\text { Elapsed } \\
\text { Days }\end{array}$ & Exchangeable & $\begin{array}{l}\text { Inorganically } \\
\text { Bound } \\
\text { al Cu, extractic }\end{array}$ & $\begin{array}{l}\text { Organically } \\
\text { Bound } \\
\text { n recovery) }\end{array}$ & $\begin{array}{l}\text { Residual } \\
\text { P2O7 }\end{array}$ & $\begin{array}{c}\text { Total } \\
\text { Recoverable Zn } \\
\mu g / g \text { oven dry soil }\end{array}$ \\
\hline \multicolumn{2}{|c|}{$\begin{array}{l}\text { Brass only (a) } \\
\text { Burbank }\end{array}$} & & .6 & 99 & -0 & nd & \\
\hline \multirow{3}{*}{\multicolumn{2}{|c|}{25}} & 100 & 1 & 35 & 54 & 10 & 15 \\
\hline & & 250 & .6 & 28 & 45 & 26 & 17 \\
\hline & & 440 & $\approx 0$ & 23.4 & 52 & 25 & 19 \\
\hline \multirow{3}{*}{\multicolumn{2}{|c|}{100}} & 100 & .5 & 53 & 27 & 19 & 63 \\
\hline & & 250 & .4 & 53 & 22 & 25 & 66 \\
\hline & & 440 & -0 & 49 & 24 & 27 & 65 \\
\hline \multirow{3}{*}{\multicolumn{2}{|c|}{500}} & 100 & .5 & 70 & 9 & 21 & 348 \\
\hline & & 250 & .5 & 76 & $=0$ & 23 & 336 \\
\hline & & 440 & .4 & 73 & $=0$ & 27 & 358 \\
\hline \multirow{3}{*}{\multicolumn{2}{|c|}{2500}} & 100 & .1 & 80 & 2 & 18 & 1693 \\
\hline & & 250 & .1 & 81 & -0 & 19 & 1715 \\
\hline & & 440 & $\approx 0$ & 78 & -0 & 23 & 1985 \\
\hline \multicolumn{8}{|c|}{ Cinebar } \\
\hline \multirow{3}{*}{\multicolumn{2}{|c|}{25}} & 100 & .5 & 6 & 44 & 49 & 18 \\
\hline & & 250 & $\approx 0$ & 5 & 55 & 40 & 14 \\
\hline & & 440 & $=0$ & 5 & 57 & 38 & 13 \\
\hline \multirow{3}{*}{\multicolumn{2}{|c|}{100}} & 100 & .4 & 8 & 56 & 36 & 69 \\
\hline & & 250 & 1 & 8 & 50 & 41 & 65 \\
\hline & & 440 & -0 & 7 & 52 & 41 & 59 \\
\hline \multirow{3}{*}{\multicolumn{2}{|c|}{500}} & 100 & 1 & 18 & 52 & 29 & 328 \\
\hline & & 250 & 1 & 19 & 45 & 34 & 302 \\
\hline & & 440 & .8 & 16 & 47 & 36 & 307 \\
\hline \multirow{3}{*}{\multicolumn{2}{|c|}{2500}} & 100 & 2 & 38 & 37 & 23 & 1789 \\
\hline & & 250 & 2 & 39 & 32 & 27 & 1691 \\
\hline & & 440 & 2 & 34 & 38 & 27 & 1702 \\
\hline \multicolumn{8}{|c|}{ Palouse } \\
\hline \multirow{3}{*}{\multicolumn{2}{|c|}{25}} & 100 & $<.1$ & 2 & 71 & 27 & 19 \\
\hline & & 250 & $=0$ & 2.4 & 62 & 36 & 20 \\
\hline & & 440 & $\approx 0$ & 3.3 & 61 & 36 & 17 \\
\hline \multirow{3}{*}{\multicolumn{2}{|c|}{100}} & 100 & 1 & 10 & 71 & 18 & 64 \\
\hline & & 250 & 2 & 9 & 67 & 23 & 66 \\
\hline & & 440 & $\approx 0$ & 9 & 66 & 25 & 63 \\
\hline \multirow{3}{*}{\multicolumn{2}{|c|}{500}} & 100 & 4 & 24 & 60 & 12 & 356 \\
\hline & & 250 & 4 & 27 & 54 & 14 & 336 \\
\hline & & 440 & 4 & 28 & 52 & 16 & 326 \\
\hline \multirow{3}{*}{\multicolumn{2}{|c|}{2500}} & 100 & 3 & 48 & 37 & 12 & 1724 \\
\hline & & 250 & 3 & 54 & 30 & 13 & 1638 \\
\hline & & 440 & 3.1 & 55 & 27 & 15 & 1630 \\
\hline
\end{tabular}


IABLE 3.26. (CONTD)

\begin{tabular}{|c|c|c|c|c|c|c|c|}
\hline Soil & $\begin{array}{l}\text { Concentration } \\
\text { [Target] }\end{array}$ & $\begin{array}{l}\text { Elapsed } \\
\text { Days }\end{array}$ & Exchangable & $\begin{array}{l}\text { Inorganically } \\
\text { bound }\end{array}$ & $\begin{array}{l}\text { Organically } \\
\text { bound }\end{array}$ & $\begin{array}{l}\text { Residual } \\
\text { P2O7 }\end{array}$ & $\begin{array}{c}\text { Total } \\
\text { Recoverable Cu }\end{array}$ \\
\hline & & & $-(\% \mathrm{Tc}$ & tal Cu, extractio & on recovery)-- & -........ & $\mu g / g$ oven dry soi \\
\hline Palo & Us $\theta+O M$ & & & & & & \\
\hline & 25 & 100 & .1 & 2 & 73 & 25 & 17 \\
\hline & & 250 & 2 & 2 & 67 & 30 & 18 \\
\hline & & 440 & $=0$ & 3.5 & 64 & 32 & 18 \\
\hline & 100 & 100 & 1 & 9 & 70 & 20 & 69 \\
\hline & & 250 & 2 & 10 & 68 & 21 & 67 \\
\hline & & 440 & $=0$ & 10 & 67 & 23 & 68 \\
\hline & 500 & 100 & 3 & 25 & 61 & 12 & 360 \\
\hline & & 250 & 4 & 28 & 56 & 12 & 337 \\
\hline & & 440 & 3.6 & 26 & 55 & 15 & 335 \\
\hline & 2500 & 100 & 2 & 47 & 39 & 12 & 1727 \\
\hline & & 250 & 3 & 51 & 34 & 13 & 1671 \\
\hline & & 440 & 3.1 & 52 & 31 & 14 & 1617 \\
\hline Over & rall Soil Averages: & & & & & & \\
\hline & 25 & 100 & $.4 \pm 5$ & $11 \pm 16$ & $60 \pm 14$ & $28 \pm 16$ & $17 \pm 2$ \\
\hline & & 250 & $.6 \pm .8$ & $9 \pm 12$ & $57 \pm 9$ & $33 \pm 6$ & $18 \pm 3$ \\
\hline & & 440 & $\approx 0 \pm 0$ & $9 \pm 10$ & $59 \pm 5$ & $33 \pm 6$ & $17 \pm 3$ \\
\hline & 100 & 100 & $.8 \pm .4$ & $20 \pm 22$ & $56 \pm 20$ & $23 \pm 8$ & $66 \pm 3$ \\
\hline & & 250 & $1.1 \pm .6$ & $20 \pm 22$ & $52 \pm 21$ & $27 \pm 9$ & $66 \pm 1$ \\
\hline & & 440 & $\approx 0 \pm 0$ & $19 \pm 20$ & $52 \pm 20$ & $29 \pm 8$ & $64 \pm 4$ \\
\hline & 500 & 100 & $2.0 \pm 1.5$ & $34 \pm 24$ & $45 \pm 25$ & $18 \pm 9$ & $348 \pm 14$ \\
\hline & & 250 & $2.5 \pm 1.9$ & $38 \pm 26$ & $39 \pm 26$ & $21 \pm 10$ & $328 \pm 17$ \\
\hline & & 440 & $2.1 \pm 1.8$ & $36 \pm 25$ & $39 \pm 26$ & $24 \pm 10$ & $332 \pm 22$ \\
\hline & 2500 & 100 & $1.7 \pm 1.1$ & $53 \pm 18$ & $29 \pm 18$ & $16 \pm 6$ & $1733 \pm 40$ \\
\hline & & 250 & $2.1 \pm 1.4$ & $56 \pm 18$ & $24 \pm 16$ & $17 \pm 7$ & $1679 \pm 32$ \\
\hline & & 440 & $2 \pm 1.4$ & $55 \pm 18$ & $24 \pm 16$ & $20 \pm 6$ & $1734 \pm 172$ \\
\hline
\end{tabular}

(a) Done as separate extractions only, not as sequential extractions.

(b) First value is at solution ratio equivalent to that used for extraction of the $2500 \mu \mathrm{g}$ brass/g soil amendment level; second value is for extraction solution: brass ratio 10x that of the first. 
The 0-time extraction of control soils and $2500-\mu \mathrm{g} / \mathrm{g}$-amended soils was done within 10 to 25 days of initial soil amendment $(0$ time). Prior to analysis, the aliquots were stored in the dark at $4^{\circ} \mathrm{C}$, in sealed poly bags. Following pyrophosphate or $\mathrm{CaCl}_{2} /$ acetic acid extraction, the extraction residues were digested in several steps in an effort to recover residual metal components after pyrophosphate or acetic acid extractions; because of these steps, digestion efficiency was probably diminished, as suggested by the level of unaccounted for $\mathrm{Cu}$. Current procedures depend on sealed-vessel (Parr) bomb acid digestion of all residual fractions. The bulk of recovered $\mathrm{Cu}$ extracted as expected in the inorganically bound fraction, but mass balance was poor. Zinc also extracted in the inorganic fraction for Burbank soil, but appeared to be more readily exchangeable in Cinebar and Palouse soils.

At the 100- to 440-day samplings (weathered), $\mathrm{Cu}$ is associated primarily with the inorganically bound fraction in Burbank soil, as it is in the 0-time amended soil (Table 3.24). In the three weathered and the 0 -time soil treatments for Palouse and Cinebar, $\mathrm{Cu}$ is associated with the inorganic-bound and organic-bound fractions, indicating the importance of soil organic matter. Zinc is found mainly in the inorganically bound fraction for Burbank (Table 3.25), but appears more readily exchangeable at the higher amendment levels in Cinebar and Palouse. The fraction of $\mathrm{Zn}$ associated with the organic-bound compartment increases with decreasing amendment level, similarly to the Cu response. This would suggest that complexation sites for solubilized $\mathrm{Zn}$ and $\mathrm{Cu}$ are limited. Distribution patterns are generally similar for the 0 -time and 100 - to 440 -day weathered soils.

In Tables 3.22 and 3.27, the data presented in Tables 3.24 and 3.25 are expressed as a \% of total Cu or $\mathrm{Zn}$, based on Parr bomb digestion for total metal. Based on the fraction percentages for the $2500-\mu \mathrm{g} / \mathrm{g}$ treatments, notable differences between the 0 -time and 100 day weathered samples exist. For Burbank, on weathering there is a decrease in $\mathrm{Cu}$ associated with the inorganically bound fraction and an increase in the fraction associated with the organically bound and residual fractions. Similar trends are observed for the Palouse and Cinebar soils, with the fraction of $\mathrm{Cu}$ associated with the organically bound increasing dramatically on weathering. This would be expected for the higher organic-matter soils. The behavior of $\mathrm{Zn}$ on weathering (Table 3.27) is similar to $\mathrm{Cu}$, except that substantially less $\mathrm{Zn}$ is found in the organically bound fraction. This would suggest that organic complexation may not play a significant role in binding solubilized $\mathrm{Zn}$.

The hot-water extraction procedure is designed to minimize the effects of microbial interactions and varying rates in approaching equilibrium between aqueous and solid phases that are common to long-term leaching studies. The 20:1 water to solids ratio is chosen to eliminate many of the mineral solubility controls without adversely sacrificing detection; the extraction time and temperature were optimized in earlier in-house work 
involving soil and ash samples. Solutions resulting from this method showed increased $\mathrm{pH}$ at the higher amendment levels, though the difference was less marked, because of the dilution effect.

Selected readily soluble components, as determined by the hot-water extraction procedure, are listed in Table 3.28. The hot-water extraction tends to increase solubilization of organic-carbon components, often with corresponding impairment of the anion/cation balance because organic anions are not analyzed. Several general observations can be made from the resulting dissolved species. Copper and $\mathrm{Zn}$ show the expected increase ir solubility with increased amendment level, but the increase is much less pronounced for Burbank than for the other soils. The ratio of $\mathrm{Zn}$ to $\mathrm{Cu}$ in the dissolution from Burbank soil is significantly lower than that from the other soils. Burbank soil also shows decreased soluble $\mathrm{Al}, \mathrm{Mn}$, and Fe with increased brass amendment level; in contrast, the other soils generally show constant or increasing levels of these three elements. Total $P$ declines with increasing brass amendment for all soils except Cinebar. Phosphate would be important to the solution chemistry of $\mathrm{Zn}$ and $\mathrm{Fe}$, and to the major cations $\mathrm{Ca}$ and $\mathrm{Mg}$ (Lindsay 1979), but it also could be involved with precipitation of $\mathrm{Al}$, depending on saturation level and availability of $\mathrm{K}$ (Van Riemsdijk and Lyklema 1980). Although detailed soils discussion is outside the scope of this project, these observations indicate that soil conditions strongly influence the weathering of brass, which in turn alters distributions of other species.

The amount of brass solubilized from the highest brass-amendment level by the hotwater extraction represents roughly $0.5 \%$ of that in Burbank soil, based on $\mathrm{Cu}$ analysis, and only 0.1 to $0.3 \%$ for $\mathrm{Zn}$. Palouse soils show 1.8 to $2.1 \%$ brass dissolved, based on $\mathrm{Cu}$, and 1.3 to $1.8 \%$ based on $\mathrm{Zn}$. For Cinebar, solubility appears to be affected by the pretreatment of the soil: for time-0 dry soil, $3.5 \%$ was soluble, based on $\mathrm{Cu}$, and $2.7 \%$, based on $\mathrm{Zn}$; for wet soil, the level dropped to $1.5 \%$ based on $\mathrm{Cu}$ and $1.1 \%$ based on $\mathrm{Zn}$. After 100 days of weathering, the value was $\sim 1.5 \%$, based on either metal.

Major cations such as $\mathrm{Ca}, \mathrm{Na}$, and $\mathrm{K}$ are not included in these tables because their soluble components changed very little with changes in brass concentration and because the high dilution factor resulting from the hot-water extract would tend to increase dissolution, thereby masking minor changes in true pore-water concentrations. Generally, from 1.2 to 3.5 times the pore-water $\mathrm{Ca}$ was solubilized by the hot-water extraction; similarly, the factors were 7 to 13 times for $\mathrm{Na}$ and 3.6 to 5 times for $\mathrm{K}$.

Major anionic components, ammonia, and $\mathrm{C}$ distribution in the hot-water extraction are listed in Table 3.29. DOC levels show no effect of brass amendment. The increase in inorganic carbon can be attributed in part to the increase in $\mathrm{pH}$ with increasing brass 
amendment. Ammonia levels increase with increasing brass amendment for all soils; nitrite levels show slight peak with 25 and 100 ppm brass for Palouse+OM and Palouse, respectively; nitrate peaks at 500 ppm brass for Burbank and Cinebar, but shows less prominent variation for Palouse+OM, and a general decrease with brass amendment for Palouse. The nitrogen species could be controlled by both chemical and microbiological processes. The markedly lower ammonia levels in the displaced pore waters, relative to the

IABLE 3.27. SUMMARY COMPARISON OF SELECTIVE EXTRACTION TECHNIQUES FOR BRASS-AMENDED SOILS: Zn

\begin{tabular}{|c|c|c|c|c|c|c|c|}
\hline Soil & $\begin{array}{c}\text { Concentration } \\
\text { [Target] }\end{array}$ & $\begin{array}{c}\text { Elapsed } \\
\text { Days }\end{array}$ & $\begin{array}{l}\text { Exchangeable } \\
-(\% \text { To }\end{array}$ & $\begin{array}{l}\text { Inorganically } \\
\text { Bound. } \\
\text { tal Zn, extractio }\end{array}$ & $\begin{array}{l}\text { Organically } \\
\text { Bound } \\
\text { recovery)-- }\end{array}$ & $\begin{array}{l}\text { Residual } \\
\text { P2O7 }\end{array}$ & $\begin{array}{c}\text { Total. } \\
\text { Recoverable } \mathrm{Zn} \\
\mu \mathrm{g} / \mathrm{g} \text { oven dry soil }\end{array}$ \\
\hline \multirow{4}{*}{\multicolumn{2}{|c|}{ 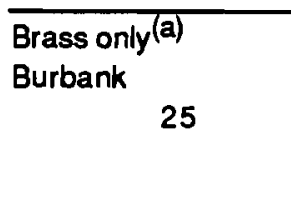 }} & & 1.2 & 96 & $<3$ & nd & \\
\hline & & 100 & 6 & 48 & bdl(b) & 47 & 8 \\
\hline & & 250 & $<b k_{1}(c)$ & 71 & bdl & 29 & 17 \\
\hline & & 440 & $=0$ & 99 & $=0$ & 1 & 4 \\
\hline \multirow{3}{*}{\multicolumn{2}{|c|}{100}} & 100 & 3 & 60 & bdl & 38 & 27 \\
\hline & & 250 & 4 & 58 & 7 & 31 & 23 \\
\hline & & 440 & $=0$ & 79 & $=0$ & 21 & 21 \\
\hline \multirow{3}{*}{\multicolumn{2}{|c|}{500}} & 100 & 11 & 58 & 2 & 29 & 135 \\
\hline & & 250 & 11 & 55 & 4 & 30 & 128 \\
\hline & & 440 & 9 & 61 & $\approx 0$ & 29 & 141 \\
\hline \multirow{3}{*}{\multicolumn{2}{|c|}{2500}} & 100 & 2 & 64 & 14 & 20 & 685 \\
\hline & & 250 & 3 & 65 & 11 & 22 & 625 \\
\hline & & 440 & 2 & 73 & $\approx 0$ & 24 & 739 \\
\hline \multicolumn{8}{|c|}{ Cinebar } \\
\hline \multirow{3}{*}{\multicolumn{2}{|c|}{25}} & 100 & 8 & 88 & bdl & 4 & 13 \\
\hline & & 250 & 8 & 28 & 21 & 43 & 6 \\
\hline & & 440 & 13 & 21 & 103 & neg & 11 \\
\hline \multirow{3}{*}{\multicolumn{2}{|c|}{100}} & 100 & 20 & 63 & .1 & 17 & 27 \\
\hline & & 250 & 10 & 17 & 12 & 61 & 41 \\
\hline & & 440 & 15 & 23 & 40 & 23 & 33 \\
\hline \multirow{3}{*}{\multicolumn{2}{|c|}{500}} & 100 & 38 & 38 & 2 & 22 & 124 \\
\hline & & 250 & 38 & 28 & 5 & 28 & 116 \\
\hline & & 440 & 30 & 32 & 7 & 31 & 130 \\
\hline \multirow{3}{*}{\multicolumn{2}{|c|}{2500}} & 100 & 36 & 36 & 5 & 22 & 713 \\
\hline & & 250 & 38 & 24 & 10 & 27 & 685 \\
\hline & & 440 & 38 & 35 & $=0$ & 27 & 643 \\
\hline \multicolumn{8}{|c|}{ Palouse } \\
\hline \multirow{3}{*}{\multicolumn{2}{|c|}{25}} & 100 & $<.1$ & 4 & 42 & 53 & 8 \\
\hline & & 250 & $<.1$ & 7 & 24 & 69 & 13 \\
\hline & & 440 & -0 & 22 & $\approx 0$ & 78 & 4 \\
\hline & 100 & 100 & 31 & 29 & 21 & 19 & 19 \\
\hline
\end{tabular}


IABLE 3.27. (CONTD)

\begin{tabular}{|c|c|c|c|c|c|c|c|}
\hline Soil & $\begin{array}{l}\text { Concentration } \\
\text { [Target] }\end{array}$ & $\begin{array}{l}\text { Elapsed } \\
\text { Days }\end{array}$ & $\begin{array}{l}\text { Exchangeable } \\
-1 \% \text { tot }\end{array}$ & $\begin{array}{l}\text { Inorgarically } \\
\text { Bound } \\
\text { tal Zn, extractio }\end{array}$ & $\begin{array}{l}\text { Organically } \\
\text { Bound } \\
\text { recovery) }\end{array}$ & $\begin{array}{l}\text { Residual } \\
\text { P2O7 }\end{array}$ & $\begin{array}{l}\text { Total } \\
\text { Recoverable Zn } \\
\mu g / g \text { oven dry soil }\end{array}$ \\
\hline \multicolumn{8}{|c|}{ Palouse (cont.) } \\
\hline \multirow{2}{*}{\multicolumn{2}{|c|}{250}} & 15 & 18 & 27 & 40 & 30 & \\
\hline & & 440 & 15 & 20 & 37 & 29 & 28 \\
\hline \multirow{3}{*}{\multicolumn{2}{|c|}{500}} & 100 & 50 & 21 & 17 & 12 & 136 \\
\hline & & 250 & 46 & 16 & 21 & 16 & 145 \\
\hline & & 440 & 42 & 29 & 10 & 20 & 134 \\
\hline \multirow{3}{*}{\multicolumn{2}{|c|}{2500}} & 100 & 44 & 31 & 13 & 12 & 680 \\
\hline & & 250 & 46 & 27 & 14 & 13 & 670 \\
\hline & & 440 & 44 & 40 & $\approx 0$ & 16 & 640 \\
\hline \multicolumn{8}{|c|}{ Palouse+OM } \\
\hline \multirow{3}{*}{\multicolumn{2}{|c|}{25}} & 100 & 5 & 12 & 38 & 44 & 8 \\
\hline & & 250 & 16 & 24 & 39 & 21 & 4 \\
\hline & & 440 & $=0$ & 352 & $\Rightarrow 0$ & $n \in g$ & 0.3 \\
\hline \multirow{3}{*}{\multicolumn{2}{|c|}{100}} & 100 & 24 & 23 & 22 & 31 & 27 \\
\hline & & 250 & 24 & 23 & 28 & 23 & 24 \\
\hline & & 440 & 18 & 26 & 36 & 20 & 26 \\
\hline \multirow{3}{*}{\multicolumn{2}{|c|}{500}} & 100 & 48 & 22 & 18 & 13 & 142 \\
\hline & & 250 & 53 & 20 & 18 & 9 & 129 \\
\hline & & 440 & 49 & 28 & 7 & 16 & 123 \\
\hline \multirow{3}{*}{\multicolumn{2}{|c|}{2500}} & 100 & 42 & 30 & 16 & 12 & 676 \\
\hline & & 250 & 45 & 27 & 16 & 12 & 651 \\
\hline & & 440 & 49 & 36 & 0.6 & 15 & 614 \\
\hline
\end{tabular}

Overall Soil Averages (see Table V.10 of Brass Monthly Report):

$\begin{array}{ccccclc}25 & 100 & 5 \pm 4 & 38 \pm 38 & 20 \pm 23 & 37 \pm 22 & 9 \pm 2 \\ & 250 & 6 \pm 8 & 33 \pm 28 & 21 \pm 16 & 41 \pm 21 & 7 \pm 4 \\ 100 & 440 & 3 \pm 7 & 123 \pm 157 & 26 \pm 52 & 53 \pm 141 & 5 \pm 5 \\ & 100 & 20 \pm 12 & 44 \pm 21 & 11 \pm 12 & 26 \pm 10 & 25+4 \\ & 250 & 13 \pm 9 & 29 \pm 19 & 19 \pm 11 & 39 \pm 16 & 29 \pm 8 \\ 500 & 440 & 12 \pm 8 & 37 \pm 28 & 28 \pm 19 & 23 \pm 4 & 27 \pm 5 \\ & 100 & 37 \pm 18 & 35 \pm 18 & 10 \pm 9 & 19 \pm 8 & 134 \pm 8 \\ & 250 & 37 \pm 18 & 30 \pm 18 & 12 \pm 9 & 21 \pm 10 & 130 \pm 12 \\ 2500 & 440 & 32 \pm 17 & 37 \pm 16 & 6 \pm 4 & 24 \pm 7 & 132 \pm 8 \\ & 100 & 31 \pm 20 & 40 \pm 16 & 12 \pm 5 & 16 \pm 5 & 688 \pm 17 \\ & 250 & 33 \pm 20 & 36 \pm 19 & 13 \pm 3 & 19 \pm 7 & 658 \pm 26 \\ & 440 & 33 \pm 2 & 146 \pm 18 & 0.1 \pm 0.3 & 21 \pm 6 & 172 \pm 659\end{array}$

(a) Done as separate extractions only, not as sequential extractions.

(b) Below detection limit (bdl) designations for the organically bound compartment are controlled by the difference between the pyrophoaphate extraction and the sum of the exchangeable and inorganically bound fraction. Since the result is then corrected for the control-soil contribution, there are cases where the resulting value is negative. We presume the value in those cases to be minor, though it could amount to a detection limit on the 25- and $100-\mu \mathrm{g} / \mathrm{g}$ amended soils of up to about 1.5 and $0.5 \%$, respectively.

(c) Value was less than the control soil, resulting in a negative value. 
TABLE 328. SOLUBILIZATION OF COMPONENTS OF BRASS-AMENDED SOILS BY HOTWATER EXTRACTION AND COMPARISON TO DIRECT PORE-WATER DISPLACEMENT: METAL ANALYSES

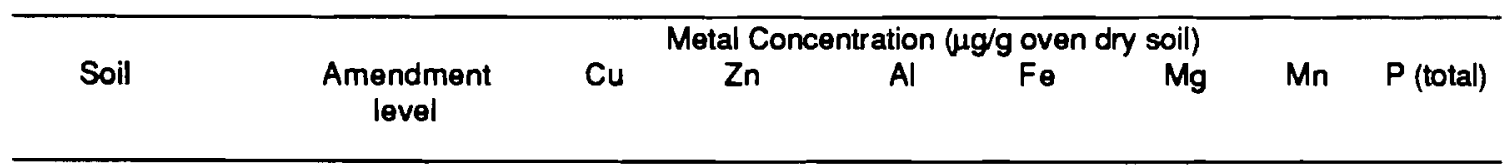

Hot-Water Extract

Time 0, at time of Soil Preparation:

$\begin{array}{llrrrrrrr}\text { Burbank } & \text { 0, dry } & 0.21 & 0.00 & 1.46 & 0.33 & 7.75 & 0.17 & 12.6 \\ \text { Burbank } & 2500, \text { dry } & 8.91 & 1.44 & 1.45 & 0.45 & 6.28 & 0.26 & 9.1 \\ \text { Burbank } & 2500 \text {, wet } & 8.86 & 0.62 & 0.50 & 0.47 & 10.68 & 0.12 & 7.9 \\ \text { Cinebar } & \text { 0, dry } & 0.17 & 0.21 & 8.04 & 2.29 & 44.38 & 25.17 & 12.1 \\ \text { Cinebar } & 2500, \text { dry } & 64.03 & 18.52 & 6.35 & 3.92 & 49.59 & 37.87 & 11.7 \\ \text { Cinebar } & 2500, \text { wet } & 27.41 & 7.75 & 15.66 & 6.83 & 46.49 & 34.64 & 12.4 \\ \text { Palouse } & \text { 0, dry } & 0.25 & 0.00 & 3.33 & 2.08 & 9.59 & 2.01 & 50.0 \\ \text { Palouse } & 2500, \text { dry } & 33.43 & 9.11 & 2.30 & 1.63 & 16.11 & 3.79 & 26.5 \\ \text { Palouse } & 2500, \text { wet } & 32.28 & 8.74 & 2.28 & 1.57 & 15.30 & 4.04 & 22.5 \\ \text { Palouse+OM } & 0, \text { dry } & 0.22 & 0.00 & 3.15 & 1.96 & 10.30 & 2.49 & 51.2 \\ \text { Palouse+OM } & 2500, \text { dry } & 38.24 & 9.87 & 6.09 & 4.15 & 18.48 & 4.53 & 29.7 \\ \text { Palouse+OM } & 2500, \text { wet } & 37.35 & 8.82 & 3.49 & 2.43 & 17.07 & 4.24 & 25.0\end{array}$

Weathered, at 100 days:

$\begin{array}{ll}\text { Burbank } & 0 \\ \text { Burbank } & 25 \\ \text { Burbank } & 100 \\ \text { Burbank } & 500 \\ \text { Burbank } & 2500 \\ \text { Burbank } & 2500 \\ \text { Cinebar } & 0 \\ \text { Cinebar } & 25 \\ \text { Cinebar } & 100 \\ \text { Cinebar } & 500 \\ \text { Cinebar } & 2500 \\ \text { Cinebar } & 2500 \\ \text { Palouse } & 0 \\ \text { Palouse } & 25 \\ \text { Palouse } & 100 \\ \text { Palouse } & 500 \\ \text { Palouse } & 2500 \\ \text { Palouse } & 2500 \\ \text { Palouse+OM } & 0 \\ \text { Palouse+OM } & 25 \\ \text { Palouse+OM } & 100 \\ \text { Palouse+OM } & 500 \\ \text { Palous }+O M & 2500 \\ \text { Palouse+OM } & 2500\end{array}$

0.14
0.85
1.99
5.37
8.59
9.47
0.16
0.38
1.04
4.46
27.01
27.47
0.16
0.54
1.41
6.24
37.46
40.65
0.24
0.68
1.51
5.80
29.26
34.94

$\begin{array}{rr}0.00 & 1.63 \\ 0.00 & 1.19 \\ 0.00 & 0.68 \\ 0.42 & 0.00 \\ 0.84 & 0.00 \\ 0.96 & 0.60 \\ 0.00 & 12.36 \\ 0.00 & 12.32 \\ 0.00 & 13.49 \\ 1.12 & 12.93 \\ 9.12 & 12.83 \\ 9.10 & 14.00 \\ 0.00 & 2.31 \\ 0.00 & 6.35 \\ 0.00 & 5.87 \\ 1.38 & 5.84 \\ 11.20 & 5.05 \\ 12.74 & 5.39 \\ 0.00 & 6.82 \\ 0.00 & 6.66 \\ 0.00 & 6.13 \\ 1.20 & 5.48 \\ 8.50 & 5.43 \\ 9.82 & 5.44\end{array}$

14.35

$3.66 \quad 13.91$

$3.83 \quad 14.72$

$3.47 \quad 19.17$

19.17
22.13

$\begin{array}{ll}3.74 & 22.13 \\ 4.43 & 16.32\end{array}$

$4.38 \quad 14.79$

3.86

14.18

$3.43 \quad 12.28$

12.28
16.16 3.69

18.33

0.26

0.38

0.48

0.44

0.18

0.20

62.79

45.49

52.17

54.97

58.99

54.94

4.62

3.32

3.74

4.06

4.89

6.46

4.45

4.66

3.70

3.25

3.79

2.81
12.5

12.9

11.7

10.5

9.8

9.2

10.7

11.4

10.8

10.8

11.5

11.8

59.7

53.9

54.3

52.2

34.1

36.2

56.3

54.2

50.2

48.2

28.3

32.1

Pore Waters:

$\begin{array}{ll}\text { Burbank } & 0 \\ \text { Burbank } & 2500 \\ \text { Cinebar } & 0 \\ \text { Cinebar } & 2500 \\ \text { Palous } \theta+O M & 0 \\ \text { Palous } \theta+O M & 2500\end{array}$

$\begin{array}{lll}0.002 & 0.000 & 0.00 \\ 0.099 & 0.021 & 0.00 \\ 0.003 & 0.009 & 0.22 \\ 0.246 & 2.600 & 0.06 \\ 0.001 & 0.000 & 0.03 \\ 0.271 & 3.652 & 0.02\end{array}$

0.00
0.00
0.00
0.01
0.00
0.00

0.1

10.74

0.00

0.1 
IABLE 3.29. SOLUBILIZATION OF COMPONENTS OF BRASS-AMENDED SOILS BY HOTWATER EXTRACTION, AND COMPARISON TO DIRECT-PORE-WATER DISPLACEMENT ANION AND ORGANIC ANALYSES

\begin{tabular}{ccccccccccc}
\hline Soil & $\begin{array}{c}\text { Amendment } \\
\text { level }\end{array}$ & $\mathrm{DOC}$ & $\mathrm{C}$ & $\mathrm{NO}_{2}$ & $\mathrm{NH}_{4}$ & $\mathrm{NO}_{3}$ & $\mathrm{SO}_{4}$ & $\mathrm{C}$ & $\mathrm{PO}_{4}$ & $\mathrm{Oxalate}$ \\
\hline
\end{tabular}

\section{Hot-Water Extract}

Time 0, at time of Soil Preparation:

$\begin{array}{llllllrrrrr}\text { Burbank } & \text { 0,dry } & \text { nd } & \text { nd } & 0.4 & 0.0 & 1.4 & 9.37 & 1.99 & 34.50 & 7.98 \\ \text { Burbank } & \text { 2500, dry } & \text { nd } & \text { nd } & 0.2 & 0.0 & 1.4 & 6.98 & 0.60 & 27.30 & 10.56 \\ \text { Burbank } & \text { 2500, wet } & \text { nd } & \text { nd } & 0.6 & 0.0 & 2.6 & 10.58 & 1.37 & 18.42 & 21.56 \\ \text { Cinebar } & \text { 0, dry } & \text { nd } & \text { nd } & 0.0 & 0.0 & 335.8 & 75.41 & 23.00 & 19.00 & 33.80 \\ \text { Cinebar } & 2500, \text { dry } & \text { nd } & \text { nd } & 0.0 & 0.0 & 269.1 & 92.13 & 21.42 & 16.16 & 67.88 \\ \text { Cinebar } & 2500, \text { wet } & \text { nd } & \text { nd } & 0.0 & 0.0 & 252.3 & 79.56 & 21.92 & 24.36 & 53.58 \\ \text { Palouse } & 0, \text { dry } & \text { nd } & \text { nd } & 1.0 & 0.0 & 175.6 & 22.30 & 1.39 & 154.11 & 4.18 \\ \text { Palouse } & \text { 2500, dry } & \text { nd } & \text { nd } & 0.4 & 0.0 & 189.9 & 37.26 & 1.98 & 75.91 & 37.66 \\ \text { Palouse } & \text { 2500, wet } & \text { nd } & \text { nd } & 0.4 & 0.0 & 175.1 & 36.78 & 1.77 & 62.16 & 36.00 \\ \text { Palouse+OM } & \text { 0, dry } & \text { nd } & \text { nd } & 0.9 & 0.0 & 148.2 & 24.24 & 6.31 & 153.70 & 6.50 \\ \text { Palouse+OM } & \text { 2500, dry } & \text { nd } & \text { nd } & 0.6 & 0.0 & 147.3 & 36.03 & 6.77 & 80.82 & 55.94 \\ \text { Palouse+OM } & 2500, \text { wet } & \text { nd } & \text { nd } & 0.4 & 0.0 & 143.0 & 35.76 & 7.59 & 70.12 & 45.35\end{array}$

Weathered, at 100 days:

\begin{tabular}{|c|c|c|c|c|c|c|c|c|c|c|}
\hline $\begin{array}{l}\text { Burbank } \\
\text { Burbank } \\
\text { Burbank } \\
\text { Burbank } \\
\text { Burbank } \\
\text { Burbank } \\
\text { Cinebar } \\
\text { Cinebar } \\
\text { Cinebar } \\
\text { Cinebar } \\
\text { Cinebar } \\
\text { Cinebar } \\
\text { Palous } \\
\text { Palouse } \\
\text { Palouse } \\
\text { Palous } \\
\text { Palouse } \\
\text { Palous } \\
\text { Palous } \theta+O M \\
\text { Palous +OM } \\
\text { Palouse+OM } \\
\text { Palous +OM } \\
\text { Palous }+O M \\
\text { Palous }+O M\end{array}$ & $\begin{array}{l}0 \\
25 \\
100 \\
500 \\
2500 \\
2500 \\
0 \\
25 \\
100 \\
500 \\
2500 \\
2500 \\
0 \\
25 \\
100 \\
500 \\
2500 \\
2500 \\
0 \\
25 \\
100 \\
500 \\
2500 \\
2500\end{array}$ & $\begin{array}{r}255 \\
302 \\
307 \\
278 \\
305 \\
283 \\
2759 \\
2714 \\
2658 \\
2551 \\
2208 \\
2860 \\
1103 \\
834 \\
741 \\
812 \\
816 \\
863 \\
889 \\
851 \\
784 \\
773 \\
693 \\
802\end{array}$ & $\begin{array}{l}17.6 \\
20.8 \\
23.2 \\
26.2 \\
46.9 \\
48.2 \\
82.2 \\
78.3 \\
74.8 \\
70.5 \\
93.8 \\
85.2 \\
13.6 \\
14.9 \\
14.8 \\
15.9 \\
36.1 \\
41.2 \\
13.8 \\
15.7 \\
15.5 \\
17.7 \\
31.3 \\
30.5\end{array}$ & $\begin{array}{l}0.5 \\
2.5 \\
0.5 \\
2.2 \\
0.5 \\
0.5 \\
0.9 \\
1.1 \\
1.0 \\
0.8 \\
1.3 \\
1.0 \\
1.5 \\
1.7 \\
3.0 \\
1.2 \\
0.9 \\
0.9 \\
1.9 \\
3.1 \\
1.4 \\
1.0 \\
0.9 \\
0.8\end{array}$ & $\begin{array}{r}2.4 \\
2.4 \\
2.8 \\
2.6 \\
4.8 \\
4.6 \\
35.9 \\
35.5 \\
36.8 \\
37.4 \\
40.7 \\
45.9 \\
11.2 \\
9.5 \\
8.2 \\
9.5 \\
13.5 \\
15.1 \\
10.4 \\
10.1 \\
10.3 \\
11.1 \\
12.8 \\
14.7\end{array}$ & $\begin{array}{r}74.6 \\
22.2 \\
16.6 \\
99.9 \\
50.7 \\
51.4 \\
825.8 \\
392.8 \\
614.3 \\
748.7 \\
290.5 \\
256.6 \\
261.7 \\
208.8 \\
186.8 \\
185.3 \\
153.7 \\
192.4 \\
264.9 \\
228.6 \\
312.6 \\
192.3 \\
273.3 \\
223.4\end{array}$ & $\begin{array}{l}10.33 \\
15.68 \\
12.04 \\
14.54 \\
12.72 \\
13.13 \\
95.25 \\
86.87 \\
94.50 \\
95.12 \\
93.31 \\
91.47 \\
38.20 \\
31.98 \\
28.64 \\
31.35 \\
39.25 \\
47.23 \\
30.11 \\
28.26 \\
30.19 \\
29.65 \\
33.14 \\
32.51\end{array}$ & $\begin{array}{r}2.44 \\
4.21 \\
3.95 \\
3.68 \\
4.41 \\
3.96 \\
34.08 \\
29.83 \\
29.01 \\
33.15 \\
25.36 \\
30.13 \\
6.97 \\
5.51 \\
5.33 \\
5.94 \\
\text { Int. }(\mathrm{a}) \\
\text { Int.(a) } \\
11.89 \\
10.03 \\
12.66 \\
11.65 \\
14.90 \\
15.00\end{array}$ & $\begin{array}{r}30.81 \\
29.51 \\
27.94 \\
29.12 \\
22.08 \\
21.47 \\
10.05 \\
13.90 \\
11.35 \\
10.63 \\
9.81 \\
10.87 \\
149.96 \\
138.04 \\
141.06 \\
136.00 \\
91.97 \\
95.29 \\
149.02 \\
141.10 \\
126.72 \\
120.83 \\
67.68 \\
67.84\end{array}$ & $\begin{array}{r}8.00 \\
10.03 \\
10.89 \\
16.11 \\
22.69 \\
23.26 \\
41.34 \\
37.42 \\
37.48 \\
39.16 \\
63.41 \\
70.48 \\
7.09 \\
5.86 \\
6.41 \\
10.38 \\
52.09 \\
58.74 \\
7.54 \\
7.46 \\
6.81 \\
10.92 \\
40.33 \\
42.78\end{array}$ \\
\hline \multicolumn{11}{|l|}{$\theta$ Waters } \\
\hline $\begin{array}{l}\text { Burbank } \\
\text { Burbank } \\
\text { Cinebar } \\
\text { Cinebar } \\
\text { Palouse+OM } \\
\text { Palouse+OM }\end{array}$ & $\begin{array}{l}0 \\
2500 \\
0 \\
2500 \\
0 \\
2500\end{array}$ & $\begin{array}{r}4.2 \\
7.5 \\
9.5 \\
11.7 \\
3.4 \\
5.4\end{array}$ & $\begin{array}{l}0.4 \\
6.5 \\
0.1 \\
0.1 \\
0.0 \\
0.1\end{array}$ & $\begin{array}{l}0.0 \\
0.0 \\
0.0 \\
0.0 \\
0.0 \\
0.0\end{array}$ & $\begin{array}{l}0.02 \\
0.09 \\
0.05 \\
0.06 \\
0.02 \\
0.05\end{array}$ & $\begin{array}{r}77.0 \\
56.5 \\
931.0 \\
346.1 \\
293.6 \\
285.0\end{array}$ & $\begin{array}{l}5.76 \\
5.49 \\
2.26 \\
3.73 \\
5.05 \\
7.90\end{array}$ & $\begin{array}{r}1.24 \\
1.39 \\
14.75 \\
5.27 \\
6.64 \\
7.37\end{array}$ & $\begin{array}{l}0.17 \\
0.04 \\
0.00 \\
0.00 \\
0.18 \\
0.00\end{array}$ & $\begin{array}{l}0.00 \\
0.00 \\
0.00 \\
0.00 \\
0.00 \\
0.00\end{array}$ \\
\hline
\end{tabular}

(a) Int: interference with the analysis of $\mathrm{Cl}$ by ion chromatograph. 
hot-water extract, would suggest that chemical processes may be prominent, since the action of the hot water extraction should have effectively eliminated further microbial transformations. In contrast, nitrate levels in the displaced pore waters correlate well with those from the hot water extractions. Sulfate solubilization is increased roughly by a factor of 2,25 to 40 , and 4 to 6 for Burbank, Cinebar, and Palouse+OM, respectively, as a result of the removal of most solubility controls. Chloride levels for Cinebar hot-water extraction are about 2 to 6 times those of the displaced pore waters. Phosphate solubility increased dramatically for all soils under hot-water extraction, demonstrating a significant pool of readily available nutrient. At 100 days, phosphate accounts for the bulk of total dissolved $P$ (Table 3.28) for Burbank (75 to $92 \%$ ), Palouse (84 to $90 \%$ ), and Palouse+OM (70 to $88 \%$ ), but only 28 to $41 \%$ for Cinebar. At initial soil amendment, phosphate accounted for 44 to $66 \%$ of the total $P$ for Cinebar, and over $90 \%$ for the other soils. Oxalate solubility is greatly increased by hot-water extraction, as is DOC in general. Oxalate increases with increasing brass amendment for all soils; oxalate and other organic acids would tend to aid in metal solubilization through complexation.

Summary of Extraction Results. Because the initial selective extractions were calculated from comparisons to Parr bomb digestions of soils, which differed from the total recovery by the extraction series, we recalculated the $\mathrm{Cu}$ and $\mathrm{Zn}$ distribution based on total metal via extraction recovery for the exchangeable, inorganically and organically bound, and residual compartments, so that these values could be more easily compared and averaged over the exposed soils. As before, the compartments resulting from the selective extraction techniques are referred to by their nominal extraction categories, without further actual proof that the categories are mutually exclusive or unaffected by readsorption reactions.

Generally, the amount of both $\mathrm{Cu}$ and $\mathrm{Zn}$ in the residual compartment increased between the $t=0$ and the $t=100$ days extractions and changed little to 440 days, but much of this increase likely was due to the improved analysis of the residual at the latter sampling time. At the highest amendment level, inorganically bound $\mathrm{Cu}$ decreased and organically bound increased with time; for $\mathrm{Zn}$, the variation in results overshadowed any trends.

All soils showed similarly low exchangeable $\mathrm{Cu}$, while exchangeable $\mathrm{Zn}$. was depressed in Burbank and increased dramatically in the other soils. The inorganically bound $\mathrm{Cu}$ is predominant for Burbank, but less important for the other soil, particularly at lower amendment levels; inorganically bound $\mathrm{Zn}$ is predominant for Burbank and a major compartment for Cinebar, but is of less importance for Palouse. Copper in the organically bound compartment is increasingly important with decreasing brass concentration, particularly for Palouse; $\mathrm{Zn}$ shows a slight similar trend. This may reflect limited organic ligands in the soils. Residual $\mathrm{Cu}$ is greatest for Cinebar, while residual $\mathrm{Zn}$ is greatest for Burbank and the lower amendments of Palouse. 


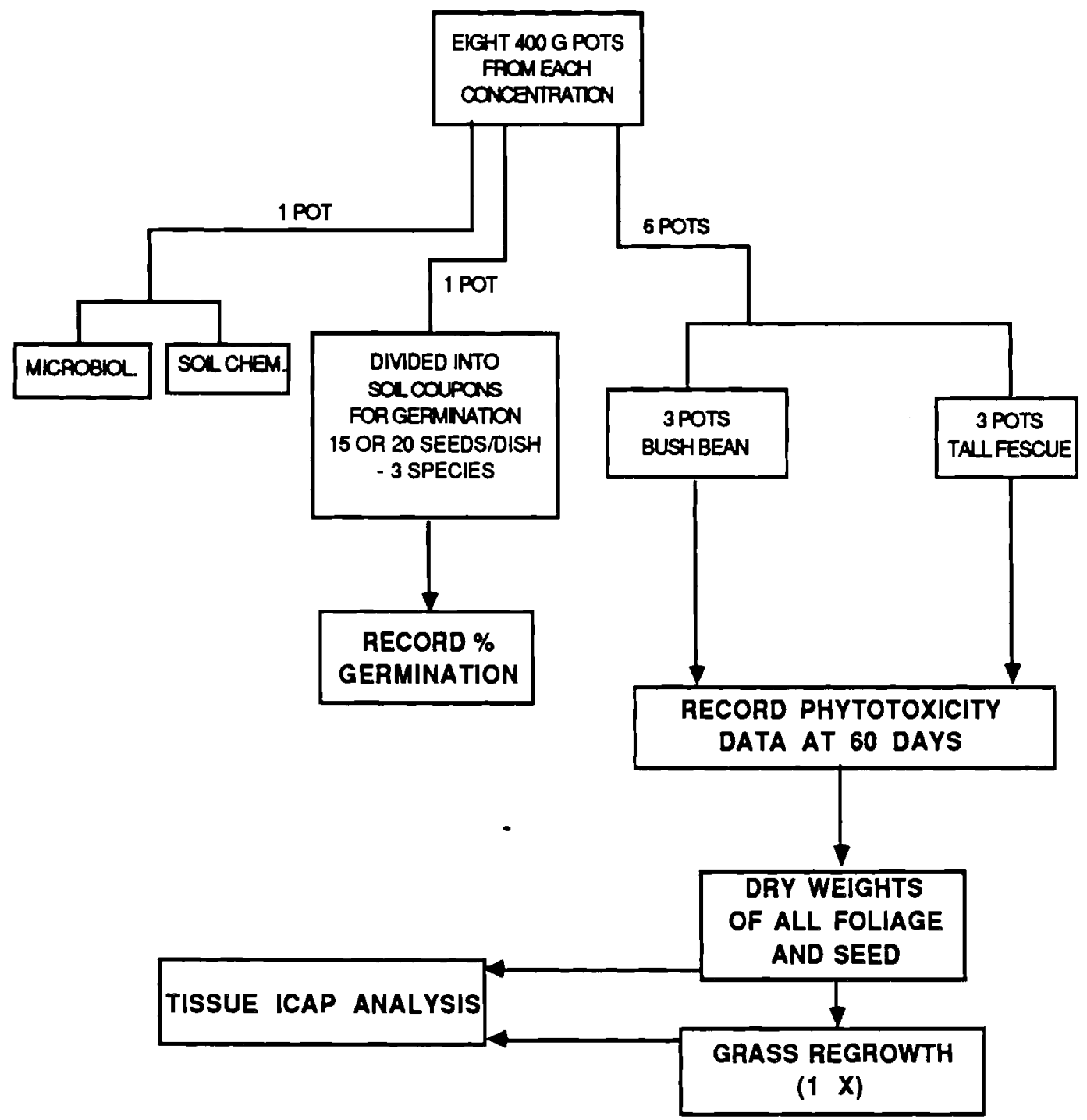

EIGURE 3.7. FLOW CHART FOR THE PROCESSING OF SAMPLES FROM THE BRASS FLAKE DIRECT SOIL AMENDMENT/WEATHERING EXPERIMENT. VEGETATION DATA TO BE RECOVERED AND REPORTED BELOW ARE GIVEN IN BOLD PRINT. SAMPLING DATES INCLUDE APPROXIMATELY 0 , 100, 300, AND 450 DAYS POST-AMENDMENT. 
In general, these data show that exchangeable $\mathrm{Cu}$ and $\mathrm{Zn}$ increase with increasing brass amendment, though the $\mathrm{Cu}$ component remains minor. The inorganically bound compartment shows increasing $\mathrm{Cu}$ but steady $\mathrm{Zn}$ with increasing brass. Organically bound and residual compartments show decreasing $\mathrm{Cu}$ and $\mathrm{Zn}$ with increasing brass amendment.

\subsubsection{Toxicity and Availability of Brass Components to Plants}

Potential effects of soil-deposited brass flake on vegetation were assessed using soilamended brass. Soils were then allowed to weather over an extended time with samples periodically taken and tested for relative phytotoxicity to different plant species. Soil treatments included Burbank, Cinebar, Palouse, and Palouse + OM $10.22 \% \mathrm{w} / \mathrm{w}$ dried and ground alfalfa). Each soil type was amended with four concentrations of the brass flake $(25,100$, 500 , and $2500 \mathrm{ppm}$ ), placed into 400-g pots, and maintained in the greenhouse. Eight pots of each soil type and concentration were selected for testing at approximately $0,100,300$, and 450 days post-amendment. The procedure for each sample period is given in a flow chart in Figure 3.7. One of the eight pots was used for both soil microbiological activity and soil chemistry, while another was divided into six soil coupons and used for germination studies, with two coupons each for the three plant species. Bush bean, alfalfa, and tall fescue were seeded with either 15 (bush bean) or 20 (alfalfa and tall fescue) seeds. Germination percentage was determined 2 weeks after seeding.

The remaining six pots were planted with either bush bean or tall fescue and maintained in the growth chamber $\left(27 / 20^{\circ} \mathrm{C}\right.$ day/night temperatures for the bean and $25 / 18$ for the grass at $400 \mu \mathrm{E} / \mathrm{m}^{2} / \mathrm{s}$ PAR) for 60 days for the bean and 120 days for the grass (two harvests at 60 and 120 days). At these times the plants were rated for phytotoxic symptomatology, using the Modified Daubenmire Rating system described earlier, and harvested. The beans were separated into various aboveground plant components such as leaves, stems, pods, and seed (when present), dried at $60^{\circ} \mathrm{C}$ for 7 days, and weighed. The grass was similarly sampled at each harvest. Aliquots from all tissues were subsequently taken, wet-digested, and processed for ICAP analysis.

Effects on Seed Germination. Tables 3.30 and 3.31 give the average percent germination, at 0 time and $\mathbf{4 5 0}$ days, respectively, for bush bean, alfalfa, and tall fescue seeds planted in soil coupons of the four soil types amended to the various brass concentrations. Results for intermediate times are not provided. Two observations may be made from these data. First, germination apparent by was not inhibited by increasing concentrations of brass in any soil type. This was true for soils at each of the four aging intervals including the last, at 450 days post-amendment (Table 3.31). This may indicate either that the brass had not 
sufficiently weathered to promote a high enough soil concentration of $\mathrm{Zn}$ or $\mathrm{Cu}$ to be toxic to germinating seeds or that the seeds themselves are not affected by external $\mathrm{Cu}$ and $\mathrm{Zn}$ levels.

IABLE 3.30. AVERAGE PERCENT GERMINATION FOR BUSH BEANS, ALFALFA, AND TALL FESCUE SEEDED IN SOIL COUPONS AMENDED WITH BRASS FLAKE AT DIFFERENT CONCENTRATIONS (PLANTING O TIME). SEEDING RATE PER COUPON: BUSH BEAN, 15; ALFALFA AND TALL FESCUE, 20. PERCENTAGES WERE RECORDED AT 14 DAYS AFTER SEEDING AND AT15 DAYS POST-AMENDMENT.

\begin{tabular}{|c|c|c|c|c|}
\hline \multirow[t]{2}{*}{ Soil } & \multirow{2}{*}{$\begin{array}{c}\text { Brass-Flake } \\
\text { Concentration }(\mu g / g)\end{array}$} & \multicolumn{3}{|c|}{ Soecies (Average $\%+$ Variance $(n=2)$} \\
\hline & & Bush Bean & Alfalfa & Tall Fescue \\
\hline \multicolumn{5}{|c|}{ Burbank } \\
\hline & 0 & $100.0 \pm 0.0$ & $77.5 \pm 10.0$ & $67.5 \pm 2.5$ \\
\hline & 25 & $100.0 \pm 0.0$ & $92.5 \pm 7.5$ & $95.0 \pm 2.5$ \\
\hline & 100 & $100.0 \pm 0.0$ & $80.0 \pm 15.0$ & $75.0 \pm 0.0$ \\
\hline & 500 & $100.0 \pm 0.0$ & $92.5 \pm 7.5$ & $60.0 \pm 5.0$ \\
\hline & 2500 & $100.0 \pm 0.0$ & $80.0 \pm 7.5$ & $85.0 \pm 10.0$ \\
\hline \multicolumn{5}{|c|}{ Cinebar } \\
\hline & 0 & $100.0 \pm 0.0$ & $90.0 \pm 0.0$ & $65.0 \pm 0.0$ \\
\hline & 25 & $100.0 \pm 0.0$ & $72.5 \pm 7.5$ & $67.5 \pm 2.5$ \\
\hline & 100 & $100.0 \pm 0.0$ & $95.0 \pm 5.0$ & $80.0 \pm 5.0$ \\
\hline & 500 & $100.0 \pm 0.0$ & $85.0 \pm 7.5$ & $70.0 \pm 0.0$ \\
\hline & 2500 & $100.0 \pm 0.0$ & $80.0 \pm 7.5$ & $77.5 \pm 2.5$ \\
\hline \multicolumn{5}{|c|}{ Palouse } \\
\hline & 0 & $50.0 \pm 1.3$ & $55.0 \pm 0.0$ & $62.5 \pm 7.5$ \\
\hline & 25 & $40.0 \pm 0.0$ & $50.0 \pm 7.5$ & $70.0 \pm 5.0$ \\
\hline & 100 & $46.7 \pm 0.0$ & $72.5 \pm 7.5$ & $60.0 \pm 5.0$ \\
\hline & 500 & $70.0 \pm 20.0$ & $75.0 \pm 0.0$ & $60.0 \pm 0.0$ \\
\hline & 2500 & $93.3 \pm 0.0$ & $80.0 \pm 10.0$ & $80.0 \pm 2.5$ \\
\hline \multicolumn{5}{|c|}{ Palouse+OM$(a)$} \\
\hline & 0 & $43.3 \pm 1.3$ & $55.5 \pm 0.0$ & $55.0 \pm 15.0$ \\
\hline & 25 & $63.3 \pm 35.0$ & $62.5 \pm 10.0$ & $62.5 \pm 7.5$ \\
\hline & 100 & $70.0 \pm 6.7$ & $65.0 \pm 5.0$ & $62.5 \pm 2.5$ \\
\hline & 500 & $56.7 \pm 33.3$ & $52.5 \pm 7.5$ & $67.5 \pm 7.5$ \\
\hline & 2500 & $86.7 \pm 6.7$ & $85.0 \pm 0.0$ & $77.5 \pm 2.5$ \\
\hline
\end{tabular}

(a) Soil with $0.22 \% \mathrm{w} / \mathrm{w}$ dried ground alfalfa. 
IABLE 3.31. AVERAGE PERCENT GERMINATION FOR BUSH BEANS, ALFALFA, AND TALL FESCUE SEEDED IN SOIL COUPONS AMENDED WITH BRASS FLAKE AT DIFFERENT CONCENTRATIONS (PLANTING C). SEEDING RATE PER COUPON: BUSH BEAN, 15; ALFALFA AND TALL FESCUE, 20. PERCENTAGES WERE RECORDED AT 14 DAYS AFTER SEEDING AND AT 15 DAYS POST-AMENDMENT.

\begin{tabular}{|c|c|c|c|c|}
\hline \multirow[t]{2}{*}{ Soil } & \multirow{2}{*}{$\begin{array}{c}\text { Brass-Flake } \\
\text { Concentration }(\mu g / g)\end{array}$} & \multicolumn{3}{|c|}{ Soocias (Average \%+ Variance, $(n=2)$} \\
\hline & & Bush Bean & Alfalfa & Tall Fescue \\
\hline \multicolumn{5}{|c|}{ Burbank } \\
\hline & 0 & $100.0 \pm 0.0$ & $90.0 \pm 5.0$ & $80.0 \pm 5.0$ \\
\hline & 25 & $100.0 \pm 0.0$ & $80.0 \pm 5.0$ & $67.5 \pm 7.5$ \\
\hline & 100 & $100.0 \pm 0.0$ & $82.5 \pm 2.5$ & $85.0 \pm 0.0$ \\
\hline & 500 & $100.0 \pm 0.0$ & $92.5 \pm 2.5$ & $72.5 \pm 7.5$ \\
\hline & 2500 & $100.0 \pm 0.0$ & $90.0 \pm 0.0$ & $65.0 \pm 10.0$ \\
\hline \multicolumn{5}{|c|}{ Cinebar } \\
\hline & 0 & $100.0 \pm 0.0$ & $90.0 \pm 5.0$ & $72.5 \pm 2.5$ \\
\hline & 25 & $100.0 \pm 0.0$ & $92.5 \pm 2.5$ & $92.5 \pm 2.5$ \\
\hline & 100 & $100.0 \pm 0.0$ & $90.0 \pm 5.0$ & $87.5 \pm 2.5$ \\
\hline & 500 & $100.0 \pm 0.0$ & $77.5 \pm 7.5$ & $77.5 \pm 7.5$ \\
\hline & 2500 & $100.0 \pm 0.0$ & $87.5 \pm 7.5$ & $87.5 \pm 7.5$ \\
\hline \multicolumn{5}{|c|}{ Palouse } \\
\hline & 0 & $53.3 \pm 26.7$ & $25.0 \pm 0.0$ & $55.5 \pm 2.5$ \\
\hline & 25 & $60.0 \pm 13.3$ & $40.0 \pm 5.0$ & $67.5 \pm 2.5$ \\
\hline & 100 & $70.0 \pm 26.7$ & $57.5 \pm 5.0$ & $57.5 \pm 7.5$ \\
\hline & 500 & $100.0 \pm 0.0$ & $85.0 \pm 10.0$ & $72.5 \pm 2.5$ \\
\hline & 2500 & $86.7 \pm 13.3$ & $77.5 \pm 7.5$ & $57.5 \pm 2.5$ \\
\hline \multicolumn{5}{|c|}{ Palouse+OM(a) } \\
\hline & 0 & $80.0 \pm 0.0$ & $30.0 \pm 7.5$ & $40.0 \pm 5.0$ \\
\hline & 25 & $63.3 \pm 20.0$ & $52.5 \pm 10.0$ & $70.0 \pm 5.0$ \\
\hline & 100 & $80.0 \pm 13.3$ & $35.0 \pm 5.0$ & $47.5 \pm 5.0$ \\
\hline & 500 & $90.0 \pm 13.3$ & $60.0 \pm 5.0$ & $67.5 \pm 2.5$ \\
\hline & 2500 & $93.3 \pm 0.0$ & $82.5 \pm 2.5$ & $62.5 \pm 5.0$ \\
\hline
\end{tabular}

(a) Soil with $0.22 \% \mathrm{w} / \mathrm{w}$ dried ground alfalfa.

However, the latter possibility is not completely accurate, because there was a stimulation in the germination percentage, particularly in the palouse bush beans and tall fescue, at all dates in the intermediate concentrations (25 to $500 \mathrm{ppm}$ ). One of the two principal ions associated with brass, most likely $\mathrm{Zn}$, because of its role as a cofactor in many respiratory enzymes, $m_{i n}$ be promoting a faster rate of growth. Alternatively, the $\mathrm{Cu}$ and $\mathrm{Zn}$, particularly for the Palouse soils, may be inhibiting soil fungi, which otherwise appeared to damage the imbibed seeds in these soils, thus lowering their overall germination percentage. 
Long-Term Effects of Brass Flake Soil Amendment on PlantPhytotoxicity. The visual damage ratings and symptomatologies for bush bean and tall fescue plants grown for 60 days in brass-flake-amended pots following different incubation (weathering) periods are given in Tables 3.32 (100 days) and 3.33 (410 days). The data indicate that up to soil concentrations of $500 \mathrm{ppm}$ the bush bean was the most resistant to any influences from the brass flake. This observation was consistent over the entire 450-day weathering, although visible phyotoxicity may have increased slightly at the lower concentrations in the Burbank soil during the latter planting periods, as shown by comparing Table 3.32 results with those in Table 3.33.

In all cases and in all soil types, significant effects were evident in the plants grown in 2500-ppm pots at all times. The degree of phytotoxicity was somewhat higher at the longer incubations, with increasing evidence of stunting and growth deficiencies along with general chlorosis and necrotic spotting. These are general characteristics of both $\mathrm{Cu}$ and $\mathrm{Zn}$ toxicities within the foliage. It was also evident that the soil type was instrumental in the onset and degree of $\mathrm{Cu}$ and $\mathrm{Zn}$ phytotoxicity. In all cases, the bush beans grown in the Burbank soil, which has the lowest CEC and therefore the greatest potential for free $\mathrm{Cu}$ and $\mathrm{Zn}$ ions to be present in the soil solution, exhibited the most severe symptoms.

The tall fescue appeared to be slightly more sensitive to the brass over time, at lower concentrations ( $\geq 500$ ppm) having greater damage (Tables 3.32 and 3.33). Again, this was particularly true for the Burbank-soil plants at 500 ppm, and again may be attributed to the soil characteristic. At the higher brass concentrations in all soil types there appeared to be a reduction in the degree of tip burn, the cause of which may have been relieved by the additional $\mathrm{Cu}$ or $\mathrm{Zn}$, although this symptom may have been masked by the increasing chlorosis of the tissue and accompanying reduction in rate of growth. Phytotoxicity at the various concentrations did not appear to increase significantly with weathering time in any of the soil types, although a slight increase for the tall fescue may have been evident for the final 470-day harvest. 
IABLE 3.32. PLANT SYMPTOMATOLOGY TO BRASS SOIL AMENDMENT. SYMPTOMATOLOGY DETERMINATIONS MADE 60 DAYS AFTER PLANTING(a) AND 160 DAYS AFTER AMENDMENT OF BRASS FLAKE TO THE VARIOUS SOILS AT $0,25,100,500$, AND $2500 \mathrm{ppm}$

\begin{tabular}{|c|c|c|c|}
\hline Species/ & \multirow[b]{2}{*}{$\begin{array}{l}\text { Soil Concentration, } \\
\qquad(\mu g / g)\end{array}$} & \multicolumn{2}{|c|}{ Toxicity Resoonse ${ }^{(a)}$} \\
\hline Soil & & $\begin{array}{c}\text { Damage Index } \\
\text { (DR Scale) }\end{array}$ & Symptomatology \\
\hline \multicolumn{4}{|l|}{ Bush Bean } \\
\hline \multirow{5}{*}{ Burbank } & 0 & 1.0 & O\&NGDH ${ }^{(b)}$ \\
\hline & 25 & 1.0 & O\&NGDH \\
\hline & 100 & 2.0 & O\&NGDH \\
\hline & 500 & 2.0 & NS, Chl \\
\hline & 2500 & 5.0 & NS, Chl, TB \\
\hline \multirow[t]{5}{*}{ Cinebar } & 0 & 1.0 & O\&NGDH \\
\hline & 25 & 1.0 & NS, Chl \\
\hline & 100 & 1.3 & $\mathrm{NS}, \mathrm{Chl}$ \\
\hline & 500 & 1.0 & $\mathrm{NS}, \mathrm{Chl}$ \\
\hline & 2500 & 6.0 & NS, Chl, Dwarfed Leaves \\
\hline \multirow[t]{5}{*}{ Palouse } & 0 & 1.0 & O\&NGDH \\
\hline & 25 & 1.3 & NS, Chl \\
\hline & 100 & 1.0 & NS, Chl \\
\hline & 500 & 1.3 & $\mathrm{NS}, \mathrm{Chl}$ \\
\hline & 2500 & 5.7 & $\mathrm{NS}, \mathrm{Chl}$ \\
\hline \multirow[t]{5}{*}{ Palouse $+O M^{(c)}$} & 0 & 1.0 & O\&NGDH \\
\hline & 25 & 1.0 & NS, Chl \\
\hline & 100 & 1.3 & $\mathrm{NS}, \mathrm{Chl}$ \\
\hline & 500 & 1.0 & $\mathrm{NS}, \mathrm{Chl}$ \\
\hline & 2500 & 6.0 & NS. Chl \\
\hline \multicolumn{4}{|l|}{ Tall Fescue } \\
\hline \multirow[t]{5}{*}{ Burbank } & 0 & 3.0 & NS, Chl, TB (7.0) ${ }^{(d)}$ \\
\hline & 25 & 3.0 & NS, Chl, TB (5.0) \\
\hline & 100 & 2.0 & NS, Chl, TB (4.5) \\
\hline & 500 & 6.0 & Chl, TB (3.0), Stunted \\
\hline & 2500 & 6.0 & Chl, TB (slight), Stunted \\
\hline \multirow[t]{5}{*}{ Cinebar } & 0 & 2.0 & NS, Chl, TB (6.0) \\
\hline & 25 & 2.0 & NS, Chl, TB (6.0) \\
\hline & 100 & 2.3 & NS, Chl, TB (6.0) \\
\hline & 500 & 2.7 & NS, Chl, TB (8.0) \\
\hline & 2500 & -0 & Chl, TB (4.0), Stunted \\
\hline
\end{tabular}


IABLE 3.32. (CONTD)

\begin{tabular}{|c|c|c|c|}
\hline \multirow{2}{*}{$\begin{array}{l}\text { Species/ } \\
\text { Soil }\end{array}$} & \multirow[b]{2}{*}{$\begin{array}{l}\text { Soil Concentration, } \\
\qquad(\mu g / g)\end{array}$} & \multicolumn{2}{|c|}{ Toxicity Response ${ }^{\text {(a) }}$} \\
\hline & & $\begin{array}{c}\text { Damage Index } \\
\text { (DR Scale) }\end{array}$ & Symptomology \\
\hline \multirow[t]{5}{*}{ Palouse } & 0 & 2.3 & NS, Chl, TB (8.0) \\
\hline & 25 & 2.0 & NS, Chl, TB (7.0) \\
\hline & 100 & 2.7 & NS, Chl, TB (7.0) \\
\hline & 500 & 2.0 & NS, Chl, TB (slight) \\
\hline & 2500 & 6.0 & $\mathrm{Chl}$, Stunted \\
\hline \multirow[t]{5}{*}{ Palouse+OM } & 0 & 2.7 & NS, Chl, TB (10.0) \\
\hline & 25 & 1.3 & NS, Chl, TB (9.0) \\
\hline & 100 & 2.0 & NS, Chl, TB (7.0) \\
\hline & 500 & 4.0 & NS, Chl, TB (slight) \\
\hline & 2500 & 6.0 & NS, Chl, Stunted \\
\hline
\end{tabular}

(a) Daubenmire scale and symptomatology definitions.

(b) New growth developing healthy.

(c) Soil with $0.22 \% \mathrm{w} / \mathrm{w}$ dried ground alfalfa.

(d) Average length, in cm, of tip burn. 
IABLE 3.33. PLANT SYMPTOMATOLOGY TO BRASS SOIL AMENDMENT. SYMPTOMATOLOGY DETERMINATIONS MADE 60 DAYS AFTER PLANTING (c) AND 470 DAYS AFTER AMENDMENT OF BRASS FLAKE TO THE VARIOUS SOILS AT 0, 25, 100, 500, AND $2500 \mathrm{ppm}$.

\begin{tabular}{|c|c|c|c|c|}
\hline \multirow[t]{2}{*}{ Species } & \multirow{2}{*}{ Soil } & \multirow[b]{2}{*}{$\begin{array}{l}\text { Soil Concentration } \\
\qquad(\mu \mathrm{g} / \mathrm{g})\end{array}$} & \multicolumn{2}{|c|}{ Toxicity Resoonse $^{(\text {a) }}$} \\
\hline & & & $\begin{array}{l}\text { Damage index } \\
\text { (DR Scale) }\end{array}$ & Symptomology \\
\hline \multicolumn{5}{|c|}{ Bush Bean } \\
\hline \multirow{5}{*}{\multicolumn{2}{|c|}{ Burbank }} & 0 & 2.0 & Chl, NS \\
\hline & & 25 & 2.0 & Chi, NS \\
\hline & & 100 & 2.0 & Chl, NS \\
\hline & & 500 & 5.0 & Chl, NS, Dwarfed \\
\hline & & 2500 & 6.0 & Chl, NS, W, Dwarfed \\
\hline \multirow{5}{*}{\multicolumn{2}{|c|}{ Cinebar }} & 0 & 1.0 & Chl, NS \\
\hline & & 25 & 1.0 & Chl, NS \\
\hline & & 100 & 1.0 & Chl, NS \\
\hline & & 500 & 2.7 & $\mathrm{Chl}, \mathrm{NS}$ \\
\hline & & 2500 & 6.0 & NS, Chl, LC, Dwarfed \\
\hline \multirow{5}{*}{\multicolumn{2}{|c|}{ Palouse }} & 0 & 1.0 & $\mathrm{Chl}$ \\
\hline & & 25 & 1.3 & $\mathrm{Chl}$ \\
\hline & & 100 & 1.0 & $\mathrm{Chl}$ \\
\hline & & 500 & 1.3 & $\mathrm{NS}, \mathrm{Chl}$ \\
\hline & & 2500 & 6.0 & NS, Chl, Dwarfed \\
\hline \multirow{5}{*}{\multicolumn{2}{|c|}{ Palouse + $O M^{(b)}$}} & 0 & 2.0 & Chl, NS \\
\hline & & 25 & 2.0 & Chl, NS \\
\hline & & 100 & 2.0 & Chl, NS \\
\hline & & 500 & 1.3 & LC, $\mathrm{Chl}$ \\
\hline & & 2500 & 6.0 & NS. Chl, Dwarfed \\
\hline \multicolumn{5}{|c|}{ Tall Fescue } \\
\hline \multirow{5}{*}{\multicolumn{2}{|c|}{ Burbank }} & 0 & 1.0 & NS, Chl \\
\hline & & 25 & 2.0 & NS,Chl \\
\hline & & 100 & 2.0 & NS, Chl \\
\hline & & 500 & 6.0 & NS, Chl, Stunted(c) \\
\hline & & 2500 & 6.0 & NS, Chl, Stunted \\
\hline \multirow{5}{*}{\multicolumn{2}{|c|}{ Cinebar }} & 0 & 2.3 & NS, Chl, TB $(11.0)^{(d)}$ \\
\hline & & 25 & 1.7 & NS, Chl, TB (11.0) \\
\hline & & 100 & 2.3 & NS, Chl, TB (16.0) \\
\hline & & 500 & 3.7 & NS, Chl, TB (19.0) \\
\hline & & 2500 & 6.0 & $\therefore 4$, Stunted \\
\hline
\end{tabular}


TABLE 3.33 (CONTD)

\begin{tabular}{|c|c|c|c|}
\hline \multirow{2}{*}{$\begin{array}{l}\text { Species/ } \\
\text { Soil }\end{array}$} & \multirow[b]{2}{*}{$\begin{array}{l}\text { Soil Concentration } \\
\qquad(\mu g / g)\end{array}$} & \multicolumn{2}{|c|}{ Toxicity Response ${ }^{(a)}$} \\
\hline & & $\begin{array}{l}\text { Damage Index } \\
\text { (DR Scale) }\end{array}$ & Symptomatology \\
\hline \multirow[t]{5}{*}{ Palouse } & 0 & 2.3 & NS, Chl, TB (6.0) \\
\hline & 25 & 2.3 & NS, Chl, TB (10.5) \\
\hline & 100 & 2.7 & NS, Chi, TB (6.0) \\
\hline & 500 & 3.7 & NS, Chl, TB (4.0) \\
\hline & 2500 & 6.0 & Chl, Stunted \\
\hline \multirow[t]{5}{*}{ Palouse+OM } & 0 & 2.0 & NS, Chl, TB (4.0) \\
\hline & 25 & 2.3 & NS, Chl, TB (8.0) \\
\hline & 100 & 2.7 & NS, Chl, TB (7.0) \\
\hline & 500 & 3.3 & NS, Chl, TB (5.0) \\
\hline & 2500 & 6.0 & NS, Chl, Stunted \\
\hline
\end{tabular}

(a) Daubenmire scale and symptomatology definitions.

(b) Soil with $0.22 \% \mathrm{w} / \mathrm{w}$ dried ground affalfa.

(c) Stunted growth for both shoot and roots.

(d) Average length, in cm, of tip burn.

Long-Term Effects of Brass Flake Soil Amendment On Dry-Matter Accumulation in Tall Fescue and Bush Bean. An interaction of brass with the different soil types, evident in the analysis of plant dry-weight data after 60 days of growth (first harvest), was observed over the entire weathering in both the bush bean (Table 3.34) and the tall fescue (Table 3.35). Since no regrowth effect was noted, data for the second harvests are not shown. All plants showed significant $(P \leq 0.01)$ reduction in growth at the highest concentrations $(2500 \mathrm{ppm})$, and plants did not exhibit any reproductive growth over the growing period. In the bush beans the largest reduction in growth (dry-matter accumulation) at higher brass concentrations was evident in those plants grown in the Burbank soil, while the least was seen in the plants grown in Cinebar (Table 3.35). No change in dry-matter production, as an indication of plant stress, is apparent when the 100-day pots are compared with the 450-day pots. 
IABLE 3.34. AVERAGE FINAL DRY WEIGHT (g) OF BUSH BEANS AND SEGMENTS GROWN IN SOILS AMENDED WITH BRASS FLAKE AT DIFFERENT CONCENTRATIONS. PLANTS WERE HARVESTED AT 470 DAYS AFTER SEEDING AND 160 DAYS POST-AMENDMENT.

\begin{tabular}{|c|c|c|c|c|c|c|}
\hline \multirow[b]{2}{*}{ Soil } & \multirow{2}{*}{$\begin{array}{c}\text { Brass Flake } \\
\text { Concentration } \\
(\mu g / g)\end{array}$} & \multicolumn{5}{|c|}{ Averace Plant Seament $D r y$ Wt $(0)+S D(n=3)$} \\
\hline & & Leaves & Stem & Pods & Seeds & Total \\
\hline \multirow[t]{5}{*}{ Burbank } & 0 & $1.78 \pm 0.19$ & $1.40 \pm 0.20$ & $1.42 \pm 0.36$ & $0.17 \pm 0.10$ & $4.77 \pm 0.57$ \\
\hline & 25 & $1.96 \pm 0.08$ & $1.64 \pm 0.17$ & $1.38 \pm 0.10$ & $0.07 \pm 0.02$ & $5.04 \pm 0.12^{(a)}$ \\
\hline & 100 & $1.92 \pm 0.13$ & $1.58 \pm 0.31$ & $1.55 \pm 0.09$ & $0.11 \pm 0.02$ & $5.16 \pm 0.49^{(a)}$ \\
\hline & 500 & $0.43 \pm 0.05$ & $0.50 \pm 0.04$ & $0.02 \pm 0.02$ & $0.00 \pm 0.00$ & $0.95 \pm 0.09^{(b)}$ \\
\hline & 2500 & $0.50 \pm 0.13$ & $0.38 \pm 0.08$ & $0.00 \pm 0.00$ & $0.00 \pm 0.00$ & $0.88 \pm 0.19^{(b)}$ \\
\hline \multirow[t]{5}{*}{ Cinebar } & 0 & $1.78 \pm 0.89$ & $1.14 \pm 0.60$ & $1.86 \pm 0.31$ & $0.36 \pm 0.13$ & $5.14 \pm 1.73$ \\
\hline & 25 & $1.77 \pm 0.55$ & $1.17 \pm 0.25$ & $2.41 \pm 0.22$ & $0.66 \pm 0.08$ & $6.01 \pm 0.68^{(a)}$ \\
\hline & 100 & $1.37 \pm 0.32$ & $1.15 \pm 0.21$ & $2.26 \pm 0.17$ & $0.62 \pm 0.29$ & $5.40 \pm 0.95^{(a)}$ \\
\hline & 500 & $1.37 \pm 0.04$ & $1.04 \pm 0.05$ & $1.75 \pm 0.34$ & $0.63 \pm 0.14$ & $4.79 \pm 0.20^{(a)}$ \\
\hline & 2500 & $0.47 \pm 0.06$ & $0.27 \pm 0.01$ & $0.00 \pm 0.00$ & $0.00 \pm 0.00$ & $0.74 \pm 0.07^{(c)}$ \\
\hline \multirow[t]{5}{*}{ Palouse } & 0 & $2.08 \pm 0.46$ & $1.49 \pm 0.25$ & $1.93 \pm 0.50$ & $0.32 \pm 0.12$ & $5.82 \pm 0.57$ \\
\hline & 25 & $1.52 \pm 0.13$ & $1.50 \pm 0.00$ & $2.36 \pm 0.50$ & $0.48 \pm 0.15$ & $5.14 \pm 0.15^{(a, d)}$ \\
\hline & 100 & $1.72 \pm 0.21$ & $1.40 \pm 0.22$ & $1.90 \pm 0.31$ & $0.48 \pm 0.13$ & $5.84 \pm 0.72^{(a)}$ \\
\hline & 500 & $0.91 \pm 0.28$ & $0.81 \pm 0.19$ & $1.11 \pm 0.40$ & $0.45 \pm 0.29$ & $3.28 \pm 1.11^{(c)}$ \\
\hline & 2500 & $0.23 \pm 0.14$ & $0.14 \pm 0.08$ & $0.00 \pm 0.00$ & $0.00 \pm 0.00$ & $0.38 \pm 0.22^{(c)}$ \\
\hline \multirow[t]{5}{*}{ Palous $\theta+O M^{(\theta)}$} & 0 & $1.55 \pm 0.55$ & $1.17 \pm 0.51$ & $1.74 \pm 0.42$ & $0.29 \pm 0.12$ & $4.75 \pm 1.21$ \\
\hline & 25 & $0.74 \pm 0.16$ & $0.65 \pm 0.09$ & $1.12 \pm 0.01$ & $0.17 \pm 0.03$ & $2.68 \pm 0.24^{(a)}$ \\
\hline & 100 & $1.19 \pm 0.09$ & $0.86 \pm 0.04$ & $1.51 \pm 0.11$ & $0.34 \pm 0.04$ & $3.89 \pm 0.02^{(a)}$ \\
\hline & 500 & $1.06 \pm 0.38$ & $0.90 \pm 0.37$ & $1.49 \pm 0.57$ & $0.30 \pm 0.18$ & $3.75 \pm 1.46^{(a)}$ \\
\hline & 2500 & $0.20 \pm 0.08$ & $0.14 \pm 0.02$ & $0.00 \pm 0.00$ & $0.00 \pm 0.00$ & $0.35 \pm 0.10^{(c)}$ \\
\hline
\end{tabular}
(a) Not Significant.
(b) Significant at 0.01 confidence level using a one-tailed t-test.
(c) Significant at 0.05 confidence level using a one-tailed t-test.
(d) Average of two pots; third plant died.
(e) Soil with $0.22 \% \mathrm{w} / \mathrm{w}$ dried ground alfalfa. 
IABLE 3.35. AVERAGE FINAL DRY WEIGHT (g) OF TALL FESCUE GROWN IN SOILS AMENDED WITH BRASS FLAKE AT DIFFERENT CONCENTRATIONS. PLANTS WERE HARVESTED AT 60 DAYS AFTER SEEDING AND 470 DAYS POST-AMENDMENT.

\begin{tabular}{|c|c|c|}
\hline Soil & $\begin{array}{c}\text { Brass Flake } \\
\text { Concentration } \\
(\mu g / g)\end{array}$ & $\begin{array}{c}\text { Average Dry-Matter Production } \\
\text { (dry weight, } g) \pm S D(n=3) \\
\text { First Harvest }\end{array}$ \\
\hline \multirow[t]{5}{*}{ Burbank } & 0 & $3.30 \pm 0.61$ \\
\hline & 25 & $3.29 \pm 0.06^{(c)}$ \\
\hline & 100 & $3.30 \pm 1.10^{(c)}$ \\
\hline & 500 & $0.11 \pm 0.02^{(\theta)}$ \\
\hline & 2500 & $0.05 \pm 0.01^{(\theta)}$ \\
\hline \multirow[t]{5}{*}{ Cinebar } & 0 & $3.07 \pm 0.39$ \\
\hline & 25 & $3.86 \pm 1.35(c)$ \\
\hline & 100 & $3.23 \pm 0.29(c)$ \\
\hline & 500 & $2.58 \pm 1.23^{(c)}$ \\
\hline & 2500 & $0.05 \pm 0.02^{(\theta)}$ \\
\hline \multirow[t]{5}{*}{ Palouse } & 0 & $2.01 \pm 0.30$ \\
\hline & 25 & $2.27 \pm 0.09(c)$ \\
\hline & 100 & $1.29 \pm 0.38^{(c)}$ \\
\hline & 500 & $0.42 \pm 0.29^{(\theta)}$ \\
\hline & 2500 & $0.02 \pm 0.00^{(\theta)}$ \\
\hline \multirow[t]{5}{*}{ Palouse+OM(b) } & 0 & $2.95 \pm 0.37$ \\
\hline & 25 & $1.61 \pm 1.03^{(c)}$ \\
\hline & 100 & $1.50 \pm 0.35^{(d)}$ \\
\hline & 500 & $0.73 \pm 0.32^{(d)}$ \\
\hline & 2500 & $0.02 \pm 0.01^{(\theta)}$ \\
\hline
\end{tabular}
(a) No growth.
(b) Soil with $0.22 \% \mathrm{w} / \mathrm{w}$ dried ground alfalfa.
(c) Not significant.
(d) Significant at 0.05 confidence level using a one-tailed t-test.
(e) Signiticant at 0.01 confidence level using a one-tailed t-test. 
The relationship between the CEC for the two soils, Burbank having the lowest $(6.0 \mathrm{meq} / 100 \mathrm{~g})$ and Cinebar the highest $(38.2 \mathrm{meq} / 100 \mathrm{~g})$, may again be an important factors in the results. The lower fertility of the Burbank may have contributed to the apparent toxicity by permitting a higher concentration of the $\mathrm{Cu}$ and $\mathrm{Zn}$ in the root zone. The overall dry-matter accumulation by the plants also corresponds to the soil CEC, with Cinebar > Palouse+OM $\geq$ Palouse > Burbank.

Similar soil-type-related effects were observed for dry-matter production in the tall fescue (Table 3.35), with Cinebar > Palouse+OM $\geq$ Palouse > Burbank, particularly in the first harvest, at 60 days after seeding. Severe growth reductions were seen at soil brass concentrations of $500 \mu \mathrm{g} / \mathrm{g}$ and greater. By the second harvest (120 days, data not shown), the differences were not as evident at the lower concentration but apparently were greater at the higher concentration ( $\geq 500 \mathrm{ppm})$. The plants grown in the other soils at the time of the second harvest were better established and more mature, and may therefore have been either slightly less sensitive to the $\mathrm{Zn}$ and $\mathrm{Cu}$ in the soil, or may have already reduced the previously available free amounts of the ions in the pots to more acceptable levels.

Long-Term Effects of Brass Flake Soil Amendment on Lonic Composition in Tall Fescue and Bush Bean. After $\mathbf{4 4 0}$ days of soil weathering, the ionic composition of tall fescue planted in brass-amended soil (Table 3.36) varied only slightly from that of the first planting at 150 days (data not shown). In the third planting the order of highest tissue accumulation for both $\mathrm{Cu}$ and $\mathrm{Zn}$ was Cinebar < Burbank < Palouse = Palouse+OM). Concentrations of $\mathrm{Cu}$ and $\mathrm{Zn}$ in individual plant tissues increased with increasing soil brass concentration. Tissue concentrations of $\mathrm{Cu}$ increased from $10 \mu \mathrm{g} / \mathrm{g}$ in the controls to as much as $500 \mu \mathrm{g} / \mathrm{g}$ in Palouse-amended soil. Levels of tissue $\mathrm{Zn}$ increased from $50 \mu \mathrm{g} / \mathrm{g}$ in control soils to a high of $6000 \mu \mathrm{g} / \mathrm{g}$ in Palouse-amended soil. It is clear from the data that the brass flake is weathering and providing increased levels of plant-available $\mathrm{Cu}$ and $\mathrm{Zn}$; however, it is also clear that soil-sorption processes are mediating the available ions.

Significant variations in the tissue concentration of other nutrient ions were observed when plants were grown in the presence of brass (Table 3.37). Analysis of tissues by ICAP clearly showed that tissue levels of $\mathrm{Mg}, \mathrm{Mn}, \mathrm{P}$, and Fe are altered by the presence of brass. Tissue concentrations of $\mathrm{Mg}$ and $\mathrm{Mn}$ increase by a factor of 2 to 3 and levels of Fe by a factor of 7 to 100 , while total $P$ levels decrease 2 to 3 . This disruption in ion homeostasis could account for the observed phytotoxicity. The disruption likely results from the imbalance of $\mathrm{Cu}$ and/or $\mathrm{Zn}$ caused by brass weathering. 
No significant differences in specific-tissue concentrations of $\mathrm{Cu}$ and $\mathrm{Zn}$ between bush beans grown in soil weathered 100 days (data not shown) or 400 days were apparent (Table 3.38). Total plant-uptake patterns for $\mathrm{Zn}$ were Burbank < Cinebar $\leq$ Palouse = Palouse+OM at the highest concentrations $(2500 \mathrm{ppm})$, while for $\mathrm{Cu}$, tissue accumulation patterns were Cinebar $\leq$ Palouse $=$ Palouse $+O M \leq$ Burbank, which was different from that seen in the tall fescue (e.g., Table 3.36). Concentration of $\mathrm{Zn}$ and $\mathrm{Cu}$ in individual plant tissues increased with increasing soil brass concentration. These increases were more pronounced for $\mathrm{Zn}$ than for $\mathrm{Cu}$. The highest tissue levels were seen in stem tissue, followed by leaves. Pod and seed concentrations of $\mathrm{Zn}$ and $\mathrm{Cu}$ were relatively constant at soil brass concentrations of $100 \mu \mathrm{g} / \mathrm{g}$; however, little reproductive growth was seen in the 500 to $2500 \mu \mathrm{g} / \mathrm{g}$ treatments. In bush bean, there did not seem to be the significant interaction of $\mathrm{Zn}$ and/or $\mathrm{Cu}$ with other nutrient ions, as was observed with the grass (Table 3.37). The levels of $\mathrm{Fe}, \mathrm{Mg}, \mathrm{Mn}$, and $\mathrm{P}$ in the leaves and stems of the beans did not vary significantly over the exposure concentrations, perhaps reflecting differences in monocot (grass) and dicot (bean) growth patterns or nutrient harvesting. 
IABLE 3.36. AVERAGE TISSUE CONCENTRATIONS OF CU AND Zn IN TALL FESCUE GROWN IN SOILS AMENDED WITH BRASS FLAKE AT DIFFERENT CONCENTRATIONS. PLANTS WERE HARVESTED AT 60 DAYS AFTER SEEDING AND 470 DAYS POST-AMENDMENT.

\begin{tabular}{|c|c|c|c|}
\hline Soil & $\begin{array}{c}\text { Brass Flake } \\
\text { Concentration } \\
(\mu g / g)\end{array}$ & $\frac{\text { Average Tissue }}{\mathrm{Cu}}$ & $\frac{d x(x)+S D(n=3)}{Z n}$ \\
\hline \multirow[t]{5}{*}{ Burbank } & 0 & $11.76 \pm 0.72$ & $59.93 \pm 1.84$ \\
\hline & 25 & $14.08 \pm 4.31$ & $77.72 \pm 15.41$ \\
\hline & 100 & $29.23 \pm 3.43$ & $153.92 \pm 22.59$ \\
\hline & 500 & $266.68 \pm 8.39$ & $1212.40 \pm 102.91$ \\
\hline & 2500 & $261.36 \pm 82.37$ & $1864.13 \pm 211.14$ \\
\hline \multirow[t]{5}{*}{ Cinebar } & 0 & $6.78 \pm 1.61$ & $56.84 \pm 14.91$ \\
\hline & 25 & $8.35 \pm 2.49$ & $55.77 \pm 17.71$ \\
\hline & 100 & $12.08 \pm 1.07$ & $75.91 \pm 4.67$ \\
\hline & 500 & $28.48 \pm 4.53$ & $257.13 \pm 26.72$ \\
\hline & 2500 & $34.11 \pm 2.56$ & $886.49 \pm 189.90$ \\
\hline \multirow[t]{5}{*}{ Palouse } & 0 & $9.26 \pm 0.56$ & $47.81 \pm 5.39$ \\
\hline & 25 & $10.91 \pm 0.88$ & $49.52 \pm 8.43$ \\
\hline & 100 & $16.04 \pm 3.94$ & $81.75 \pm 20.81$ \\
\hline & 500 & $38.54 \pm 6.69$ & $531.66 \pm 122.33$ \\
\hline & 2500 & $537.94 \pm 209.19$ & $5828.45 \pm 1123.82$ \\
\hline \multirow[t]{5}{*}{ Palouse+OM(a) } & 0 & $7.86 \pm 0.16$ & $38.62 \pm 0.68$ \\
\hline & 25 & $11.36 \pm 3.16$ & $53.18 \pm 14.44$ \\
\hline & 100 & $19.51 \pm 1.39$ & $92.08 \pm 11.69$ \\
\hline & 500 & $45.51 \pm 18.30$ & $551.12 \pm 59.12$ \\
\hline & 2500 & $337.13 \pm 285.77$ & $5974.97 \pm 4694.80$ \\
\hline
\end{tabular}

(a) Soil with $0.22 \% \mathrm{w} / \mathrm{w}$ dried ground alfalfa. 
IABLE 3.37. AVERAGE TISSUE CONCENTRATION OF Mg, Mn, P, AND Fe IN TALL FESCUE GROWN IN SOILS AMENDED WITH BRASS FLAKE AT DIFFERENT

CONCENTRATIONS AS DETERMINED THROUGH ICAP ANALYSIS. PLANTS WERE HARVESTED AT 60 DAYS AFTER SEEDING AND 470 DAYS POSTAMENDMENT.

\begin{tabular}{|c|c|c|c|c|c|}
\hline \multirow[b]{2}{*}{ Soil } & \multirow{2}{*}{$\begin{array}{c}\text { Brass Flake } \\
\text { Concentration } \\
(\mu g / g)\end{array}$} & \multicolumn{4}{|c|}{ Element Concentration (uogacty wh) } \\
\hline & & $\mathrm{Mg}$ & $\mathrm{Mn}$ & $P$ & $\mathrm{Fe}$ \\
\hline \multirow[t]{2}{*}{ Burbank } & 0 & $2323.93 \pm 268.08$ & $93.09 \pm 24.84$ & $4739.41 \pm 166.68$ & $6.31 \pm 1.11$ \\
\hline & $2500^{(a)}$ & $7092.05 \pm 106.61$ & $138.54 \pm 14.80$ & $1350.62 \pm 775.71$ & $95.12 \pm 19.52$ \\
\hline Cinebar & $\begin{array}{r}0 \\
2500\end{array}$ & $\begin{array}{l}2310.95 \pm 455.64 \\
5447.14 \pm 530.70\end{array}$ & $\begin{array}{l}168.04 \pm 18.77 \\
536.04 \pm 148.68\end{array}$ & $\begin{array}{l}2130.58 \pm 234.64 \\
1543.56 \pm 384.39\end{array}$ & $\begin{array}{c}1.45 \pm 0.36 \\
138.96 \pm 97.31\end{array}$ \\
\hline Palouse & $\begin{array}{r}0 \\
2500\end{array}$ & $\begin{array}{l}2360.73 \pm 360.28 \\
9032.77 \pm 520.24\end{array}$ & $\begin{array}{l}106.06 \pm 3.78 \\
183.98 \pm 50.41\end{array}$ & $\begin{array}{l}4141.59 \pm 653.11 \\
2626.86 \pm 500.82\end{array}$ & $\begin{array}{c}6.78 \pm 3.28 \\
58.36 \pm 35.49\end{array}$ \\
\hline Palouse+OM ${ }^{(b}$ & b) $\begin{array}{r}0 \\
2500\end{array}$ & $\begin{array}{c}2307.96 \pm 367.60 \\
10561.48 \pm 1598.07\end{array}$ & $\begin{array}{l}137.53 \pm 18.88 \\
234.67 \pm 60.94\end{array}$ & $\begin{array}{l}3931.73 \pm 172.57 \\
1835.86 \pm 797.10\end{array}$ & $\begin{array}{c}7.30 \pm 1.84 \\
49.85 \pm 22.26\end{array}$ \\
\hline
\end{tabular}

\footnotetext{
(a) Average of two pots, third plant died.

(b) Soil with $0.22 \% \mathrm{w} / \mathrm{w}$ dried ground affalfa.
} 
IABLE 3.38. AVERAGE TISSUE CONCENTRATIONS OF CU AND Zn IN BUSH BEANS GROWN IN SOILS AMENDED WITH BRASS FLAKE AT DIFFERENT CONCENTRATIONS AS DETERMINED THROUGH ICAP ANALYSIS. PLANTS WERE HARVESTED AT 60 DAYS AFTER SEEDING AND 470 DAYS POST-AMENDMENT.

\begin{tabular}{|c|c|c|c|c|c|}
\hline \multirow[b]{2}{*}{ Soil } & \multirow{2}{*}{$\begin{array}{l}\text { Brass Flake } \\
\text { Concentration } \\
(\mu g / g)\end{array}$} & \multicolumn{4}{|c|}{ Average Tissue Concentration (uo/a dry $w t)+S D(n=3)$} \\
\hline & & Leaves & Stem & Pods & Seeds \\
\hline \multirow[t]{5}{*}{ Burbank } & 0 & $4.11 \pm 0.39$ & $4.02 \pm 0.24$ & $5.97 \pm 2.11$ & $7.01 \pm 4.95$ \\
\hline & 100 & $10.99 \pm 3.17$ & $12.50 \pm 0.77$ & $9.97 \pm 1.78$ & $14.60 \pm 2.18$ \\
\hline & 500 & $19.19 \pm 2.89$ & $19.35 \pm 3.73$ & $20.52 \pm 9.63$ & - \\
\hline & 2500 & $47.32 \pm 29.64$ & $42.84 \pm 28.54$ & - & - \\
\hline & & & $\cdot$ & & \\
\hline \multirow[t]{4}{*}{ Cinebar } & 0 & $4.64 \pm 2.04$ & $6.51 \pm 5.10$ & $3.87 \pm 0.41$ & $6.97 \pm 1.09$ \\
\hline & 100 & $4.44 \pm 1.03$ & $6.20 \pm 2.03$ & $4.01 \pm 0.05$ & $6.22 \pm 0.12$ \\
\hline & 500 & $7.58 \pm 0.43$ & $8.85 \pm 2.00$ & $5.36 \pm 0.26$ & $8.10 \pm 0.53$ \\
\hline & 2500 & $12.94 \pm 1.74$ & $33.84 \pm 6.40$ & - & - \\
\hline \multirow[t]{4}{*}{ Palouse } & 0 & $2.21 \pm 0.63$ & $4.16 \pm 0.23$ & $4.51 \pm 0.77$ & $6.56 \pm 4.03$ \\
\hline & 100 & $3.66 \pm 0.87$ & $6.42 \pm 0.56$ & $4.89 \pm 0.59$ & $8.75 \pm 1.92$ \\
\hline & 500 & $15.95 \pm 1.59$ & $17.30 \pm 4.88$ & $8.89 \pm 1.79$ & $11.13 \pm 3.24$ \\
\hline & 2500 & $23.91 \pm 9.58$ & $102.26 \pm 40.35$ & - & - \\
\hline & 0 & $3.21 \pm 0.68$ & $4.07 \pm 0.38$ & $5.10 \pm 1.13$ & $6.94 \pm 1.80$ \\
\hline \multirow[t]{3}{*}{$+O M^{(b)}$} & 100 & $4.36 \pm 0.75$ & $6.05 \pm 0.86$ & $4.49 \pm 0.33$ & $6.57 \pm 3.78$ \\
\hline & 500 & $11.74 \pm 1.74$ & $15.79 \pm 5.28$ & $8.03 \pm 2.16$ & $12.54 \pm 5.43$ \\
\hline & 2500 & $18.59 \pm 5.05$ & $31.70 \pm 11.51$ & - & - \\
\hline \multirow[t]{4}{*}{ Burbank } & 0 & $54.10 \pm 2.62$ & $25.72 \pm 1.42$ & $26.46 \pm 10.38$ & $57.27 \pm 40.14$ \\
\hline & 100 & $58.42 \pm 14.52$ & $52.80 \pm 2.19$ & $31.05 \pm 0.27$ & $104.36 \pm 9.75$ \\
\hline & 500 & $176.54 \pm 14.87$ & $198.69 \pm 38.34$ & $115.36 \pm 22.65$ & - \\
\hline & 2500 & $209.34 \pm 41.05$ & $231.20 \pm 49.35$ & - & - \\
\hline \multirow[t]{4}{*}{ Cinebar } & 0 & $36.84 \pm 8.20$ & $37.17 \pm 9.98$ & $20.58 \pm 1.24$ & $59.95 \pm 7.26$ \\
\hline & 100 & $46.33 \pm 11.26$ & $45.20 \pm 6.27$ & $20.37 \pm 2.06$ & $52.49 \pm 5.93$ \\
\hline & 500 & $180.26 \pm 8.58$ & $171.33 \pm 29.61$ & $27.63 \pm 1.60$ & $61.84 \pm 3.14$ \\
\hline & 2500 & $301.45 \pm 56.47$ & $892.24 \pm 129.36$ & - & - \\
\hline \multirow[t]{4}{*}{ Palouse } & 0 & $31.42 \pm 10.14$ & $37.19 \pm 5.91$ & $20.32 \pm 3.36$ & $84.39 \pm 26.64$ \\
\hline & 100 & $43.68 \pm 2.44$ & $65.15 \pm 7.28$ & $20.35 \pm 1.83$ & $77.80 \pm 16.45$ \\
\hline & 500 & $232.00 \pm 36.63$ & $254.18 \pm 34.19$ & $37.12 \pm 4.98$ & $67.46 \pm 0.55$ \\
\hline & 2500 & $861.42 \pm 269.56$ & $4139.50 \pm 1990.50$ & - & - \\
\hline \multirow{4}{*}{$\begin{array}{l}\text { Palouse } \\
+\mathrm{OM}^{(\mathrm{b})}\end{array}$} & 0 & $41.91 \pm 5.18$ & $34.01 \pm 8.71$ & $22.84 \pm 0.88$ & $71.67 \pm 17.20$ \\
\hline & 100 & $49.05 \pm 3.76$ & $61.28 \pm 7.78$ & $21.29 \pm 1.06$ & $49.64 \pm 20.88$ \\
\hline & 500 & $239.46 \pm 56.25$ & $261.79 \pm 108.8$ & $38.46 \pm 16.47$ & $77.43 \pm 12.28$ \\
\hline & 2500 & $678.71 \pm 404.95$ & $2429.08 \pm 1115.33$ & - & - \\
\hline
\end{tabular}

\footnotetext{
(a) Average of two pots; third plant died.

(b) Soil with $0.22 \% \mathrm{w} / \mathrm{w}$ dried ground alfalfa.
} 


\subsection{SOIL MICBOBIALEFFECTS OF BRASS FLAKE}

\subsubsection{Soil Dehydrogenase Activity}

Soil dehydrogenase activity, a measure of the general activity of the soil microbial population, is an index of endogenous soil microbial activity (Moore and Russell, 1972). Dehydrogenase enzymes are intracellular and are involved in microbial respiratory processes necessary for the breakdown of organic compounds in soil. Soil microbial activity can alter nutrient cycling, influence plant growth, and affect the ability of a soil to decompose organic matter and detoxify xenobiotics.

PotAmendments. Soil dehydrogenase activities were severely impacted by brass flake (Figure 3.8). Five days after brass flake had been amended at $25 \mu \mathrm{g} / \mathrm{g}$, the lowest amendment level, soil dehydrogenase activity declined to 35 to $75 \%$ of the control in the four soils. Inhibition of soil dehydrogenase activity increased with increasing brass-flake concentrations. At $2,500 \mu \mathrm{g} / \mathrm{g}$, the highest amendment level, soil dehydrogenase activity was extremely low, 1 to $4 \%$ of the control for all soils. Burbank soil amended with brass at 100 to $2500 \mu \mathrm{g} / \mathrm{g}$ remained inhibited ( 19 to $25 \%$ ) 420 days later, while this soil amended with $25 \mu \mathrm{g} / \mathrm{g}$ was able to recover to $70 \%$ of control level. In Palouse soil, with or without the organic matter addition, 500 and $2500 \mu \mathrm{g} / \mathrm{g}$ brass amendment reduced dehydrogenase activity to 0 to $4 \%$, while the other two lower concentrations ( 25 and $100 \mu \mathrm{g} / \mathrm{g}$ ) exerted less inhibition, 56 to $67 \%$. Soil dehydrogenase activity in Cinebar soil with 25,100 , or $500 \mu \mathrm{g} / \mathrm{g}$ brass amendment was able to recover to 65 to $71 \%$ of the control after 420 days, but soil dehydrogenase activity remained severely depressed at $2500 \mu \mathrm{g} / \mathrm{g}$. All values noted for dehydrogenase activity were significantly different from controls based on t-test $(p \leq 0.05)$.

We calculated the ecological dose (Babich et al. 1983) of brass flake causing $50 \%$ inhibition $\left(\mathrm{ECD}_{50}\right)$ of soil dehydrogenase activity at the various days of incubation. This calculation was based on the equations of best fit obtained from the dose-response curve, as illustrated in Figure 3.9. The $\mathrm{ECD}_{50}$ for soil dehydrogenase activity at all assay times are presented in Figure 3.10 and Table 3.39. The low $\mathrm{ECD}_{50}$ value for dehydrogenase activity in Burbank soil indicates that this soil is very susceptible to brass flake exposure and has limited recovery. In contrast, Cinebar soil, although it was initially impacted, was capable of recovering with a much higher $E \mathrm{CD}_{50}$ value. Palouse soil, with or with organic matter, had an intermediate $\mathrm{ECD}_{50}$ value, and the soil recovered over time, but to a lesser extent than Cinebar soil. The impact of brass flake on dehydrogenase activity for the soils is Burbank > Palouse+OM $\geq$ Palouse > Cinebar based on their 420 -day $E c D_{50}$ values of $24,113,189$, and $1082 \mu \mathrm{g} / \mathrm{g}$, respectively. 

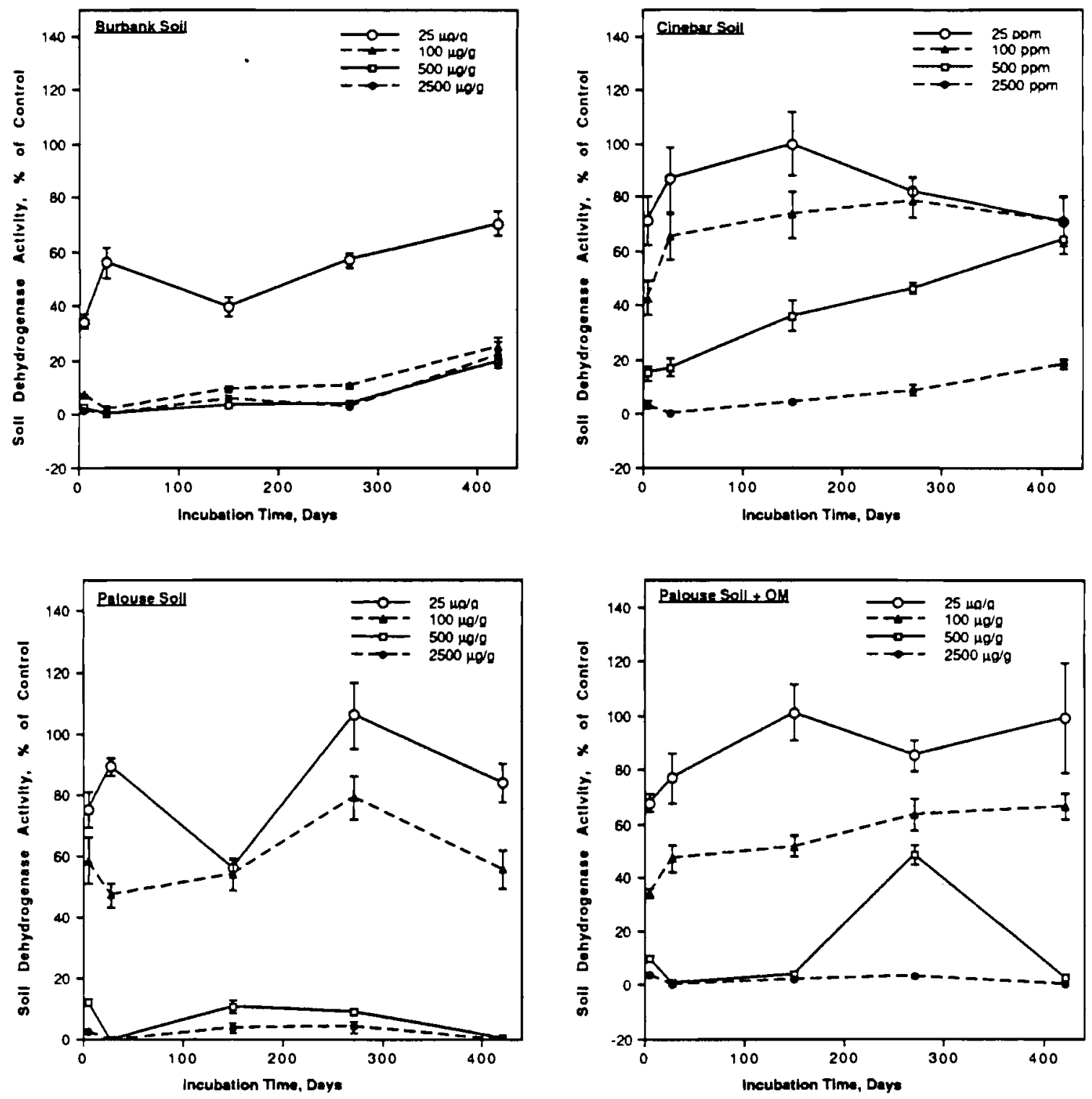

EIGURE 3.8. THE EFFECT OF BRASS-FLAKE CONCENTRATION ON SOIL DEHYDROGENASE ACTIVITY 


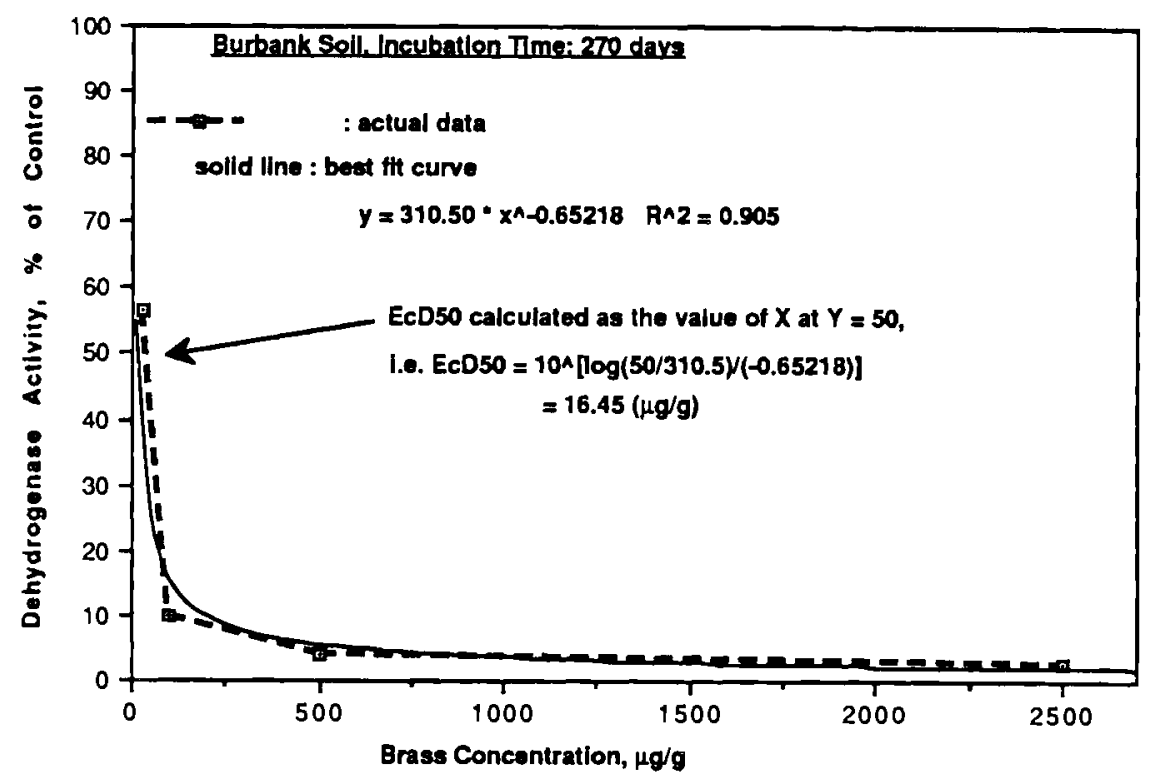

FIGURE 3.9. AN EXAMPLE CALCULATION OF THE ECOLOGICAL DOSE OF BRASS FLAKE CAUSING $50 \%$ INHIBITION $\left(\mathrm{ECD}_{50}\right)$ OF MICROBIAL ACTIVITY

The inhibition of soil microbial activity likely is due to the soluble $\mathrm{Cu}$ and $\mathrm{Zn}$ in the brass. The lower CEC of the Burbank might explain the higher inhibition of dehydrogenase activity in this soil.

Aerosol Deposition to Soils. Exposure to the mixed smoke of brass flake/fog oil (BR/FO) at $4.5 \mathrm{~m} / \mathrm{s}$ initially reduced the dehydrogenase activity in all of the four soils to 3 to $8 \%$ of control level, and activity remained reduced 28 days later (Figure 3.11 and Table 3.40). Twenty-eight days after the exposure BR/FO exposed to soils at the lower wind speed ( 0.9 $\mathrm{m} / \mathrm{s}$ ) caused a more severe impact to Burbank soil (6\%) than to the other three soils (44 to $53 \%$ ). All values noted for dehydrogenase activity were significantly different from controls based on t-test $(p \leq 0.05)$. 


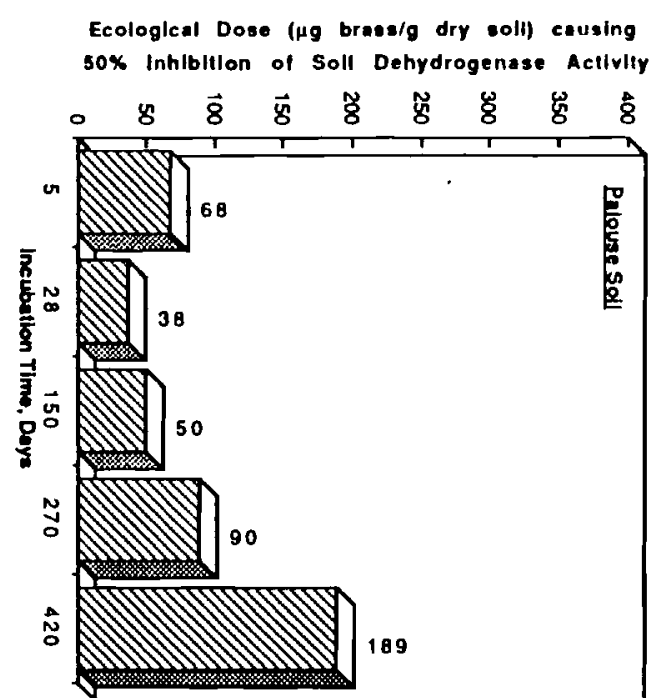

Ecologieal Dose ( $\mu$ g brass/g dry soll) causing sox Inhibition of Soll Dehydrogenese Activity

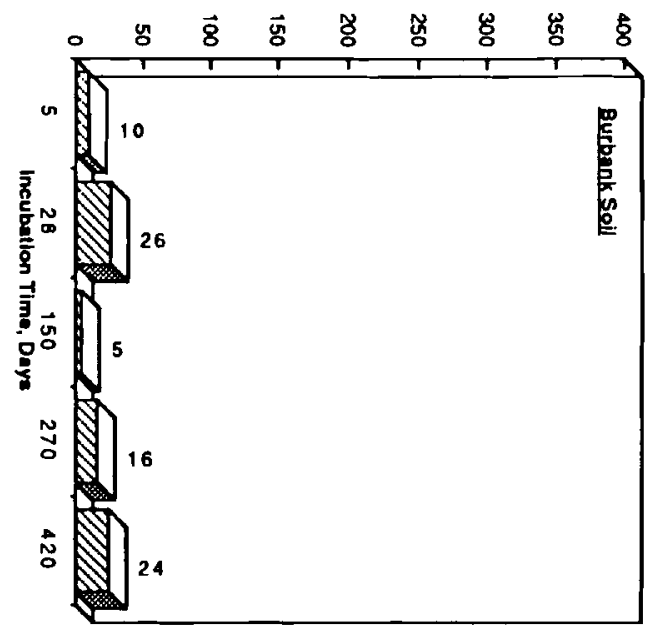

Ecologlcal Dose (ug brase/g dry soll) caueing 50x Inhiblition of Soll Dehydrogenaee Activity

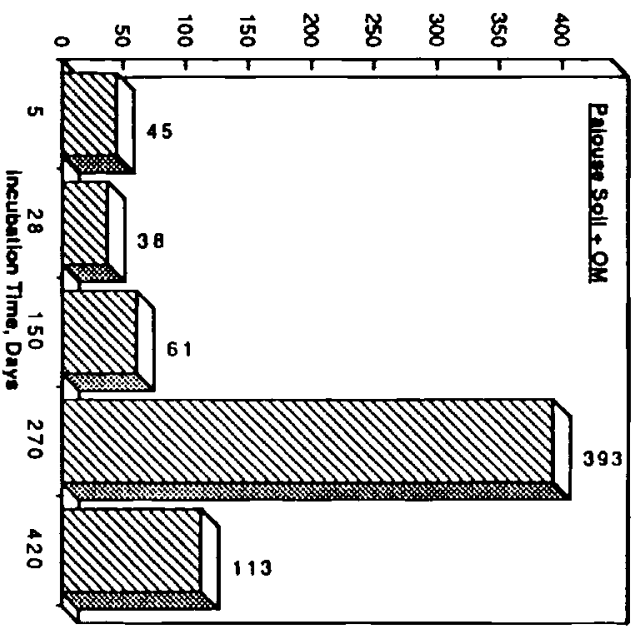

Ecologlcal Dose ( $\mu$ g brese/g dry soll) caueing sox Inhibition of Soll Dehydrogenaes Acllvity

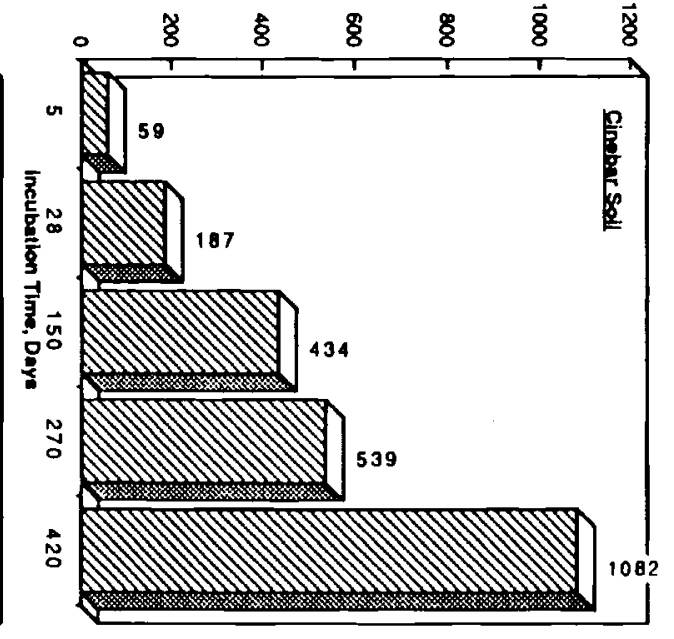


IABLE 3.39. BRASS ECD 50 VALUES FOR MICROBIAL PARAMETERS

\begin{tabular}{|c|c|c|c|c|c|c|c|c|c|}
\hline \multirow{3}{*}{$\begin{array}{l}\text { Microbial } \\
\text { Parameter }\end{array}$} & \multicolumn{9}{|c|}{ EcD50 ( $\mu$ g brass $/ g$ dry soil) $(\mathrm{a})$} \\
\hline & $\begin{array}{l}\text { Post-Exposure } \\
\text { Time (days) }\end{array}$ & \multicolumn{2}{|c|}{ Burbank } & \multicolumn{2}{|c|}{ Cinebar } & \multicolumn{2}{|c|}{ Palouse } & \multicolumn{2}{|c|}{ Palouse+OM } \\
\hline & 5 & 10 & $(0.96)$ & 59 & $(0.97)$ & 68 & $(0.95)$ & 45 & $(1.00)$ \\
\hline Dehydrogenase & 28 & 26 & $(0.87)$ & 187 & (0.99) & 38 & $(0.83)$ & 38 & (0.99) \\
\hline \multirow[t]{2}{*}{ Activity } & 150 & 5 & $(0.67)$ & 434 & (0.98) & 50 & $(0.92)$ & 61 & $(0.92)$ \\
\hline & $\begin{array}{l}270 \\
420\end{array}$ & $\begin{array}{l}16 \\
24\end{array}$ & $\begin{array}{l}(0.91) \\
(0.63)\end{array}$ & $\begin{array}{r}539 \\
1082\end{array}$ & $\begin{array}{l}(1.00) \\
(1.00)\end{array}$ & $\begin{array}{r}90 \\
189\end{array}$ & $\begin{array}{l}(0.93) \\
(0.96)\end{array}$ & $\begin{array}{l}393 \\
113\end{array}$ & $\begin{array}{l}(1.00) \\
(1.00)\end{array}$ \\
\hline Soil & 4 & 662 & $(0.97)$ & 2106 & $(1.00)$ & 673 & $(0.97)$ & 1610 & $(0.99)$ \\
\hline Phosphatase & 28 & 105 & (0.98) & 2103 & $(0.99)$ & 1275 & $(1.00)$ & 1947 & $(0.98)$ \\
\hline Activity & $\begin{array}{l}150 \\
270 \\
420\end{array}$ & $\begin{array}{r}485 \\
53 \\
129\end{array}$ & $\begin{array}{l}(0.73) \\
(0.99) \\
(0.92)\end{array}$ & $\begin{array}{l}1729 \\
2046 \\
2093\end{array}$ & $\begin{array}{l}(0.98) \\
(0.96) \\
(0.98)\end{array}$ & $\begin{array}{l}1715 \\
1901 \\
1284\end{array}$ & $\begin{array}{l}(0.98) \\
(0.94) \\
(1.00)\end{array}$ & $\begin{array}{l}1024 \\
1627 \\
1233\end{array}$ & $\begin{array}{l}(1.00) \\
(0.99) \\
(0.98)\end{array}$ \\
\hline Soil & 7 & 375 & $(0.81)$ & 1468 & $(1.00)$ & 3166 & $(1.00)$ & 2442 & $(1.00)$ \\
\hline ATP - Biomass & 28 & 125 & $(0.96)$ & 2907 & $(1.00)$ & 1948 & $(0.93)$ & 3048 & $(0.87)$ \\
\hline Level & $\begin{array}{l}150 \\
270 \\
420\end{array}$ & $\begin{array}{l}500 \\
304 \\
304\end{array}$ & $\begin{array}{l}(0.81) \\
(0.91) \\
(0.99)\end{array}$ & $\begin{array}{l}5204 \\
2474 \\
2515\end{array}$ & $\begin{array}{l}(0.96) \\
(1.00) \\
(0.99)\end{array}$ & $\begin{array}{r}1087 \\
568 \\
1451\end{array}$ & $\begin{array}{l}(0.95) \\
(0.99) \\
(0.97)\end{array}$ & $\begin{array}{l}1865 \\
1515 \\
1335\end{array}$ & $\begin{array}{l}(0.98) \\
(0.99) \\
(0.97)\end{array}$ \\
\hline
\end{tabular}

(a) $\mathrm{EcD}_{50}$, the ecological concentration of brass flake causing $50 \%$ inhibition of microbial parameter, was calculated from the curve that best fit the data. Numbers in parenthesis denotes $\mathrm{r}$, the coefficient of determination for the best fit curve used in the $\mathrm{EcD}_{50}$ calculation.

The concentration of brass in the BR/FO mixed-smoke exposure was estimated to be 800 and $4,000 \mu \mathrm{g} / \mathrm{g}$ for the $0.9 \mathrm{~m} / \mathrm{s}$ and the $4.5 \mathrm{~m} / \mathrm{s}$ exposures, respectively, based on the soilcoupon and filter-membrane deposition data. The anticipated effect at $800 \mu \mathrm{g} / \mathrm{g}$ brass concentration, which can be calculated from the equation of best fit for the dose-response curves for soil dehydrogenase activity (Table 3.41), is presented in Table 3.42. These results indicate that the impact of BR/FO exposure on soil dehydrogenase activity is less than that from brass alone, suggesting a beneficial synergistic effect of fog oil in the BR/FO mixedsmoke exposure. Fog-oil exposure has been shown to stimulate soil dehydrogenase activity (Cataldo et al. 1989). This stimulation may offset the detrimental effect of the brass. We do not know how long this beneficial synergism would last, because our incubations stopped at 28 days. 

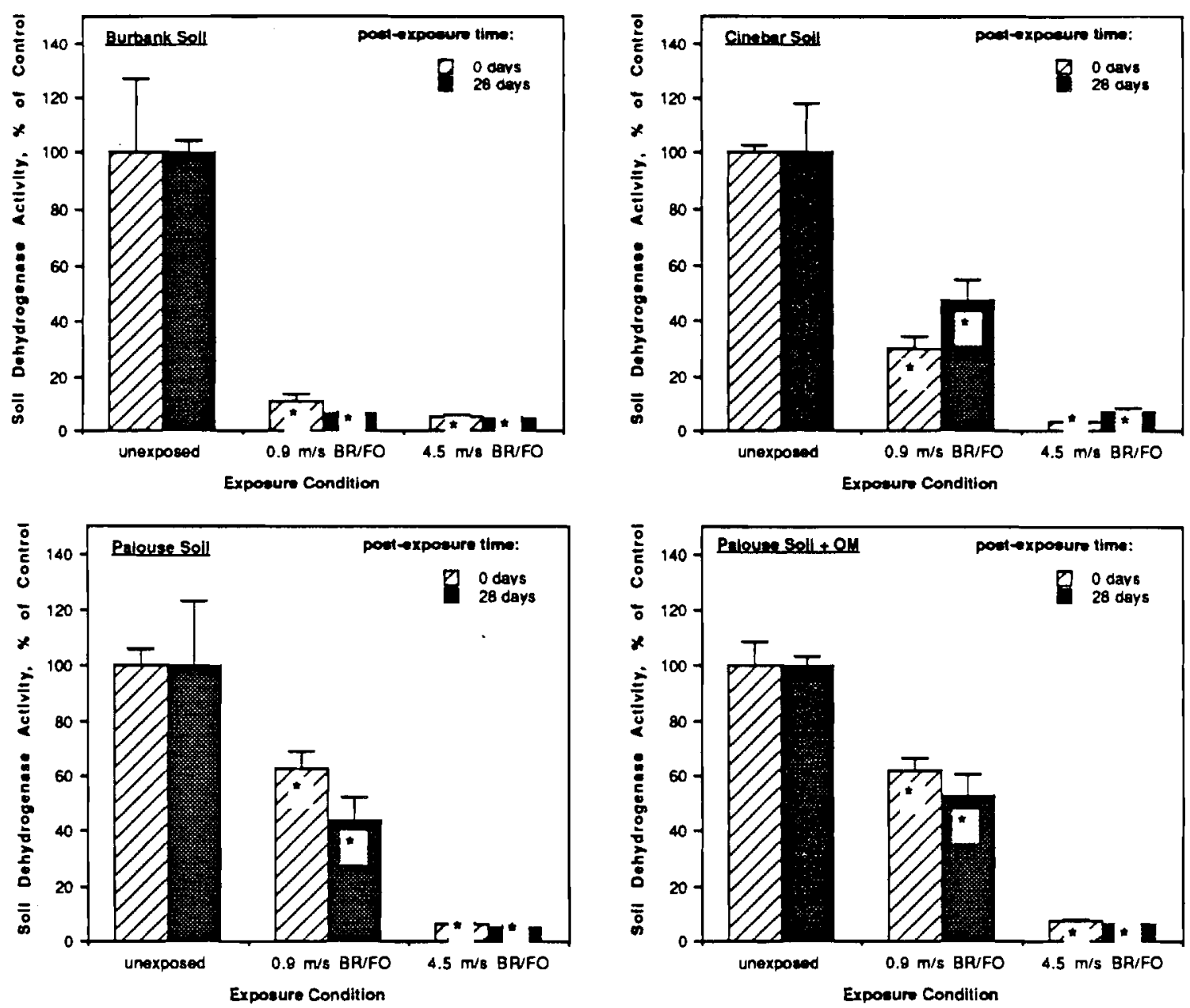

EIGURE 3.11. THE EFFECT OF BRASS FLAKE/FOG OIL MIXED SMOKE ON SOIL DEHYDROGENASE ACTIVITY 
IABLE 3.40. THE EFFECT OF BRASS FLAKE/FOG OIL MIXED SMOKE ON SOIL DEHYDROGENASE ACTIVITY

\begin{tabular}{|c|c|c|c|c|c|}
\hline \multirow[b]{2}{*}{$\begin{array}{l}\text { Exposure } \\
\text { Condition }\end{array}$} & \multirow[b]{2}{*}{$\begin{array}{r}\text { Post-Exposure } \\
\text { Time (days) }\end{array}$} & \multicolumn{4}{|c|}{ Dehydrogenase Activity (\% of Control) ${ }^{(a)}$} \\
\hline & & Burbank & Cinebar & Palouse & Palouse+OM \\
\hline \multicolumn{2}{|l|}{ unexposedo } & $100.00(27.19)$ & $100.00(3.01)$ & $100.00(6.03)$ & $100.00(8.68)$ \\
\hline \multicolumn{2}{|l|}{$0.9 \mathrm{~m} / \mathrm{s}$ BR $\mathrm{FO}$} & $10.81(2.55)^{\star(b)}$ & $30.22(4.25)^{*}$ & $62.47(6.74)^{*}$ & $62.21(4.10)^{*}$ \\
\hline $4.5 \mathrm{~m} / \mathrm{s}$ BR/FO & 0 & $4.92(1.13)^{*}$ & $3.02(0.39)^{*}$ & $6.18(0.79)^{*}$ & $7.55(0.73)^{*}$ \\
\hline unexposed & 28 & $100.00(4.72)$ & $100.00(18.38)$ & $100.00(23.45)$ & $100.00(3.61)$ \\
\hline $0.9 \mathrm{~m} / \mathrm{s}$ BR/FO & 28 & $6.25(0.56)^{*}$ & $47.68(7.21)^{*}$ & $44.32(7.93)^{*}$ & $52.72(8.23)^{*}$ \\
\hline $4.5 \mathrm{~m} / \mathrm{s}$ BRFO & 28 & $4.15(1.05)^{*}$ & $7.01(1.32)^{*}$ & $4.81(1.21)^{*}$ & $6.16(0.22)$ \\
\hline
\end{tabular}

(a) Mean (standard deviation), $n=3$.

(b) "Denotes significant difference from control based on t-test, $p \leq 0.05$.

\subsubsection{Soil Phosphatase Activity}

Soil phosphatases, which can exist extracellularly, are a broad group of enzymes that cleave both esters and anhydrides of phosphates from complex organophosphorus compounds. Their activities in soil are important for the mineralization of phosphorus from soil organic matter to the chemical forms available to plants (Ramirez-Martinez 1968). The enzymes are classified as either acid or alkaline phosphatases because they show their optimal activities in acid and alkaline ranges, respectively. The acid phosphatase was chosen for this study because the $\mathrm{pH}$ of soils used for brass exposure ranged from 5.4 to 7.4.

Soil Amendment. The effect of brass on soil phosphatase activity depended on brass concentration and soil type (Figure 3.12 and Table 3.43). In Burbank soil, a brass concentration of $25 \mu \mathrm{g} / \mathrm{g}$ did not affect soil dehydrogenase activity initially (4 days incubation), but with prolonged incubation, concentrations of 25 to $2500 \mu \mathrm{g} / \mathrm{g}$ all inhibited the activities from 17 to $70 \%$ of control. Activity was affected at all brass levels, with inhibition increasing as brass concentrations increased. In the other three soils, brass concentrations below $500 \mu \mathrm{g} / \mathrm{g}$ did not inhibit soil phosphatase activity. In fact, activity was slightly enhanced by 25 to 100 $\mu \mathrm{g} / \mathrm{g}$ brass amendment in the Cinebar and Palouse soil. However, at $2500 \mu \mathrm{g} / \mathrm{g}$, activity in the three soils was reduced to less than $45 \%$ of the control, and it remained inhibited 420 days later. The $\mathrm{EcD}_{50}$ at various incubation times, calculated according to the best-fit curves (Table 3.44), are presented in Figure 3.13 and Table 3.39. At 4 days, $\mathrm{ECD}_{50}$ was $662,2106,673$, 
IABLE 3.41. EQUATION FOR THE BEST FIT FROM THE DOSE-RESPONSE CURVE FOR SOIL DEHYDROGENASE ACTIVITY AS AFFECTED BY BRASS $^{(a)(b)(c)}$

Incubation Time 5 days

Burbank

$Y=(232.36) * X^{\wedge}-0.68214$

$r^{2}=0.955$

Cinebar

$Y=(740.03) * X^{\wedge}-0.66123$

$r^{2}=0.969$

Palouse

$Y=(1309.5) * X^{\wedge}-0.77410$

$r^{2}=0.946$

Palouse + OM

$Y=(591.50) * X^{\wedge}-0.64782$

$r^{2}=0.995$

Incubation Time 28 days

Burbank

Cinebar

$Y=(1.2719 E+7) * X^{\wedge}-3.8236$

$r^{2}=0.873$

$Y=(170.86) * 10^{\wedge}(-2.8613 E-3 * X)$

$r^{2}=0.992$

Palouse

$Y=1.6097 E+8 * X^{\wedge}-4.1289$

$r^{2}=0.825$

Palouse + OM

$Y=63.649$ * $10^{\wedge}(-2.7475 E-3 * X)$

$r^{2}=0.994$

Incubation Time 150 days

Burbank

Cinebar

Palouse

Palouse + OM

$Y=98.779 * X^{\wedge}-0.43241$

$r^{2}=0.669$

$Y=83.385 * 10^{\wedge}(-5.1158 E-4 * X)$

$r^{2}=0.982$

$Y=622.79 * X^{\wedge}-0.64314$

$r^{2}=0.924$

$Y=2092.2 * X^{\wedge}-0.90943$

$r^{2}=0.923$

Incubation Time 270 days

Burbank

Cinebar

$Y=310.50 * X^{\wedge}-0.65218$

$r^{2}=0.905$

$Y=80.935 * 10^{\wedge}(-3.8791 E-4 * X)$

$r^{2}=0.995$

Palouse

$Y=1668.0 * X^{\wedge}-0.77952$

$r^{2}=0.934$

Palouse + OM

$Y=83.942 * 10^{\wedge}(-5.7282 E-4 * X)$

$r^{2}=0.995$

Incubation Time 420 days

Burbank

Cinebar

$Y=105.87 * X^{\wedge}-0.23515$

$r^{2}=0.628$

$Y=73.487-2.1708 \mathrm{E}-2 * X$

$r^{2}=0.996$

Palouse

$Y=80.9-0.16312^{*} X$

$r^{2}=0.962$

Palouse + OM

$Y=120.95 * 10^{\wedge}(-3.383 E-3 * X)$

$r^{2}=1.000$

(a) Dose-response curve constructed from data in Table 1.1.

(b) $Y$ axis = dehydrogenase activity expressed as a percent of control; $X$-axis = brass concentration in $\mu \mathrm{g} / \mathrm{g}$ soil.

(c) $r^{2}=$ the coefficient of determination for the best-fit curve. 
IABLE 3.42. COMPARISON OF EXPOSURES OF BRASS FLAKE AND MIXED SMOKE OF BRASS/FOG OIL ON SOIL DEHYDROGENASE ACTIVITY

\begin{tabular}{lcccc}
\hline \multirow{2}{*}{$\begin{array}{l}\text { Exposure } \\
\text { Type }\end{array}$} & \multicolumn{3}{c}{ Dehydrogenase Activity (\% of Control) $(\mathrm{a})$} \\
\cline { 2 - 5 } & Burbank & Cinebar & Palouse & Palouse+OM \\
\hline Brass $(800 \mu \mathrm{g} / \mathrm{g})-5$ days $(\mathrm{a})$ & 2.43 & 8.91 & 7.41 & 7.79 \\
BR/FO $(0.9 \mathrm{~m} / \mathrm{s})-0$ days & 10.81 & 30.22 & 62.47 & 62.61 \\
Brass $(800 \mu \mathrm{g} / \mathrm{g})$ - 28 days $(\mathrm{a})$ & $1 \times 10^{-4}$ & 0.88 & $1.7 \times 10^{-4}$ & 0.40 \\
BR/FO $(0.9 \mathrm{~m} / \mathrm{s})-28$ days & 6.25 & 47.68 & 44.32 & 52.72 \\
\hline
\end{tabular}

(a) Calculated from the equations of best fit of dose-response curves in Table 3.41.

and $1610 \mu \mathrm{g} / \mathrm{g}$ for Burbank, Cinebar, Palouse, and Palouse+OM, respectively. By 420 days the $\mathrm{ECD}_{50}$ decreased five-fold in Burbank soil and increased two-fold in Palouse, while it stayed rather unchanged in the other two soils. The impact of brass flake on soil phosphatase activity is ranked Burbank $>$ Palouse $+O M \geq$ Palouse $>$ Cinebar. Again, soil characteristics play an important role in the potential toxicity of the brass flake to soil microorganisms, the lower CEC in Burbank explaining the higher inhibition of phosphatase activity in that soil.

Aerosol Deposition to Soils. The effect of BR/FO smoke exposure is presented in Figure 3.14 and Table 3.45. Exposure to the BR/FO smoke at $0.9 \mathrm{~m} / \mathrm{s}$ had no effect on Cinebar or Palouse+OM soil and a moderate effect on Palouse, while Burbank soil declined to $67 \%$ of control initially and to $33 \%$ after 28 days. At $4.5 \mathrm{~m} / \mathrm{s}$, all four soils were affected: at 28 days Burbank was reduced to $27 \%$ of the control, Cinebar to $85 \%$, Palouse to $55 \%$, and Palouse+OM to $60 \%$.

Based on the estimated concentration of $800 \mu \mathrm{g} / \mathrm{g}$ brass in the BR/FO mixed smoke for the $0.9 \mathrm{~m} / \mathrm{s}$ exposure, the anticipated brass effect at $800 \mu \mathrm{g} / \mathrm{g}$ can be calculated from the equation of best fit of the dose-response curve for soil phosphatase activity (Table 3.44). The calculated effect is presented in Table 3.46. These results indicate that the impact on soil phosphatase activity by the mixed-smoke exposure of BR/FO is less than that of brass alone, suggesting a beneficial synergistic effect of fog oil in the BR/FO mixea-smoke exposure. Because earlier studies with fog-oil exposure did not include its effect on soil phosphatase activity, corroboration of synergism is limited. 

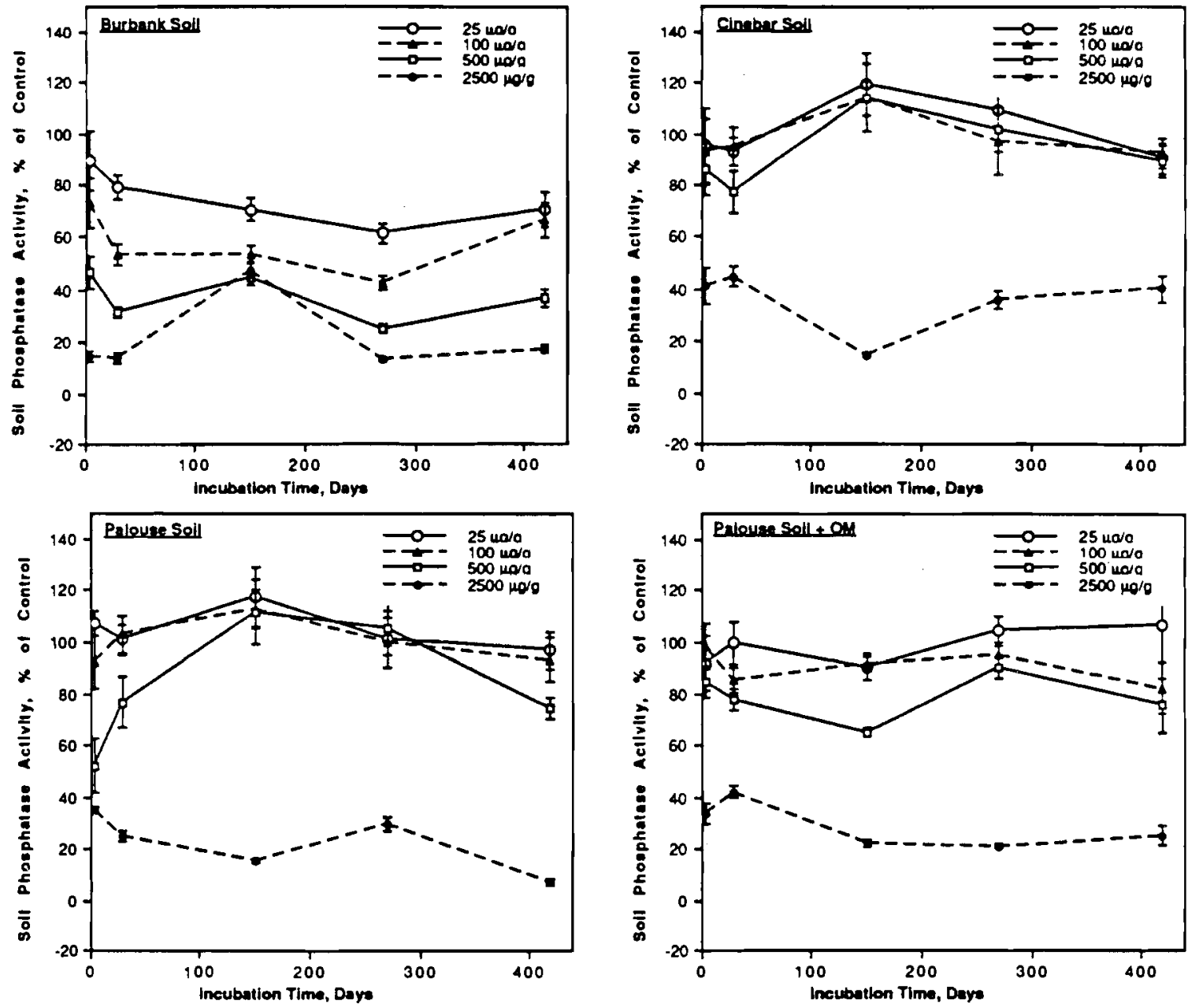

FIGURE 3.12. THE EFFECT OF BRASS-FLAKE CONCENTRATION ON SOIL PHOSPHATASE ACTIVITY 
IABLE 3.43. THE EFFECT OF BRASS FLAKE CONCENTRATION ON SOIL PHOSPHATASE ACTIVITY

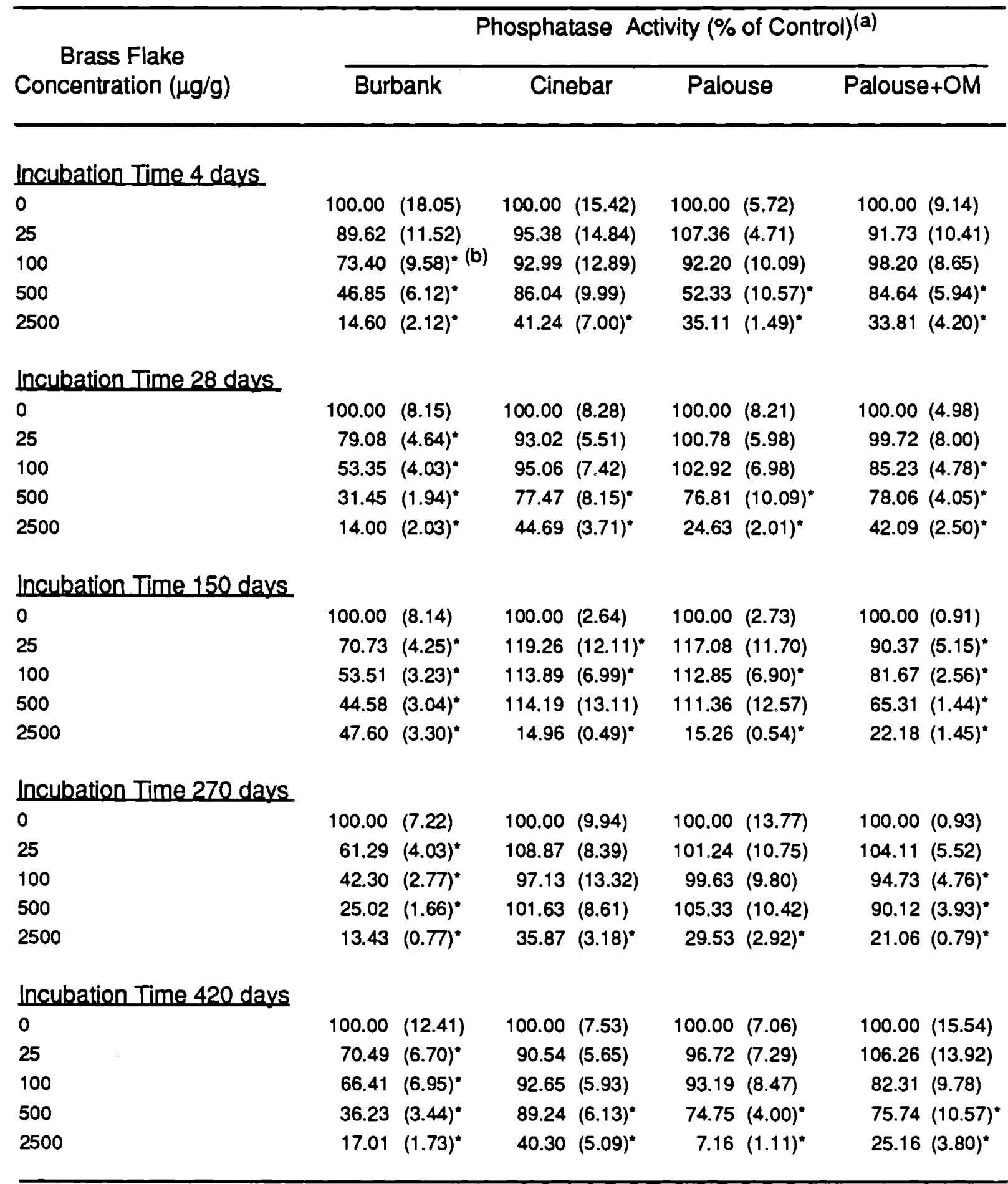

(a) Mean (standard deviation), $n=3$.

(b) Denotes significant difference from control based on t-test, $p \leq 0.05$. 
IABLE 3.44. EQUATION FOR THE BEST FIT FROM THE DOSE-RESPONSE CURVE FOR SOIL PHOSPHATASE ACTIVITY AS AFFECTED BY BRASS(a)(b)(c)

Incubation Time 5 days

Burbank Soil

Cinebar Soil

$Y=78.847 * 10^{\wedge}(-2.9887 E-4 * X)$

$r^{2}=0.973$

$Y=95.961-2.1822 E-2 * X$

$r^{2}=0.999$

Palouse Soil

$Y=263.87 * X^{\wedge}-0.25548$

$r^{2}=0.972$

Palouse Soil + OM

$Y=99.502 * 10^{\wedge}(-1.8563 E-4 * X)$

$r^{2}=0.988$

Incubation Time 28 davs

Burbank Soil

$Y=282.54 \cdot X^{\wedge}-0.37235$

$r^{2}=0.982$

Cinebar Soil

$Y=94.076{ }^{\circ} 10^{\wedge}(-1.3056 \mathrm{E}-4 \cdot \mathrm{*})$

$r^{2}=0.990$

Palouse Soil

Palouse Soil + OM

$Y=104.7^{*} 10^{\wedge}(-2.5183 E-4 * X)$

$r^{2}=0.998$

$Y=93.421 \cdot 10^{\wedge}\left(-1.3946 E-4^{*} X\right)$

$r^{2}=0.978$

Incubation Time 150 days

Burbank Soil

Cinebar Soil

Palouse Soil

Palouse Soil + OM

$Y=85.777 * X^{\wedge}-8.7279 E-2$

$r^{2}=0.727$

$Y=124.02-4.2805 E-2 * X$

$r^{2}=0.976$

$Y=121.87-4.1903 E-2 * X$

$r^{2}=0.979$

$Y=88.146^{*} 10^{\wedge}(-2.4057 E-4 * X)$

$r^{2}=0.998$

Incubation Time 270 davs

Burbank Soil

$Y=185.62 * X^{\wedge}-0.33012$

$r^{2}=0.994$

Cinebar Soil

$Y=108.04-2.8368 E-2 * X$

$r^{2}=0.962$

Palouse Soil

Palouse Soil + OM

$Y=107.61-3.0302 E-2 * X$

$r^{2}=0.943$

$Y=102.93-3.2541 E-2 * X$

$r^{2}=0.991$

Incubation Time 420 days

Burbank Soil

$Y=235.67 * X^{\wedge}-0.31902$

$r^{2}=0.922$

Cinebar Soil

$Y=94.967 \cdot 2.1484 E-2 * X$

$r^{2}=0.979$

Palouse Soil

$Y=95.86-3.5719 E-2 * X$

$r^{2}=0.997$

Palouse Soil + OM

$Y=97.606^{*} 10^{\wedge}(-2.3553 E-4 * X)$

$r^{2}=0.981$

(a) Dose-response curve constructed from data in Table 6.

(b) $Y$-axis = phosphatase activity expressed as a percent of control; $X$-axis = brass concentration in $\mu \mathrm{g} / \mathrm{g}$ soil.

(c) $\mathrm{r}^{2}=$ the coefficient of determination for the best-fit curve. 

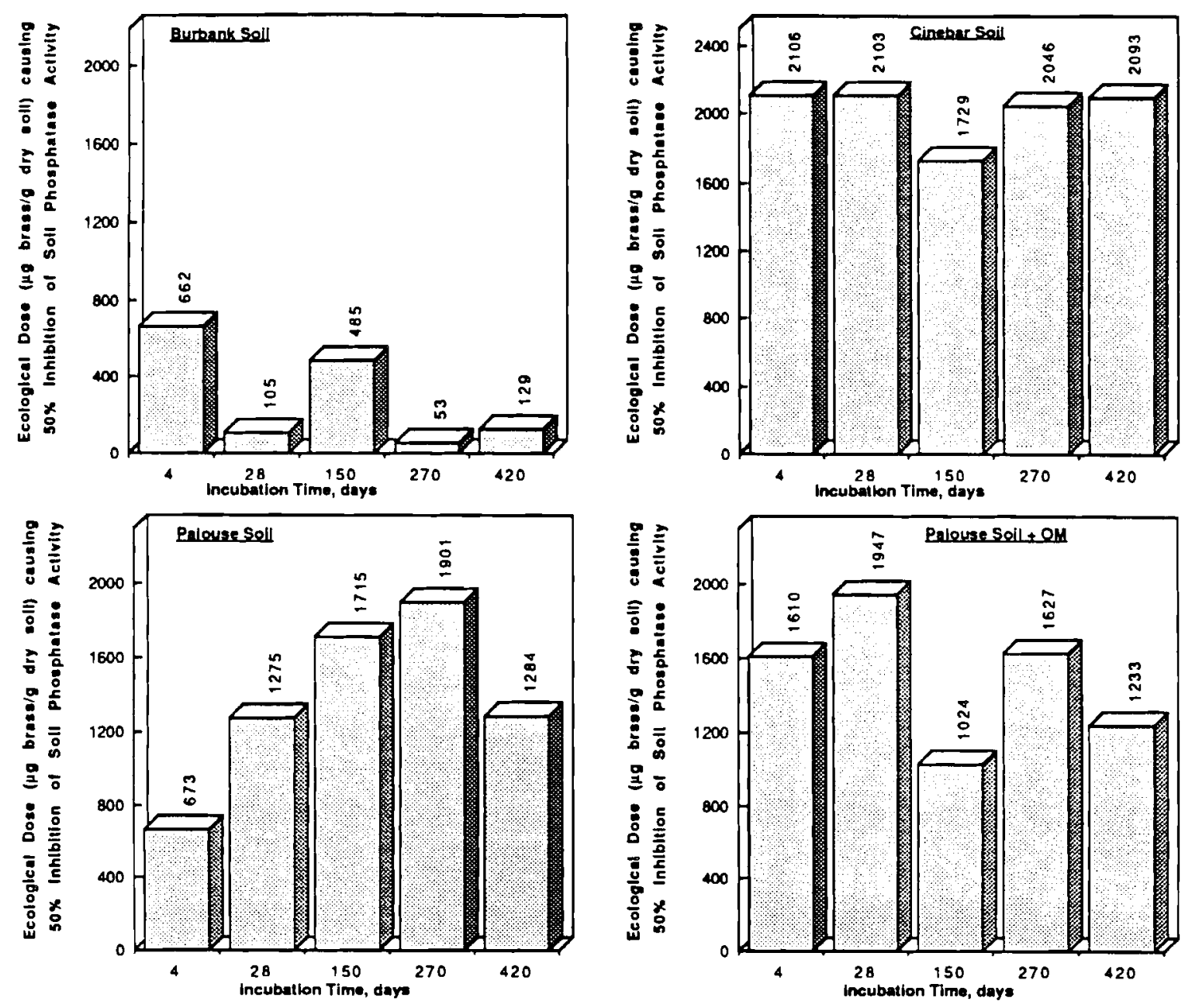

FIGURE 3.13. ECOLOGICAL DOSE CAUSING 50\% INHIBITION $\left(E \mathrm{CD}_{50}\right)$ OF SOIL PHOSPHATASE ACTIVITY 
IABLE 3.45. THE EFFECT OF BRASS FLAKE/FOG OIL MIXED SMOKE ON SOIL PHOSPHATASE ACTIVITY

\begin{tabular}{|c|c|c|c|c|c|}
\hline \multirow{3}{*}{$\begin{array}{l}\text { Exposure } \\
\text { Condition } \\
\text { unexposed }\end{array}$} & \multirow{2}{*}{$\begin{array}{l}\text { Post-Exposure } \\
\text { Time (days) }\end{array}$} & \multicolumn{4}{|c|}{ Phosphatase Activity (\% of Control) ${ }^{(a)}$} \\
\hline & & \multirow{2}{*}{$\begin{array}{l}\text { Burbank } \\
100.50(11.51)\end{array}$} & Cinebar & Palouse & Palouse+OM \\
\hline & 0 & & 100.00 & 100.00 & 100.00 \\
\hline $0.9 \mathrm{~m} / \mathrm{s}$ BR/FO & 0 & $67.36(7.55)^{*(b)}$ & $92.36 \quad(9.51)$ & $93.25(5.24)^{*}$ & $97.54(7.28)$ \\
\hline $4.5 \mathrm{~m} / \mathrm{s}$ BR/FO & 0 & $25.47(6.57)^{*}$ & $69.34(5.86)^{*}$ & $64.74(3.83)^{*}$ & $69.22(4.10)^{*}$ \\
\hline unexposed & 28 & $100.00(0.41)$ & $100.00 \quad(7.76)$ & 100.00 & $100.00(6.12)$ \\
\hline $0.9 \mathrm{~m} / \mathrm{s}$ BR/FO & 28 & $33.06(1.19)^{\star}$ & $100.87(7.24)$ & $82.13(5.08)^{*}$ & 99.66 (5.69) \\
\hline $4.5 \mathrm{~m} / \mathrm{s}$ BR/FO & 28 & $26.50(5.36)^{*}$ & $84.65(5.15)^{\star}$ & $54.73(3.24)^{\star}$ & $59.82(4.42)^{*}$ \\
\hline
\end{tabular}

(a) Mean (standard deviation), $n=3$.

(b) "Denotes significant difference from control based on t-test, $p \leq 0.05$.

\subsubsection{Soil ATP - Soil Microbial Biomass}

Measuring soil microbial biomass levels after the addition of a compound can indicate how well the soil microbial population will survive. Changes in soil microbial biomass can influence nutrient cycling, decomposition processes, and other important biotic functions, which contribute to a stable ecosystem. Extracting and in measuring ATP from the soil microbial biomass is an easy method to measure the soil microbial biomass.

Pot Amendments. Soil microbial biomass, as represented by the soil ATP level, decreased at 7 days to approximately $30 \%$ of control in Burbank soil at 500 and $2500 \mu \mathrm{g} / \mathrm{g}$ brass (Table 3.47 and Figure 3.15). In the three other soils, only the largest brass amendment $(2500 \mu \mathrm{g} / \mathrm{g})$ caused ATP levels to drop, in Cinebar soil to approximately $50 \%$ and in Palouse soil or Palouse+OM to approximately $35 \%$. At an incubation time of 7 days, the $\mathrm{ECD}_{50}$ values were $375,1468,3166$, and $2442 \mu \mathrm{g} / \mathrm{g}$ for Burbank, Cinebar, Palouse, and Palouse+OM, respectively (Figure 3.16 and Table 3.39). After 420 days the $\mathrm{ECD}_{50}$ decreased to 304,1451 , and $1335 \mu \mathrm{g} / \mathrm{g}$ in Burbank, Palouse, and Palouse+OM, respectively, while in Cinebar the $\mathrm{ECD}_{50}$ increased to $2515 \mu \mathrm{g} / \mathrm{g}$. The impact of brass flake on soil ATP level thus is ranked Burbank $>$ Palouse $+O M \geq$ Palouse $>$ Cinebar. This ranking in general is the same as for the dehydrogenase and phosphatase activities. Once more, the lower CEC in Burbank soil explains the lower levels of ATP, or soil microbial biomass, in Burbank soil. 

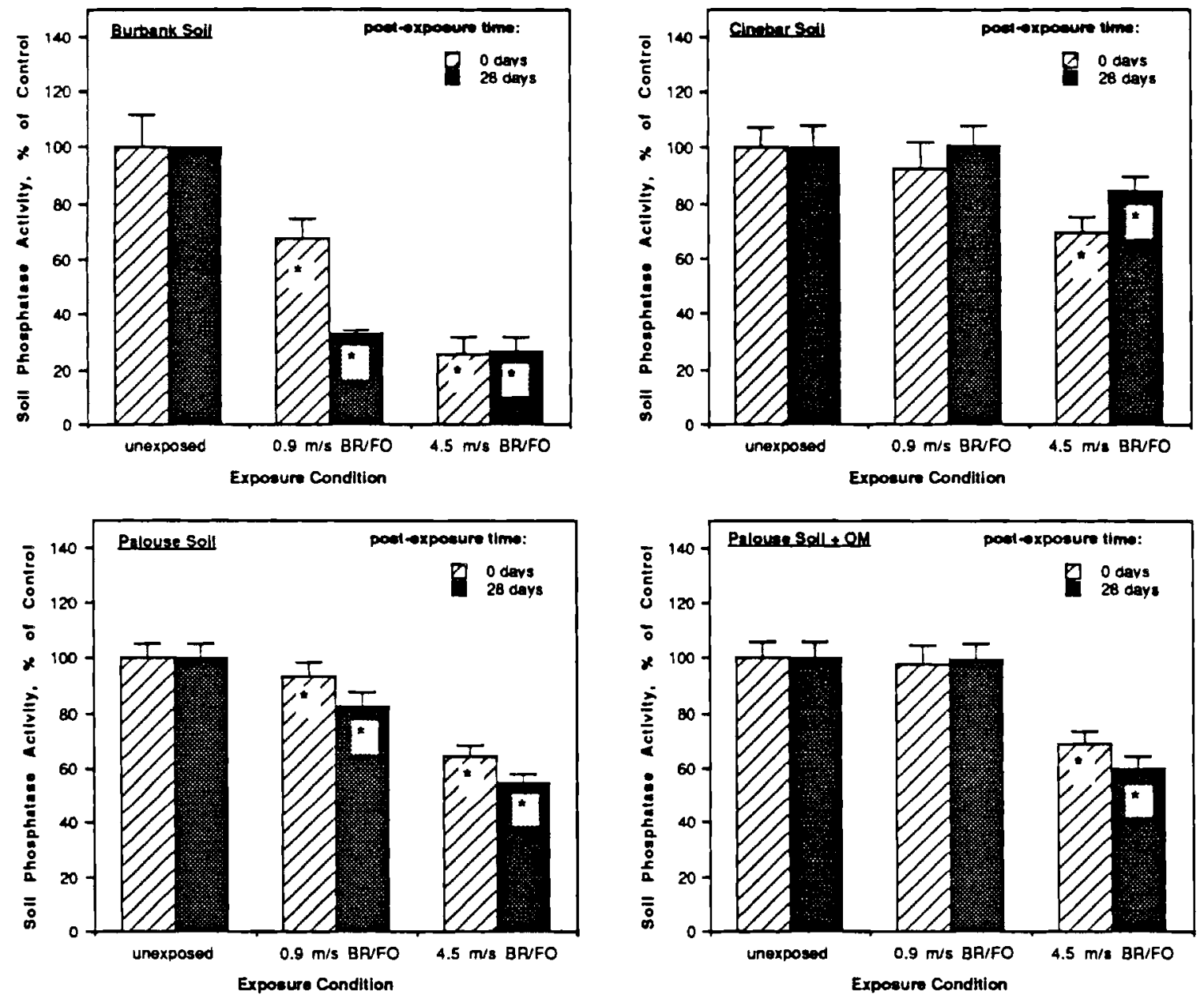

FIGURE 3.14. THE EFFECT OF BRASS FLAKE/FOG OIL MIXED SMOKE ON SOIL PHOSPHATASE ACTIVITY 
IABLE 3.46. COMPARISON OF EXPOSURES OF BRASS FLAKE AND MIXED SMOKE OF BRASS/FOG OIL OF ON SOIL PHOSPHATASE ACTIVITY

\begin{tabular}{lcccc}
\hline \multirow{2}{*}{$\begin{array}{l}\text { Exposure } \\
\text { Type }\end{array}$} & \multicolumn{3}{c}{ Phosphatase Activity (\% of Control) ${ }^{(a)}$} & \\
\cline { 2 - 5 } & Burbank & Cinebar & Palouse & Palous + +OM \\
\hline Brass $(800 \mu \mathrm{g} / \mathrm{g})-4$ days $(\mathrm{a})$ & 45.46 & 78.50 & 47.83 & 70.68 \\
BR/FO $(0.9 \mathrm{~m} / \mathrm{s})-0$ days & 67.36 & 93.26 & 93.25 & 97.54 \\
Brass $(800 \mu \mathrm{g} / \mathrm{g})-28$ days $(\mathrm{a})$ & 23.45 & 73.97 & 65.84 & 72.26 \\
BRFF $(0.9 \mathrm{~m} / \mathrm{s})-28$ days & 33.06 & 100.87 & 82.13 & 99.66 \\
\hline
\end{tabular}

(a) Calculated from the equations of best fit of dose-response curves in Table 3.43.

Aerosol Deposition to Soils. Exposure to the BR/FO mixed smoke at $0.9 \mathrm{~m} / \mathrm{s}$ or $4.5 \mathrm{~m} / \mathrm{s}$ had no effect on Cinebar, Palouse, or Palouse+OM soil ATP levels immediately after exposure or 28 days later (Figure 3.17 and Table 3.48). Initially, Burbank soil was not affected by the 0.9 $\mathrm{m} / \mathrm{s}$ BR/FO exposure, but the ATP levels declined to $54 \%$ of control after 28 days. When exposed to BR/FO smoke at the higher wind speed of $4.5 \mathrm{~m} / \mathrm{s}$, ATP level in Burbank soil decreased to $44 \%$ immediately and continued to decline to $12 \%$ after 28 days.

Based on the estimated concentration of $800 \mu \mathrm{g} / \mathrm{g}$ brass in the BR/FO mixed smoke exposure for the $0.9 \mathrm{~m} / \mathrm{s}$ wind speed, the anticipated brass-only effect at $800 \mu \mathrm{g} / \mathrm{g}$ can be calculated from the equation of best fit for the dose-response curve for soil ATP level (Table 3.49). The calculated effect is presented in Table 3.50. These results indicate that the impact of BR/FO on soil ATP levels is less than that of brass alone, suggesting a beneficial synergistic effect of fog oil in the BR/FO mixed smoke. However, no soil ATP data was available for the fog oil alone, thus corroboration of synergism is limited. 
IABLE 3.47. THE EFFECT OF BRASS FLAKE CONCENTRATION ON ATP - SOIL MICROBIAL BIOMASS

ATP Level (\% of Control) $)^{(a)}$

Brass Flake

Concentration $(\mu \mathrm{g} / \mathrm{g})$

Burbank

Cinebar

Palouse

Palouse+OM

Incubation Time 7 days

$\begin{array}{lrlrlrlrl}0 & 100.00 & (7.58) & 100.00 & (10.02) & 100.00 & (5.86) & 100.00 & (0.79) \\ 25 & 90.06 & (7.00) & 72.28 & (7.07)^{*}(b) & 95.15 & (4.01) & 101.88 & (1.03) \\ 100 & 109.29 & (6.54) & 68.01 & (10.94)^{*} & 92.54 & (8.24) & 100.46 & (3.99) \\ 500 & 37.27 & (2.96)^{*} & 62.90 & (6.37)^{*} & 83.31 & (4.88)^{*} & 90.50 & (6.70) \\ 2500 & 29.19 & (1.76)^{*} & 39.08 & (4.48)^{*} & 57.36 & (4.09)^{*} & 49.02 & (2.46)^{*}\end{array}$

Incubation Time 28 days

$\begin{array}{lrlrlrlrl}0 & 100.00 & (12.61) & 100.00 & (8.35) & 100.00 & (5.14) & 100.00 & (4.04) \\ 25 & 119.25 & (13.72) & 105.76 & (7.43) & 100.04 & (4.01) & 93.57 & (13.88) \\ 100 & 82.87 & (10.01) & 111.01 & (6.73) & 105.01 & (6.72) & 99.74 & (11.53) \\ 500 & 16.69 & (1.67)^{*} & 91.32 & (8.05)^{*} & 110.83 & (4.88) & 107.64 & (36.08) \\ 2500 & 7.00 & (1.37)^{*} & 39.50 & (2.52)^{*} & 38.27 & (4.25)^{*} & 55.46 & (5.05)^{*}\end{array}$

Incubation Time 150 days

$\begin{array}{lrlrlrlrl}0 & 100.00 & (0.70) & 100.00 & (14.90) & 100.00 & (8.72) & 100.00 & (4.99) \\ 25 & 106.82 & (7.56) & 93.07 & (9.82) & 81.34 & (5.11)^{*} & 88.02 & (5.74) \\ 100 & 85.44 & (1.91)^{*} & 90.36 & (11.15) & 88.61 & (5.75)^{*} & 90.56 & (3.26) \\ 500 & 49.81 & (1.02)^{*} & 84.76 & (9.48) & 90.04 & (5.74)^{*} & 86.71 & (3.66)^{*} \\ 2500 & 54.82 & (0.53)^{*} & 71.89 & (8.44)^{*} & 20.26 & (1.36)^{*} & 34.37 & (1.31)^{*}\end{array}$

Incubation Time 270 days

$\begin{array}{lrlrlrlrl}0 & 100.00 & (11.53) & 100.00 & (2.56) & 100.00 & (4.58) & 100.00 & (1.46) \\ 25 & 69.86 & (5.78)^{*} & 96.76 & (3.97) & 61.94 & (2.60)^{*} & 83.05 & (1.75)^{*} \\ 100 & 65.52 & (6.07)^{*} & 98.38 & (4.94)^{*} & 67.29 & (8.53)^{*} & 83.56 & (0.93)^{*} \\ 500 & 41.49 & (3.75)^{*} & 89.72 & (5.98)^{*} & 55.15 & (2.29)^{*} & 78.91 & (3.20)^{*} \\ 2500 & 38.18 & (3.15)^{*} & 49.32 & (2.09)^{*} & 16.99 & (0.85)^{*} & 25.36 & (1.08)^{*}\end{array}$

Incubation Time 420 days

$\begin{array}{lrlrlrlrl}0 & 100.00 & (15.47) & 100.00 & (4.71) & 100.00 & (3.10) & 100.00 & (8.96) \\ 25 & 105.07 & (15.44) & 107.72 & (9.16) & 100.04 & (3.68) & 85.14 & (7.51)^{*} \\ 100 & 81.82 & (11.76) & 121.76 & (19.23) & 82.58 & (2.58)^{*} & 90.16 & (9.52)^{*} \\ 500 & 15.35 & (4.83)^{*} & 118.35 & (8.31) & 79.34 & (12.84)^{*} & 87.07 & (5.60)^{*} \\ 2500 & 29.25 & (6.54)^{*} & 49.63 & (5.59)^{*} & 18.55 & (2.98)^{*} & 10.05 & (1.52)^{*}\end{array}$

(a) Mean (standard deviation), $n=3$.

(b) "Denotes significant difference from control based on t-test, $p \leq 0.05$. 

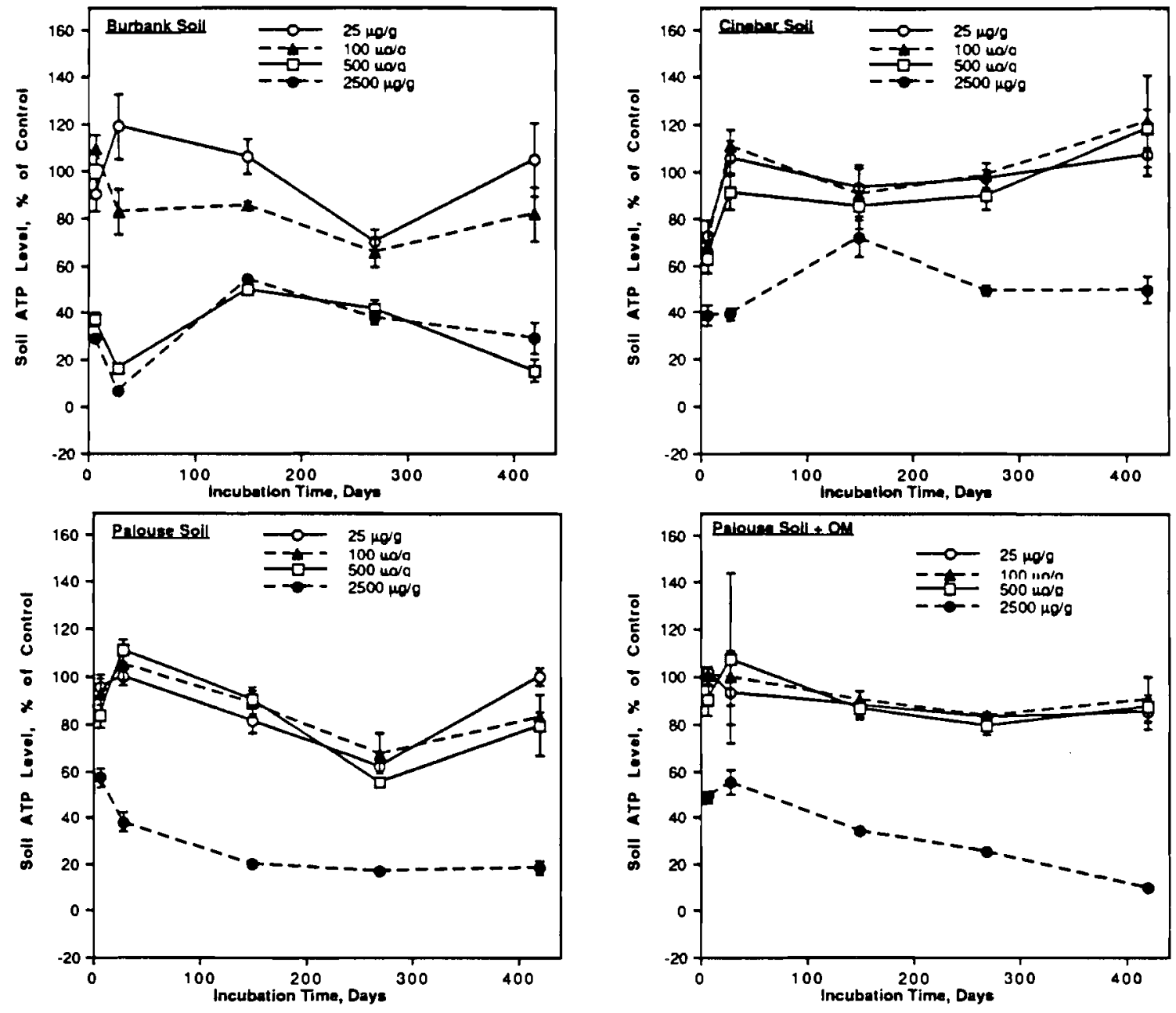

EIGURE 3.15. THE EFFECT OF BRASS FLAKE CONCENTRATION ON ATP - SOIL MICROBIAL BIOMASS 

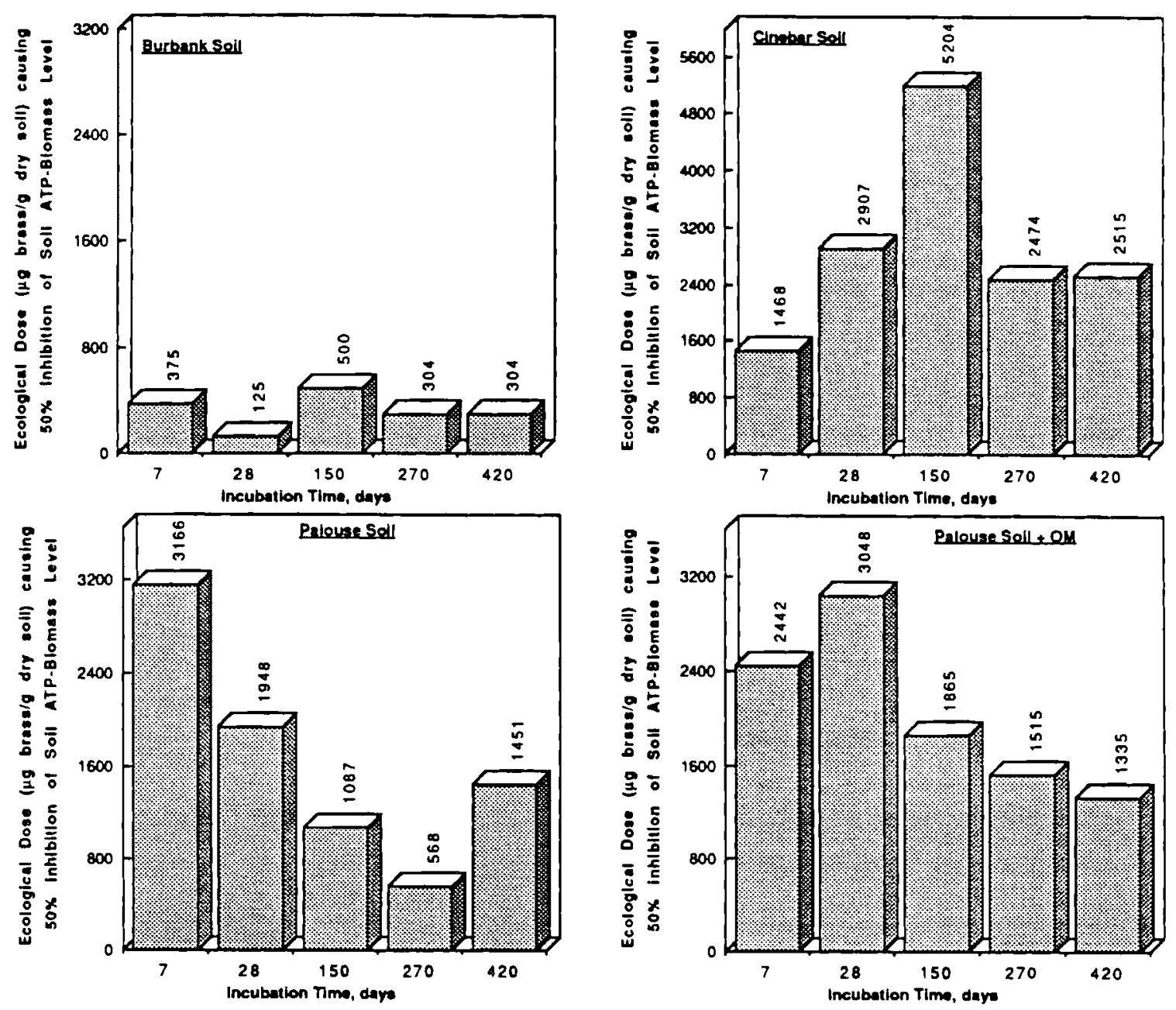

FIGURE 3.16. ECOLOGICAL DOSE CAUSING 50\% INHIBITION $\left(\mathrm{ECD}_{50}\right)$ OF ATP - SOIL MICROBIAL BIOMASS 

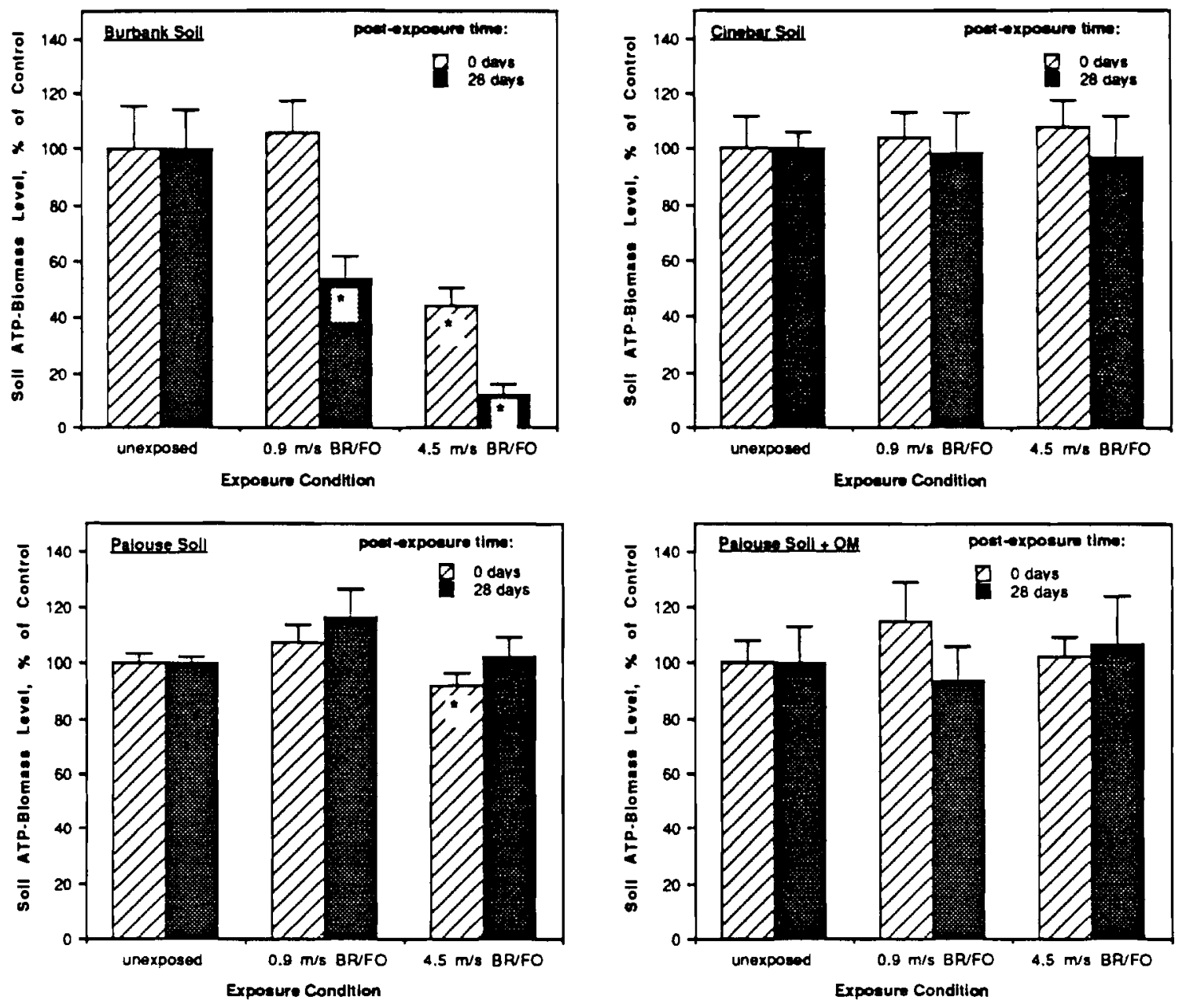

FIGURE 3.17. THE EFFECT OF BRASS FLAKE/FOG OIL MIXED SMOKE ON ATP SOIL MICROBIAL BIOMASS 
IABLE 3.48. THE EFFECT OF BRASS FLAKE/FOG OIL MIXED SMOKE ON ATP SOIL MICROBIAL BIOMASS

\begin{tabular}{|c|c|c|c|c|c|}
\hline \multirow{2}{*}{$\begin{array}{l}\text { Exposure } \\
\text { Condition }\end{array}$} & \multirow{2}{*}{$\begin{array}{l}\text { Post-Exposure } \\
\text { Time (days) }\end{array}$} & \multicolumn{4}{|c|}{ ATP Level (\% of Control) ${ }^{(a)}$} \\
\hline & & Burbank & Cinebar & Palouse & Palouse+OM \\
\hline unexposed & 0 & $100.00(15.27)$ & $100.00(11.84)$ & 100.00 & $100.00(7.76)$ \\
\hline $0.9 \mathrm{~m} / \mathrm{s}$ BRFO & 0 & $105.97(11.75)$ & $104.10 \quad(9.09)$ & $107.19(6.65)$ & $114.97(13.76)$ \\
\hline $4.5 \mathrm{~m} / \mathrm{s}$ BR/FO & 0 & $43.78(6.45)^{*(b)}$ & 107.97 & $92.04(4.23)^{*}$ & $101.91(6.99)$ \\
\hline unexposed & 28 & 100.00 & $100.00 \quad(5.93)$ & 100.00 & 100.00 \\
\hline $0.9 \mathrm{~m} / \mathrm{s}$ BR/FO & 28 & $53.93(7.82)^{*}$ & $98.44(14.85)$ & $116.41 \quad(10.21)$ & 93.59 (12.28) \\
\hline $4.5 \mathrm{~m} / \mathrm{s}$ BP/FO & 28 & $11.81(3.99)^{*}$ & 97.01 (14.72) & $102.20(7.10)$ & $106.79(16.98)$ \\
\hline
\end{tabular}

(a) Mean (standard deviation), $n=3$.

(b) Denotes significant difference from control based on t-test, $p \leq 0.05$.

\subsubsection{Iotal Soil Heterotrophic Bacteria}

Aerosol Deposition to Soil. The effect of brass flake amendment or BR/FO smoke exposure to the total soil heterotrophic bacteria was moderate, and in most cases, not significant (Figures 3.18 and 3.19; Tables 3.51 and 3.52). Concentration effects demonstrated in the two soil-enzyme assays and the soil ATP levels discussed above, were not seen here. The assay of total number of organisms able to grow out of a soil apparently is not able to detect the ecological effects of brass-flake exposure.

\subsubsection{Soil Microbjal Diversity Index}

Microbial diversity may be a useful parameter for assessing the effects of stress on the soil microbial community (Atlas 1984b). The stability of the microbial community requires a certain amount of diversity, while the addition of stress or insult may influence ecosystem structure and function. The two main measures of species diversity are the total number of different species in the community and the number within each species. One can determine whether an insult or stress has changed the total number of species, the dominant species, or even selected for new populations to develop. A widely used measure of species diversity is the Shannon-Weaver index of species diversity, which is a general diversity index sensitive both to species richness and relative species abundance. We chose this index of species diversity to measure the soil microbial species diversity. 


\section{IABLE 3.49. EQUATION FOR THE BEST FIT FROM THE DOSE-RESPONSE CURVE FOR SOIL ATP - SOIL MICROBIAL BIOMASS AS AFFECTED BY BRASS$^{(a)(b)(c)}$}

Incubation Time 7 days

$\begin{array}{lll}\text { Burbank Soil } & Y=283.00^{*} X^{\wedge}-0.29252 & r^{2}=0.808 \\ \text { Cinebar Soil } & Y=71.114^{*} 10^{\wedge}(-1.042 E-4 * X) & r^{2}=0.996 \\ \text { Palouse Soil } & Y=94.155^{*} 10^{\wedge}(-8.6828 E-5 * X) & r^{2}=0.995 \\ \text { Palouse Soil + OM } & Y=103.64 * 10^{\wedge}(-1.2962 E-4 * X) & r^{2}=0.999\end{array}$

Incubation Time 28 days

Burbank Soil

$Y=1200.1 * X^{\wedge}-0.65872$

$r^{2}=0.963$

Cinebar Soil

$Y=111.47 * 10^{\wedge}(-1.7978 E-4 * X)$

$r^{2}=0.995$

Palouse Soil

$Y=113.53^{*} 10^{\wedge}(-1.8286 E-4 * X)$

$r^{2}=0.934$

Palouse Soil + OM

$Y=104.32 * 10^{\wedge}(-1.0479 E-4 * X)$

$r^{2}=0.872$

Incubation Time 150 days

Burbank Soil

$Y=173.07 * X^{\wedge}-0.16391$

$r^{2}=0.813$

Cinebar Soil

$Y=91.206-7.9179 E-3 * X$

$r^{2}=0.960$

Palouse Soil

Palouse Soil + OM

$Y=96.864 * 10^{\wedge}(-2.6425 E-4 * X)$

$r^{2}=0.949$

$Y=92.88-2.2995 E-2 * X$

$r^{2}=0.978$

Incubation Time 270 days

Burbank Soil

Cinebar Soil

$Y=116.36 * X^{\wedge}-0.14775$

$r^{2}=0.906$

$Y=99.031-1.9822 \mathrm{E}-2 * X$

$r^{2}=0.997$

Palouse Soil

Palouse Soil + OM

$Y=68.423 * 10^{\wedge}(-2.3979 E-4 * X)$

$r^{2}=0.990$

$Y=86.60-2.4166 \mathrm{E}-2{ }^{*} \mathrm{X}$

$r^{2}=0.988$

Incubation Time 420 days

Burbank Soil

$$
Y=105.19-0.18134 * X
$$

$r^{2}=0.989$

Cinebar Soil

$Y=129.07-3.1443 E-2 * X$

$r^{2}=0.987$

Palouse Soil

$Y=93.616-3.0066 \mathrm{E}-2$ * $X$

$r^{2}=0.969$

Palouse Soil + OM

$Y=93.644-3.269 E-2 * X$

$r^{2}=0.965$

(a) Dose-response curve constructed from data in Table 10.

(b) $Y$ axis = ATP level expressed as a percent of control; $X$ axis = brass concentration in $\mu \mathrm{g} / \mathrm{g}$ soil.

(c) $r^{2}=$ the coefficient of determination for the best-fit curve. 
IABLE 3.50. COMPARISON OF EXPOSURES OF BRASS FLAKES AND A MIXED SMOKE OF BRASS/FOG OIL ON ATP - SOIL MICROBIAL BIOMASS

\begin{tabular}{lcccc}
\hline \multirow{2}{*}{$\begin{array}{l}\text { Exposure } \\
\text { Type }\end{array}$} & \multicolumn{4}{c}{ ATP Level $\left(\%\right.$ of Control) ${ }^{(a)}$} \\
\cline { 2 - 5 } & Burbank & Cinebar & Palouse & Palouse+OM \\
\hline Brass $(800 \mu \mathrm{g} / \mathrm{g})-7$ days $(\mathrm{a})$ & 40.04 & 58.69 & 80.02 & 81.44 \\
BR/FO $(0.9 \mathrm{~m} / \mathrm{s})-0$ days & 105.97 & 104.10 & 107.19 & 114.97 \\
Brass $(800 \mu \mathrm{g} / \mathrm{g})-28$ days $(\mathrm{a})$ & 14.68 & 80.04 & 81.06 & 86.01 \\
BR/FO $(0.9 \mathrm{~m} / \mathrm{s})-28$ days & 53.93 & 98.44 & 102.20 & 93.59 \\
\hline
\end{tabular}

(a) Calculated from the equations of best fit of dose-response curves in Table 12.

The effect of brass-flake amendment on soil microbial diversity (Figure 3.20 and Table 3.53) appeared to be slight. At $100 \mu \mathrm{g} / \mathrm{g}$ brass, a small enhancement was observed for Cinebar and Palouse+OM between 28 and 270 days of incubation. At $2500 \mu \mathrm{g} / \mathrm{g}$ brass, inhibition was noted in Burbank, Cinebar, and Palouse soil at 420 days.

Microbial diversity in soil exposed to BR/FO mixed smoke was not significantly impacted

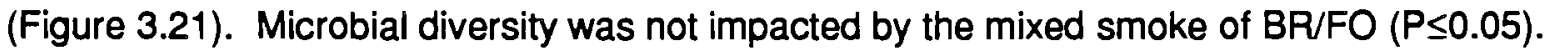

\subsubsection{Soil Nitrifying Bacteria}

Nitrogen is the nutrient most limiting in agricultural (Stevenson 1982) and arid land ecosystems (West and Skujins, 1978) for both plant and soil microbial growth and function. The conversion of organic nitrogen to available inorganic forms involves two distinct microbiological processes: ammonification, which converts organic nitrogen to ammonia, and nitrification, which transforms ammonia to nitrate. Nitrification in soil is mediated by the soil nitrifying bacteria. The Nitrosomonas sp. type microorganisms are responsible for the conversion of ammonia to nitrite and the Nitrobacter sp. type microorganisms are responsible for the further oxidization of nitrite to nitrate, a soluble and mobile form of nitrogen in soil utilizable by plants and by other microorganisms. 

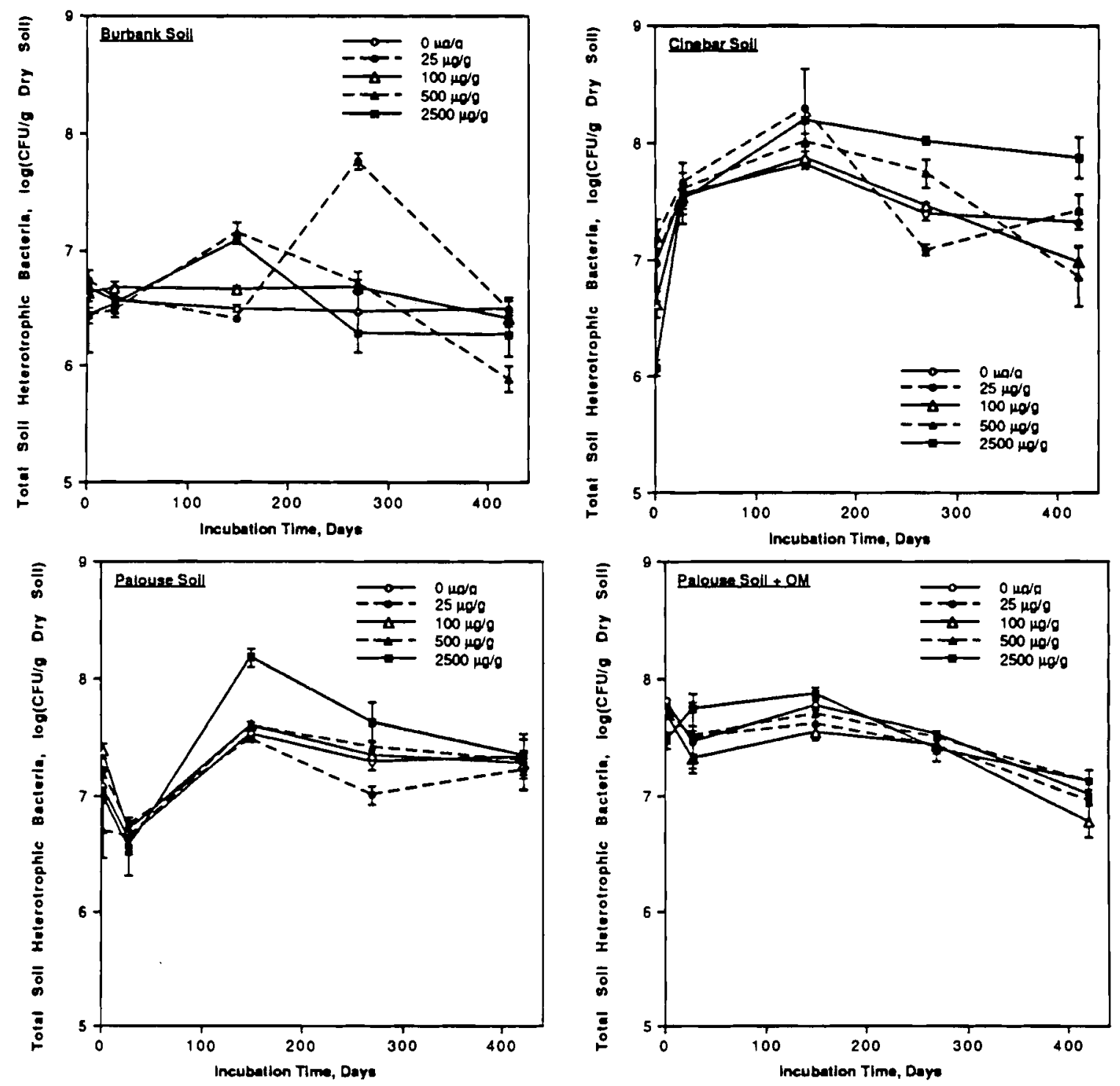

FIGURE 3.18. THE EFFECT OF BRASS FLAKE CONCENTRATION ON THE POPULATION OF TOTAL SOIL HETEROTROPHIC BACTERIA 
IABLE 3.51. THE EFFECT OF BRASS FLAKE CONCENTRATION ON THE POPULATION OF TOTAL SOIL HETEROTROPHIC BACTERIA

\begin{tabular}{|c|c|c|c|c|}
\hline \multirow{2}{*}{$\begin{array}{l}\text { Brass-Flake } \\
\text { Concentration }(\mu \mathrm{g} / \mathrm{g})\end{array}$} & \multicolumn{4}{|c|}{ Total Soil Heterotrophic Bacteria, $\log \left(\right.$ CFU/g dry soil) ${ }^{(a)}$} \\
\hline & Burbank & Cinebar & Palouse & Palouse+OM \\
\hline \multicolumn{5}{|l|}{ Incubation Time 2 days } \\
\hline 0 & $6.68(0.07)$ & $6.97(0.21)$ & $7.09(0.12)$ & $7.81(0.02)^{*}$ \\
\hline 25 & $6.75(0.08)$ & $7.18(0.08)$ & $7.23(0.00)$ & $7.74(0.02)^{*}$ \\
\hline 100 & $6.64(0.08)$ & $6.62(0.11)$ & $7.39(0.06)^{*}(b)$ & $7.71(0.05)^{*}$ \\
\hline 500 & $6.44(0.07)^{*}$ & $7.00(0.35)$ & $6.71(0.25)$ & $7.70(0.03)^{*}$ \\
\hline 2500 & $6.43(0.32)$ & $6.07(0.07)^{\star}$ & $7.01(0.06)$ & $7.48(0.07)^{\star}$ \\
\hline \multicolumn{5}{|c|}{ Incubation Time 28 days } \\
\hline 0 & $6.56(0.07)$ & $7.57(0.26)$ & $6.64(0.14)$ & $7.46(0.10)$ \\
\hline 25 & $6.59(0.10)$ & $7.66(0.08)$ & $6.74(0.08)$ & $7.51(0.03)$ \\
\hline 100 & $6.67(0.06)$ & $7.53(0.09)$ & $6.71(0.05)$ & $7.33(0.13)$ \\
\hline 500 & $6.48(0.02)$ & $7.61(0.22)$ & $6.65(0.14)$ & $7.52(0.28)$ \\
\hline 2500 & $6.53(0.11)$ & $7.50(0.04)$ & $6.55(0.24)$ & $7.74(0.14)$ \\
\hline \multicolumn{5}{|c|}{ Incubation Time 150 days } \\
\hline 0 & $6.50(0.03)$ & $7.82(0.04)$ & $7.53(0.06)$ & $7.78(0.04)$ \\
\hline 25 & $6.41(0.00)$ & $8.30(0.33)$ & $7.49(0.03)$ & $7.62(0.14)$ \\
\hline 100 & $6.66(0.03)^{*}$ & $7.88(0.11)$ & $7.61(0.03)$ & $7.55(0.06)^{*}$ \\
\hline 500 & $7.16(0.08)^{*}$ & $8.01(0.08)^{*}$ & $7.61(0.03)$ & $7.70(0.03)^{*}$ \\
\hline 2500 & $7.09(0.03)^{\star}$ & $8.20(0.00)^{*}$ & $8.18(0.08)^{*}$ & $7.88(0.05)^{*}$ \\
\hline \multicolumn{5}{|c|}{ Incubation Time 270 days } \\
\hline 0 & $6.47(0.22)$ & $7.40(0.06)$ & $7.29(0.07)$ & $7.53(0.03)$ \\
\hline 25 & $7.76(0.07)^{\star}$ & $7.09(0.05)^{\star}$ & $7.01(0.08)^{*}$ & $7.43(0.06)$ \\
\hline 100 & $6.68(0.06)$ & $7.46(0.03)$ & $7.35(0.04)$ & $7.43(0.06)$ \\
\hline 500 & $6.72(0.09)$ & $7.74(0.12)^{\star}$ & $7.42(0.05)$ & $7.51(0.03)$ \\
\hline 2500 & $6.28(0.17)$ & $8.02(0.04)^{*}$ & $7.64(0.16)^{*}$ & $7.41(0.12)$ \\
\hline \multicolumn{5}{|c|}{ Incubation Time 420 days } \\
\hline 0 & $6.50(0.09)$ & $7.33(0.06)$ & $7.34(0.15)$ & $7.01(0.04)$ \\
\hline 25 & $6.50(0.07)$ & $7.42(0.15)$ & $7.23(0.17)$ & $6.96(0.03)$ \\
\hline 100 & $6.41(0.07)$ & $6.98(0.13)$ & $7.28(0.06)$ & $6.78(0.14)$ \\
\hline 500 & $5.89(0.11)^{\star}$ & $6.86(0.26)$ & $7.31(0.02)$ & $7.13(0.03)$ \\
\hline 2500 & $6.27(0.19)$ & $7.88(0.08)^{*}$ & $7.35(0.19)$ & $7.12(0.10)$ \\
\hline
\end{tabular}

\footnotetext{
(a) Log(colony-forming-unit per gram dry soil), expressed as mean (standard deviation), $n=3$.

(b) "Denotes significant difference from control based on t-test, $p \leq 0.05$.
} 

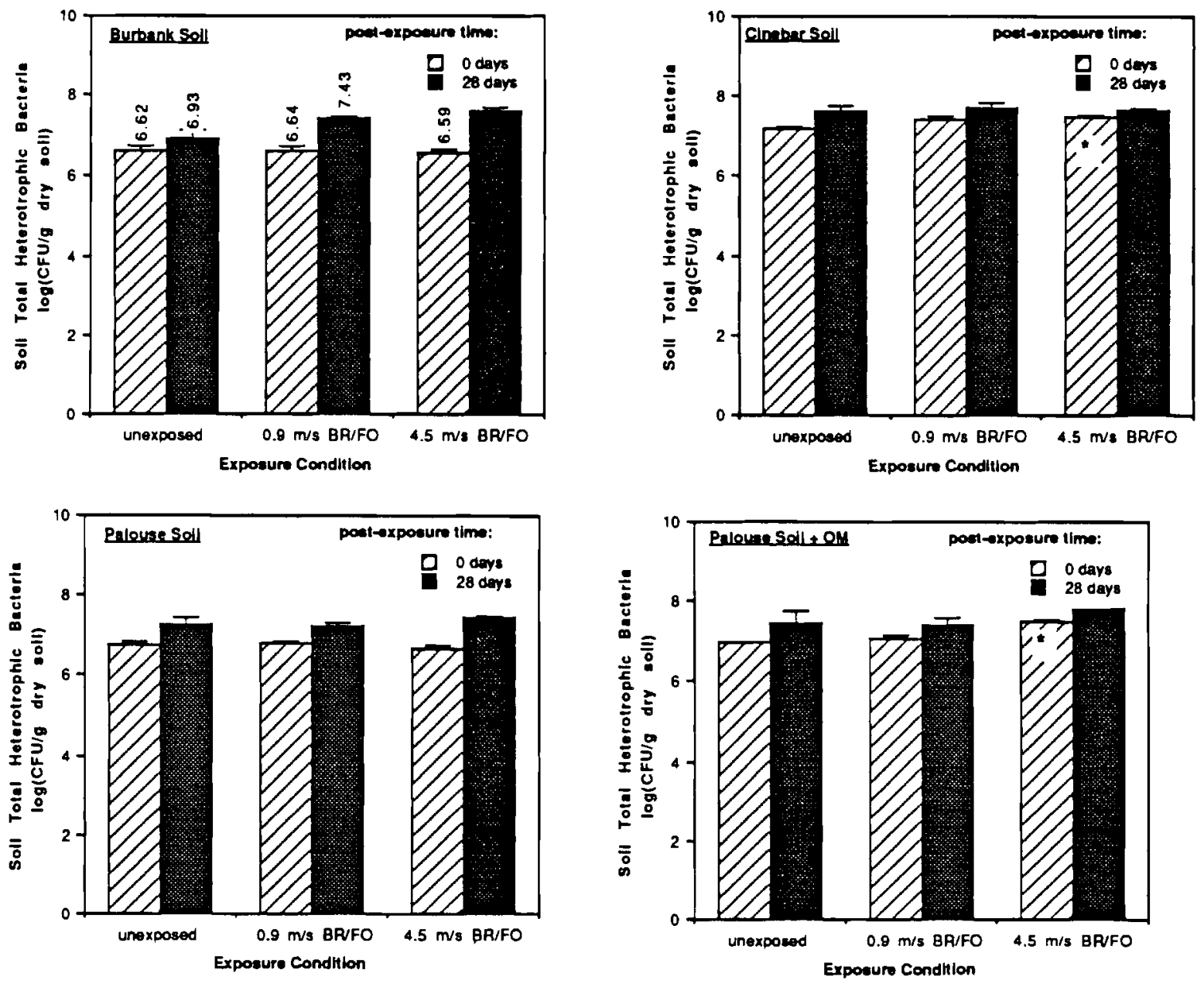

\section{EIGURE 3.19. THE EFFECT OF BRASS FLAKE/FOG OIL MIXED SMOKE ON THE POPULATION OF TOTAL SOIL HETEROTROPHIC BACTERIA}


IABLE 3.52. THE EFFECT OF BRASS-FLAKE/FOG-OIL MIXED SMOKE ON THE POPULATION OF TOTAL SOIL HETEROTROPHIC BACTERIA

\begin{tabular}{lccccc}
\hline \multirow{2}{*}{$\begin{array}{l}\text { Exposure } \\
\text { Condition }\end{array}$} & $\begin{array}{c}\text { Post-Exposure } \\
\text { Time (days) }\end{array}$ & \multicolumn{3}{c}{ Total Heterotrophic Bacteria, log(CFU/g dry soil) } \\
\cline { 3 - 6 } & & Burbank & Cinebar & Palouse & Palouse+OM \\
\hline unexposed & 0 & $6.62(0.15)$ & $7.18(0.07)$ & $6.75(0.10)$ & $6.95(0.02)$ \\
$0.9 \mathrm{~m} / \mathrm{s}$ BRFO & 0 & $6.64(0.12)$ & $7.42(0.08)$ & $6.78(0.05)$ & $7.07(0.06)$ \\
$4.5 \mathrm{~m} / \mathrm{s}$ BRFO & 0 & $6.59(0.08)$ & $7.48(0.05)^{*}(b)$ & $6.68(0.06)$ & $7.49(0.03)^{*}$ \\
& & & & & \\
unexposed & 28 & $6.93(0.20)$ & $7.64(0.13)$ & $7.26(0.18)$ & $7.44(0.30)$ \\
$0.9 \mathrm{~m} / \mathrm{s}$ BRFO & 28 & $7.43(0.04)$ & $7.70(0.15)$ & $7.21(0.12)$ & $7.41(0.17)$ \\
$4.5 \mathrm{~m} / \mathrm{s}$ BRFO & 28 & $7.60(0.09)$ & $7.65(0.07)$ & $7.44(0.06)$ & $7.86(0.06)$ \\
\hline
\end{tabular}
(a) Log(colony-forming-unit per gram dry soil), expressed as mean (standard deviation), $n=3$.
(b) *Denotes significant difference from control based on t-test, $p \leq 0.05$.

Pot Amendment. Except in Cinebar soil, populations of soil Nitrosomonas sp. decreased dramatically 2 to 28 days after the addition of $2500 \mu \mathrm{g} / \mathrm{g}$ brass. No effect was found for soil amended at concentrations of 25 to $500 \mu \mathrm{g} / \mathrm{g}$ except for Burbank soil exposed to 500 $\mu \mathrm{g} / \mathrm{g}$ (Table 3.54). A recovery and increase in the Nitrosomonas sp. population occurred after a prolonged incubation time of 420 days (Figure 3.22 ).

Numbers of soil Nitrobacter sp. declined when exposed to brass flake at $2500 \mu \mathrm{g} / \mathrm{g}$ and incubated for 2 to 28 days (Figure 3.24 and Table 3.56). However, as in the case with Nitrosomonas sp., the population was able to recover over time.

Aerosol Deposition to Soil. The population of soil Nitrosomonas sp. was not affected by the BR/FO exposure at $0.9 \mathrm{~m} / \mathrm{s}$, but it was inhibited by the $4.5 \mathrm{~m} / \mathrm{s}$ exposure in Burbank and Cinebar soil immediately after exposure (Figure 3.23 and Table 3.54 ). The population was able to recover to the level of the unexposed soil after 28 days.

Soil populations of Nitrobactersp. were not affected by the BR/FO smoke exposure at $0.9 \mathrm{~m} / \mathrm{s}$, but were initially inhibited by the $4.5 \mathrm{~m} / \mathrm{s}$ exposure in Burbank and Cinebar soils. After 28 days, these soils recovered to the control levels, while the Palouse soil had a significant decrease at this time (Figure 3.25 and Table 3.57). 

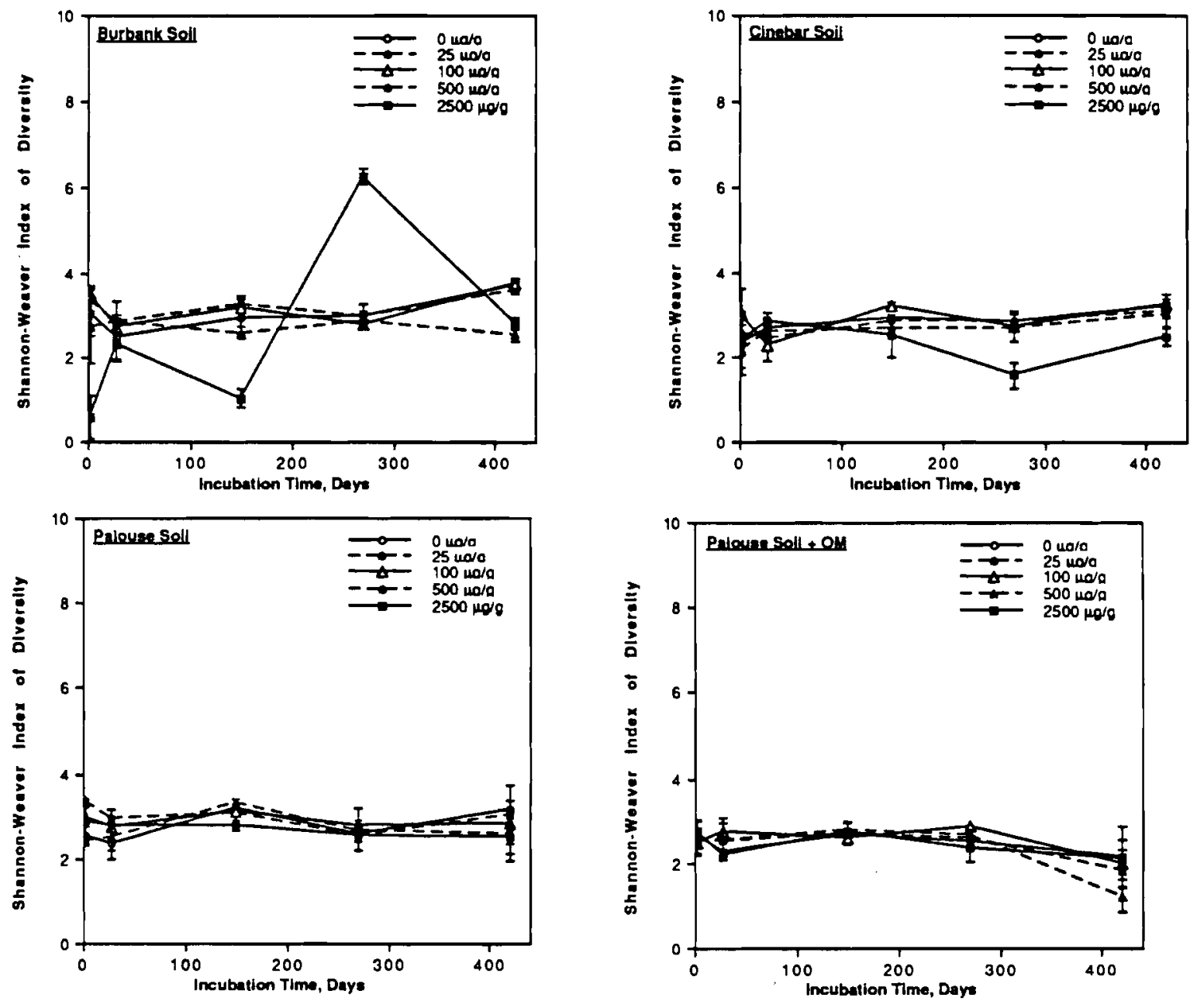

EIGURE 3.20. THE EFFECT OF BRASS-FLAKE CONCENTRATION ON SOIL MICROBIAL SPECIES DIVERSITY 
IABLE 3.53. THE EFFECT OF BRASS FLAKE CONCENTRATION ON SOIL MICROBIAL SPECIES DIVERSITY

\begin{tabular}{|c|c|c|c|c|}
\hline \multirow{2}{*}{$\begin{array}{l}\text { Brass Flake } \\
\text { Concentration }(\mu \mathrm{g} / \mathrm{g})\end{array}$} & \multicolumn{4}{|c|}{ Shannon-Weaver Index of Diversity(a) } \\
\hline & Burbank & Cinebar & Palouse & Palouse+OM \\
\hline \multicolumn{5}{|l|}{ Incubation Time 2 days } \\
\hline 0 & $3.06(0.54)$ & $2.32(0.00)$ & $2.58(0.24)$ & $2.68(0.14)$ \\
\hline 25 & $3.37(0.30)$ & $2.56(0.52)$ & $3.38(0.00)$ & $2.61(0.12)$ \\
\hline 100 & $3.50(0.18)$ & $3.02(0.60)$ & $3.00(0.25)$ & $2.46(0.21)$ \\
\hline 500 & $2.73(0.88)$ & $2.17(0.60)$ & $2.42(0.11)$ & $2.60(0.40)$ \\
\hline 2500 & $0.58(0.50)^{*}$ & $2.39(0.66)$ & $2.87(0.33)$ & $2.75(0.31)$ \\
\hline \multicolumn{5}{|c|}{ Incubation Time 28 days } \\
\hline 0 & $2.48(0.53)$ & $2.69(0.03)$ & $2.34(0.36)$ & $2.29(0.23)$ \\
\hline 25 & $2.86(0.06)$ & $2.43(0.26)$ & $2.98(0.19)$ & $2.50(0.27)$ \\
\hline 100 & $2.71(0.07)$ & $2.28(0.36)$ & $2.78(0.13)$ & $2.78(0.17)^{*}$ \\
\hline 500 & $2.84(0.48)$ & $2.61(0.05)$ & $2.53(0.34)$ & $2.58(0.52)$ \\
\hline 2500 & $2.30(0.39)$ & $2.85(0.19)$ & $2.80(0.15)$ & $2.19(0.12)$ \\
\hline \multicolumn{5}{|c|}{ Incubation Time 150 days } \\
\hline 0 & $2.91(0.17)$ & $2.92(0.07)$ & $3.22(0.19)$ & $2.70(0.25)$ \\
\hline 25 & $3.26(0.10)$ & $2.84(0.15)$ & $3.09(0.10)$ & $2.73(0.28)$ \\
\hline 100 & $3.18(0.29)$ & $3.22(0.09)^{*}$ & $3.11(0.17)$ & $2.59(0.11)$ \\
\hline 500 & $2.58(0.15)$ & $2.70(0.17)$ & $3.32(0.08)$ & $2.79(0.19)$ \\
\hline 2500 & $1.03(0.22)^{*}$ & $2.50(0.50)$ & $2.79(0.11)^{\star}$ & $2.76(0.06)$ \\
\hline \multicolumn{5}{|c|}{ Incubation Time 270 days } \\
\hline 0 & $2.97(0.10)$ & $2.83(0.19)$ & $2.62(0.17)$ & $2.52(0.09)$ \\
\hline 25 & $2.95(0.29)$ & $2.85(0.20)$ & $2.56(0.38)$ & $2.59(0.22)$ \\
\hline 100 & $2.76(0.12)$ & $2.73(0.36)$ & $2.81(0.41)$ & $2.87(0.02)^{*}$ \\
\hline 500 & $2.85(0.19)$ & $2.68(0.08)$ & $2.70(0.11)$ & $2.69(0.12)$ \\
\hline 2500 & $1.79(0.14)^{\circ}$ & $1.57(0.29)^{*}$ & $2.56(0.02)$ & $2.35(0.32)^{*}$ \\
\hline \multicolumn{5}{|c|}{ Incubation Time 420 days } \\
\hline 0 & $3.69(0.09)$ & $3.20(0.17)$ & $3.18(0.20)$ & $2.16(0.72)$ \\
\hline 25 & $3.58(0.07)$ & $3.09(0.17)$ & $3.05(0.10)$ & $1.83(0.10)$ \\
\hline 100 & $3.72(0.14)$ & $3.24(0.26)$ & $2.83(0.89)$ & $2.01(0.54)$ \\
\hline 500 & $2.50(0.14)^{*}$ & $3.01(0.30)$ & $2.60(0.47)$ & $1.23(0.39)$ \\
\hline 2500 & $2.80(0.13)^{*}$ & $2.47(0.20)^{*}$ & $2.51(0.26)^{*}$ & $2.10(0.20)$ \\
\hline
\end{tabular}

(a) Mean (standard deviation), $n=3$.

(b) "Denotes significant difference from control based on t-test, $p \leq 0.05$. 

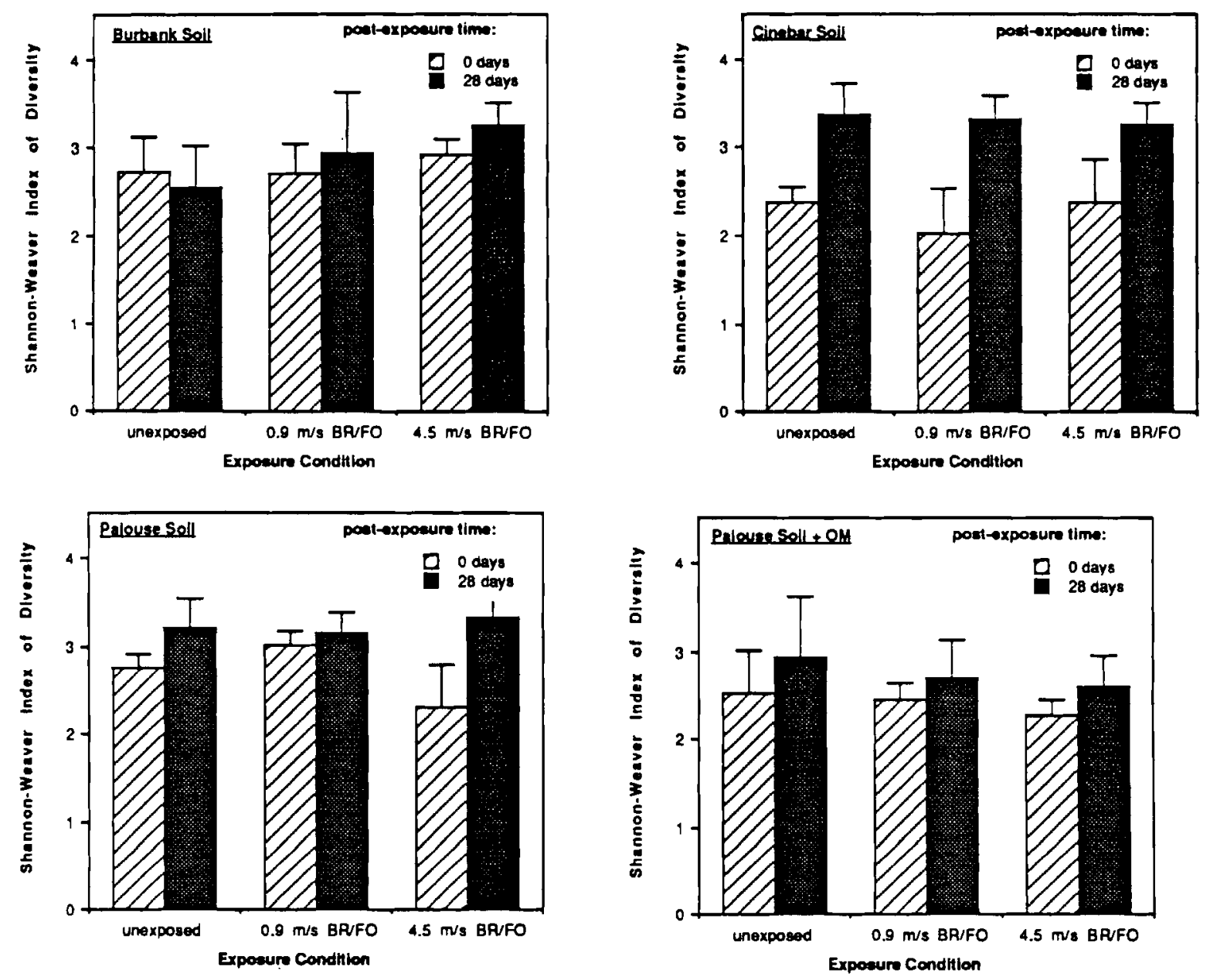

FIGURE 3.21. THE EFFECT OF BRASS FLAKE/FOG OIL MIXED SMOKE ON SOIL MICROBIAL SPECIES DIVERSITY 

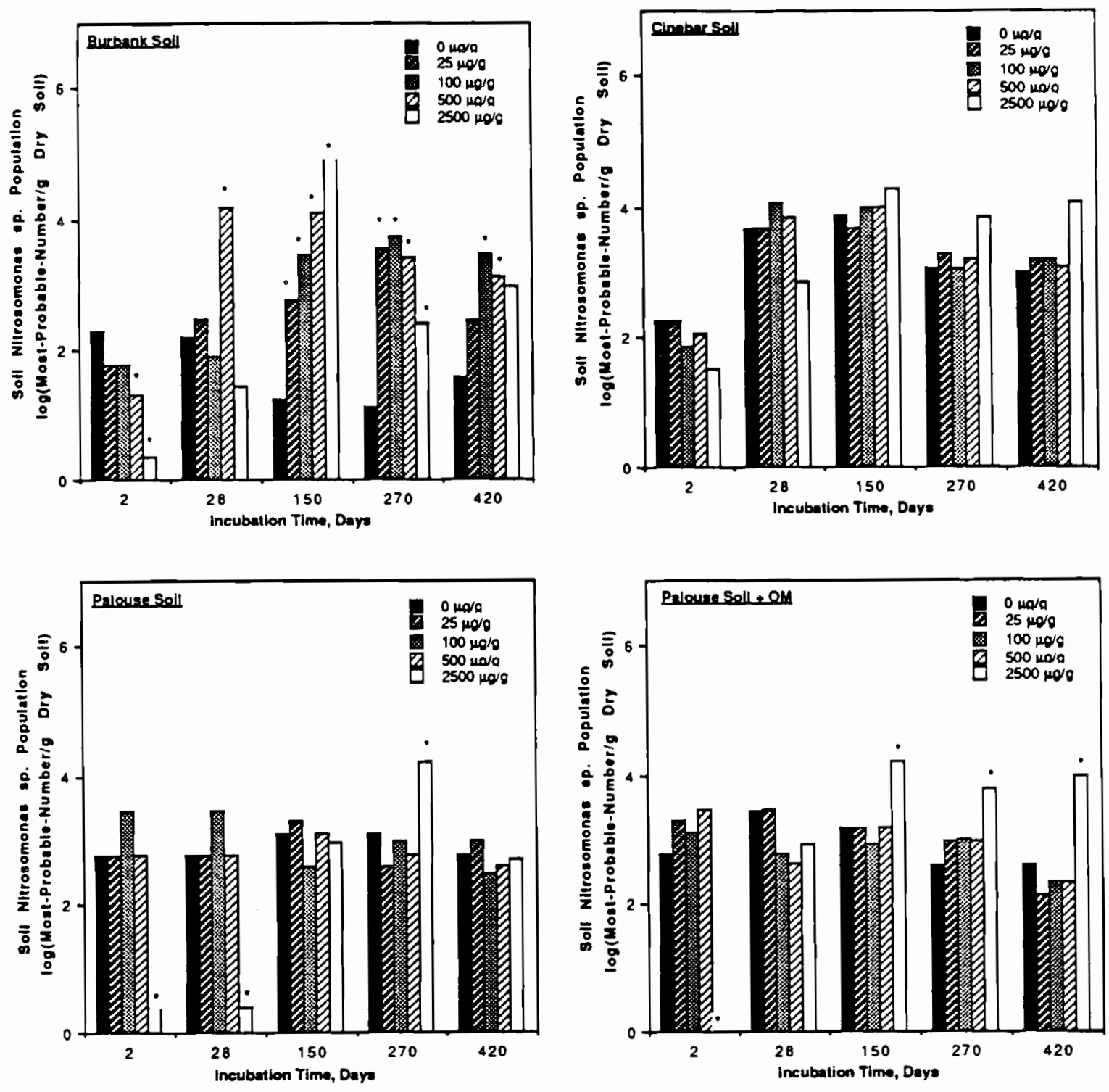

FIGURE 3.22. THE EFFECT OF BRASS FLAKE CONCENTRATION ON SOIL NITRIFYING BACTERIA-NITROSOMONAS SPECIES 
IABLE 3.54. THE EFFECT OF BRASS FLAKE CONCENTRATION ON SOIL NITRIFYING BACTERIA-NITROSOMONAS sp.

\begin{tabular}{|c|c|c|c|c|}
\hline \multirow{2}{*}{$\begin{array}{l}\text { Brass Flake } \\
\text { Concentration }(\mu \mathrm{g} / \mathrm{g})\end{array}$} & \multicolumn{4}{|c|}{ Soil Nitrobacter sp. Population, $\log (\mathrm{MPN} / \mathrm{g}$ dry soil) (a) } \\
\hline & Burbank & Cinebar & Palouse & Palouse+OM \\
\hline \multicolumn{5}{|l|}{ Incubation Time 2 days } \\
\hline 0 & 2.32 & 2.27 & 2.79 & 2.79 \\
\hline 25 & 1.78 & 2.27 & 2.79 & 3.33 \\
\hline 100 & 1.78 & 1.85 & 3.48 & 3.14 \\
\hline 500 & $1.32 *$ (b) & 2.05 & 2.79 & 3.48 \\
\hline 2500 & $0.34^{*}(c)$ & 1.52 & $0.40^{*}$ & $0.00^{*}$ \\
\hline \multicolumn{5}{|c|}{ Incubation Time 28 days } \\
\hline 0 & 2.20 & 3.67 & 2.79 & 3.44 \\
\hline 25 & 2.47 & 3.67 & 2.79 & 3.48 \\
\hline 100 & 1.92 & 4.06 & 3.48 & 2.79 \\
\hline 500 & $4.20^{\star}$ & 3.85 & 2.79 & 2.62 \\
\hline 2500 & 1.43 & 2.85 & $0.40^{*}$ & 2.94 \\
\hline \multicolumn{5}{|c|}{ Incubation Time 150 days } \\
\hline 0 & 1.23 & 3.86 & 3.14 & 3.21 \\
\hline 25 & $2.78^{*}$ & 3.68 & 3.32 & 3.21 \\
\hline 100 & $3.47^{*}$ & 3.99 & 2.61 & 2.93 \\
\hline 500 & $4.13^{*}$ & 4.00 & 3.13 & 3.21 \\
\hline 2500 & $4.93^{*}$ & 4.27 & 2.99 & $4.21^{* *}$ \\
\hline \multicolumn{5}{|c|}{ Incubation Time 270 days } \\
\hline 0 & 1.12 & 3.06 & 3.14 & 2.61 \\
\hline 25 & $3.58^{\star}$ & 3.28 & 2.61 & 2.99 \\
\hline 100 & $3.74^{*}$ & 3.06 & 3.00 & 3.00 \\
\hline 500 & $3.43^{*}$ & 3.21 & 2.78 & 2.99 \\
\hline 2500 & $2.42^{*}$ & 3.85 & $4.21^{*}$ & $3.79^{*}$ \\
\hline \multicolumn{5}{|c|}{ Incubation Time 420 days } \\
\hline 0 & 1.59 & 3.00 & 2.79 & 2.61 \\
\hline 25 & 2.45 & 3.21 & 3.00 & 2.14 \\
\hline 100 & $3.47^{*}$ & 3.21 & 2.48 & 2.33 \\
\hline 500 & $3.12^{*}$ & 3.07 & 2.61 & 2.33 \\
\hline 2500 & 2.99 & 4.06 & 2.70 & $3.99^{*}$ \\
\hline
\end{tabular}

(a) Log (most-probable-number population per gram dry soil), 95\% confidence level for the MPN enumeration with 5-replicate, 10 -fold dilution method is \pm 0.52 .

(b) "*Denotes significant difference from control based on t-test, $p \leq 0.10$.

(c) "Denotes significant difference from control based on t-test, $p \leq 0.05$. 

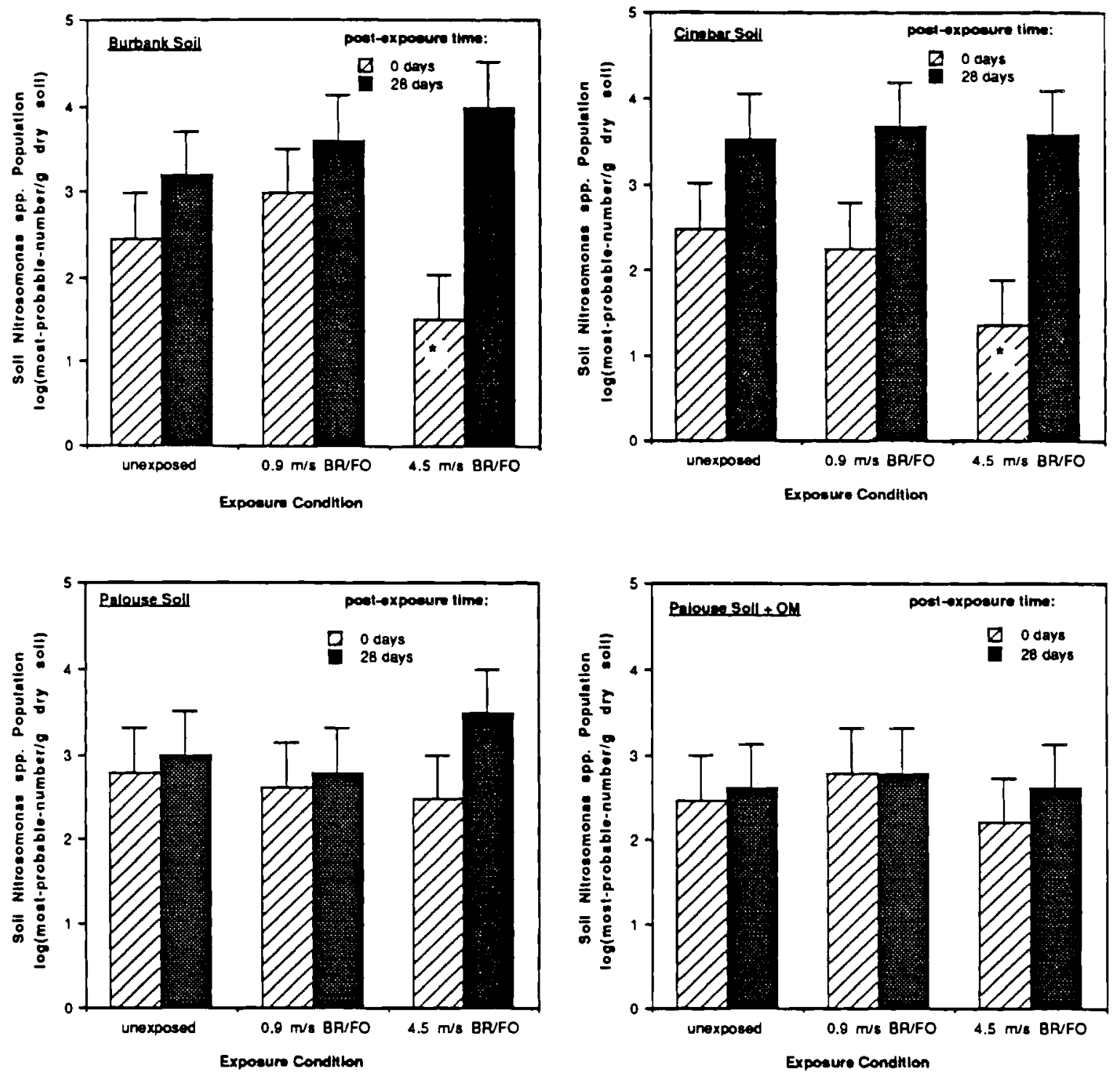

FIGURE 3.23. THE EFFECT OF BRASS FLAKE CONCENTRATION ON SOIL NITRIFYING BACTERIA-NITROBACTER SPECIES 

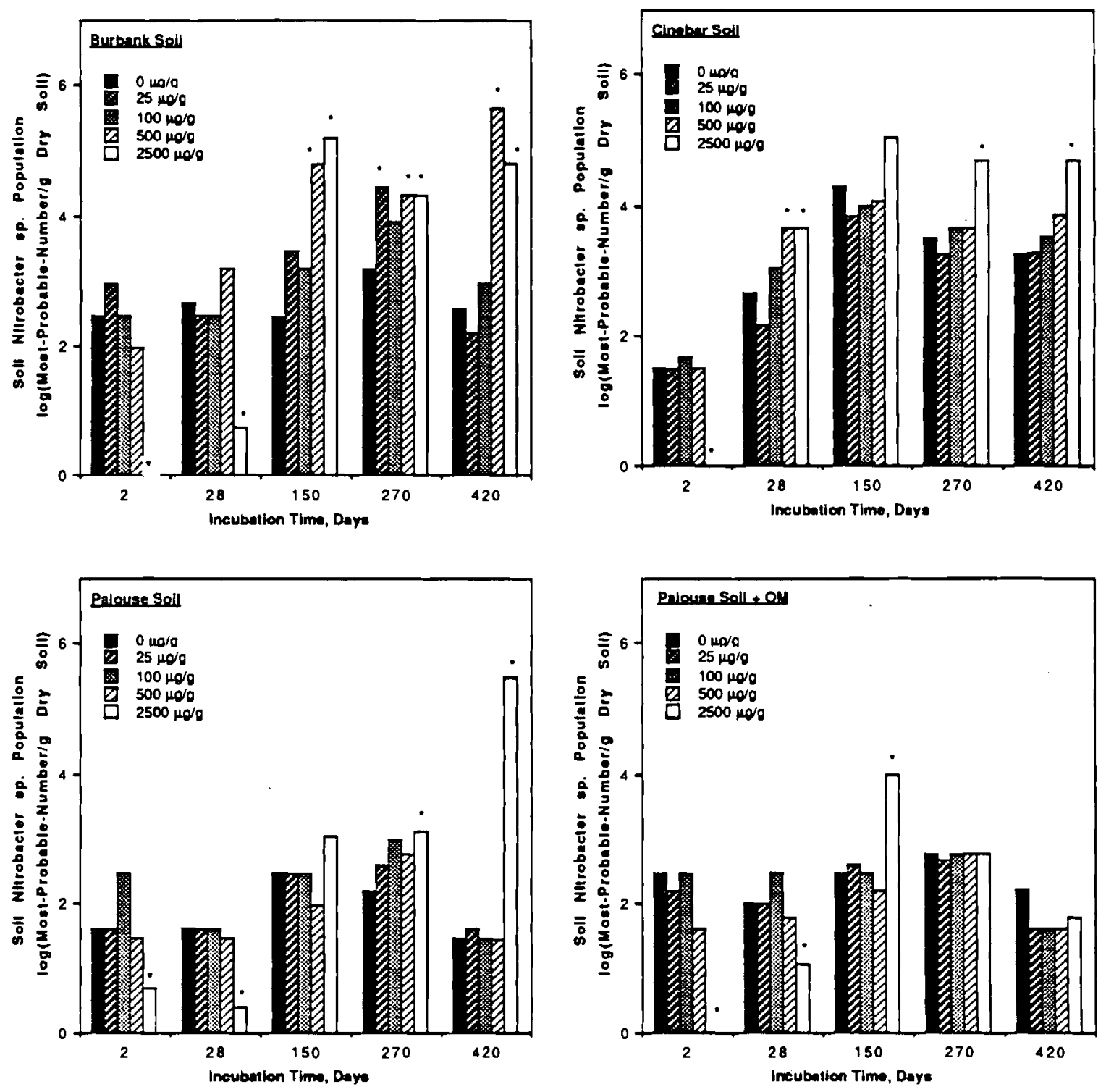

EIGURE 3.24. THE EFFECT OF BRASS FLAKE/FOG OIL MIXED SMOKE ON SOIL NITRIFYING BACTERIA-NITROSOMONAS SPECIES 
IABLE 3.55. THE EFFECT OF BRASS FLAKE CONCENTRATION ON SOIL NITRIFYING BACTERIA-NITROBACTER sp.

\begin{tabular}{|c|c|c|c|c|}
\hline \multirow{2}{*}{$\begin{array}{l}\text { Brass Flake } \\
\text { Concentration }(\mu \mathrm{g} / \mathrm{g})\end{array}$} & \multicolumn{4}{|c|}{ Soil Nitrobacter sp. Population, log (MPN/g dry soil)(a) } \\
\hline & Burbank & Cinebar & Palouse & Palouse+OM \\
\hline \multicolumn{5}{|l|}{ Incubation Time: 2 days } \\
\hline 0 & 2.47 & 1.52 & 1.62 & 2.48 \\
\hline 25 & 2.99 & 1.51 & 1.62 & 2.21 \\
\hline 100 & 2.47 & 1.68 & 2.48 & 2.48 \\
\hline 500 & 1.99 & 1.52 & 1.46 & 1.62 \\
\hline 2500 & $0.00 *(b)$ & $0.00^{*}$ & $0.70^{* *(c)}$ & $0.00^{*}$ \\
\hline \multicolumn{5}{|c|}{ Incubation Time: 28 days } \\
\hline 0 & 2.69 & 2.67 & 1.62 & 2.00 \\
\hline 25 & 2.47 & 2.19 & 1.62 & 2.00 \\
\hline 100 & 2.47 & 3.06 & 1.62 & 2.48 \\
\hline 500 & 3.20 & $3.67^{\star * *}$ & 1.46 & 1.79 \\
\hline 2500 & $0.74^{*}$ & $3.67^{* *}$ & $0.40^{*}$ & $1.07^{* *}$ \\
\hline \multicolumn{5}{|c|}{ Incubation Time: 150 days } \\
\hline 0 & 2.46 & 4.29 & 2.48 & 2.47 \\
\hline 25 & 3.47 & 3.85 & 2.47 & 2.61 \\
\hline 100 & 3.20 & 3.99 & 2.47 & 2.47 \\
\hline 500 & $4.78^{*}$ & 4.07 & 1.99 & 2.21 \\
\hline 2500 & $5.20^{*}$ & 5.05 & 3.06 & $3.99^{*}$ \\
\hline \multicolumn{5}{|c|}{ Incubation Time: 270 days } \\
\hline 0 & 3.19 & 3.52 & 2.21 & 2.78 \\
\hline 25 & $4.45^{*}$ & 3.28 & 2.61 & 2.69 \\
\hline 100 & 3.91 & 3.68 & 3.00 & 2.79 \\
\hline 500 & $4.31^{* *}$ & 3.68 & 2.78 & 2.79 \\
\hline 2500 & $4.31^{* *}$ & $4.68^{* *}$ & $3.13^{* *}$ & 2.79 \\
\hline \multicolumn{5}{|c|}{ Incubation Time: 420 days } \\
\hline 0 & 2.59 & 3.28 & 1.46 & 2.24 \\
\hline 25 & 2.22 & 3.29 & 1.62 & 1.61 \\
\hline 100 & 2.99 & 3.55 & 1.46 & 1.62 \\
\hline 500 & $5.63^{*}$ & 3.86 & 1.45 & 1.62 \\
\hline 2500 & $4.78^{*}$ & $4.68^{*}$ & $5.48^{*}$ & $1.79^{*}$ \\
\hline
\end{tabular}

(a) Log (most-probable-number population per gram dry soil), $95 \%$ confidence level for the MPN enumeration. with 5-replicate, 10 -fold dilution method is \pm 0.52 .

(b) "Denotes significant difference from control based on t-test, $p \leq 0.05$.

(c) "Denotes significant difference from control based on t-test, $p \leq 0.10$. 
IABLE 3.56. THE EFFECT OF BRASS FLAKE/FOG OIL MIXED SMOKE ON SOIL NITRIFYING BACTERIA-NITROSOMONAS sp.

\begin{tabular}{|c|c|c|c|c|c|}
\hline \multirow{2}{*}{$\begin{array}{l}\text { Exposure } \\
\text { Condition }\end{array}$} & \multirow{2}{*}{$\begin{array}{l}\text { Post-Exposure } \\
\text { Time (days) }\end{array}$} & \multicolumn{4}{|c|}{ Soil Nitrobacter sp. Population, $\log \left(\mathrm{MPN} / \mathrm{g}\right.$ dry soil) ${ }^{(a)}$} \\
\hline & & Burbank & Cinebar & Palouse & Palouse+OM \\
\hline unexposed & 0 & 2.46 & 2.49 & 2.79 & 2.47 \\
\hline $0.9 \mathrm{~m} / \mathrm{s} \mathrm{BR} / \mathrm{FO}$ & 0 & 2.98 & 2.26 & 2.62 & 2.79 \\
\hline $4.5 \mathrm{~m} / \mathrm{s} \mathrm{BR} / \mathrm{FO}$ & 0 & $1.51^{* *(b)}$ & $1.37^{*}$ & 2.48 & 2.21 \\
\hline unexposed & 28 & 3.19 & 3.53 & 2.99 & 2.61 \\
\hline $0.9 \mathrm{~m} / \mathrm{s} \mathrm{BR} / \mathrm{FO}$ & 28 & 3.60 & 3.67 & 2.79 & 2.79 \\
\hline $4.5 \mathrm{~m} / \mathrm{s} \mathrm{BR} / \mathrm{FO}$ & 28 & 3.98 & 3.58 & 3.48 & 2.61 \\
\hline
\end{tabular}

(a) Log(most-probable-number population per gram dry soil), $95 \%$ confidence level for the MPN enumeration with 5 -replicate, 10 -fold dilution method is \pm 0.52 . No significant difference from control was found based on t-test, $p \leq 0.05$.

(b) *- Denotes significant difference from control based on $t$-test, $p \leq 0.10$.

\subsection{EFFECTS OF BRASS AND BRASS/FOG OIL ON SOILINVERTEBRATES}

We sought to determine the effects of brass flake on the survivability and viability/activity of invertebrates. Earthworms (Eisenia foetida) were placed in coupons containing artificial soil $(70 \mathrm{~g})$ and were then exposed to the brass flake during the tests. The results, given in Table 3.58, indicate only a slightly deleterious effect on the populations, particularly at the higher wind speeds and therefore the higher loading levels (> $445 \mu \mathrm{g} / \mathrm{cm}^{2}$ ). This is most evident at the $10 \mathrm{mph}$ test, where the animals appeared to lose some of their responsiveness to stimuli (handling) by 14 days post-exposure. However, in contrast to experiments with some other smokes (e.g., WP and HC; Van Voris et al. 1986; Cataldo et al. 1990), where decided numbers of deaths occurred during this period, no fatalities among the populations exposed were noted. In fact, egg casings and juvenile hatching were noted in some of the coupons.

Exposure of earthworms to BR/FO aerosols (Table 3.59) at mass loadings of $200 \mu \mathrm{g}$ brass $/ \mathrm{cm}^{2}$ had no effect on survivability and only moderately affected tactile activity. Thus there is no indication that fog oil ameliorates or intensifies the effects of brass. 

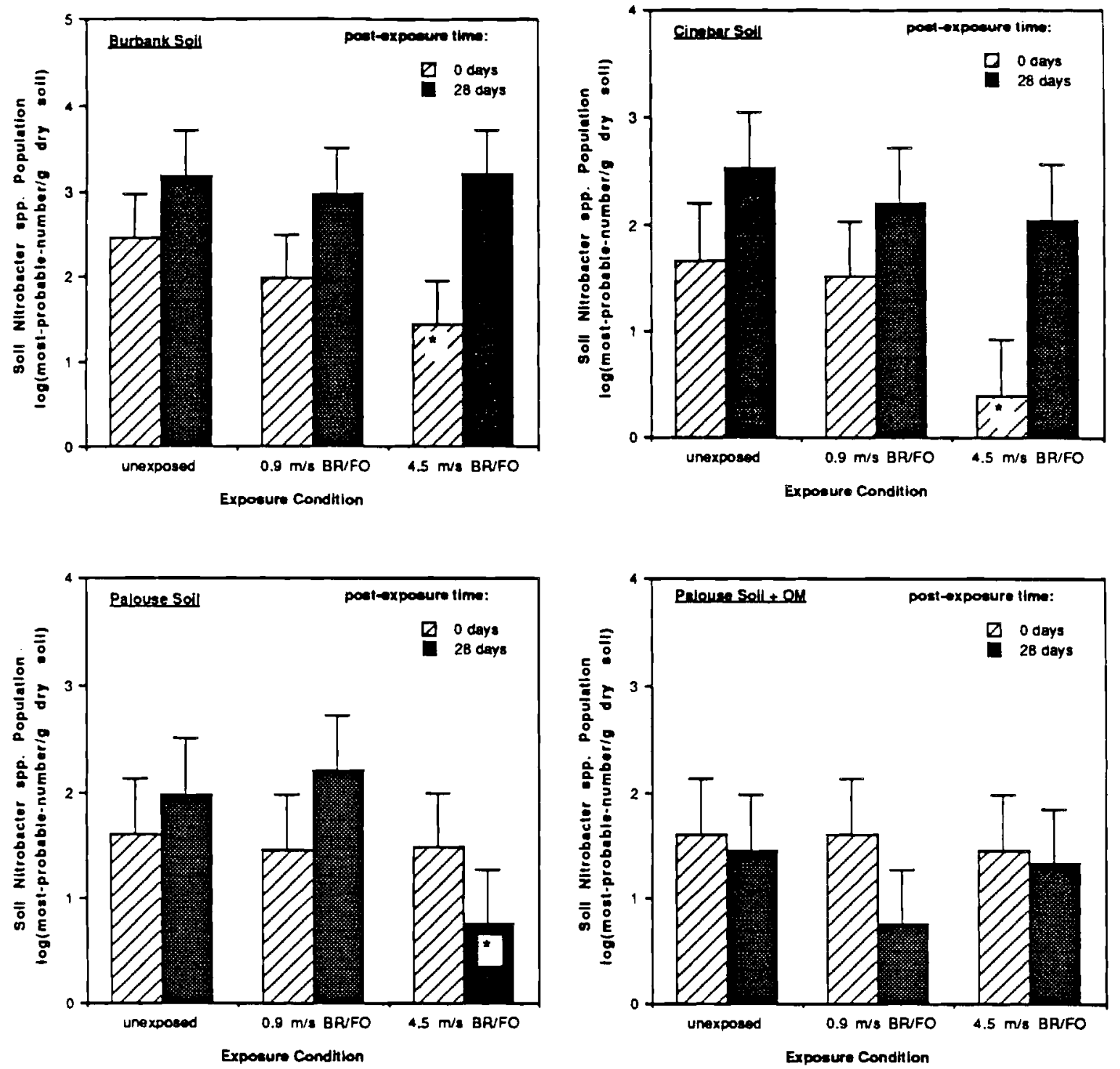

EIGURE 3.25. THE EFFECT OF BRASS FLAKE/FOG OIL MIXED SMOKE ON SOIL NITRIFYING BACTERIA-NITROBACTER SPECIES 
IABLE 3.57. THE EFFECT OF BRASS FLAKE/FOG OIL MIXED SMOKE ON SOIL NITRIFYING BACTERIA-NITROBACTER sp.

\begin{tabular}{|c|c|c|c|c|c|}
\hline \multirow{2}{*}{$\begin{array}{l}\text { Exposure } \\
\text { Condition }\end{array}$} & \multirow{2}{*}{$\begin{array}{l}\text { Post-Exposure } \\
\text { Time (days) }\end{array}$} & \multicolumn{4}{|c|}{ Soil Nitrobacter sp. Population, log (MPN/g dry soil)(a) } \\
\hline & & Burbank & Cinebar & Palouse & Palouse+OM \\
\hline unexposed & 0 & 2.46 & 1.67 & 1.61 & 1.61 \\
\hline $0.9 \mathrm{~m} / \mathrm{s} \mathrm{BR} / \mathrm{FO}$ & 0 & 1.98 & 1.51 & 1.46 & 1.61 \\
\hline $4.5 \mathrm{~m} / \mathrm{s} \mathrm{BR} / \mathrm{FO}$ & 0 & $1.44^{* *}$ (b) & $0.40^{*}(\mathrm{c})$ & 1.48 & 1.46 \\
\hline unexposed & 28 & 3.19 & 2.53 & 1.99 & 1.46 \\
\hline $0.9 \mathrm{~m} / \mathrm{s} \mathrm{BR} / \mathrm{FO}$ & 28 & 2.98 & 2.19 & 2.21 & 0.75 \\
\hline $4.5 \mathrm{~m} / \mathrm{s}$ BR/FO & 28 & 3.20 & 2.04 & $0.75^{*}$ & 1.33 \\
\hline
\end{tabular}

(a) Log (most-probable-number population per gram dry soil), $95 \%$ confidence level for the MPN enumeration with 5-replicate, 10-fold dilution method is \pm 0.52 .

(b) "Denotes significant difference from control based on t-test, $p \leq 0.10$.

(c) "Denotes significant difference from control based on t-test, $p \leq 0.05$.

IABLE 3.58. INFLUENCE OF SOIL-DEPOSITED BRASS FLAKE ON THE SURVIVAL OF EARTHWORMS (Eisenia foetida). WORMS WERE PLACED IN ARTIFICIAL SOILS (70 g), EXPOSED TO BRASS FLAKE, AND HELD FOR 14 DAYS POST-EXPOSURE.

\begin{tabular}{|c|c|c|c|c|}
\hline $\begin{array}{l}\text { Experiment } \\
\text { Number }\end{array}$ & $\begin{array}{l}\text { Wind Speed } \\
(\mathrm{m} / \mathrm{s})\end{array}$ & $\begin{array}{l}\text { Soil Mass Loading } \\
\qquad\left(\mu \mathrm{g} / \mathrm{cm}^{2}\right)\end{array}$ & $\begin{array}{c}\text { Survival } \\
\text { (Average } \mathrm{SD}, \mathrm{n}=3 \text { ) }\end{array}$ & Condition \\
\hline BR-13 & 0.9 & $73.3 \pm 29.5$ & $\begin{array}{l}10 / 10 \\
10 / 10 \\
10 / 10\end{array}$ & $\begin{array}{l}\text { Healthy, Active } \\
\text { Healthy, Active } \\
\text { Healthy, Active }\end{array}$ \\
\hline BR-12 & 1.8 & $107.5 \pm 65.0$ & $\begin{array}{l}10 / 10 \\
11^{(a) / 10} \\
10 / 10\end{array}$ & $\begin{array}{l}\text { Healthy, Active } \\
\text { Healthy, Active } \\
\text { Healthy, Active }\end{array}$ \\
\hline BR-11 & 2.7 & $204.1 \pm 39.6$ & $\begin{array}{l}10 / 10 \\
10 / 10 \\
10 / 10\end{array}$ & $\begin{array}{l}\text { Moderate Activity } \\
\text { Healthy, Active } \\
\text { Moderate Activity }\end{array}$ \\
\hline BR-10 & 4.5 & $445.5 \pm 169.4$ & $\begin{array}{l}10 / 10 \\
12^{(a)} / 10 \\
10 / 10\end{array}$ & $\begin{array}{l}\text { Sluggish, Inactive } \\
\text { Moderate Activity } \\
\text { Healthy, Active }\end{array}$ \\
\hline
\end{tabular}

(a) Eggs laid and hatched. 
IABLE 3.59. INFLUENCE OF SOIL-DEPOSITED BRASS FLAKE/FOG OIL ON THE SURVIVAL OF EARTHWORMS (Eisenia foetida). WORMS WERE PLACED IN ARTIFICIAL SOILS (70 g), EXPOSED TO BRASS FLAKE IN BR/FO, AND HELD FOR 14 DAYS POST-EXPOSURE.

\begin{tabular}{|c|c|c|c|c|}
\hline $\begin{array}{l}\text { Experiment } \\
\text { Number }\end{array}$ & $\begin{array}{l}\text { Wind Speod } \\
\qquad(\mathrm{m} / \mathrm{s})\end{array}$ & $\begin{array}{l}\text { Soil Mass Loading } \\
\qquad\left(\mu \mathrm{g} / \mathrm{cm}^{2}\right)\end{array}$ & $\begin{array}{c}\text { Survival } \\
\text { (Average } \pm S D, n=3 \text { ) }\end{array}$ & Condition \\
\hline BR/FO-03 & 0.9 & $145.45 \pm 32.88$ & $\begin{array}{l}8 / 10 \\
10 / 10 \\
10 / 10\end{array}$ & $\begin{array}{l}\text { Moderate Activity } \\
\text { Healthy, Active } \\
\text { Moderate Activity }\end{array}$ \\
\hline BR/FO-06 & 4.5 & $216.36 \pm 189.79$ & $\begin{array}{l}10 / 10 \\
11^{(a)} / 10 \\
11^{(a)} / 10\end{array}$ & $\begin{array}{l}\text { Moderate Activity } \\
\text { Moderate Activity } \\
\text { Moderate Activity }\end{array}$ \\
\hline
\end{tabular}

(a) Eggs laid and hatched.

\subsection{SOIL MOBILITY OF BRASS - SOIL COLUMN STUDIES}

Brass flake was neutron-activated to produce a ${ }^{65} \mathrm{Zn}$-tagged brass. This material then was applied to column surfaces to determine the mobility of weathered soluble constituents, using $\mathrm{Zn}$ as the indicator ion. Radioactive brass was uniformly mixed with soil and applied to the upper $0.5 \mathrm{~cm}$ of the soil columns. At periodic intervals the columns were scanned to spatially locate both the radioactivity and any downward migration. The indicators of migration used included peak width (PW) and peak maximum depth (PMD), as shown in Table 3.60. The PMD values for the 8- and 24-week periods (note standard deviations) indicate that any column settling occurred before 8 weeks. Between 24 and 48 weeks, the PMD increased by 0.06 to $0.43 \mathrm{~cm}$ in the four soil treatments. In addition, the average PW values increase by 0.7 to $0.9 \mathrm{~cm}$ over the 40-week interval. This was the result of a downward migration of solublized $\mathrm{Zn}$. Although there are slight differences in migration for the four soils, it is clear that the CEC of these soils is effective in retarding solubilized brass constituents. For Cinebar soil leached with $\mathrm{pH} 6.5$ versus 4.5 rainwater, no significant differences $(P \geq 0.1)$ in migration are noted; this likely indicates that the added acidity did not exceed the buffering capacity of the soil. 
IABLE 3,60. MOBILITY OF ACTIVATED BRASS FLAKE (ZINC-65) IN SOIL COLUMNS WITH TIME. COLUMNS OF FIVE SOIL TYPES WERE SURFACE-

AMENDED WITH $0.5 \mathrm{~cm}$ OF ACTIVATED BRASS FLAKE, WATERED WEEKLY TO SLIGHTLY ABOVE FIELD CAPACITY USING ARTIFICIAL RAINWATER OF EITHER PH 6.5 OR 4.5, AND SCANNED AT PERIODIC INTERVALS OVER A 48-WEEK PERIOD. DATA ARE AVERAGES \pm SD OF COLUMNS $(n=3)$ AND INCLUDE PEAK WIDTH AND DISTANCE OF PEAK CENTER MOVEMENT INTO COLUMN (cm).

\begin{tabular}{|c|c|c|c|c|c|c|}
\hline \multirow[b]{2}{*}{$\begin{array}{l}\text { Rainwater } \\
\mathrm{pH} / \text { Soil }\end{array}$} & \multicolumn{2}{|c|}{8 Weeks } & \multicolumn{2}{|c|}{24 Weeks } & \multicolumn{2}{|c|}{48 Weoks } \\
\hline & $\begin{array}{l}\text { Peak } \\
\text { Width } \\
\text { (cm) }\end{array}$ & $\begin{array}{l}\text { Peak Maximum } \\
\text { Depth } \\
\text { (cm) }\end{array}$ & $\begin{array}{l}\text { Peak } \\
\text { Width } \\
\text { (cm) }\end{array}$ & $\begin{array}{l}\text { Peak Maximum } \\
\text { Depth } \\
\text { (cm) }\end{array}$ & $\begin{array}{l}\text { Peak } \\
\text { Width } \\
\text { (cm) }\end{array}$ & $\begin{array}{c}\text { Peak Maximum } \\
\text { Depth } \\
\text { (cm) }\end{array}$ \\
\hline
\end{tabular}

pH 6.5

$\begin{array}{lllllll}\text { Burbank } & 2.03 \pm 0.06(a) & 0.00(a) & 2.95 \pm 0.14 & -0.29 \pm 0.24 & 2.94 \pm 0.00 & 0.43 \pm 0.20 \\ \text { Palouse } & 2.27 \pm 0.06 & 0.00 & 2.99 \pm 0.20 & -0.26 \pm 0.23 & 3.20 \pm 0.00 & 0.06 \pm 0.13 \\ \text { Palouse/OM } & 2.20 \pm 0.00 & 0.00 & 2.86 \pm 0.07 & -0.14 \pm 0.41 & 3.07 \pm 0.00 & 0.33 \pm 0.30 \\ \text { Cinebar } & 2.30 \pm 0.00 & 0.00 & 3.03 \pm 0.20 & -0.14 \pm 0.25 & 3.03 \pm 0.27 & 0.23 \pm 0.14\end{array}$

pH 4.5

Cinebar

$2.30 \pm 0.10$

0.00

$3.16 \pm 0.15 \quad-0.09 \pm 0.31$

$3.11 \pm 0.15$

$0.08 \pm 0.2$

(a) Baseline measurement following initial column equilibration. 


\subsection{CONCLUSIONS}

The environmental fate and effects of brass were investigated for the two principal routes of biological exposure, airborne deposition of brass and brass/fog-oil obscurant mixtures and brass weathering in soil. Soils were amended to simulate weathering and potential impacts from deposition. Aerosols containing brass were generated and characterized, and deposition both to foliar surfaces and to soils was determined. Impacts of deposited brass were assessed based on their contact toxicity to vegetation. Soil amendment studies were performed to ascertain weathering rates and to determine the effects of different brass concentrations on plant growth and on soil microbial processes. In addition, soil columns were used to determine whether brass weathering influenced the migration of $\mathrm{Cu}$ and $\mathrm{Zn}$ through soil profiles.

\subsection{AEROSOL CHABACTERIZATION}

Brass aerosol mass concentrations ranged from 132 to $177 \mathrm{mg} / \mathrm{m}^{3}$ during the brassonly (BR) wind-speed tests, were approximately $90 \mathrm{mg} / \mathrm{m}^{3}$ during the brass range-finding tests, and ranged from 19 to $83 \mathrm{mg} / \mathrm{m}^{3}$ during the brass/fog oil (BR/FO) wind-speed tests. Particle size distributions during BR and BR/FO tests were based on total particulate mass deposited to the various stages of Andersen cascade impactors. Measured distributions indicate an AMMD for brass aerosols of approximately 5 to $6 \mu \mathrm{m}$. Those of FO aerosols were .shown by Cataldo et al. (1989) to be about 2 to $3 \mu \mathrm{m}$. In addition to having different particle sizes, the dry brass particles have surface attraction characteristics different from the liquid FO droplets. Thus the transport and deposition characteristics of the two obscurant aerosols were not expected to be similar.

\subsection{DEPOSITION VELOCITIES FOR PLANT AND SOIL SUREACES}

The deposition velocity $\left(V_{d}\right)$ of brass alone to foliar surfaces increases with increasing wind speed, and ranges from $0.1 \mathrm{~cm} / \mathrm{s}$ at $0.9 \mathrm{~m} / \mathrm{s}(2 \mathrm{mph})$ to $1.0 \mathrm{~cm} / \mathrm{s}$ at $4.5 \mathrm{~m} / \mathrm{s}$ (10 mph). Interception or collection efficiency was higher for sagebrush than for the other plant species. Values of $V_{d}$ are at least one to two orders of magnitude greater than those reported for $P, F O$, and HC smokes (Van voris et al. 1987; Cataldo et al. 1989, 1990a). The deposition velocity of brass delivered as BR/FO aerosols ranged from 0.3 to $60 \mathrm{~cm} / \mathrm{s}$ for foliar surfaces. This velocity is substantially greater than that observed for brass alone. Deposition to bush bean and tall fescue foliage is nearly an order of magnitude less than that for sagebrush and pines. The co-deposition of the fog oil to the leaf surface apparently either prevented resuspension of the deposited brass or affected brass agglomeration, increasing its effective size and deposition rate. 


\subsection{CONTACT PHYTOTOXICITY AND RESIDUAL EFEECTS OF BR AND BR/FO AEROSOLS}

Contact toxicity of brass alone was not observed at mass loadings of up to $700 \mu \mathrm{g} / \mathrm{cm}^{2}$, equivalent to a field exposure of $100 \mathrm{mg} \mathrm{brass} / \mathrm{m}^{3}$ for $24 \mathrm{~h}$. Exposing plants to aerosols containing BR/FO resulted in moderate toxicity, but this is assumed to be the result of the FO, not the brass. Brass deposition to foliage has only a short-term, minimal effect on plant gas exchange, a result, we believe, of the shading effect of foliar-deposited brass. Similarly, reduced dry-matter production in brass-contaminated plants most likely results from the shading effect. No residual effects of second-harvest biomass production were noted following brass deposition, indicating that neither $\mathrm{Cu}$ nor $\mathrm{Zn}$ was significantly weathered and foliarly absorbed.

\subsection{BRASS SOIL AMENDMENT STUDIES}

Soils were uniformily mixed with brass flake to provide treatments containing 0,25 , 100,500 , and $2500 \mu \mathrm{g}$ brass/g dry wt soil. These treatments were used to assesss solubilization/weathering of the brass, soil ionic balance, plant impacts, and soil microbial effects.

\section{Soil Chemistry}

The $\mathrm{pH}$ of soils decreased with increasing brass amendment level and time of incubation. The $\mathrm{pH}$ of soils increased by 0.8 to $1.0 \mathrm{pH}$ units over the 440 -day incubation. The change in $\mathrm{pH}$ results either from a disruption of hydrogen ion equilibrium by solubilized components of the brass or from the effects of brass constituents on microbial activity.

Selective extractions were used to evaluate brass weathering and to determine the fate of solubilized $\mathrm{Cu}$ and $\mathrm{Zn}$. In general, the amount of extractable $\mathrm{Cu}$ and $\mathrm{Zn}$ in soils increased by 100 days post-amendment and changed little by 440 days. In the intervening period, weathered $\mathrm{Cu}$ and $\mathrm{Zn}$ likely became tightly sorbed to nonexchangeable sites, disrupting the extractable quantities of other ions in soil. Most noticeably, $P$ decreases and ammonia and nitrate concentrations increase; this likely results from a disruption on soil microbial processes.

All soils show similarly low exchangeable $\mathrm{Cu}$, while exchangeable $\mathrm{Zn}$ is depressed in Burbank and dramatically increased in the other soils. Inorganically bound $\mathrm{Cu}$ predominants in Burbank but is less important for the other soil treatments, particularly at lower amendment levels; inorganically bound $\mathrm{Zn}$ predominates in Burbank and is a major compartment in Cinebar, but it is less important for Palouse. Copper in the organically bound compartment is increasingly important with decreasing brass concentration, particularly for Palouse, and $\mathrm{Zn}$ slightly shows a similar trend. These trends may reflect limited organic 
ligands in the soils used. Residual $\mathrm{Cu}$ is greatest for Cinebar, while residual $\mathrm{Zn}$ is greatest for Burbank and for the lower amendments of Palouse.

In general, exchangeable $\mathrm{Cu}$ and $\mathrm{Zn}$ increase with increasing brass amendment, though the $\mathrm{Cu}$ component remains minor. With increasing brass, $\mathrm{Cu}$ increases in the inorganically bound compartment, but $\mathrm{Zn}$ remains steady. Organically bound and residual compartments show decreasing $\mathrm{Cu}$ and $\mathrm{Zn}$ with increasing brass amendment. Based on the most severe extraction method (the hot water extraction), the highest brass amendment level (2500 $\mu \mathrm{g} / \mathrm{g}$ soil), and 100 days incubation, Cu solubilization amounted to $0.5,2.0$, and $3.5 \%$ for Burbank, Palouse, and Cinebar soils, respectively; $Z n$ solubilization was $0.2,1.5$, and $2.7 \%$ for Burbank, Palouse, and Cinebar soils, respectively. Since the rates of weathering appear constant between 100 and $\mathbf{4 4 0}$ days, it is assumed that an equilibrium is established between exchangeable and non exchangeable metal pools in soils.

\section{PlantEffects}

Seed-germination studies with bush bean, alfalfa, and tall fescue indicate no effects of brass at any of the concentrations used or after up to $\mathbf{4 5 0}$ days of weathering. After 160 days of incubation, plants developed visual toxicity symptoms, including necrosis and chlorosis.

Except for tall fescue grown on Burbank, only moderate damage was noted for concentrations $\leq 500 \mu \mathrm{g}$ brass $/ \mathrm{g}$. In general, the toxicity of brass, based on visual symptomatology, became more severe with increasing incubation or weathering time. Biomass production in plants reflected the soil concentration trends for visual symptoms, in that severe dry-weight reductions were observed at soil concentrations of $>500 \mu \mathrm{g}$ brass $/ \mathrm{g}$ soil. Plants grown on low-CEC soil, namely Burbank and Palouse, exhibit effects at lower soil concentrations.

Concentrations of $\mathrm{Cu}$ and $\mathrm{Zn}$ in plant tissues are proportional to soil brass levels. In tall fescue, shoot tissue concentrations of Cu ranged from $34 \mu \mathrm{g} / \mathrm{g}$ for Cinebar to $500 \mu \mathrm{g} / \mathrm{g}$ for Palouse soil containing 2500 ppm brass. In comparison, $\mathrm{Zn}$ concentrations ranged from 900 to $6000 \mu \mathrm{g} / \mathrm{g}$. In bush bean, the concentration of $\mathrm{Cu}$ in leaves was highest for Burbank soil $(50 \mu \mathrm{g} / \mathrm{g})$, while $\mathrm{Zn}$ concentrations were highest in Palouse-grown plants $(850 \mu \mathrm{g} / \mathrm{g})$.

Analysis of the nutrient-ion concentrations of tall fescue grown on brass-amended soil showed that the elevated soil concentrations of $\mathrm{Cu}$ and $\mathrm{Zn}$ caused the tissue concentrations of $\mathrm{Mg}$ and $\mathrm{Mn}$ to increase by a factor of 2 to 3, levels of Fe to increase by a factor of 7 to 100 , and $P$ levels to decrease by a factor of 2 to 3 . This disruption in ion homeostasis can account for the observed phytotoxicity of brass. Similar ion imbalances were not observed for bush bean. 


\section{Soil Microbjal Processes}

The degree of brass-flake impact on soil microbial activities depended on soil type, brass concentration, and the microbial index studied. Soil with higher organic matter and cation exchange capacity (Cinebar) tended to be less impacted by the brass flake than soil with lower organic matter and CEC (Burbank). Organic matter in soils can adsorb and bind heavy metals, the extent of which depends on $\mathrm{pH}$. Soil organic matter also contributes to the CEC of the soil, thereby further influencing the bioavailability, and hence, toxicity of deposited heavy metals. The greater the CEC of the soil, the greater is its ability to adsorb and immobilize heavy metals and reduce their toxic effects. The CEC and organic matter of the soils used in this study can be ranked Burbank soil < Palouse soil $\leq$ Palouse soil $+O M<$ Cinebar soil. Burbank soil, with its low CEC and low organic matter, was most impacted by the brass-flake exposure.

Impacts on soil microbial activities increased with increasing brass concentration. Concentrations above $500 \mu \mathrm{g} / \mathrm{g}$ severely inhibited several soil microbial activities, especially soil dehydrogenase activity, which was diminished to below detection limit.

Soil dehydrogenase activity, or the activity of the soil microbial community, was more susceptible to the toxicity of brass flake than was soil phosphatase or soil microbial biomass, which were moderately affected by the brass flake. Soil nitrifying bacteria and total heterotrophic bacteria in general were not significantly affected by the brass flake. In fact, these two indexes were slightly enhanced by the brass flake. The microbial diversity index was significantly decreased in Burbank soil, and was moderately inhibited in Palouse soil at $2500 \mu \mathrm{g} / \mathrm{g}$ brass flake. Among the soil microbial parameters studied, the impact ranking was soil dehydrogenase activity $>$ soil phosphatase activity $>$ soil microbial biomass $>$ soil microbial population (total heterotrophic and nitrifying bacteria) $\approx$ microbial species diversity index.

The ecological dose of brass flake causing $50 \%$ inhibition $\left(E c D_{50}\right)$ in soil microbial activity increased with incubation time, indicating a general trend of recovery as a function of time, and suggesting an immobilization of the metals and a transient nature of the brass effect. Weathering of brass-amended soil substantially increased organically bound copper and zinc (see the chemistry section of this report) and thus may have contributed to the recovery from brass toxicity over time.

When soil was exposed to a mixed smoke of brass flake and fog oil, the deleterious effect was less intense than when soil was exposed to brass only, suggesting a beneficial synergistic effect of fog oil. 


\section{Effects of Brass On Soil Invertebrates}

Brass flake deposited to soil has only a slightly deleterious effect on the earthworms at mass-loading levels $>445 \mu \mathrm{g} / \mathrm{cm}^{2}$. This is most evident in the $4.5 \mathrm{~m} / \mathrm{s}$ test, where the animals appeared to lose some of their responsiveness to stimuli (handling) by 14 days postexposure. However, in contrast to previous experiments with other smokes (e.g., WP and HC smokes; [(Van Voris et al. 1987; Cataldo et al. 1990)], where decided numbers of deaths occurred during this period, we noted no fatalities among the populations exposed. In fact, egg casings and juvenile hatching were noted in some of the coupons. Exposure of earthworms to BR/FO aerosols at mass loadings of $200 \mu \mathrm{g} \mathrm{brass} / \mathrm{cm}^{2}$ had no effect on survivability and only moderately affected tactile activity, indicating that fog oil neither ameliorates nor intensifies the effects of brass.

\subsection{SOIL COLUMNS AND BRASS MOBILITY IN SOIL}

Brass flake was neutron-activated to produce a ${ }^{65} \mathrm{Zn}$-tagged brass and applied to column surfaces to determine the mobility of weathered soluble constituents, using $\mathrm{Zn}$ as the indicator ion. Analysis of migration, peak width (PW), and peak maximum depth (PMD) clearly indicates that appreciable downward migration of $\mathrm{Zn}$, and likely $\mathrm{Cu}$, does not occur to any great extent over the time used (440 days). Peak maximum depth increased by 0.06 to $0.43 \mathrm{~cm}$ in the four soil treatments. The average PW values increase from 0.7 to $0.9 \mathrm{~cm}$. Although slight differences in migration rates for the four soils were noted, it is clear that the CEC of these soils effectively retards solubilized brass constituents. For Cinebar soil leached with pH 6.5 versus 4.5 rainwater, no significant differences $(P \geq 0.1)$ are noted in migration; this likely indicates that the added acidity did not exceed the buffering capacity of the soil. 


\subsection{REFERENCES}

Alexander, M., and F. E. Clark. 1965. "Nitrifying Bacteria." In Methods of Soil Analysis. Part2 (1st Ed), pp. 1477-1483. C. A. Black (ed.). Am. Soc. Agronomy, Madison, Wisconsin.

Alexander, M. 1982. "Most Probable Number Method for Microbial Populations." In Methods of Soil Analysis. Part2 (2nd Ed.), pp. 815-820. A. L. Page (ed.). Am. Soc. Agronomy, Madison, Wisconsin.

Atlas, R. M. 1984a. "Diversity of Microbial Communities." In Advances in Microbial Ecology Vol. 7, K. C. Marshall (ed.). Plenum Press, New York and London.

Atlas, R. M. 1984b. "Use of Microbial Diversity Measurements to Assess Environmental Stress." In Current Perspectives in Microbial Ecoleay. M. J. Klug and C. A. Reddy (eds.), pp. 540-545. American Society for Microbiology, Washington, D.C.

Atlas, R. M., and R. Bartha. 1987. "Evolution and Structure of Microbial Communities." In Microbial Ecology: Fundamentals and Applications, (2nd Ed.). The Benzamin/Cumings Publishing Co., Menlo Park, California.

Babcock, M. F., D. W. Evans, and J. J. Alberts. 1983. "Comparative Uptake and Translocation of Trace Elements from Coal Ash by Typha Latifolia." Sci. of the Total Environ. 28:203214.

Babich, H., R. J. F. Bewley, and G. Stotzky. 1983. "Application of the Ecological Dose Concept to the Impact of Heavy Metals on Some Microbe-Mediated Ecological Processes in Soil." Arch. Environ. Contam. Toxicol, 12:421.

Baes, C. F., Jr., and R. E. Mesmer. 1976. The Hydrolysis of Cations. John Wiley and Sons, New York.

Black, C.A. 1968. Soil-PlantRelationships. John Wiley and Sons, New York.

Bowen, H. J. M. 1979. Environmental Chemistry of the Elements. Academic Press, New York, New York.

Bowen, J. E. 1987. "Physiology of Genotypic Differences in Zinc and Copper Uptake in Rice and Tomato." Plant and Soil 99:115-125.

Brady, N. C. 1974. The Nature and Properties of Soils. 8th edition. Macmillan Inc., New York, New York.

Cataldo, D. A., T. R. Garland, and R. E. Wildung. 1981. "Foliar Retention and Leachability of Submicron Plutonium and Americium Particles." L.Environ. Qual. 10:31-37. 
Cataldo, D. A., B. D. McVeety, P. Van Voris, S. W. Li, M. W. Ligotke, H. Bolton, Jr., R. J. Fellows, and J. K. Fredrickson. 1989. Evaluate and Characterize Mechanisms Controlling Iransport. Fate and Effects of Army Smokes in an Aerosol Wind Tunnel. Transport. Iransformations. Fate and Terrestrial Ecological Effects of Fog Oil Obscurant Smokes. ADA-204314. Final Report to U. S. Army Biomedical Research and Development Laboratory, Fort Detrick, Frederick, Maryland.

Cataldo, D. A., M. W. Ligotke, R. J. Fellows, S. W. Li, K. M. McFadden, B. D. McVeety, H. Bolton, Jr., P. Van Voris. 1990a. Evaluate and Characterize Mechanisms Controlling Iransport. Fate and Terrestrial Ecological Effects of Hexachloroethane Obscurant Smokes. PNL-7166. U.S. Army Medical Research and Development Command. Fort Detrick, Frederick, Maryland.

Cataldo, D. A., M. W. Ligotke, R. J. Fellows, Shu-Mei W. Li, K.M. McFadden, B. D. McVeety, H. Bolton, Jr., P. Van Voris. 1990b. Evaluate and Characterize Mechanisms Controlling Iransport. Fate and Terrestrial Ecological Effects of Mixed Obscurant Smokes. PNL-7313, U.S. Army Medical Research and Development Command, Fort Detrick, Frederick, Maryland.

Daubenmire, R. 1959. "A Canopy Cover Method of Vegetation Analysis." Northwest Sci. 33:43-64.

Delhaize, E., M. J. Dilworth, and J. Webb. 1986. "The Effects of Copper Nutrition and Developmental State on the Biosynthesis of Diamine Oxidase in Clover Leaves." Plant Physiol. 82:1126-1131.

Drucker, H., T. R. Garland, and R. E. Wildung. 1979. "Metabolic Response of Microbiota to Chromium and Other Metals." In Irace Metals in Health and Disease. N. Kharasch (ed.), pp. 1-25. Raven Press, New York.

Environmental Protection Agency (EPA). 1987. Water Quality Criteria Summary. U.S. Environmental Protection Agency Office of Water Regulations and Standards Division, Standards Branch (WH-585). Washington, D.C. Note that Cu criteria reference is 1985 Federal Register while Zn criteria is 1987 Federal Register.

Foy, C. D., R. L. Chaney, and M. C. White. 1978. "The Physiology of Metal Toxicity in Plants." Ann. Rev Plant Phrsiol. 29:511-66.

Grill, E., E. L. Winnacker, and M. H. Zenk. 1987. "Phytochelatins, a Class of Heavy-MetalBinding Peptides from Plants, Are Functionally Analogous to Metallothioneins." Proc. Nat. Acad. Sci. 84:439-443.

Hinds, W. C. 1982. Aerosol Technology. John Wiley and Sons, New York. 
Ligotke, M. W., D. A. Cataldo, P. Van Voris, and C. A. Novich. June, 1986. "Analysts Use Wind Tunnel to Study Particle Behavior in the Environment." Research and Development 28(6):82-85.

Lindsay, W. L. 1979. Chemical Equilibria in Soils. John Wiley and Sons, New York.

McLaren R. G., and D. V. Crawford. 1973. "Studies on Soil Copper." Journal of Soil Science 24:172-181.

Moore, A. W., and J. S. Russell. 1972. "Factors Affecting Dehydrogenase Activity as an Index of Soil Fertility." Plant Soil 37:675-682.

Mullins, G. L., L. E. Sommers, and T. L. Housley. 1986. "Metal Speciation in Xylem and Phloem Exudates." Plant Soil 96:377-391.

Parkinson, D., and E. A. Paul. 1982. "Microbial biomass." In Methods of Soil Analysis. Part 2: Chemical and Microbiological Properties. A. L. Page (ed.), pp. 821-830. American Society of Agronomy, Madison, Wisconsin.

Ramirez-Martinez, J. R. 1968. "Organic Phosphorus Mineralization and Phosphatase Activity in Soils." Eolia Microbiol. 13:161-174.

Reese, R. N., and G. J. Wagner. 1987. "Effects of Buthionine Sulfoximine on Cd-Binding Peptide Levels in Suspension-Cultured Tobacco Cells Treated with Cd, Zn, or Cu." Plant Physiol. 84:574-577.

Rogers, J. E., and S. W. Li. 1985. "Effect of Metals and Other Inorganic Ions on Soil Microbial Actvity: Soil Dehydrogenase Assay as a Simple Toxicity Test." Bull. Environ. Contam. Toxicol. 34:858-865.

Rowe, R., R. Todd, and J. Waide. 1977. "Microtechnique for Most-Probable-Number Analysis." Appl.Environ. Microbiol. 33:675-680.

Rubin, A. J. 1974. Aqueous-Environmental Chemistry of Metals. Ann Arbor Science, Ann Arbor, Michigan.

Shinn, J. H., S. A. Martins, P. L. Cederwall, L. B. Gratt. 1985. A First Order Environmental Screening and Ranking of Army Smokes and Obscurants: Summary Report. AD (Draft Report), Lawrence Livermore National Laboratory, Berkeley, California.

Schmidt, E. L., and L. W. Belser. 1982. "Nitrifying Bacteria." In Methods of Soil Analysis. Part 2. Chemical and Microbiological Properties. A. L. Page (ed.), pp. 1027-1042. American Society of Agronomy, Madison, Wisconsin. 
Sims, J. T. 1987. "Soil pH Effects on the Distribution and Plant Availability of Manganese, Copper, and Zinc." Soil Sci. Soc. Am. Proc. 50:367-373.

Singh, D. P,. and S. P. Singh. 1987. "Action of Heavy Metals on Hill Activity and $\mathrm{O}_{2}$ Evolution in Anacystis nidulans." Plant Physiol. 83:12-14.

Sposito, G., L. J. Lund, and A. C. Chang. 1982. "Trace Metal Chemistry in Arid-Zone Field Soils Amended with Sewage Sludge: I. Fractionation of $\mathrm{Ni}, \mathrm{Cu}, \mathrm{Zn}, \mathrm{Cd}$, and $\mathrm{Pb}$ in Solid Phases." Soil Sci. Soc. Am.J. 46:260-264.

Stevenson, F. J. 1982. Nitrogen in Agricultural Soils. American Society of Agronomy, Madison, Wisconsin.

Tabatabai, M. A. 1982. "Soil Enzymes." In Metheds of Soil Analysis. Part 2; Chemical and Microbiological Properties. A. L Page (ed.), pp. 903-945. American society of Agronomy, Madison, Wisconsin.

Vallee, B. L. 1976. "Zinc Biochemistry: A Perspective". Irends in Biochemical Sciences. $1: 88-91$.

Van Riemsdijk, W. H., and J. Lyklema. 1980. "Reaction of Phosphate with Gibbsite [AI(OH)3] Beyond the Adsorption Maximum." L Colloid and Interface Sci. 76(1):55-66.

Van Voris, P., M. W. Ligotke, K. M. McFadden, S. W. Li, B. L. Thomas, D. A. Cataldo, T. R. Garland, J. K. Fredrickson, R. M. Bean, and D. W. Carlile. 1987. Evaluate and Characterize Mechanisms Controlling Transport. Fate. and Effects or Army Smokes in the Aerosol Wind Tunnel. Transport. Transformations. Fate and Terrestrial Ecolocical Effects of Red Phosphorus-Butyl Rubber and Phosphorus Obscurant Smokes. AD-A-191109. U.S. Army Medical Research and Development Command, Fort Detrick, Frederick, Maryland.

Wallace, A., and W. L. Berry. 1983. "Shift in Threshold Toxicity Levels in Plants When More Than One Trace Metal Contaminates Simultaneously." Sci. Total Environ. 28:257-268.

Wentsel, R. S. 1986. Eate and Effects of Brass Powder on the Environment. CRDEC-TR86044, Chemical Research Development and Engineering Center, Aberdeen Proving Ground, Maryland.

Wentsel, R. S. and M. A. Guelta. 1986a. The Fate of Brass Powder in Soils. CRDEC-TR86040, Chemical Research Development and Engineering Center, Aberdeen Proving Ground, Maryland.

Wentsel, R. S. and M. A. Guelta. 1986b. Texicity of Brass Powder in Soil to Earthworms. CRDEC-TR-86005. Chemical Research Development and Engineering Center, Aberdeen Proving Ground, Maryland. 
Wentsel, R. S., T. M. Mann and L. T. Bailes. 1986a. The Effects of Brass Powder in Soil on Terrestrial Plants. CRDEC-TR-86006. Chemical Research Development and Engineering Center, Aberdeen Proving Ground, Maryland.

Wentsel, R. S., W. T. Muse, and E. P. Riley. 1986b. The Acquatic Fate of Brass Powder. CRDEC-TR-86042. Chemical Research Development and Engineering Center, Aberdeen Proving Ground, Maryland.

West, N. E., and J. Skujins. 1978. "Summary, Conclusions and Suggestions for Further Research." In Nitrogen in Desert Ecosystems, N. E. West and J. Skujins (eds.), pp. 244253, US/IBP Synthesis Series no. 9. Dowden, Hutchinson \& Ross, Stroudsburg, Pennsylvania. 
-

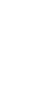

,

$-$ 
No. of

Copies

OFFSITE

2 DOE/Office of Scientific and Technical Information

25 Commander

U.S. Army Biomedical Research and Development Laboratory

ATTN: SGRD-UBZ-RA

Fort Detrick

Frederick, MD 21701-5010

2 Commander

U.S. Army Medical Research and Development Command

ATTN: SGRD-RMI-S

Fort Detrick

Frederick, MD 21701-5012
No. of

Copies

\section{ONSITE}

41 Pacific Northwest Laboratery

H. Bolton, Jr.

D. A. Cataldo (25)

J. W. Falco

R. J. Fellows

P. C. Hays

S. W. Li

M. W. Ligotke

J.P. McKinley

L. E. Rogers

W. T. Pennell

$P$. Van Voris

Publishing Coordination

Technical Report Files (5) 